Universidad deValladolid

PROGRAMA DE DOCTORADO EN INGENIERÍA INDUSTRIAL

\author{
TESIS DOCTORAL:
}

\title{
VALORIZACIÓN DE RESIDUOS \\ AGROALIMENTARIOS Y GANADEROS MEDIANTE DIGESTIÓN ANAEROBIA. Codigestión de residuos del tratamiento de aceites vegetales usados con purín porcino.
}

Presentada por Jesús $\mathrm{M}^{\mathrm{a}}$ Martín Marroquín para optar al grado de

Doctor por la Universidad de Valladolid

Dirigida por:

Dr. Gregorio Antolín Giraldo

Dra. $\mathrm{M}^{\mathrm{a}}$ Dolores Hidalgo Barrio

Valladolid, septiembre 2018 

A Loly, Adrian, Alejandra y Sofía. 



\section{Agradecimientos}

En primer lugar quiero dar las gracias a Loli, mi mujer y codirectora de Tesis, que gracias a su ayuda e impulso diario, tanto en el plano técnico, como anímico, ha posibilitado que pudiera realizar esta tesis.

También quiero agradecer al profesor, Dr. Gregorio Antolín, por su orientación y apoyo en todo momento para que esta tesis llegara a buen puerto.

A la Fundación CARTIF, que gracias al empeño del Director General, D. José Ramón Perán, facilita e impulsa el que los que trabajamos allí podamos alcanzar el grado de doctor.

A mis compañeros y amigos de la División de Agroalimentación y Procesos Sostenibles de Fundación CARTIF, que me han apoyado y brindado su ayuda en la realización práctica de los diferentes ensayos experimentales, en especial a Francisco Corona, Marta Gómez, Alicia Agüado y Emilia Sastre

Al Instituto de Tecnologías Avanzadas de la Producción (ITAP), que con su soporte y gestión ha facilitado la consecución de esta tesis.

A mis padres y hermana, que me han apoyado, aguantado, y animado durante todos estos años para la realización de esta tesis.

Muchas gracias a todos. 



\section{Preámbulo}

De acuerdo con la normativa vigente de presentación y defensa de la tesis doctoral (Acuerdos del Consejo de Gobierno de la Universidad de Valladolid de fecha 29 de noviembre de 2012), esta Tesis Doctoral se presenta como compendio de publicaciones. Además de incluir los artículos publicados, también se incluyen otros trabajos realizados en el marco de esta línea de investigación y los que están en proceso de elaboración para su posterior publicación.

Los artículos incluidos en este documento son:

Artículos publicados con factor de impacto incluidos dentro del compendio de publicaciones que ha dado lugar a la tesis:

a) Hidalgo, D.; Martín-Marroquín, J. M.; Sastre, E. (2014). Single-phase and twophase anaerobic co-digestion of residues from the treatment process of waste vegetable oil and pig manure. BioEnergy Research, 7(2), 670-680.

Factor de impacto: 3.398 Categoría: Feedstock biology Ranking:Q1

b) Hidalgo, D.; Martín-Marroquín, J. M. (2014). Effects of inoculum source and codigestion strategies on anaerobic digestion of residues generated in the treatment of waste vegetable oils. Journal of environmental management, 142, 17-22.

Factor de impacto: 3.188 Categoría: Environmental management Ranking:Q1

c) Hidalgo, D.; Gómez, M.; Martín-Marroquín, J. M.; Aguado, A., Sastre, E. (2015). Two-phase anaerobic co-digestion of used vegetable oils' wastes and pig manure. International Journal of Environmental Science and Technology, 12(5), 1727-1736.

Factor de impacto:1.794 Categoría: Science and Technology Ranking:Q2

Otros artículos publicados con factor de impacto que no han sido incluidos dentro del compendio de publicaciones:

a) Hidalgo, D.; Martín-Marroquín, J. M.; Gómez, M.; Aguado, A.; Antolín-Giraldo, G. (2014). Sistema integral y sostenible para el reciclado y valorización de residuos múltiples. DYNA-Ingeniería e Industria, 89(3), 309-315.

Factor de impacto:0.200 Categoría: Ingeniería e Industria Ranking:Q4 
b) Hidalgo, D.; Gómez, M.; Aguado, A.; Martín-Marroquín, J. M.; Sastre, E. (2014). Valorización de los residuos generados en el procesado de aceites vegetales usados. Dyna Colombia, 81(184), 20-27.

Factor de impacto:0.217 Categoría: Engineering, multidisciplinary. Ranking:Q4

c) Hidalgo, D.; Martín-Marroquín, J. M.; Gómez, M.; Aguado, A.; Antolín-Giraldo, G. (2014). Integrated and sustainable system for multi-waste valorization. Environmental Engineering \& Management Journal (EEMJ), 13(10), 2067-2475.

Factor de impacto:0.849 Categoría: Environmental Engineering. Ranking:Q3

d) Hidalgo, D.; Corona, F.; Martín-Marroquín, J. M.; Del Alamo, J.; Aguado, A. (2016). Resource recovery from anaerobic digestate: struvite crystallisation versus ammonia stripping. Desalination and Water Treatment, 57(6), 2626-2632.

Factor de impacto:1.631 Categoría: Science and Engineering. Ranking:Q3

e) Hidalgo, D.; Martín-Marroquín, J. M.; Corona, F. (2018). La gestión de los residuos biodegradables en el marco de la economía circular. DYNA, 94(2).

Factor de impacto:0.522 Categoría: Ingeniería e Industria. Ranking:Q4

Artículos en publicaciones sin factor de impacto:

a) Hidalgo, D.; Gómez, M.; Aguado, A.; Martín-Marroquín, J. M.; Sastre, E. (2013). Valorización integral de purines porcinos $y$ otras deyecciones ganaderas. Retema: Revista técnica de medio ambiente, 26(169), 42-50.

b) Hidalgo, D.; Corona, F.; Basany, M.; \& Martín-Marroquín, J. M. (2014). Residuos: las nuevas fuentes de energía y materias primas. Retema: Revista técnica de medio ambiente, 27(173), 8-17.

c) Martín-Marroquín, J. M.; Hidalgo, D. (2014). Livestock waste: Fears and opportunities. In Environment, Energy and Climate Change I. Springer, Cham, 341-373.

d) Hidalgo, D.; Martín-Marroquín, J.M.; Corona, F. (2017). Transformación de biogás en biometano: revisión de las tecnologías disponibles. DYNA Energía y Sostenibilidad, 6(1). 
Artículos publicados en congresos:

a) Hidalgo, D.; Martín-Marroquín, J.M.; Corona, F. Comparison of different treatment scenarios for mixtures of organic waste streams in a centralised plant.

Proceedings of International Congress on Water, Waste and Energy Management. Oporto (Portugal). 16-18/07/2014.

b) Hidalgo, D.; Martín-Marroquín, J.M.

Biochemical methane potential of agro-food wastes from the Castilla and León

Region (Spain)

Proceedings of Biogas production from agricultural biomass and organic residues:

Progress in Biogas III

Stuttgart (Germany). 10-11/09/2014

c) Hidalgo, D.; Martín-Marroquín, J.M.; Corona, F.

Co-digestion of meat-processing by-products, manure and residual glycerin

Proceedings of 4th International Conference on Sustainable Solid Waste

Management, Limassol, 23-25 June 2016

Limassol (Chipre). 23-25/06/2016

d) Corona, F.; Hidalfo, D.; Lipsa, L.; Martín-Marroquín, J.M.

Struvite crystallisation in a fluidised bed reactor: modelisation and operation

Proceedings of 19th Conference "Process Integration, Modelling and Optimisation for Energy Saving and Pollution Reduction"

Praga. 28-31/08/2016

e) Martín-Marroquín, J.M.; Corona, F.; Hidalgo, D.

Anaerobic co-digestion of category 2 animal byproducts: influence of ultrasonic pretreatment.

Proceedings of International Conference Progress in Biogas IV

Stuttgart. 8-11/03/2017

Artículos enviados a congresos y a revistas con factor de impacto:

a) Corona, F., Hidalgo, D.; Martín-Marroquín J.M.; Antolín, G. Study of the influence of the reaction parameters on nutrients recovering from digestate by struvite crystallization. Bioresource technology.

Factor de impacto:5.651 Categoría: Bioresource technology. Ranking:Q1 .

Por último, se hace constar que el presente documento adopta el formato de Tesis Doctoral como compendio de publicaciones y por lo tanto consiste en una síntesis de los conceptos teóricos que sustentan los trabajos de investigación publicados en lugar del formato tradicional de documento extenso autocontenido. 


\section{Resumen}

La codigestión anaerobia de los residuos agroalimentarios y ganaderos tiene el potencial de conseguir una reducción eficiente de la contaminación al mismo tiempo que la ventaja de producir energía y proveer beneficios medioambientales y socioeconómicos. Por otro lado, es bien conocido el hecho de que la digestión anaerobia de residuos ricos en aceites y grasas, como ocurre con muchos de los residuos agroalimentarios, no siempre es sencilla, dado que los microorganismos anaerobios son muy sensibles a la materia rica en lípidos a la vez que a los compuestos intermedios del proceso de degradación de los residuos grasos. Además, los lípidos ocasionan problemas operacionales en los digestores anaerobios debido a que producen obstrucción de las tuberías, originan problemas de transferencia de materia de los sustratos solubles y, puesto que quedan adheridos a la superficie de la biomasa bacteriana, provocan el lavado de la biomasa activa al facilitar la flotación de la misma.

Sin embargo, los lípidos son sustratos muy atractivos para la codigestión anaerobia debido al mayor rendimiento obtenido en este proceso cuando se comparan con proteínas y carbohidratos, lo que hace a los residuos ricos en lípidos una fuente potencial de energía renovable. La práctica de añadir lípidos a un digestor para aumentar su producción de metano es, pues, un enfoque prometedor que debe ser explorado.

Por otra parte, los sistemas de digestión anaerobia en dos fases permiten la selección y enriquecimiento de diferentes tipos de microbiota en cada reactor. En la primera fase, los contaminantes complejos como las proteínas o carbohidratos, son degradados por las bacterias acidogénicas a ácidos grasos volátiles (AGV), los cuales son subsecuentemente convertidos a metano y dióxido de carbono por las bacterias acetogénicas y metanogénicas en la segunda fase. Esta configuración permite incrementar la estabilidad de los procesos mediante el control de la fase de acidificación con objeto de prevenir sobrecargas y la producción de compuestos tóxicos para las bacterias metanogénicas. La primera etapa puede actuar como un buffer metabólico evitando golpes de $\mathrm{pH}$ a la producción metanogénica. Los microorganismos acidogénicos y metanogénicos difieren, no solo en términos de sus requerimientos nutricionales y de $\mathrm{pH}$, sino también con respecto a su fisiología, cinéticas de crecimiento y consumo de nutrientes y en su particular capacidad de soportar cambios medioambientales. Consecuentemente, las condiciones que son favorables para el crecimiento de las bacterias formadoras de ácidos (cortos tiempos hidráulicos de residencia (THR) y bajo $\mathrm{pH}$ ) pueden ser inhibidoras de las bacterias formadoras de metano. Una ventaja añadida del digestor en dos fases es que sus condiciones operacionales pueden ser selectivamente determinadas en orden a maximizar el crecimiento, no solo de los microorganismos precursores de ácidos, sino también el de los precursores de metano.

Teniendo en cuenta las ventajas potenciales de la digestión anaerobia en dos fases, y continuando con la investigación en mejorar la codigestión anaerobia de diferentes residuos, en esta Tesis se ha abordado el desarrollo de un sistema anaerobio de 
codigestión en dos fases para el tratamiento, dentro de los residuos ganaderos, de purín porcino (PM), y dentro de los residuos agroalimentarios con alto contenido en lípidos, de los residuos generados en el proceso de pretratamiento de aceites vegetales usados para la producción de biodiesel (OW). Por lo tanto se estudia el tratamiento de purines y residuos ricos en lípidos y se proponen soluciones a los problemas que supone su gestión.

Finalmente se realiza un estudio del cierre del ciclo de aprovechamiento de nutrientes presentes en los residuos mediante valorización del digestato producido en el proceso de codigestión anaerobia. Para ello se realiza un breve repaso de la legislación que afecta al digestato, tanto a nivel europeo como español, así como también se realiza un breve análisis de las diferentes tecnologías de precipitación del fertilizante estruvita que permiten recuperar de forma simultánea fósforo y amonio de la corriente residual. 


\begin{abstract}
Anaerobic codigestion of agro-food and livestock waste have the potential to get an efficient reduction in waste pollution and, at the same time, the advantage to produce energy and provide environmental and socio-economy benefits. On the other hand, it is well known that the anaerobic digestion of waste rich in oils and fats, as occur with many agro-food waste, is not always simple, because anaerobic microorganisms are very sensitive to lipid rich matter and to the intermediates of the degradation process of fatty waste. In addition, lipids produce operational problems in anaerobic digesters because they cause pipes obstruction, create problems of mass transfer of soluble substrates and, since they adhere to the surface of the bacterial biomass, trigger the wash of the active biomass by facilitating their flotation.
\end{abstract}

However, lipids are very attractive substrates for anaerobic codigestion due to the higher yield obtained in biogas production when they are digested in comparison with proteins and carbohydrates, what makes waste rich in lipids a potential source of renewable energy. The practice of adding lipids to a digester to increase the methane production is a promising approach which should be explored.

Moreover, anaerobic digestion systems with two phases allow a selection and enrichment of different types of microbiota in each reactor. In the first phase, complex pollutants, like proteins or carbohydrates, are degraded by acidogenic bacteria to volatile fatty acids (VFA), which subsequently are converted to methane and carbon dioxide by the acetogenic and methanogenic bacteria in the second phase. This configuration enables the increase of stability in the process through the control of the acidification phase to prevent overloads and production of toxic compounds for methanogenic bacteria. The first stage could act like a metabolic buffer to prevent $\mathrm{pH}$ hits to methanogenic production. Acidogenic and methanogenic microorganisms differ not only in nutritional and $\mathrm{pH}$ requirement terms, but also with respect to their physiology, growth kinetics and nutrient consumption and their particular ability to withstand environmental changes. Consequently, conditions which are favorable for the growth of acid forming bacteria (short hydraulic retention time, low $\mathrm{pH}$ ) could be inhibitors of methane forming bacteria. An added advantage of two-phase digester is that its operational conditions could be selectively determined in order to maximize the increase, not only of acid precursor microorganisms, but also of the methane precursors.

Given the potential advantages of two-phase anaerobic digestion, and keeping on with the investigation to improve the anaerobic co-digestion of different residues, this Thesis work has approached the development of a two-phase anaerobic co-digestion system for the treatment, in the case of livestock waste, of pig manure (PM) and, in the case of agro-food, waste with high lipids content, of waste generated in the pretreatment process of used vegetable oils to produce biodiesel (OW). Therefore, the treatment of pig manure and lipid-rich waste is studied and solutions to the problems involved in their management are proposed. 
Finally, a closed-loop study of waste nutrients use is carried out by evaluating the digestate produced in the anaerobic codigestion process. To do this, a brief review of the legislation affecting the digestate, both at European and Spanish level, is carried out, as well as a brief analysis of the different precipitation technologies for struvite fertilizer production, that allows the simultaneous recovery of phosphorus and ammonium from the waste stream. 


\section{Índice General}

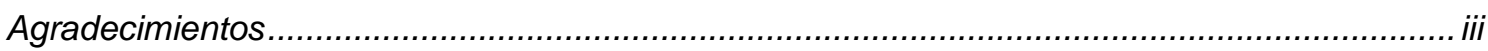

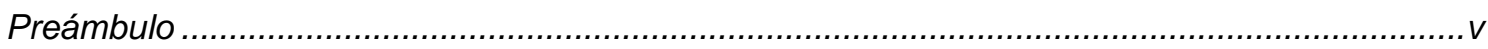

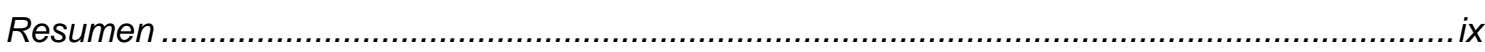

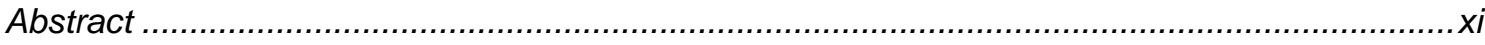

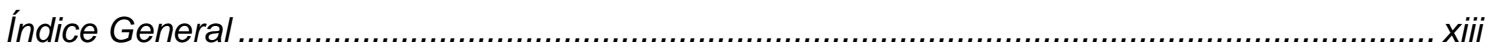

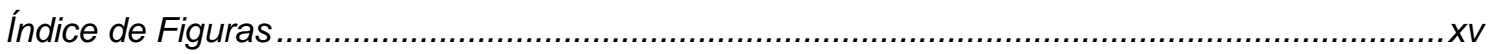

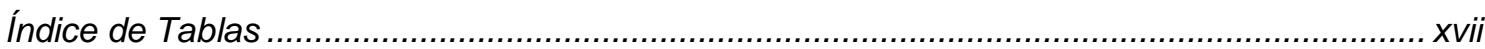

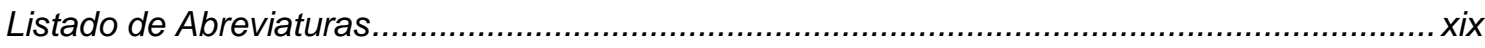

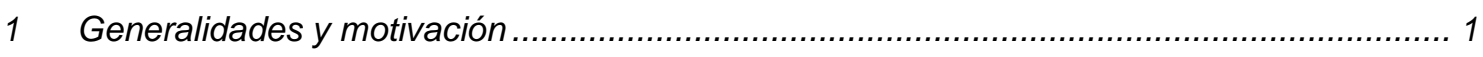

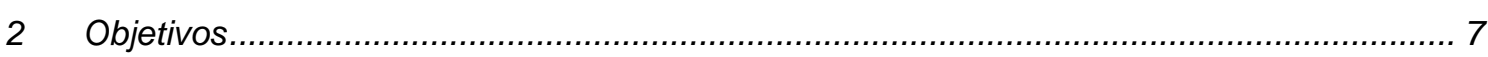

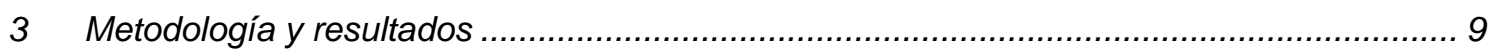

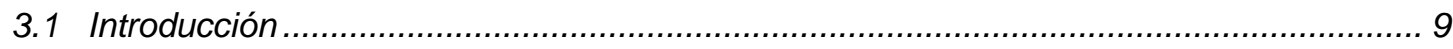

3.2 Selección y procedimientos utilizados para la caracterización de muestras

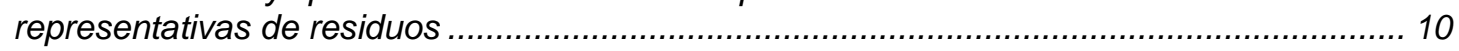

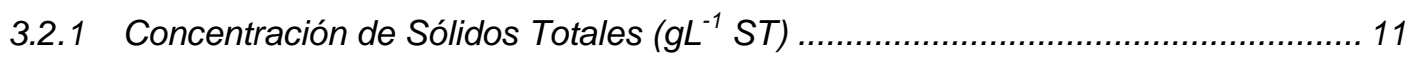

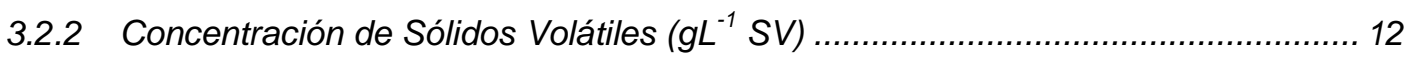

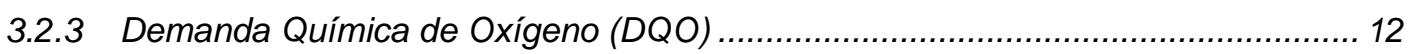

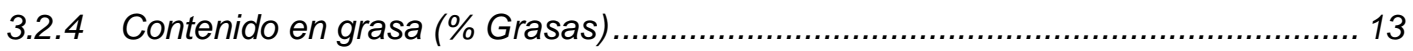

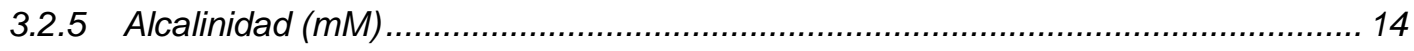

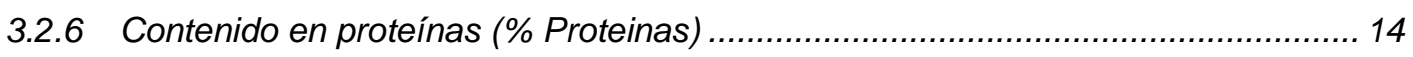

3.2.7 Nitrógeno amoniacal $\left(\mathrm{gNL}^{-1} \mathrm{~N}-\mathrm{NH}_{4}\right)$............................................................. 15

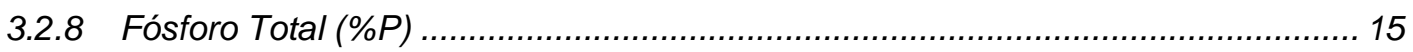

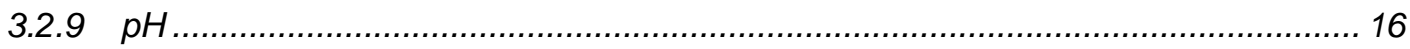

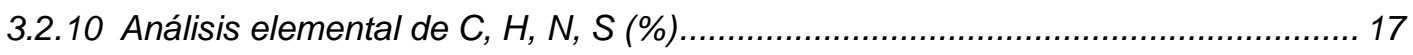

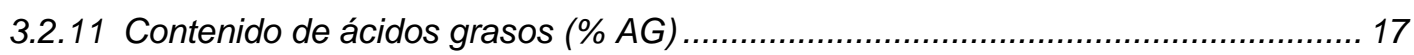

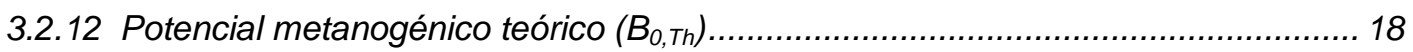

3.2.13 Procedimiento para la realización de los test de actividad metanogénica............... 19

3.2.14 Procedimiento para la realización de los test de biodegradabilidad ....................... 20

3.3 Resultados obtenidos de la caracterización de cada uno de los residuos ..................... 21

3.4 Influencia del inóculo utilizado en el potencial metanogénico del residuo...................... 24

3.5 Estudio comparativo de sistemas de digestión anaerobia en una y dos fases a

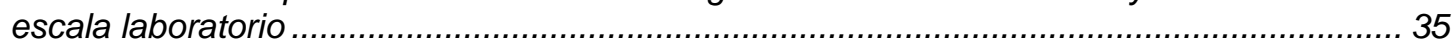

3.6 Diseño, construcción y operación en continuo de una planta piloto de digestión

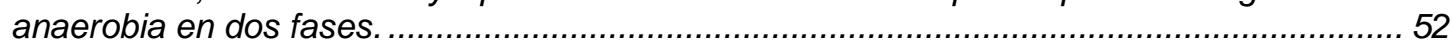

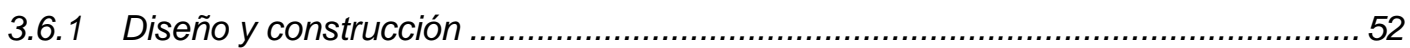

3.6.2 Operación en continúo de la planta piloto ............................................................. 58 
3.7 Estudio del cierre de ciclo de aprovechamiento de nutrientes mediante

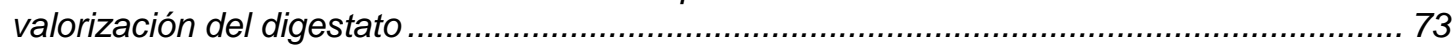

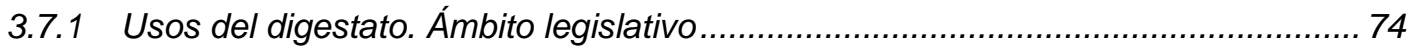

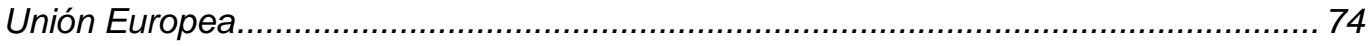

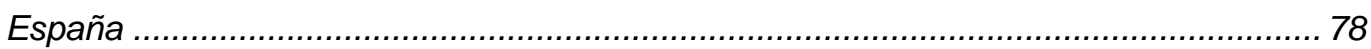

3.7.2 Proceso de precipitación de estruvita ....................................................... 79

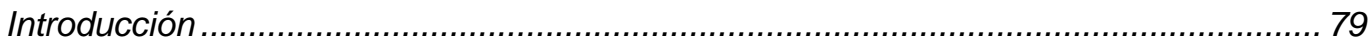

Opciones comerciales para la obtención de estruvita:........................................ 81

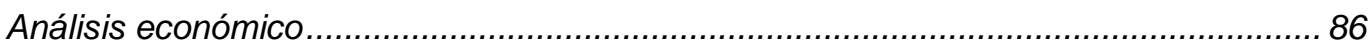

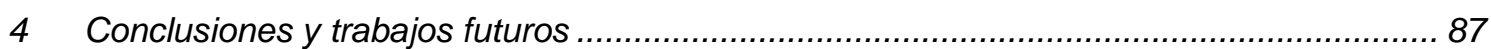

4.1 Conclusiones y aportaciones de la tesis ...................................................... 87

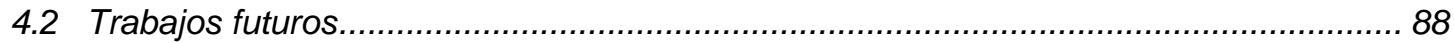

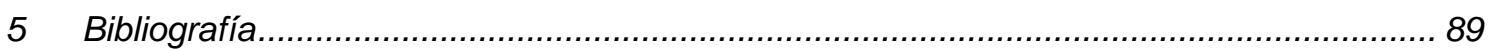




\section{Índice de Figuras}

Figura 1-1. Esquema del proceso de digestión anaerobia. Fuente: Silvestre, 2014. ................ 4

Figura 3-1. Esquema del pretratamiento de aceites vegetales usados. ................................ 10

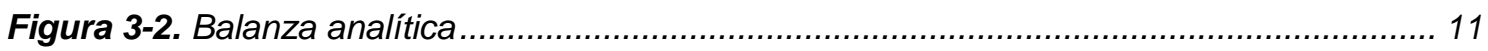

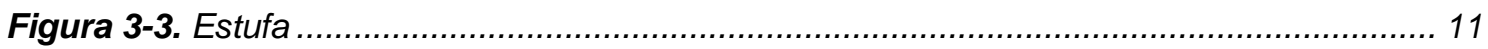

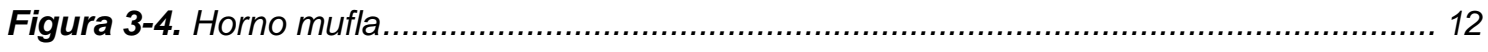

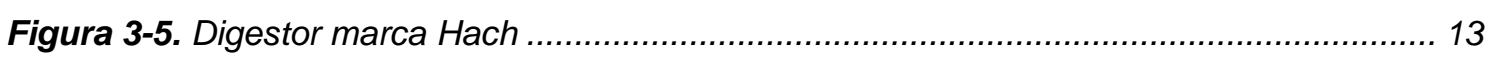

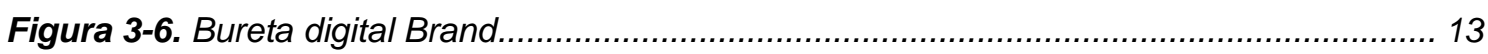

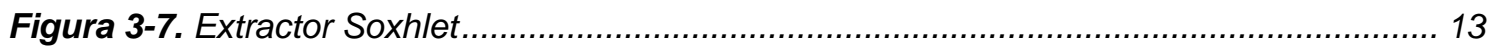

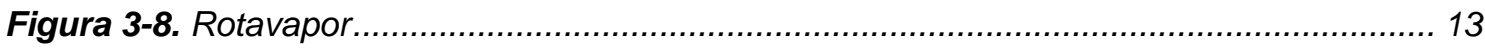

El nitrógeno Kjedahl total determina el contenido de nitrógeno orgánico de una muestra después de su mineralización. No se incluye el nitrógeno en forma de nitrito o nitrato. El método empleado ha sido un método titulométrico, por el cual la muestra se mineraliza en medio ácido con ácido sulfúrico, sulfato potásico para aumentar el punto de ebullición y sulfato de cobre como catalizador. Durante la mineralización a altas temperaturas, el nitrógeno orgánico, el amoníaco libre y el amonio se convierten en sulfato amónico. Posteriormente, se destila en medio alcalino recogiendo el destilado sobre ácido bórico. Finalmente, se valora por desplazamiento el borato amónico con ácido clorhídrico o ácido sulfúrico. En los análisis se ha dispuesto de un digestor marca Selecta, modelo RAT 2 (Figura 3-9), un destilador marca Tecator, modelo 1026 (Figura 3-10) y una bureta digital marca Brand (Figura 3-6).

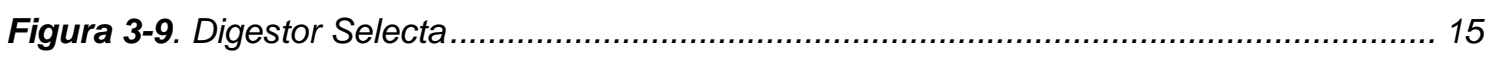

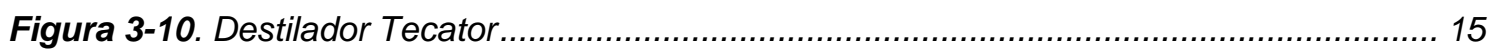

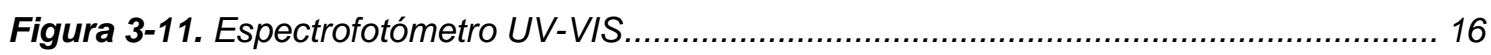

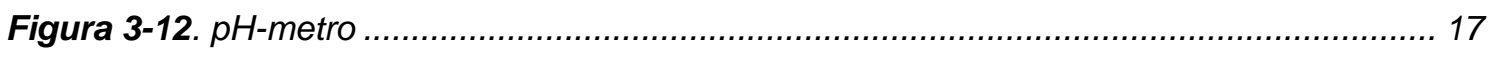

Figura 3-13. Detalle del interior del módulo CHNS del analizador elemental.......................... 17

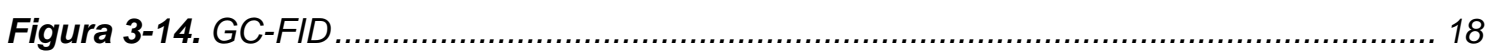

Figura 3-15. Determinación de presión en el interior de los digestores................................... 20

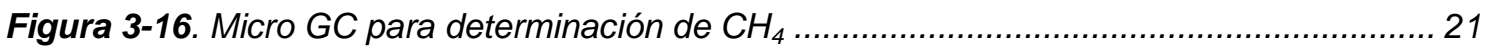

Figura 3-17. Producción acumulada de metano para cada uno de los residuos que componen OW, y para cada uno de los inóculos: a) inóculo procedente de mWWTP, b) inóculo procedente de HORECA.

Figura 3-18. Contenido de metano en el biogás producido durante los ensayos de biodegradabilidad para cada uno de los residuos que componen el OW y para cada uno de los inóculos ensayados

Figura 3-19. Producción acumulada de metano para el residuo OW y diferentes mezclas con PM, para cada uno de los inóculos: a) inóculo procedente de mWWTP, b) inóculo

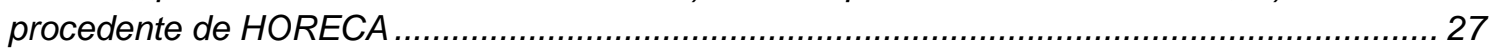

Figura 3-20. Esquema experimental: a) sistema monofásico; b) sistema de dos fases........... 35

Figura 3-21. Fotografía: a) sistema monofásico; b) sistema de dos fases ............................ 36 
Figura 3-22. Producción acumulada de metano para diferentes relaciones de alimentación y con inoculo aclimatado: a) sistema monofásico; b) sistema de dos fases

Figura 3-23. Velocidad de carga orgánica para diferentes relaciones de alimentación y con inoculo aclimatado: a) sistema monofásico; b) sistema de dos fases

Figura 3-24. Porcentaje de eliminación de sólidos volátiles para diferentes relaciones de alimentación y con inoculo aclimatad: a) sistema monofásico; b) sistema de dos fases.

Figura 3-25. Producción de metano para diferentes relaciones de alimentación y con inoculo aclimatado: a) sistema monofásico; b) sistema de dos fases ........................................ 39

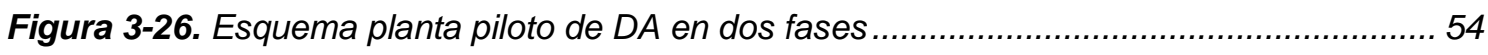

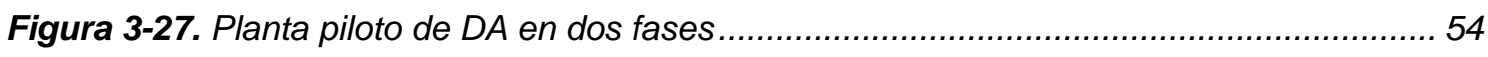

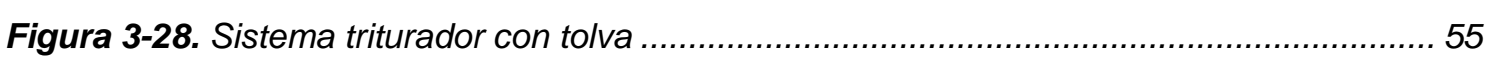

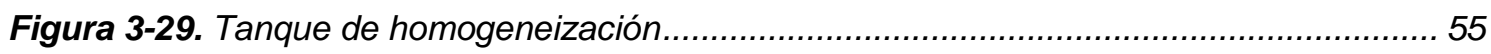

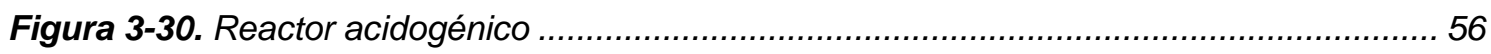

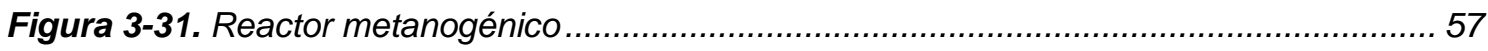

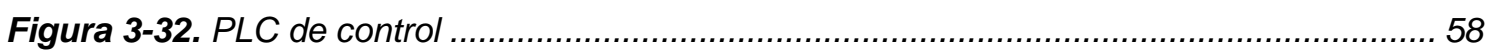

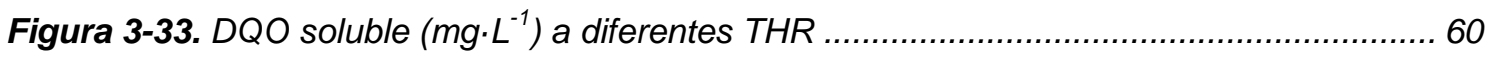

Figura 3-34. Porcentaje de eliminación de DQO a diferentes THR ....................................... 60

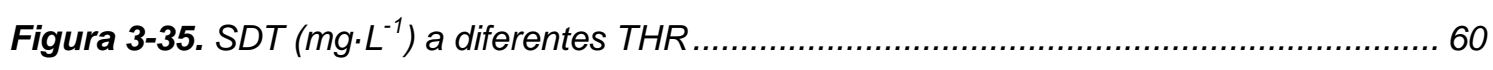

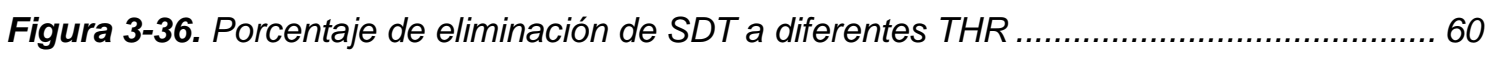

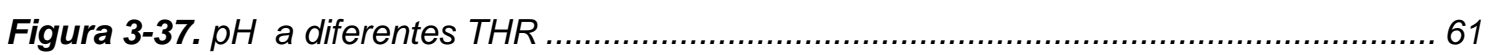

Figura 3-38. Representación gráfica del proceso y del reactor de Ostara Pearl. Fuente:.......... 82

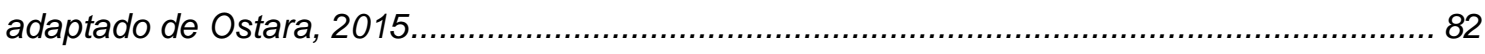

Figura 3-39. Esquema representativo del sistema Nuresys de recuperación de fósforo. Fuente: adaptado de Nuresys, 2018.

Figura 3-40. Esquema representativo del proceso y reactor Crystalactor. Fuente: adaptado de Crystalactor, 2018

Figura 3-41. Esquema del proceso y reactor Phospaq de recuperación de fósforo. Fuente: adaptado de Paques, 2018e: adaptado de Paques, 2018. 


\section{Índice de Tablas}

Tabla 1-1. Tendencia en la producción de varios productos ganaderos, 2011-2020.

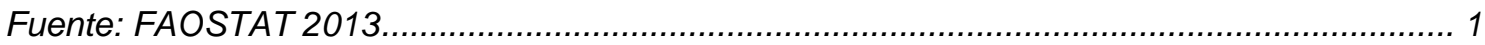

Tabla 3-1. Disolución de macronutrientes y elementos traza.................................................. 19

Tabla 3-2. Condiciones del método de análisis de biogás mediante Micro-G .......................... 21

Tabla 3-3. Caracterización de los residuos y de sus mezclas................................................ 21

Tabla 3-4. Composición elemental y potencial metanogénico teórico de los residuos y de sus mezclas.

Tabla 3-5. Contenido en ácidos grasos de cada uno de los residuos que forman la muestra

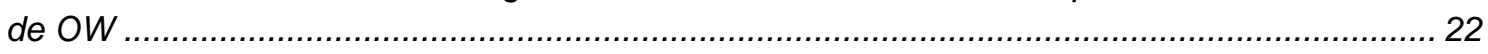

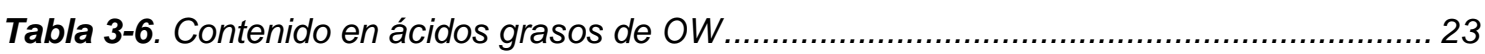

Tabla 3-7. Potencial metanogénico teórico y experimental de los residuos y de sus mezclas.....

Tabla 3-8. Coeficientes de variación calculados para la producción de biogás y eliminación

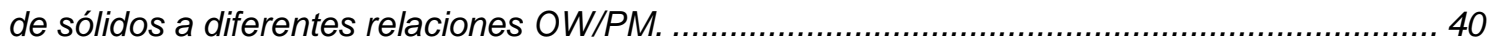

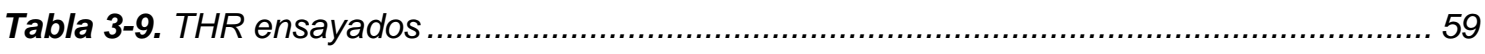

Tabla 3-10. Requerimientos de residuos de fermentación (Reglamento (CE) 142/2011) ......... 75

Tabla 3-11. Requerimientos específicos del estiércol transformado para puesta en el

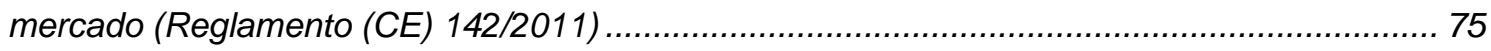

Tabla 3-12. Tecnologías utilizadas a escala industrial para la obtención de estruvita................ 81 


\section{Listado de Abreviaturas}

\begin{tabular}{|c|c|}
\hline AVU & Aceites vegetales usados \\
\hline$A G$ & Ácidos grasos \\
\hline AGV & Ácidos grasos volátiles \\
\hline $\mathrm{B}_{0, \mathrm{Ex}}$ & Potencial metanogénico experimental \\
\hline $\mathrm{B}_{0, \mathrm{Th}}$ & Potencial metanogénico teórico \\
\hline BD100 & Biodiesel puro, sin adición de diésel. \\
\hline CV & Coeficiente de variación \\
\hline DA & Digestión anaerobia \\
\hline DDS & $\begin{array}{l}\text { Residuo líquido procedente del lavado de los tanques donde se } \\
\text { almacenan los aceites vegetales usados tras su filtración, una vez } \\
\text { eliminados los residuos sólidos sedimentados }\end{array}$ \\
\hline DQO & Demanda química de oxígeno \\
\hline DQOs & Demanda química de oxígeno soluble \\
\hline DS & $\begin{array}{l}\text { Residuo sólido sedimentado en el tanque donde se almacenan los } \\
\text { aceites vegetales usados tras su filtración }\end{array}$ \\
\hline DTS & $\begin{array}{l}\text { Residuo semisólido que se obtiene tras la centrifugación de los } \\
\text { residuos decantados después del calentamiento de los aceites } \\
\text { filtrados. }\end{array}$ \\
\hline
\end{tabular}

GEI Gases de efecto invernadero

HORECA Hoteles, restaurantes y catering

LCFA Long chain fatty acids (Ácidos grasos de cadena larga)

mWWTP Municipal waste water treatment plant (Planta municipal de tratamiento de aguas residuales)

NNP Nitrógeno no proteico

$\mathrm{N}-\mathrm{NH}_{4} \quad$ Nitrógeno amoniacal

OLR Organic Loading Rate (Velocidad de carga orgánica)

OPT Aguas residuales que se obtienen tras la centrifugación de los residuos decantados después del calentamiento de los aceites filtrados

OW Residues from the pre-treatment process of waste vegetable oil for biodiesel production (Residuos del proceso de pretratamiento de aceites vegetales usados para la obtención de biodiesel)

P Fósforo total

PM Pig manure (Purin porcino) 
RIF Residuo sólido que se obtiene tras el filtrado de los aceites vegetales usados en la primera etapa del pretratamiento

SD Desviación estándar

SDT Sólidos disueltos totales

SDV Sólidos disueltos volátiles

ST Sólidos totales

SV Sólidos volátiles

S/X Relación sustrato / inóculo

THR Tiempo hidráulico de residencia 


\section{GENERALIDADES Y MOTIVACIÓN}

\section{Residuos ganaderos. Generación y problemática}

Desde 1960 hasta 2010, la población mundial se ha duplicado, mientras que el número de animales se ha incrementado en un $50 \%$ para los rumiantes, un $200 \%$ para el ganado porcino y un $280 \%$ para las aves de corral. En cuanto a la carne que aporta cada una de las especies, la de cerdo es la que ha aumentado en mayor proporción, alcanzando una producción anual de 45 Mt, seguida con 42 y 29 Mt para el ganado vacuno y las aves de corral, respectivamente (Garg y Makkar, 2012).

Por otra parte, según se indica en la Tabla 1-1, el crecimiento simultáneo de la demanda de productos ganaderos sugiere que desde el año 2011 y hasta el año 2020 la producción anual deberá crecer, sólo en el mundo desarrollado, en otras 13 Mt de leche y $7 \mathrm{Mt}$ de carne. Tal aumento requerirá más que la simple adaptación de las prácticas actuales de gestión y tratamiento de residuos ganaderos, tal como existen en los países desarrollados.

Tabla 1-1. Tendencia en la producción de varios productos ganaderos, 2011-2020. Fuente: FAOSTAT 2013

\begin{tabular}{|c|c|c|c|c|}
\hline \multirow{2}{*}{ Region/Producto } & \multirow{2}{*}{$\begin{array}{c}\Delta \text { Producción }(\%) \\
\text { 2011-2020 }\end{array}$} & \multicolumn{2}{|c|}{ Producción total (Mt) } & \multirow{2}{*}{$\begin{array}{c}\Delta \text { Producción }(\mathrm{Mt}) \\
\text { 2011-2020 }\end{array}$} \\
\hline & & 2011 & 2020 & \\
\hline \multicolumn{5}{|c|}{ Mundo desarrollado } \\
\hline Ganado vacuno & 6,90 & 29 & 31 & 2 \\
\hline Ganado porcino & 4,44 & 45 & 47 & 2 \\
\hline Aves de corral & 11,90 & 42 & 47 & 5 \\
\hline Carne & 5,60 & 125 & 132 & 7 \\
\hline Leche & 3,59 & 362 & 375 & 13 \\
\hline \multicolumn{5}{|c|}{ Mundo en desarrollo } \\
\hline Ganado vacuno & 22,22 & 18 & 22 & 4 \\
\hline Ganado porcino & 25,00 & 48 & 60 & 12 \\
\hline Aves de corral & 28,13 & 32 & 41 & 9 \\
\hline Carne & 24,55 & 110 & 137 & 27 \\
\hline Leche & 28,65 & 171 & 220 & 49 \\
\hline
\end{tabular}

Adaptado de Delgado et al. 1999.

Para 2050 se espera que la población mundial sea de más de 9 mil millones de personas y esto, combinado con el aumento de los ingresos en el mundo desarrollado, hace que se prevea una mayor demanda de productos alimenticios que son más sensibles al aumento de los ingresos en los países en desarrollo (como los productos pecuarios y lácteos, o los aceites vegetales). La demanda de estos productos crecerá más rápidamente que la de los cereales. Por ejemplo, el consumo de productos lácteos y de carne aumentará en un $74 \%$ y 58\%, respectivamente (Garg y Makkar, 2012).

El estiércol es un subproducto inevitable de la producción ganadera y, cuando se gestiona adecuadamente, puede ser utilizado como una fuente de nutrientes y sirve para mejorar las propiedades del suelo. Por otro lado, el estiércol manejado inadecuadamente puede representar una amenaza para el suelo, el agua, la calidad 
del aire y la salud humana y animal. La contaminación del suelo es un problema generalizado causado por la insostenible deposición de exceso de nutrientes, sustancias químicas y agentes patógenos en la tierra en las inmediaciones de las granjas de cría de ganado. La mala calidad del aire es consecuencia de la liberación localizada de cantidades significativas de gases tóxicos y sustancias olorosas, así como partículas y bioaerosoles que contienen una variedad de microorganismos y patógenos para el ser humano. Resultados adversos desde el punto de vista ecológico incluyen la carga excesiva de nutrientes y la eutrofización de las aguas superficiales, dando como resultado zonas muertas pobres en oxígeno en las aguas interiores y marinas superficiales, donde se repiten las floraciones de algas, muerte de peces, y una disminución de las poblaciones de diferentes especies y de la biodiversidad (Halden y Schwab, 2008).

El ganado es responsable del $64 \%$ de las emisiones de amoníaco antropogénico $\left(\mathrm{NH}_{3}\right)$, del $37 \%$ de metano antropogénico $\left(\mathrm{CH}_{4}\right)$ y del $65 \%$ del óxido nitroso antropogénico $\left(\mathrm{N}_{2} \mathrm{O}\right)$ (Steinfeld et al., 2006). Alrededor del 30\% de los gases de efecto invernadero (GEI) generados por la producción ganadera se atribuyen a la gestión del estiércol.

\section{Aceites vegetales usados. Generación y problemática}

Sólo en España, anualmente se consumen unas 850 kt de aceite (MAGRAMA, 2015). De acuerdo con los actuales hábitos culinarios y de consumo, se estima que pueden

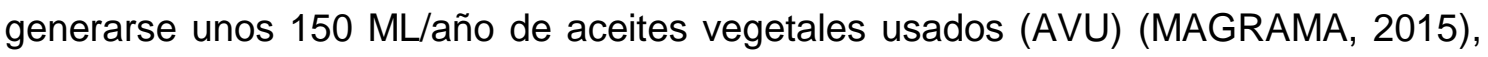
procedentes tanto de domicilios (preparación, cocinado y condimento de alimentos en las cocinas de los hogares), como de actividades comerciales (preparación, cocinado y condimento de alimentos en establecimientos de restauración y hostelería: bares y restaurantes, hoteles, comedores colectivos de empresas, etc.), como de la Administración pública (preparación, cocinado y condimento de alimentos en las cocinas de centros educativos, comedores sociales, instituciones, etc.). En la Unión Europea se estima que la producción de aceites vegetales usados se encuentra entre 0.7 y $1 \mathrm{Mt} / \mathrm{año}$.

Los AVU recogidos separadamente pueden recibir tratamientos mediante los cuales se preparan para la producción de biocarburantes (biodiesel), jabones y otros productos para la industria química (ceras, barnices, otros), reduciendo así el uso de recursos procedentes de materias primas e impulsando la actividad económica y empleos más verdes.

La producción de biodiesel puro (BD100), a partir de aceites usados comporta un ahorro de energía fósil del $21 \%$ en relación al uso de aceites crudos y un ahorro del 96\% de energía fósil respecto a la producción del diésel (MAGRAMA, 2015). Cada kilogramo de aceite recogido se puede transformar en 0,92-0,97 kg de biodiesel. Pero para que este aceite pueda ser utilizado, después de su recolección pasa a un proceso de pretratamiento para eliminar la humedad y las partículas gruesas, y posteriormente va a un proceso de refinado para eliminar principalmente los ácidos grasos libres. La gran cantidad de residuos generados, tanto en las etapas de pretratamiento, como en la de refinado del aceite vegetal usado, crean grandes problemas medioambientales, por lo que se hace necesaria la búsqueda de procesos en los que estas corrientes puedan servir como materia prima aprovechable. 
Es bien conocido que la digestión anaerobia de esta clase de residuos no es una tarea fácil, ya que los microorganismos anaerobios son muy sensibles tanto a los compuestos con un alto contenido en lípidos, como a los surfactantes producidos durante la hidrólisis de los aceites y a los compuestos intermedios generados en los aceites residuales durante el proceso de degradación de los mismos (Hidalgo et al., 2013; Hutňan et al., 2009; Neves et al., 2009; Thi 2011; Tokumoto et al., 2012; Zhang et al., 2010). Además, los lípidos pueden causar problemas operacionales en digestores anaerobios debido a que pueden provocar obstrucciones en las conducciones, pueden causar problemas de transferencia de materia en sustratos solubles, ya que pueden ser adsorbidos por la superficie de la biomasa microbiana y dañar su membrana celular (Fernández et al., 2005; Göblös et al., 2008), y pueden provocar pérdidas de biomasa activa por lavado al producirse flotación de la misma al adherirse la grasa a su superficie (Cirne et al., 2007).

Sin embargo, los lípidos son sustratos atractivos para la digestión anaerobia cuando son digeridos con otras corrientes (codigestión), debido a que comparados con proteínas o hidratos de carbono producen una gran cantidad de metano. En este contexto, los residuos ricos en lípidos puede ser considerado como una gran fuente potencial de energía renovable (Amon et al., 2006; Astals et al., 2011; Astals et al., 2012; Mobarak-Qamsari et al., 2012).

A modo de ejemplo, Ahrin (2003) describió un aumento significativo $(100 \%)$ en el rendimiento de metano cuando se añadió aceite de pescado a un digestor de estiércol. El beneficio de la adición de lípidos a un digestor con el fin de mejorar la producción de metano, por lo tanto, es una enfoque prometedor que debe ser mejor explorado.

\section{Digestión anaerobia. Base teórica}

El proceso de digestión anaerobia (DA) consiste en una cadena secuencial de rutas metabólicas y acciones de los diferentes grupos tróficos de bacterias anaerobias, que participan en la conversión de la materia orgánica compleja en metano y dióxido de carbono. Debido a la complejidad del proceso, es esencial que exista una relación equilibrada y coordinada entre los distintos grupos de bacterias presentes.

El proceso de la digestión anaerobia se compone de 4 etapas diferenciadas: 1) Desintegración e hidrólisis, 2) Acidogénesis, 3) Acetogénesis y 4) Metanogénesis, durante las cuales la materia orgánica va transformándose en distintos compuestos intermedios hasta convertirse en biogás (metano y dióxido de carbono principalmente) (Figura 1-1). El proceso posee una microbiología compleja, en la que intervienen distintas poblaciones microbianas con una relación simbiótica entre ellas. 
A continuación se describe cada una de las 4 etapas:

- 1) Hidrólisis: los microorganismos anaerobios excretan enzimas hidrolíticas que rompen los enlaces de los polisacáridos, proteínas y lípidos que forman el sustrato, produciendo unidades simples de azúcares, aminoácidos, y ácidos grasos.

- 2) Acidogénesis: los compuestos son asimilados por algunos microorganismos y/o fermentados, produciendo una gran cantidad de ácidos grasos volátiles. Se producen también gases como dióxido de carbono, hidrógeno y pequeñas cantidades de amoníaco, ácido sulfhídrico y alcoholes, en especial glicerol.

- 3) Acetogénesis: bacterias denominadas acetogénicas de lento crecimiento, metabolizan los alcoholes y los ácidos grasos volátiles, produciendo ácido acético e hidrógeno.

- 4) Metanogénesis: el acetato, hidrógeno, y dióxido de carbono producido, son transformados por acción de las bacterias metanogénicas, formando metano, dióxido de carbono y agua.

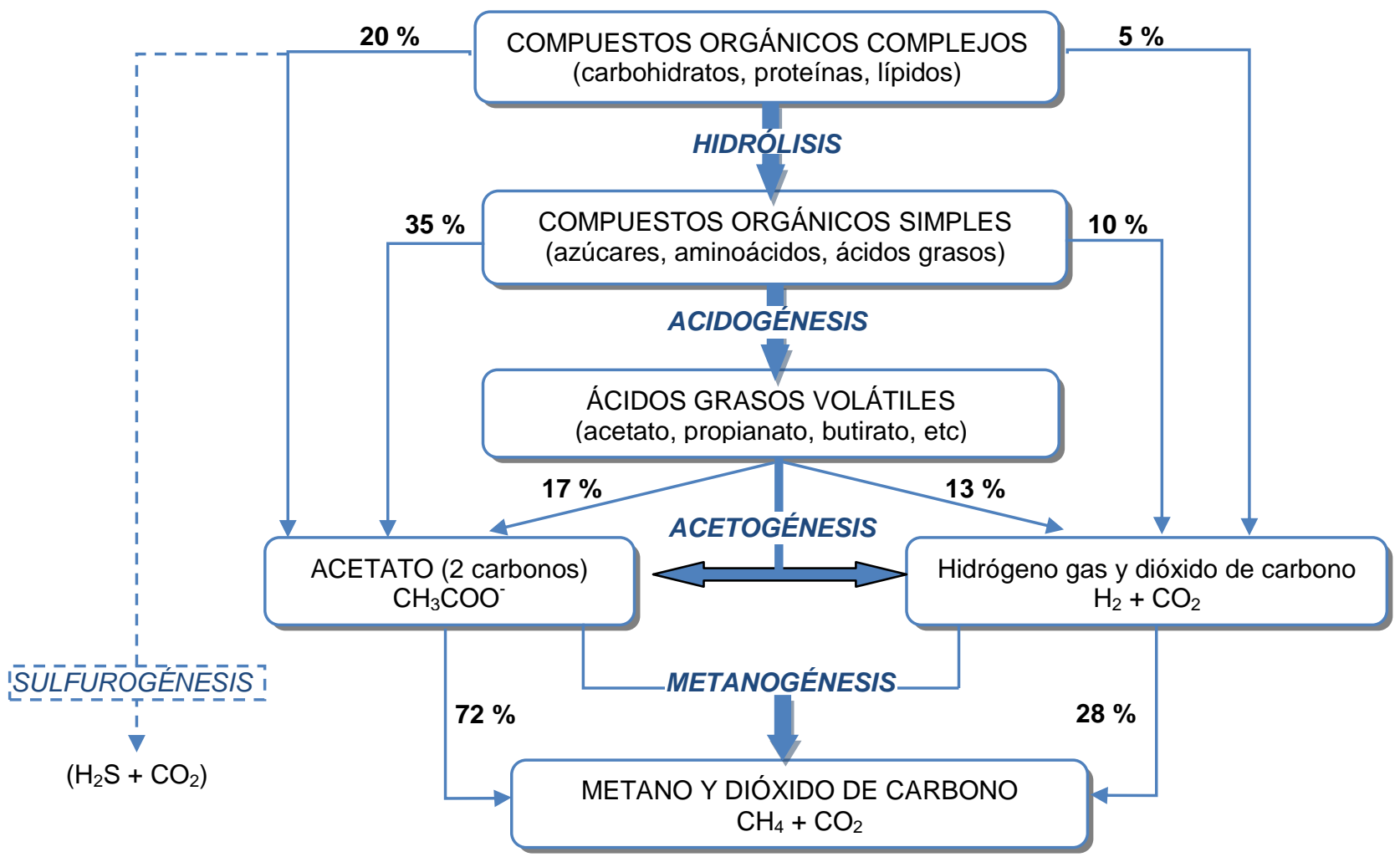

Figura 1-1. Esquema del proceso de digestión anaerobia. Fuente: Silvestre, 2014.

La digestión anaerobia tradicional se desarrolla en "digestores" donde en un mismo espacio físico se lleva a cabo todo el proceso biológico descrito anteriormente, incluyendo las cuatro etapas, con tiempos hidráulicos de residencia (THR) variables en función de la tipología de sustrato que se alimenta a los digestores, así como de otros factores como la temperatura, velocidad de carga orgánica, etc. Este tipo de digestión anaerobia es el más utilizado en la actualidad debido a su simplicidad de configuración y de operación. 
Una alternativa en auge es la digestión anaerobia en dos fases, que consiste en separar, de manera física, las etapas microbiológicas: en un primer digestor, el digestor acidogénico, se llevarían a cabo las dos primeras etapas, la hidrólisis y la acidogénesis de la materia orgánica, y en el segundo digestor, digestor metanogénico, alimentado con el efluente del digestor acidogénico, tendrían lugar las otras dos etapas, la acetogénesis y la metanogénesis.

Los microorganismos acidogénicos y metanogénicos no sólo difieren en términos de su capacidad nutricional y de requerimientos de $\mathrm{pH}$, sino también respecto a su fisiología, crecimiento y cinética de absorción de nutrientes, y en su capacidad a soportar los cambios ambientales. En consecuencia, las condiciones que son favorables para el crecimiento de las bacterias formadoras de ácidos (THR cortos, pH bajo), pueden ser inhibitorias para las bacterias formadoras de metano. Una ventaja de la DA en dos fases es que sus condiciones de funcionamiento pueden ser selectivamente determinadas para maximizar tanto el crecimiento de las bacterias formadoras de ácidos como de las bacterias formadoras de metano.

Por tanto, en este tipo de sistemas de DA en dos fases, se dispone de un reactor con las condiciones ideales ( $\mathrm{pH}$, concentración de substratos y carga orgánica) para el desarrollo de las bacterias acidogénicas y otro reactor con las condiciones ideales para las bacterias metanogénicas.

En la bibliografía puede verse como han sido propuestos sistemas de DA en dos fases más codigestión (tratamiento conjunto de dos o más residuos), para el tratamiento de corrientes de residuos que contienen altos niveles de lípidos, tales como residuos de cocina (Li et al., 2010 Yang et al., 2013; Zhang et al., 2007), residuos de productos lácteos (Demirer y Chen, 2005; Ince, 1998), efluentes de fábricas de helados (Borja y Banks, 1995), residuos de procesamiento de harina de pescado (Guerrero et al., 1999), residuos de mataderos (Wang y Banks, 2003) o residuos sólidos de almazara (Beccari et al., 1998; Borja et al., 2002; Travieso et al., 2008). Estos estudios han ilustrado las ventajas potenciales de la DA en dos fases sobre sistemas monofásicos en el tratamiento de sustancias complejas, por ejemplo tiempos de retención más cortos, eficiencia de conversión en gas más elevada y mayor concentración de metano en el gas producido (Bouallagui et al., 2005;. Demirer y Chen, 2005; Senthilkumar et al., 2011; Yu et al., 2002). Además, por un lado, puede permitir una reducción en el volumen total del reactor (Demirel y Yenigun, 2002; Ince, 1998), y por otro lado, la codigestión alivia el efecto inhibidor causado por altas concentraciones de grasa en alguna de las corrientes de alimentación (Yang et al., 2013).

El sistema de DA en dos fases permite que, en la primera fase, los contaminantes complejos sean degradados por las bacterias acidogénicas a ácidos grasos volátiles (AGV), para posteriormente ser convertidos a metano y dióxido de carbono por las bacterias acetogénicas y metanogénicas en la segunda fase. Esta configuración también incrementa la estabilidad del proceso mediante el control de la fase de acidificación para prevenir sobrecargas y la acumulación de material tóxico para la fase metanogénica (Demirel y Yenigün, 2002). Por otra parte, la primera etapa puede actuar como un búfer metabólico, previniendo un choque de $\mathrm{pH}$ a la población metanogénica. Con los residuos que contienen altas concentraciones de lípidos, la primera fase sirve principalmente para solubilizar los sólidos y, por lo tanto, conseguir 
posteriormente mayores velocidad de operación y de una forma más estable (Palenzuela, 1999).

Por otro lado, mediante la codigestión anaerobia se aprovecha la sinergia de las mezclas y se compensan las carencias de cada uno de los sustratos por separado, produciéndose, en muchos casos, un incremento en el rendimiento de la producción de metano y de biogás (Jensen et al., 2014; Silvestre et al., 2015).

Por tanto, el tratamiento conjunto de residuos ganaderos (purín de cerdo) y agroalimentarios (residuos procedentes del pretratamiento de aceites vegetales usados para la obtención de biodiesel) mediante codigestion anerobia en dos fases es un proceso que no se debe desaprovechar y que merece la pena investigar en más profundidad en un marco de economía circular como el existente en las políticas actuales de la Unión Europea, por la abundancia del primero de los residuos, la previsible tendencia al alza del segundo y su elevado potencial en la producción de energía. 


\section{OBJETIVOS}

Teniendo en cuenta las ventajas potenciales de la DA en dos fases y continuando la investigación en la mejora de la codigestión anaerobia de diferentes residuos, el objetivo general del presente trabajo ha sido profundizar en el estudio de un sistema de DA en dos fases para la codigestión de residuos ganaderos (purín de cerdo) y agroalimentarios (residuos procedentes del pretratamiento de aceites vegetales usados para la obtención de biodiesel) trabajando en el rango mesófilo de temperatura.

Más concretamente, los objetivos de este trabajo han sido los siguientes:

- Ratificar las ventajas de la DA en dos fases frente a la DA en una fase para el tratamiento de residuos procedentes del pretratamiento de AVU para la obtención de biodiesel, con alto contenido en lípidos.

- Diseño y construcción de un prototipo de planta de digestión anaerobia en dos fases, demostrando la viabilidad técnica del proceso.

- Evaluación de los valores óptimos de producción de biogás y de eliminación de materia orgánica de los residuos bajo diferentes condiciones de operación.

- Análisis de las sinergias derivadas de la codigestión de mezclas de residuos en diferentes proporciones.

- Estudio del cierre del ciclo de aprovechamiento de nutrientes mediante valorización del digestato. 


\section{METODOLOGÍA Y RESULTADOS}

\subsection{Introducción}

La metodología de trabajo seguida comprende los siguientes aspectos:

- Selección y caracterización de muestras representativas de purín porcino y residuos del proceso de pretratamiento de aceites vegetales usados para la obtención de biodiesel (PM y OW de sus siglas en inglés). Se realiza una caracterización físico - química de las mismas y se determina el potencial metanogénico para dos tipos de inóculos. Como resultado de este apartado ha sido publicado el artículo "Effects of inoculum source and co-digestion strategies on anaerobic digestion of residues generated in the treatment of waste vegetable oils".

- Estudio comparativo de sistemas de digestión anaerobia en una y dos fases a escala laboratorio. Se diseñan y construyen dos montajes, uno para el sistema de DA en una fase y otro para el sistema de DA en dos fases, y se realiza un análisis comparativo a escala laboratorio del comportamiento de ambos sistemas. El estudio de ambos sistemas se ha realizado en paralelo, con las mismas condiciones de operación (tipo de inóculo, tipo de residuo, tiempo hidráulico de residencia total, temperatura, $\mathrm{pH}$ y velocidad de carga orgánica). Se buscan las condiciones óptimas de tratamiento para el sistema en dos fases y se analiza su estabilidad frente al sistema en una fase. Como resultado de este estudio ha sido publicado el artículo "Single-phase and two-phase anaerobic co-digestion of residues from the treatment process of waste vegetable oil and pig manure".

- Diseño, construcción y operación en continuo de una planta piloto de digestión anaerobia en dos fases. Se evalúan los rendimientos de eliminación de sólidos volátiles, generación de biogás y los parámetros de diseño, principalmente tiempos hidráulicos de residencia y carga orgánica asimilada por el sistema. Antes de introducir la alimentación en el digestor, se estudia el sistema de pretratamiento más adecuado con el propósito de trabajar con un flujo de entrada al sistema tan homogéneo como sea posible, en condiciones físicas adecuadas y sin elementos extraños que puedan dañar el sistema. Como resultado de este punto de la tesis ha sido publicado el artículo "Two-phase anaerobic co-digestion of used vegetable oils' wastes and pig manure".

- Estudio del cierre de ciclo mediante valorización del digestato. Se recopilan diferentes técnicas de recuperación de nutrientes, incidiendo en el aprovechamiento del fósforo y nitrógeno que contiene el digestato a partir de su transformación en estruvita mediante un proceso de cristalización. 
En los siguientes apartados se desarrollan estos puntos y se muestran los resultados obtenidos.

\subsection{Selección y procedimientos utilizados para la caracterización de muestras representativas de residuos}

Para el presente trabajo de tesis se han seleccionado, por las razones indicadas en el apartado 1 "Generalidades y Motivación", y dentro del abanico existente de residuos ganaderos, el purín porcino, y dentro de los residuos agroalimentarios, los residuos generados en el proceso de pretratamiento de residuos de aceites vegetales usados para la producción de biodiesel.

Las muestras de OW y PM se recogieron semanalmente y fueron almacenadas a $4 \stackrel{\circ}{\circ} \mathrm{C}$ en un frigorífico hasta su utilización. OW fue suministrado por una empresa de producción de biodiesel situada en Madrid y las muestras de PM por una granja de cría de cerdos situada a $30 \mathrm{~km}$ de Valladolid.

Las muestras de OW recogidas de la etapa de pretratamiento de aceites vegetales usados para la obtención de biodiesel se componen a su vez de los siguientes residuos:

- RIF: residuo sólido que se obtiene tras el filtrado de los aceites vegetales usados en la primera etapa del pretratamiento. Son restos de comida con alta carga orgánica.

- DS: residuo sólido sedimentado en el tanque donde se almacenan los aceites vegetales usados tras su filtración.

- DDS: residuo líquido procedente del lavado de los tanques donde se almacenan los aceites vegetales usados tras su filtración, una vez eliminados los residuos sólidos sedimentados.

- DTS: residuo semisólido que se obtiene tras la centrifugación de los residuos decantados después del calentamiento de los aceites filtrados.

- OPT: aguas residuales que se obtienen tras la centrifugación de los residuos decantados después del calentamiento de los aceites filtrados.

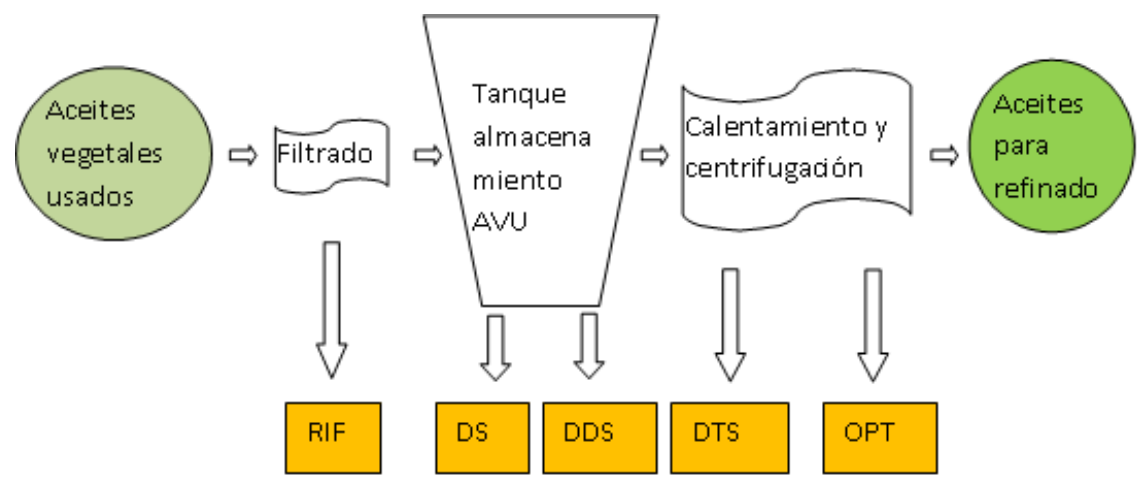

Figura 3-1. Esquema del pretratamiento de aceites vegetales usados.

El porcentaje en el que participa cada uno de los residuos que componen el OW es el siguiente: $40 \%$ RIF, $15 \%$ DS, $15 \%$ DDS, $15 \%$ DTS y $15 \%$ OPT. 
Para la caracterización del PM y del OW se determinó la concentración de sólidos totales y volátiles (ST, SV), la demanda química de oxígeno (DQO), el contenido en grasa, la alcalinidad, el contenido en proteínas, el contenido en nitrógeno amoniacal $\left(\mathrm{N}-\mathrm{NH}_{4}\right.$ ), el contenido en fósforo, el pH, la composición elemental (contenido en $\mathrm{C}, \mathrm{N}$, $H, y S$ ), la concentración de ácidos grasos (AG), el contenido en cenizas, y el potencial metanogénico teórico. El contenido en oxígeno no se midió de forma directa, sino que fue estimado asumiendo que en la muestra no había otros compuestos distintos de $\mathrm{C}$, $H, N, S$ y $P$.

A continuación se explica brevemente como se ha realizado la determinación de cada uno de estos parámetros:

\subsubsection{Concentración de Sólidos Totales $\left(g L^{-1} S T\right)$}

La determinación de los sólidos totales de las muestras se ha realizado mediante un método gravimétrico, por el cual se determinan los contenidos de materias disueltas y suspendidas presentes en la muestra. Su determinación se basa en una medición cuantitativa de la variación de peso que experimenta una cápsula, previamente tarada, tras la evaporación de la muestra y secado a $105^{\circ} \mathrm{C}$, hasta peso constante.

Las referencias seguidas en la determinación han sido:

- APHA-AWWA-WPCF "Métodos Normalizados para el análisis de aguas residuales y potables. Sólidos totales secados a 103-105 ㄷ․

- Norma UNE 77030:2002. "Método de análisis de aguas industriales. Residuo Total". "Calidad del agua". AENOR.

En la determinación de la concentración de sólidos totales se ha empleado una balanza analítica, marca Sartorius, modelo TE 214S (Figura 3-2) y una estufa marca Selecta, modelo Digitronic (Figura 3-3).

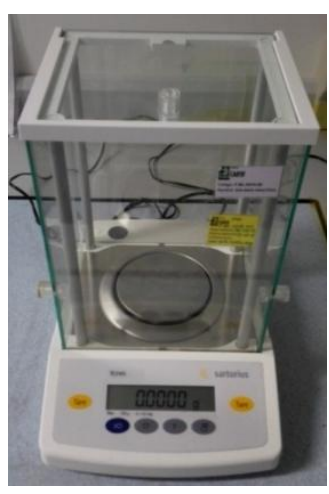

Figura 3-2. Balanza analítica

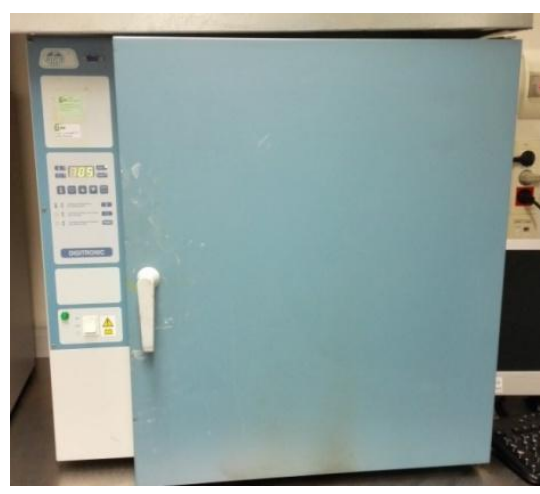

Figura 3-3. Estufa 


\subsubsection{Concentración de Sólidos Volátiles $\left(g \mathrm{~L}^{-1} \mathrm{SV}\right)$}

La medida de concentración de sólidos volátiles de las diferentes muestras se ha realizado a partir de un método gravimétrico, en el que se ha determinado la cantidad de muestra capaz de volatilizarse por el efecto de la calcinación a $550{ }^{\circ} \mathrm{C}$ hasta pesada constante.

Para ello, se ha utilizado una balanza analítica marca Sartorius, modelo TE $214 S$ (Figura 3-2), estufa marca Selecta, modelo Digitronic (Figura 3-3) y un horno mufla marca Carbolite, modelo ELF11/14 1201 (Figura 3-4).

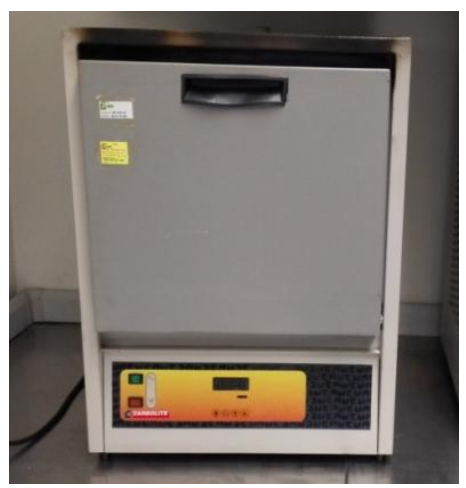

Figura 3-4. Horno mufla

La referencia seguida en la determinación ha sido:

- APHA-AWWA-WPCF "Métodos Normalizados para el análisis de aguas residuales y potables. Sólidos fijos y volátiles incinerados a $550^{\circ} \mathrm{C}$ ".

\subsubsection{Demanda Química de Oxígeno (DQO)}

La demanda química de oxígeno es un parámetro que mide la cantidad de sustancias que hay disueltas 0 en suspensión en una muestra líquida susceptibles de ser oxidadas por medios químicos. Para ello se empleó un método titulométrico, en el cual la muestra se llevó a ebullición en reflujo cerrado en presencia de dicromato potásico y en medio ácido. La materia orgánica se oxida de esta forma por el dicromato, valorando el exceso de este reactivo.

Los equipos necesarios para la realización de este análisis fueron: un digestor marca Hach, modelo COD Reactor (Figura 3-5) y una bureta digital marca Brand (Figura 3-6). 


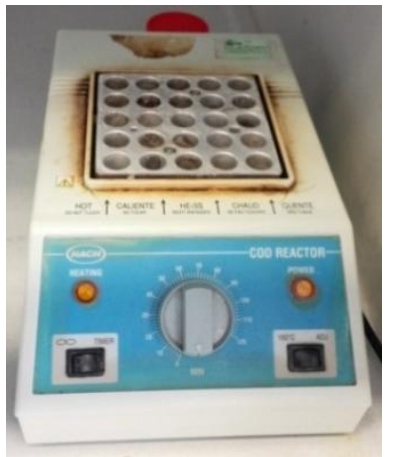

Figura 3-5. Digestor marca Hach

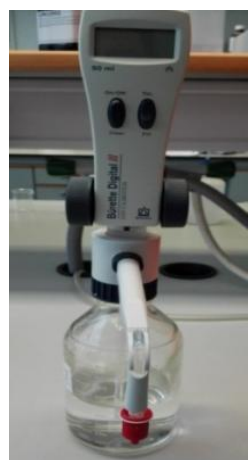

Figura 3-6. Bureta digital Brand

Las referencias seguidas en la ejecución del análisis fueron:

- APHA-AWWA-WPCF "Métodos Normalizados para el análisis de aguas residuales y potables. 5220C. Reflujo cerrado, método titulométrico".

- Norma UNE 77-0004:2002. "Calidad del agua. Determinación de la Demanda Química de Oxígeno (DQO). Método del dicromato". AENOR.

\subsubsection{Contenido en grasa (\% Grasas)}

La determinación del contenido en grasa de una muestra se ha realizado mediante extracción sólido-líquido (extracción Soxhlet), donde se determinan cuantitativamente grupos de sustancias con la característica común de su solubilidad en n-hexano. La muestra se debe acidificar a $\mathrm{pH}<2$ para eliminar aceites y grasas en solución. Después se aíslan por filtración, se extraen con n-hexano, se evapora el solvente y se pesa el residuo.

Para ello, se ha utilizado una balanza analítica marca Sartorius, modelo TE 214S (Figura 3-2), estufa marca Selecta, modelo Digitronic (Figura 3-3), un extractor Soxhlet (Figura 3-7), y un rotavapor (Figura 3-8).

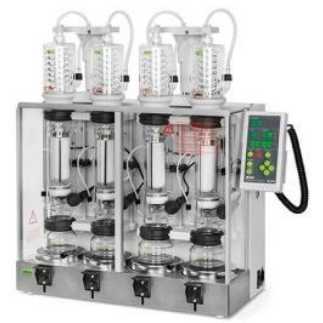

Figura 3-7. Extractor Soxhlet

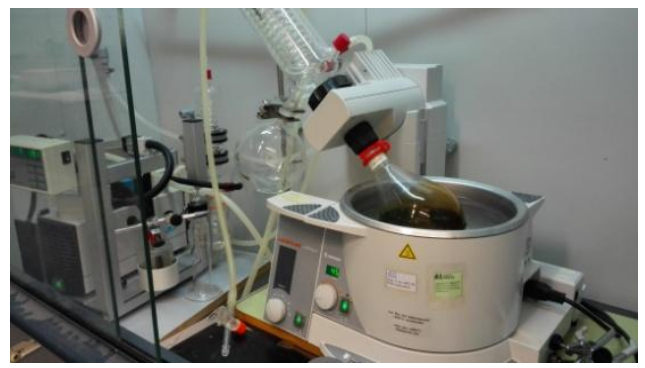

Figura 3-8. Rotavapor

La referencia seguida en la ejecución del análisis fue:

- $\quad$ APHA-AWWA-WPCF. "Métodos Normalizados para el Análisis de aguas residuales y potables". Parte 5520, aceite y grasa. 


\subsubsection{Alcalinidad (mM)}

La alcalinidad de una solución acuosa es su capacidad para neutralizar ácidos y es la suma de todas las bases titulables. Es la cantidad de ácido que se requiere por litro de solución acuosa para disminuir el pH a un valor aproximado de 4,3. Esta capacidad se puede atribuir a la presencia de bases como carbonatos, bicarbonatos e hidróxidos, así como a especies presentes en pequeñas concentraciones de silicatos, boratos, amoníaco, fosfatos y bases orgánicas. Su valor puede variar significativamente con el $\mathrm{pH}$ del punto final. La muestra se valora con una solución de ácido clorhídrico hasta $\mathrm{pH} 8,3$ y 4,5. Estos puntos finales determinados visualmente mediante indicadores adecuados, son los puntos de equivalencia seleccionados para la determinación de los tres componentes fundamentales. Con el indicador de fenolftaleína, el pH 8,3 está próximo al punto de equivalencia para las concentraciones de carbonato y dióxido de carbono y representa la valoración de todo el hidróxido y la mitad del carbonato, mientras que con el indicador anaranjado de metilo, el pH inferior $(4,5)$ está próximo al punto de equivalencia para el ión hidrógeno y el bicarbonato y permite determinar la alcalinidad total.

Los equipos necesarios para la realización de este análisis fueron: una bureta digital marca Brand (Figura 3-5) y un agitador magnético.

La referencia seguida en la ejecución del análisis fue:

- $\quad$ APHA-AWWA-WEF (2005) Standard Methods for the Examination of Water and Wastewater. 21th Edition. New York, 2-27 a 2-29, método 2320.

\subsubsection{Contenido en proteínas (\% Proteinas)}

El contenido en proteínas se ha calculado a partir de la determinación del nitrógeno Kjedahl de la muestra y aplicando al resultado un factor de conversión empírico de 6,25 , ya que las diferentes proteínas existentes coinciden en una proporción similar de nitrógeno orgánico. La mayor desventaja del método Kjeldah es que no diferencia entre nitrógeno protéico y no-protéico (NNP) y exiten ciertos productos animales de desecho los cuales pueden contener cantidades considerables de NNP, como por ejemplo, la gallinaza seca, pero no es el caso del PM o del OW.

El nitrógeno Kjedahl total determina el contenido de nitrógeno orgánico de una muestra después de su mineralización. No se incluye el nitrógeno en forma de nitrito 0 nitrato. El método empleado ha sido un método titulométrico, por el cual la muestra se mineraliza en medio ácido con ácido sulfúrico, sulfato potásico para aumentar el punto de ebullición y sulfato de cobre como catalizador. Durante la mineralización a altas temperaturas, el nitrógeno orgánico, el amoníaco libre y el amonio se convierten en sulfato amónico. Posteriormente, se destila en medio alcalino recogiendo el destilado sobre ácido bórico. Finalmente, se valora por desplazamiento el borato amónico con ácido clorhídrico o ácido sulfúrico. En los análisis se ha dispuesto de un digestor marca Selecta, modelo RAT 2 (Figura 3-9), un destilador marca Tecator, modelo 1026 (Figura 3-10) y una bureta digital marca Brand (Figura 3-6). 


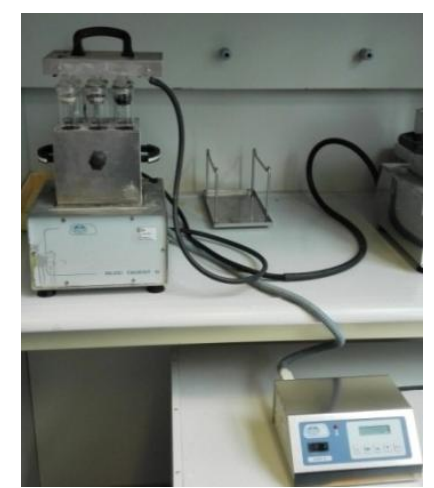

Figura 3-9. Digestor Selecta

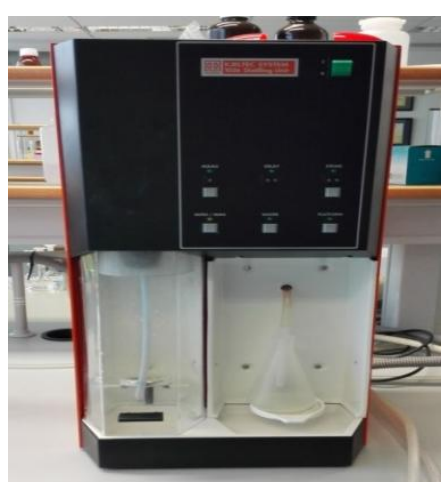

Figura 3-10. Destilador Tecator

Las referencias seguidas en la realización del análisis son:

- Norma UNE-EN 25663:1994. "Calidad del agua". "Determinación de Nitrógeno Kjedahl. Método de mineralización con Selenio". AENOR.

- APHA-AWWA-WPCF "Métodos Normalizados para el análisis de aguas residuales y potables. Nitrógeno".

\subsubsection{Nitrógeno amoniacal $\left(\mathrm{gNL}^{-1} \mathrm{~N}-\mathrm{NH}_{4}\right)$}

Se determina el nitrógeno amoniacal contenido en muestras acuosas mediante el método titulométrico. La muestra se tampona a pH 9,5 con un tampón de borato para reducir la hidrólisis de los cianatos y los compuestos orgánicos nitrogenados. Se destila, en medio alcalino, recogiendo el destilado sobre una solución de ácido bórico y se valora con ácido clorhídrico o sulfúrico. En los análisis, se ha dispuesto de un destilador marca Tecator, modelo 1026 (Figura 3-10) y una bureta digital marca Brand (Figura 3-6).

Las referencias seguidas en la realización del análisis son:

- APHA-AWWA-WPCF. "Métodos Normalizados para el Análisis de Aguas Residuales y Potables". "Nitrógeno".

- Norma UNE 77028:2002. "Calidad del Agua. Determinación del nitrógeno amoniacal. Método por destilación y valoración o colorimetría”. AENOR.

\subsubsection{Fósforo Total (\%P)}

La determinación del fósforo total se ha efectuado por espectrofotometría del ácido vanadomolibdofosfórico. El fósforo es digerido para liberarlo de la materia orgánica a la que pudiera estar unido, convirtiéndose en ortofosfato, que reacciona con molibdato 
amónico y vanadio generando un compuesto de color amarillo, que es proporcional a la cantidad de fósforo de la muestra.

Los análisis se han realizado en un espectrofotómetro UV-VIS marca Shimadzu, modelo UV-1603 (Figura 3-11) y un digestor marca Selecta, modelo RAT 2 (Figura 3-9).

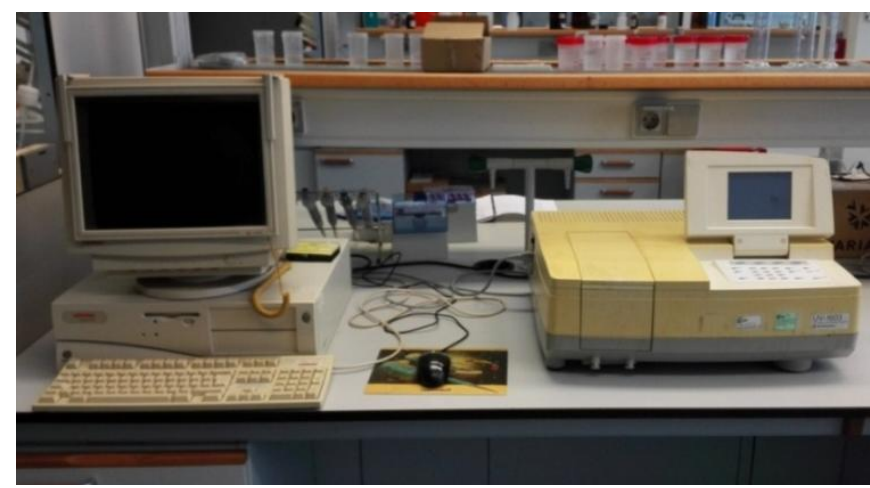

Figura 3-11. Espectrofotómetro UV-VIS

Las referencias seguidas en la realización del análisis son:

- APHA-AWWA-WPCF "Métodos normalizados para el análisis de aguas residuales y potables". "4500-PC. Método colorimétrico del ácido vanadomolibdofosfórico".

- Norma UNE-EN ISO 6878 "Calidad del agua". "Determinación del fósforo. Método espectrométrico del molibdato amónico". 2005. AENOR.

\subsection{9 $p H$}

La determinación del $\mathrm{pH}$ se ha realizado a partir de un método potenciométrico, con el cual se cuantifica la actividad de los iones hidrógeno mediante un electrodo indicador y otro de referencia. Para realizar las medidas se ha empleado un $\mathrm{pH}$-metro marca Crison, modelo pH25 (Figura 3-12).

La referencia seguida en la medida de $\mathrm{pH}$ de las muestras ha sido:

- APHA-AWWA-WPCF "Métodos Normalizados para el análisis de aguas residuales y potables. Valor de $\mathrm{pH}$ ". 


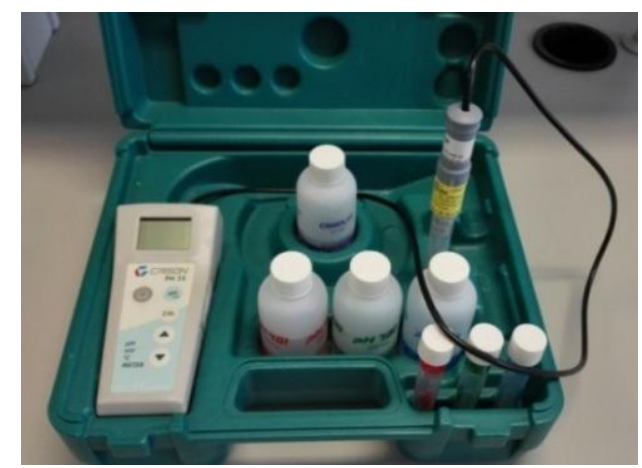

Figura 3-12. $\mathrm{pH}$-metro

\subsubsection{Análisis elemental de $C, H, N, S(\%)$}

Para la determinación del contenido en carbono, hidrógeno, nitrógeno y azufre de las muestras se ha utilizado un analizador elemental Marca LECO, modelo TruSpec CHNS (Figura 3-13). La técnica está basada en la completa e instantánea oxidación de la muestra mediante una combustión con oxígeno puro a una temperatura variable entre 100 y $1000 \stackrel{\circ}{\circ}$. Los diferentes productos de combustión $\mathrm{CO}_{2}, \mathrm{H}_{2} \mathrm{O}$ y SO $\mathrm{SO}_{2}$, son posteriormente cuantificados mediante celda de infrarrojo, mientras que en el caso de $\mathrm{N}_{2}$ se cuantifica con una celda de conductividad térmica.

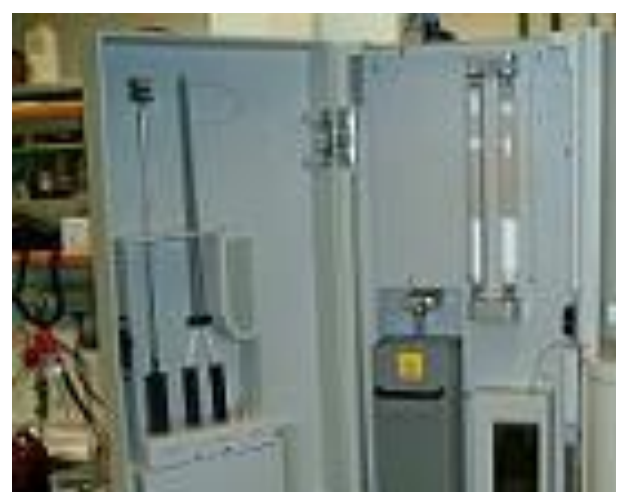

Figura 3-13. Detalle del interior del módulo CHNS del analizador elemental

\subsubsection{Contenido de ácidos grasos (\% AG)}

El método empleado en la determinación de los AG es el Reglamento (CE) № 2568/91 de la Comisión. Anexo X. Dicho método recoge las indicaciones para determinar, mediante cromatografía de gases, la composición cualitativa y cuantitativa de una mezcla de ácidos grasos de una muestra.

Para la realización de los análisis se ha utilizado un cromatógrafo de gases acoplado a un detector de ionización de llama (GC-FID), modelo CP 3800 GC de VARIAN 
(Figura 3-14) equipado con una columna capilar CP -Sil 88 (60 m 0,25 mm, Varian) y un autoinyector CP - 8410, todo de la marca Varian Inc.

Las condiciones de operación fueron las siguientes:

- Volumen de inyección: $2 \mu \mathrm{l}\left(\right.$ a $\left.220^{\circ} \mathrm{C}\right)$.

- Gas portador: helio $(1 \mathrm{ml} / \mathrm{min})$.

- Temperatura de detector: constante a $235^{\circ} \mathrm{C}$.

- Temperatura de columna: $120{ }^{\circ} \mathrm{C}$ durante 1 minuto y luego se aumentó a 170 ${ }^{\circ} \mathrm{C}$ a una velocidad de $3{ }^{\circ} \mathrm{C} / \mathrm{min}$, se mantuvo durante 1 min y finalmente ascendió a $235{ }^{\circ} \mathrm{C}$ en incrementos de $6{ }^{\circ} \mathrm{C} / \mathrm{min}$, quedando finalmente 5 minutos a $235^{\circ} \mathrm{C}$.

La identificación de los ácidos grasos se basó en la comparación de tiempos de retención del patrón, y el área bajo la curva de los picos. Se cuantificó usando el software de la estación de trabajo Galaxie.

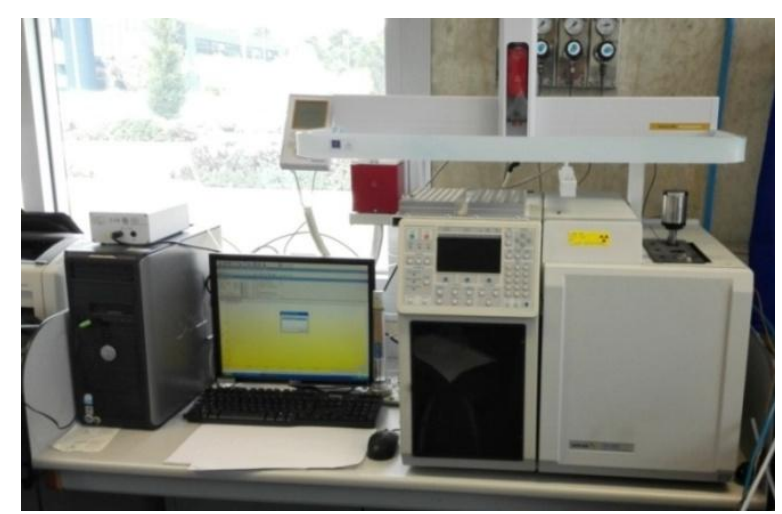

Figura 3-14. GC-FID

\subsubsection{Potencial metanogénico teórico $\left(B_{0, T h}\right)$}

El potencial metanogénico teórico ha sido calculado según la ecuación de Buswell (Ec.1), a partir de los resultados de los análisis de composición elemental realizados a cada uno de los residuos. Esta ecuación asume una producción de metano para una degradación completa de un residuo con una composición elemental dada, donde $\mathrm{C}_{\mathrm{n}} \mathrm{H}_{\mathrm{a}} \mathrm{O}_{\mathrm{b}} \mathrm{N}_{\mathrm{c}}$ representa la formula química del compuesto orgánico biodegradable (el contenido de $\mathrm{S}$ y $\mathrm{P}$ no se tiene en cuenta). Según Buswell, el potencial metanogénico teórico, en condiciones estándar de presión y de temperatura, puede ser calculado según la ecuación 1 , donde $n, a$, b y c corresponden a los índices estequiométricos del $\mathrm{C}, \mathrm{H}, \mathrm{O}$ y $\mathrm{N}$ respectivamente.

$C_{n} H_{a} O_{b} N_{c}+\left(n-\frac{a}{4}-\frac{b}{2}+\frac{3 c}{4}\right) \mathrm{H}_{2} \mathrm{O} \rightarrow\left(\frac{n}{2}+\frac{a}{8}-\frac{b}{4}-\frac{3 c}{8}\right) \mathrm{CH}_{4}+\left(\frac{n}{2}-\frac{a}{8}+\frac{b}{4}+\frac{3 c}{8}\right) \mathrm{CO}_{2}+c \mathrm{NH}_{3}$

$\mathrm{B}_{0, \mathrm{Th}}=\frac{\left(\frac{\mathrm{n}}{2}+\frac{\mathrm{a}}{8}-\frac{\mathrm{b}}{4}-\frac{3 \mathrm{c}}{8}\right) \cdot 22.4}{12 \mathrm{n}+\mathrm{a}+16 \mathrm{~b}+14 \mathrm{c}}|=| \frac{\mathrm{L} \mathrm{CH}_{4}}{\mathrm{~g} \mathrm{SV}} \quad$ Ec. 1. Ecuación de Buswell. 


\subsubsection{Procedimiento para la realización de los test de actividad metanogénica}

Para determinar la actividad metanogénica específica de cada inóculo se realizaron test de actividad a cada uno de ellos, utilizando una mezcla de ácido acético, ácido propiónico y ácido butírico en la proporción 2:0.5:0.5 $\mathrm{g} \cdot \mathrm{L}^{-1}$, con lo que se tiene una carga orgánica de $2,5 \mathrm{gDQO} \mathrm{L}^{-1}$.

El procedimiento seguido para la realización de los test de actividad ha sido el siguiente:

- Se adiciona a los digestores una cantidad de agua destilada calculada previamente para obtener una relación gas/volumen total del sistema de 0,3 .

- Para asegurar la ausencia de oxígeno en el medio, se añade $1 \mathrm{~mL} \cdot \mathrm{L}^{-1}$ de disolución concentrada de sulfuro de sodio $\left(100 \mathrm{~g} \mathrm{Na}_{2} \mathrm{~S} \cdot 9 \mathrm{H}_{2} \mathrm{O} \cdot \mathrm{L}^{-1}\right)$.

- Se añade la disolución de macronutrientes y elementos traza $\left(1 \mathrm{~mL} \cdot \mathrm{L}^{-1}\right)$.

Tabla 3-1. Disolución de macronutrientes y elementos traza

\begin{tabular}{|l|c|}
\hline \multicolumn{2}{|c|}{ Disolución de macronutrientes } \\
\hline $\mathrm{NH}_{4} \mathrm{Cl}$ & $170 \mathrm{~g} \cdot \mathrm{L}^{-1}$ \\
\hline $\mathrm{KH}_{2} \mathrm{PO}_{4}$ & $38 \mathrm{~g} \cdot \mathrm{L}^{-1}$ \\
\hline $\mathrm{CaCl}_{2} \cdot 2 \mathrm{H}_{2} \mathrm{O}$ & $8 \mathrm{~g} \cdot \mathrm{L}^{-1}$ \\
\hline $\mathrm{MgSO}_{4} \cdot 4 \mathrm{H}_{2} \mathrm{O}$ & $9 \mathrm{~g} \cdot \mathrm{L}^{-1}$ \\
\hline \multicolumn{2}{|c|}{ Disolución de elementos traza } \\
\hline $\mathrm{FeCl}_{3} \cdot 4 \mathrm{H}_{2} \mathrm{O}$ & $2000 \mathrm{mg} \cdot \mathrm{L}^{-1}$ \\
\hline $\mathrm{CoCl}_{2} \cdot 6 \mathrm{H}_{2} \mathrm{O}$ & $2000 \mathrm{mg} \cdot \mathrm{L}^{-1}$ \\
\hline $\mathrm{MnCl}_{2} \cdot 4 \mathrm{H}_{2} \mathrm{O}$ & $500 \mathrm{mg} \cdot \mathrm{L}^{-1}$ \\
\hline $\mathrm{CuCl}_{2} \cdot 2 \mathrm{H}_{2} \mathrm{O}$ & $30 \mathrm{mg} \cdot \mathrm{L}^{-1}$ \\
\hline $\mathrm{ZnCl}_{2}$ & $50 \mathrm{mg} \cdot \mathrm{L}^{-1}$ \\
\hline $\mathrm{H}_{3} \mathrm{BO}_{3}$ & $50 \mathrm{mg} \cdot \mathrm{L}^{-1}$ \\
\hline$\left(\mathrm{NH}_{4}\right)_{6} \mathrm{Mo}_{7} \mathrm{O}_{24} \cdot 4 \mathrm{H}_{2} \mathrm{O}$ & $90 \mathrm{mg} \cdot \mathrm{L}^{-1}$ \\
\hline $\mathrm{Na}_{2} \mathrm{SeO}_{3} \cdot 5 \mathrm{H}_{2} \mathrm{O}$ & $100 \mathrm{mg} \cdot \mathrm{L}^{-1}$ \\
\hline $\mathrm{NiCl}_{2} \cdot 6 \mathrm{H}_{2} \mathrm{O}$ & $50 \mathrm{mg} \cdot \mathrm{L}^{-1}$ \\
\hline $\mathrm{EDTA}^{2}$ & $1000 \mathrm{mg} \cdot \mathrm{L}^{-1}$ \\
\hline $\mathrm{Resorcina}$ & $500 \mathrm{mg} \cdot \mathrm{L}^{-1}$ \\
\hline
\end{tabular}

- Se añade la cantidad de inóculo necesario para obtener una concentración de $10,0 \mathrm{~g}$ SSVinóculo $\mathrm{L}^{-1}$.

- Se añade como sustrato una mezcla de ácido acético $\left(2,0 \mathrm{~g} \cdot \mathrm{L}^{-1}\right)$, ácido propiónico $\left(0,5 \mathrm{~g} \cdot \mathrm{L}^{-1}\right)$ y ácido butírico $\left(0,5 \mathrm{~g} \cdot \mathrm{L}^{-1}\right)$ para obtener una $\mathrm{DQO}=2,5 \mathrm{~g} \cdot \mathrm{L}^{-1}$.

- Se ajustan todos los ensayos a pH 7,5 \pm 0.1 con $\mathrm{HCl}$ y $\mathrm{NaOH}$.

- Se toma una muestra líquida para determinar la DQO al inicio del ensayo.

- Se purga el aire de todos los digestores mediante la introducción de nitrógeno, y se sellan.

- Se colocan los digestores en el agitador orbital, dentro de una cámara termostática (35 $\left.\pm 2{ }^{\circ} \mathrm{C}\right)$, y se inicia la agitación (100 rpm).

- Se realizan medidas periódicas de la presión en el interior de los reactores (Figura 3-15). 
- Periódicamente durante el ensayo se analiza la composición del biogás según se indica en el apartado 3.2.14 "Procedimiento para la realización de los test de biodegradabilidad".

- Al final del ensayo se mide la composición del biogás, se despresuriza el sistema y se toma muestra del medio líquido para analizar la DQO y el pH.

\subsubsection{Procedimiento para la realización de los test de biodegradabilidad}

El procedimiento seguido para la realización de los test de biodegradabilidad ha sido el siguiente:

- Se adiciona a los digestores una cantidad de agua destilada calculada previamente para obtener una relación gas/volumen total del sistema de 0,3 .

- Para asegurar la ausencia de oxígeno en el medio, se añade $1,0 \mathrm{~mL} \cdot \mathrm{L}^{-1}$ de disolución concentrada de sulfuro de sodio $\left(100 \mathrm{~g} \mathrm{Na}_{2} \mathrm{~S} \cdot 9 \mathrm{H}_{2} \mathrm{O} \cdot \mathrm{L}^{-1}\right)$. Con el fin de evitar la acidificación del ensayo se añade $\mathrm{NaHCO}_{3} \mathrm{Como}_{\text {tampón, en }}$ una concentración de $5,0 \mathrm{~g}$ de $\mathrm{NaHCO}_{3} \cdot \mathrm{L}^{-1}$.

- Se añade la cantidad de inóculo necesario para obtener una concentración de $5,0 \mathrm{~g}$ SSVinóculo $\cdot \mathrm{L}^{-1}$.

- Se añade el residuo a tratar, en una relación $S / X=0,5 \mathrm{gSSVresiduo \cdot gSSV}{ }^{-1}$ inóculo. Se trabaja con ensayos por triplicado para cada residuo, y se realiza también un conjunto de ensayos de blanco sin residuo (sólo inóculo) por triplicado, para determinar la producción de metano endógena.

- Se ajustan todos los ensayos a pH 7,5 $\pm 0,1 \mathrm{con} \mathrm{HCl}$ y $\mathrm{NaOH}$.

- Se purga el aire de todos los digestores mediante la introducción de nitrógeno, y se sellan.

- Se colocan los digestores en el agitador orbital, dentro de una cámara termostática ( $35 \pm 2{ }^{\circ} \mathrm{C}$ ), y se inicia la agitación (100 rpm).

- Se realizan medidas periódicas de la presión en el interior de los reactores (Figura 3-15).

- Periódicamente durante el ensayo se analiza la composición del biogás.

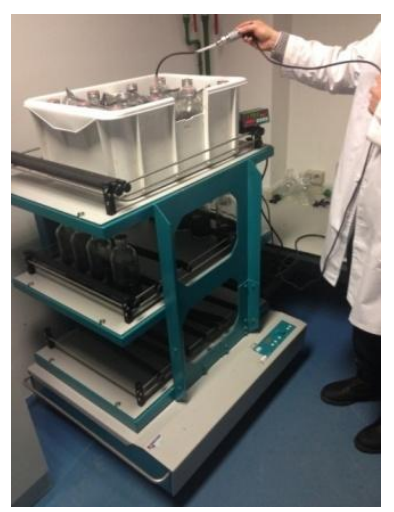

Figura 3-15. Determinación de presión en el interior de los digestores 
La producción de biogás fue medida manualmente mediante un transmisor de presión (Druck, PTX 1400, rango 1 bar) conectado al espacio libre en la cabeza de cada reactor. Las diferencias de presión eran convertidas a volumen de biogás utilizando la ley de gases ideales y condiciones normales de presión y temperatura ( $P=1$ bar y $T=0 \stackrel{\circ}{ } \mathrm{C})$. La composición del biogás fue medida de forma previa a cada liberación mediante un equipo Varian CP-4900 Micro-GC con detector térmico de conductividad (Figura 3-16).

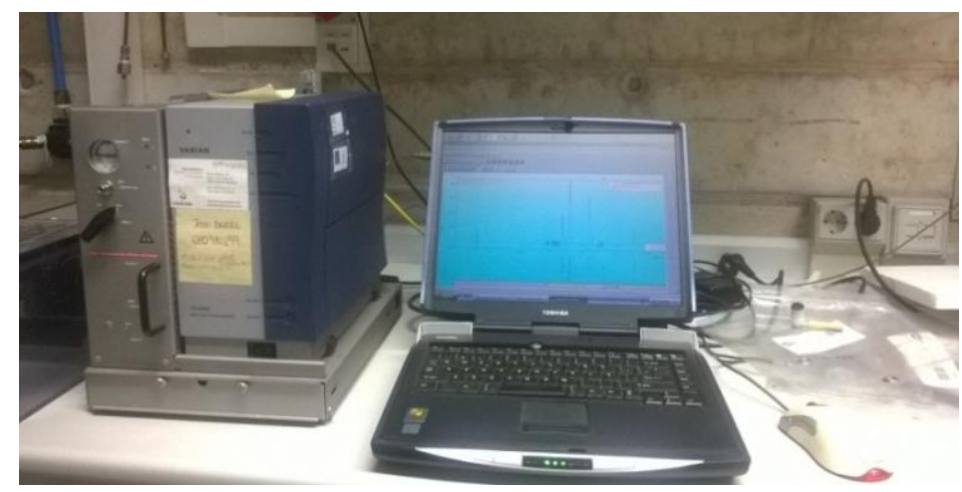

Figura 3-16. Micro GC para determinación de $\mathrm{CH}_{4}$

El método empleado en la realización de los análisis del biogás aparece en la Tabla 3-2.

Tabla 3-2. Condiciones del método de análisis de biogás mediante Micro-G

\begin{tabular}{|ll|}
\hline & Canal B \\
\hline Temperatura de inyección & $110^{\circ} \mathrm{C}$ \\
\hline Temperatura del horno & $60^{\circ} \mathrm{C}$ \\
\hline Tiempo de adquisición & $40 \mathrm{~s}$ \\
\hline Tiempo de inyección & $10 \mathrm{~ms}$ \\
\hline Presión & $10 \mathrm{psi}$ \\
\hline Gas portador & $\mathrm{He}$ \\
\hline
\end{tabular}

\subsection{Resultados obtenidos de la caracterización de cada uno de los residuos}

En la Tabla 3-3 y Tabla 3-4 se recogen los resultados obtenidos de la caracterización de los residuos seleccionados. Todas las muestras se analizaron por triplicado y la desviación estándar para todos los parámetros analizados fue menor del 15\%.

Tabla 3-3. Caracterización de los residuos y de sus mezclas

\begin{tabular}{|cccccccccc|}
\hline Residuo & $\mathrm{pH}$ & Alcalinidad & $\mathbf{N}-\mathrm{NH}_{4}$ & $\mathrm{DQO}$ & $\mathrm{ST}$ & $\mathrm{SV}$ & \multicolumn{2}{c|}{ SV/ST } & \multicolumn{2}{c|}{ Grasas } & Proteínas \\
& - & $\mathbf{m M}$ & $\mathbf{g N ~ \mathbf { ~ } ^ { - 1 }}$ & $\mathbf{g ~ L}^{-1}$ & $\mathbf{g ~ L}^{-1}$ & $\mathbf{g ~ L}^{-1}$ & - & $\%$ & $\%$ \\
\hline RIF & 5,0 & 76 & 0,2 & 1.926 & 968,0 & 890,6 & 0,92 & 41,21 & 3,40 \\
\hline DS & 5,2 & 30 & - & 1.185 & 509,2 & 469,5 & 0,92 & 46,92 & 2,70 \\
\hline DDS & 5,1 & 15 & 0,1 & 25,6 & 10,3 & 6,0 & 0,97 & 1,5 & 52,99 \\
\hline DTS & 3,9 & 45 & 0,2 & 1710 & 842,8 & 830,1 & 0,98 & 34,68 & 5,79 \\
\hline OPT & 6,5 & 25 & - & 48,2 & 35,5 & 23,0 & 0,96 & 1,2 & 41,94 \\
\hline PM & 7,7 & 282 & 4,9 & 49 & 45,0 & 31,0 & 0,69 & 8,2 & - \\
\hline OW & 5,1 & 55 & 0,1 & 1010 & 448,0 & 350,0 & 0,78 & 51,5 & 17,12 \\
\hline
\end{tabular}


Los parámetros analizados muestran valores contrapuestos para la muestra de PM y para la muestra de $\mathrm{OW}$, es decir, el resultado del análisis de un parámetro determinado que para la muestra de OW tiene un valor alto, para la muestra de PM el análisis de ese mismo parámetro resulta en un valor bajo en comparación con el resultado obtenido para la muestra de OW. Esto indica que son dos residuos que se complementan de forma perfecta para poder realizar codigestión anaerobia de forma eficiente, ya que generan mezclas con una composición equilibrada.

El potencial metanogénico teórico (Tabla 3-4), calculado según la ecuación de Buswell (Ec.1), corrobora el mayor potencial metanogénico del OW respecto al del PM.

Tabla 3-4. Composición elemental y potencial metanogénico teórico de los residuos y de sus mezclas.

\begin{tabular}{|c|c|c|c|c|c|c|c|c|}
\hline \multirow[t]{2}{*}{ Residuo } & \multicolumn{4}{|c|}{ Composición elemental } & \multicolumn{4}{|r|}{$\begin{array}{c}\text { Potencial } \\
\text { metanogénico } \\
\text { teórico }^{c}\end{array}$} \\
\hline & $\% \mathrm{C}$ & $\% \mathrm{H}$ & $\% N$ & $\% P$ & $\% S$ & \%Cenizas & $\% 0^{b}$ & $\mathrm{~B}_{0, \mathrm{Th}} \mathrm{mlCH}_{4} \cdot \mathrm{gSV}^{-1}$ \\
\hline RIF & 57,2 & 8,2 & 2,1 & 0,6 & 0,4 & 7,9 & 23,6 & 730 \\
\hline DS & 47,7 & 6,5 & 1,8 & 0,3 & 0,3 & 7,8 & 36,6 & 535 \\
\hline DDS & 71,8 & 10,3 & 6,6 & 3,0 & 0,5 & 2,9 & 4,9 & 958 \\
\hline DTS & 52,1 & 9,2 & 2,3 & 0,1 & 0,1 & 1,5 & 34,7 & 618 \\
\hline OPT & 69,1 & 9,6 & 5,9 & 0,5 & 0,1 & 3,7 & 11,1 & 876 \\
\hline PM & 34,5 & 4,7 & 2,8 & 0,4 & 0,7 & 32,2 & 25,3 & 516 \\
\hline OW & 63,1 & 10,6 & 1,2 & 0,2 & 0,1 & 4,2 & 20,6 & 843 \\
\hline
\end{tabular}

a en peso de materia seca

b\% estimado

${ }^{c}$ Calculado suponiendo una composición de $C_{n} H_{a} O_{b} N_{c}$ (S y $P$ no se tienen en cuenta al considerarse poco influyentes dentro de la composición elemental del residuo)

En la Tabla 3-5 se recoge el contenido en AG de cada uno de los residuos que forman la muestra de OW, y en la Tabla 3-6 se muestra el contenido en AG de la muestra de OW.

Tabla 3-5. Contenido en ácidos grasos de cada uno de los residuos que forman la muestra de OW

\begin{tabular}{|lrrrrr|}
\hline Tipo de AG & \multicolumn{6}{c}{ Contenido en AG $(\%)$} & \\
\hline & \multicolumn{1}{c}{ RIF } & \multicolumn{1}{c}{ DS } & \multicolumn{1}{c}{ DDS } & \multicolumn{1}{c|}{ DTS } & \multicolumn{1}{c|}{ OPT } \\
\hline Ácido araquídico & 0,47 & 0,41 & - & 0,29 & - \\
\hline Ácido behénico & 0,86 & 1,07 & 0,02 & 0,72 & 0,01 \\
\hline Ácido caprico & 0,03 & 0,01 & - & 0,01 & - \\
\hline Ácido caprílico & 0,05 & 0,02 & - & 0,08 & - \\
\hline Ácido estearico & 6,42 & 6,26 & 0,15 & 5,55 & 0,10 \\
\hline Ácido heneicosanoico & 0,05 & 0,02 & - & 0,01 & - \\
\hline Ácido laurico & 0,07 & 0,04 & - & 0,01 & - \\
\hline Ácido lignocerico & 0,34 & 0,43 & - & 0,01 & - \\
\hline Ácido linoleico & 35,51 & 23,47 & 40,25 & 40,80 & 28,17 \\
\hline Ácido linolelaidico & 0,07 & 0,07 & - & 0,17 & - \\
\hline Ácido margarico & 0,14 & 0,15 & - & 0,01 & - \\
\hline Ácido miristico & 0,57 & 0,40 & 0,12 & 0,73 & 0,07 \\
\hline Ácido oleico & 36,05 & 53,66 & 49,03 & 40,24 & 52,00 \\
\hline Ácido palmítico & 18,77 & 13,49 & 10,25 & 11,16 & 19,50 \\
\hline Ácido palmitoleico & 0,60 & 0,50 & 0,18 & 0,22 & 0,15 \\
\hline
\end{tabular}


Tabla 3-6. Contenido en ácidos grasos de OW

\begin{tabular}{|lc|}
\hline Tipo de AG & Total AG (\%) \\
\hline Ácido araquídico & 0,45 \\
\hline Ácido behénico & 0,77 \\
\hline Ácido caprico & 0,01 \\
\hline Ácido caprílico & 0,05 \\
\hline Ácido estearico & 5,92 \\
\hline Ácido heneicosanoico & 0,01 \\
\hline Ácido laurico & 0,05 \\
\hline Ácido lignocerico & 0,25 \\
\hline Ácido linoleico & 31,76 \\
\hline Ácido linolelaidico & 0,09 \\
\hline Ácido margarico & 0,11 \\
\hline Ácido miristico & 0,46 \\
\hline Ácido oleico & 46,65 \\
\hline Ácido palmítico & 13,84 \\
\hline Ácido palmitoleico & 0,55 \\
\hline
\end{tabular}

En la Tabla 3-5 y Tabla 3-6 se observa como los ácidos oleico, linoleico y palmítico son los ácidos grasos de cadena larga más abundantes en las muestras analizadas. Estos ácidos grasos, incluso a bajas concentraciones, pueden inhibir la producción de metano por la bacterias metanogénicas al poder ser adsorbidos por la pared celular de las bacterias e interferir en la transferencia de materia a través de dicha pared (Pastor et al., 2013; Pereira et al., 2005). El ácido oleico ha sido identificado como el ácido graso de cadena larga más tóxico, produciendo inhibición de las bacterias metanogénicas a concentraciones mayores de $200 \mathrm{mg} \mathrm{L}^{-1}$ (Palatsi et al., 2009).

Para algunos autores la inhibición del proceso de DA es debida a la concentración en nitrógeno amoniacal cuando ésta es superior a $1.500 \mathrm{mg} \cdot \mathrm{L}^{-1}$, siendo tóxica al alcanzar los $30.000 \mathrm{mg} \cdot \mathrm{L}^{-1}$ (Deubleinet al, 2008). Gerardi (2003) establece los siguientes efectos según el rango de nitrógeno amoniacal en digestores anaerobios:

\begin{tabular}{|c|c|}
\hline Concentración $\mathrm{N}-\mathrm{NH}_{4}{ }^{+}$ & Efecto \\
\hline $50-200 \mathrm{mg} / \mathrm{L}$ & Beneficioso \\
\hline $200-1.500 \mathrm{mg} / \mathrm{L}$ & No efectos adversos \\
\hline $1.500-3.000 \mathrm{mg} / \mathrm{L}$ & Inhibidor a pH > 7 \\
\hline
\end{tabular}

En cuanto al efecto que tiene la alcalinidad del digestor sobre el proceso de DA, estudios previos han demostrado que valores normales de alcalinidad oscilan entre los 1.000 y $5.000 \mathrm{mg} \mathrm{CaCO}{ }_{3} \cdot \mathrm{L}^{-1}$, asegurando un buen control del $\mathrm{pH}$ y una adecuada estabilidad del sistema (Montsoriu et al., 1996). Un criterio para verificar si la carga orgánica suministrada al digestor es adecuada para el proceso anaerobio, es la relación a de la alcalinidad debida a los bicarbonatos entre la alcalinidad total. El valor de $\alpha$ durante el arranque deberá mantenerse por encima de 0,5. Un valor superior a 0,6 muestra una operación estable e indica que es posible aumentar la carga del digestor (Speece, 1996).

El resultado de los análisis realizados a las materias primas muestra indicios de que los OW podrían ser tratados de forma satisfactoria sin dilución y sin adición de 
substancias químicas si son co-digeridos con sustratos como PM con alto contenido en nitrógeno amoniacal y elevada alcalinidad para compensar su escasez en este tipo de residuos.

\subsection{Influencia del inóculo utilizado en el potencial metanogénico del residuo}

En esta parte del trabajo se ha estudiado el potencial metanogénico de OW y sus diferentes mezclas con PM, teniendo en cuenta la influencia de la procedencia del inóculo utilizado.

El estudio se ha llevado a cabo en tres etapas:

- Influencia del inóculo en el tratamiento anaerobio de cada una de las corrientes residuales que componen el residuo $\mathrm{OW}$.

- Influencia del inóculo en el tratamiento anaerobio del residuo OW.

- Influencia del inóculo en el tratamiento anaerobio con codigestión de OW y PM en las relaciones OW/PM: $1 / 0 ; 1 / 3 ; 1 / 1 ; 3 / 1$.

Para el estudio de cada una de las tres etapas se han realizado ensayos de biodegradabilidad con los diferentes residuos y dos tipos de inóculo, uno procedente de un reactor anaerobio industrial que se alimenta con residuos orgánicos de hoteles, restaurantes y catering (HORECA), que tenía una concentración de $14 \mathrm{gSVL}^{-1}$, y otro inóculo procedente de una planta municipal de tratamiento de aguas residuales (mWWTP), que tenía una concentración de $12 \mathrm{gSVL}^{-1}$. Cada test de biodegradabilidad se ha realizado por triplicado en reactores de $1 \mathrm{~L}$ de volumen total y $300 \mathrm{~mL}$ de volumen efectivo.

La actividad metanogénica del inóculo procedente de mWWTP y HORECA fue de 42,6 y $55,5 \mathrm{~mL} \mathrm{CH}_{4} \mathrm{gVS}^{-1} \mathrm{~d}^{-1}$, respectivamente. Además en los ensayos de actividad de cada inóculo se determinó que el inóculo procedente de mWWTP comenzaba a producir metano mucho más tarde que el inóculo procedente de HORECA, por lo que se puede afirmar que el inóculo HORECA tenía una concentración de microorganismos activos frente a los sustratos empleados mayor que el inóculo mWWTP.

En la Figura 3-17 se muestra la influencia de cada inóculo en los resultados del test de potencial metanogénico de cada uno de los residuos que componen el OW. 
a)

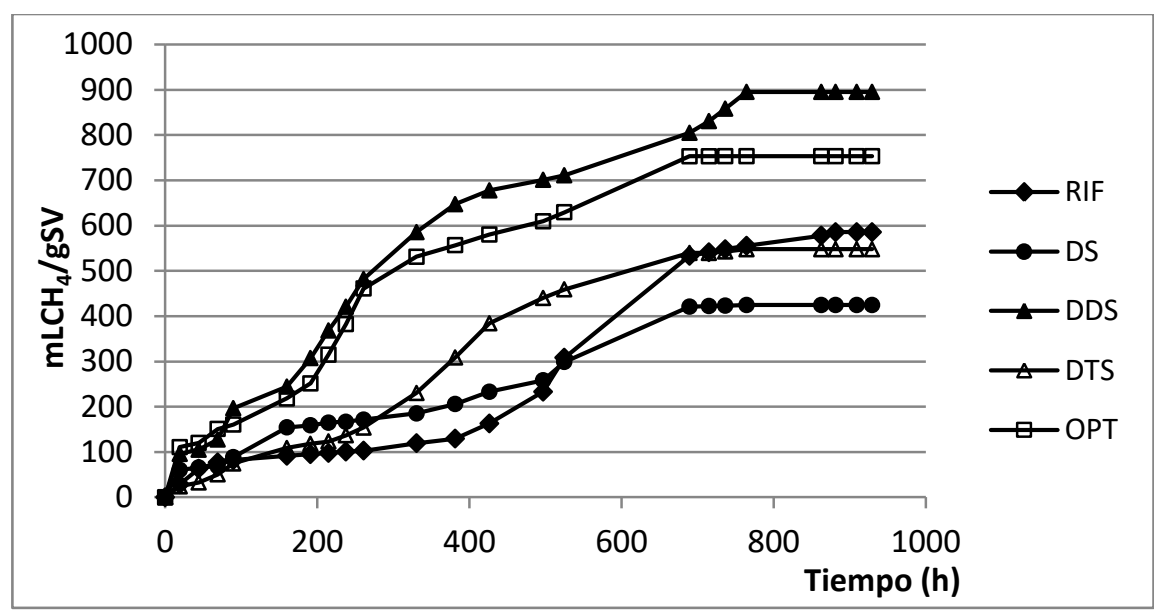

b)

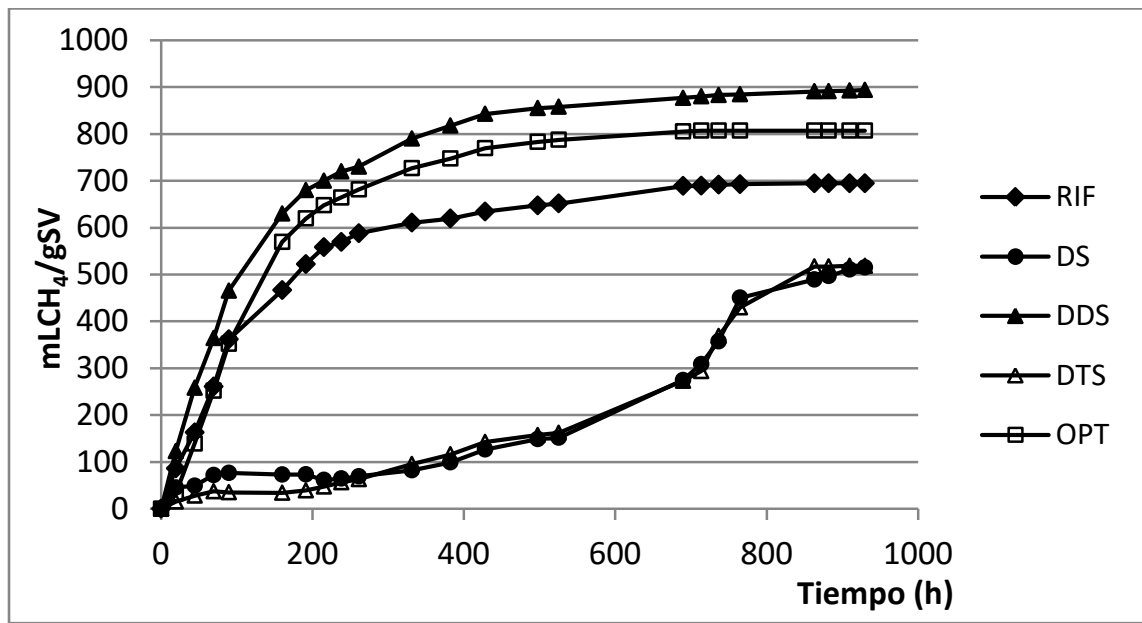

Figura 3-17. Producción acumulada de metano para cada uno de los residuos que componen OW, y para cada uno de los inóculos: a) inóculo procedente de mWWTP, b) inóculo procedente de HORECA

El residuo RIF para el inoculo procedente de mWWTP y el residuo DS y DTS para ambos inóculos presentan un elevado tiempo de latencia inicial en la producción de metano, que puede ser atribuido a una rápida acumulación de ácidos grasos de cadena larga (Salminen et al., 2000), ya que estos residuos, como puede verse en la Tabla 3-5, son los que tienen un mayor contenido graso.

La velocidad de producción de metano fue similar para DDS y OPT para ambos inóculos y superior a la del resto de residuos. Estos resultados concuerdan con los de Arsova (2010) que encontró altas velocidades de producción de metano en sistemas con exceso de proteínas y bajas velocidades de hidrólisis en los ensayos con exceso de lípidos. Sin embargo, aparecen efectos inhibitorios cuando se realizan ensayos con exceso de lípidos y exceso de proteínas, debido a la acumulación de ácidos grasos de cadena larga (LCFA) y nitrógeno amoniacal, respectivamente.

Después de 40 días de ensayo, la producción media de metano fue de $585 \pm 24$, $424 \pm 25,885 \pm 24,547 \pm 19$, y $753 \pm 10 \mathrm{~mL} \mathrm{CH}_{4} \cdot \mathrm{gSV}^{-1}$ para RIF, DS, DDS, DTS y 
OPT, respectivamente, cuando los ensayos de biodegradabilidad se realizaron con el inóculo procedente de mWWTP y $694 \pm 20,515 \pm 14,894 \pm 8,518 \pm 15$ y $807 \pm 19 \mathrm{~mL}$ $\mathrm{CH}_{4} \cdot \mathrm{gSV}^{-1}$, cuando el inoculo procedía de HORECA. Estos resultados concuerdan con los obtenidos a través de la ecuación de Buswell, aunque los valores experimentales son en todos los casos algo menores, puesto que Buswell no tiene en cuenta que parte de la materia biodegradable utilizada por las bacterias para su crecimiento no contribuye a la producción de biogás.

El contenido en metano del biogás se encuentra entre el $60,8 \%$ y el $75,6 \%$ como se muestra en la Figura 3-18. En general, los microorganismos procedente de HORECA producen un biogás de mejor calidad, con un contenido medio en metano del $71,3 \%$ $(S D=2,0)$, comparado con el $68,8 \%(S D=5,3)$ para el caso del inoculo procedente de mWWTP.

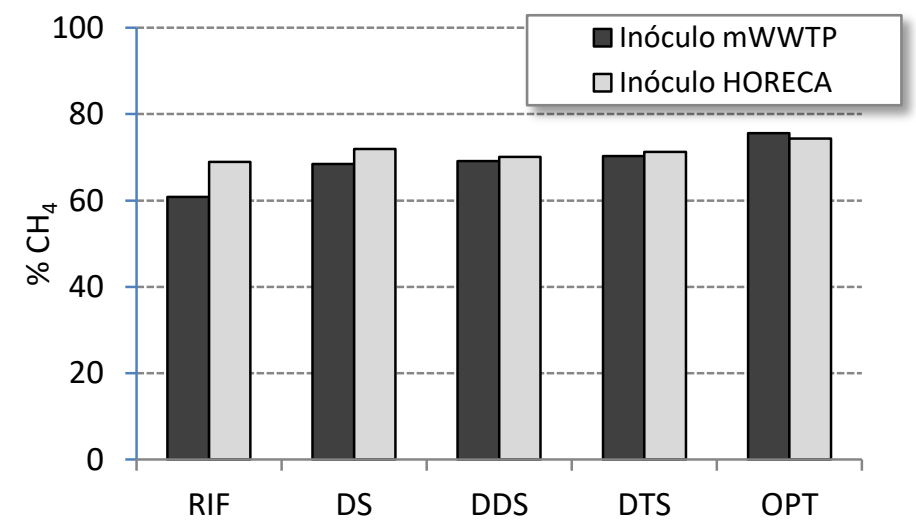

Figura 3-18. Contenido de metano en el biogás producido durante los ensayos de biodegradabilidad para cada uno de los residuos que componen el OW y para cada uno de los inóculos ensayados

A continuación, en la Figura 3-19, se muestran los resultados obtenidos en los ensayos de biodegradabilidad para la muestra OW y sus mezclas con PM para cada uno de los inóculos.

En todos los casos se obtienen elevados porcentajes de eliminación de SV, y para mezclas OW/PM de $1 / 0,1 / 3,1 / 1$ y $3 / 1$, los resultados fueron $70 \%$ (SD =5,6), $76 \%(S D=5,2), 73 \%(S D=3,1)$ y $71 \%(S D=4,6)$ en los ensayos con inoculo procedente de mWWTP y $72 \%(S D=0,8), 81 \%(S D=1,4), 79 \%(S D=2,6)$ y $74 \%$ $(S D=3,9)$ para los ensayos con inoculo procedente de HORECA, respectivamente. En los ensayos donde se ha utilizado PM como co-sustrato, el tiempo de latencia disminuía de 400 h a 100 h y apenas se apreciaba inhibición. 
a)

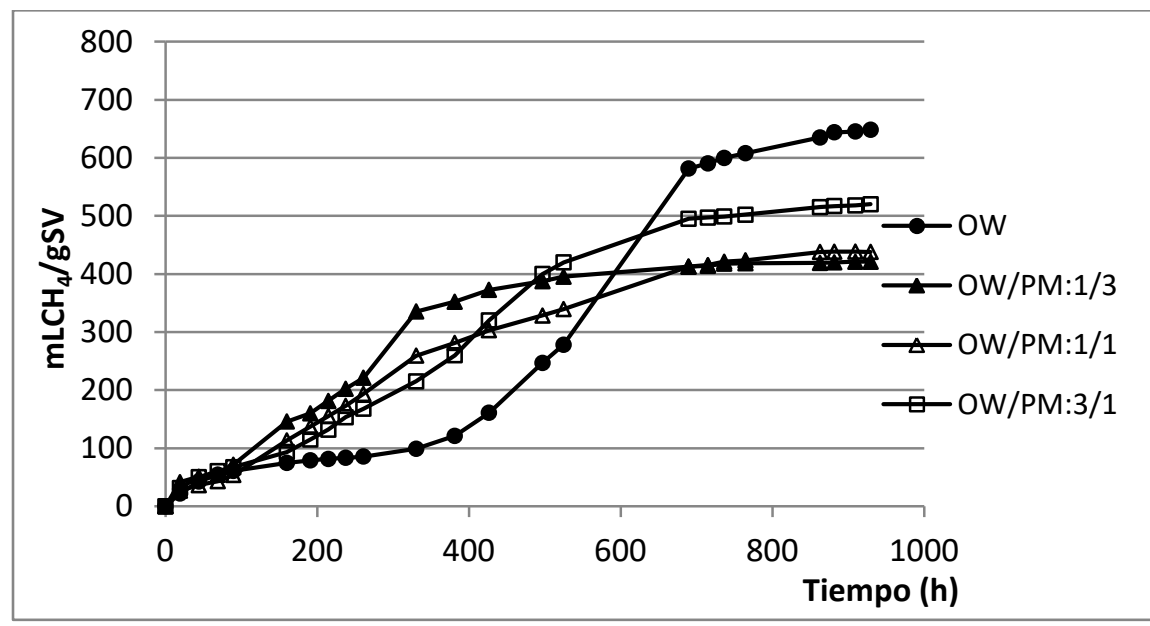

b)

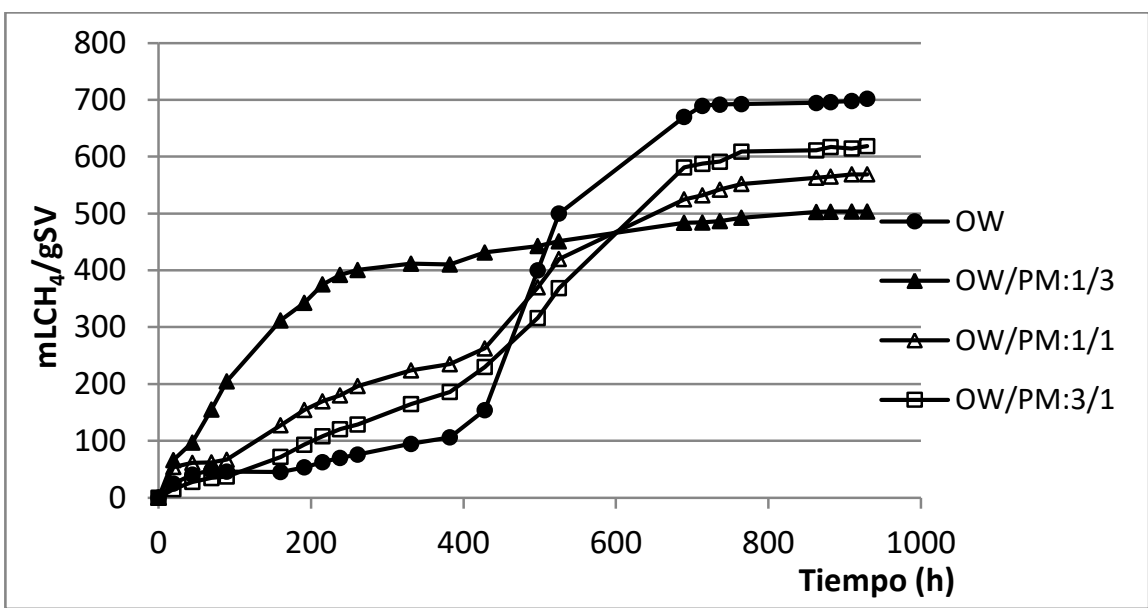

Figura 3-19. Producción acumulada de metano para el residuo OW y diferentes mezclas con PM, para cada uno de los inóculos: a) inóculo procedente de mWWTP, b) inóculo procedente de HORECA

La velocidad de producción de metano durante la digestión de OW es menor que cuando se hace codigestión con PM. Además se constata que la cantidad de biogás producido es mayor en los ensayos con inoculo procedente de HORECA, y que ese biogás es de mejor calidad, con un contenido medio en metano de $71,1 \%(\mathrm{SD}=1,6)$, comparado con el $69,5 \%$ (SD = 1,2) en metano que hay en el biogas obtenido en los ensayos realizados con inóculo procedente de fango de depuradora.

La mayor velocidad de degradación, calculada según la pendiente máxima de las curvas, se obtiene para una relación $\mathrm{OW} / \mathrm{PM}=1 / 3$, obteniéndose como resultado $26,7 \pm 4,3$ y $42,0 \pm 1,5 \mathrm{~mL} \mathrm{CH}_{4} \mathrm{gSV}^{-1} \mathrm{~d}^{-1}$, para los ensayos con inóculo procedente de mWWTP y HORECA, respectivamente. Las otras mezclas tiene velocidad de degradación menor, incluso aunque tengan una mayor producción de biogas $\left(20,6 \pm 3,3\right.$ and $38,9 \pm 5,6 \mathrm{~mL} \mathrm{CH}_{4}$ gSV $^{-1} \mathrm{~d}^{-1}$ para OW/PM:1/1 para ensayos con inoculo procedente de mWWTP y HORECA respectivamente; y 17,1 $\pm 2,3$ y 


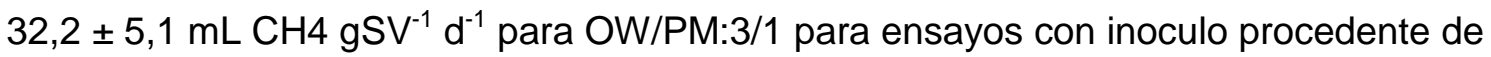
mWWTP y HORECA respectivamente).

En la Tabla 3-7 se muestra una comparativa entre el potencial metanogénico teórico y experimental para cada uno de los residuos y de sus mezclas.

Tabla 3-7. Potencial metanogénico teórico y experimental de los residuos y de sus mezclas

\begin{tabular}{|c|c|c|c|}
\hline Residuo & $\begin{array}{c}\text { Potencial } \\
\text { metanogénico } \\
\text { teórico }^{c}\end{array}$ & $\begin{array}{c}\text { Potencial } \\
\text { metanogénico } \\
\text { experimental con } \\
\text { inóculo } \mathrm{mWWTP}\end{array}$ & $\begin{array}{c}\text { Potencial } \\
\text { metanogénico } \\
\text { experimental con } \\
\text { inóculo HORECA }\end{array}$ \\
\hline & $\mathrm{B}_{0, \mathrm{Th}} \mathrm{mlCH}_{4} \cdot \mathrm{gSV}^{-1}$ & $\mathrm{~B}_{0, \mathrm{Ex}} \mathrm{mlCH}_{4} \cdot \mathrm{gSV}^{-1}$ & $\mathrm{~B}_{0, \mathrm{Ex}} \mathrm{mlCH}_{4} \cdot \mathrm{gSV}^{-1}$ \\
\hline RIF & 730 & 585 & 694 \\
\hline DS & 535 & 424 & 515 \\
\hline DDS & 958 & 885 & 894 \\
\hline DTS & 618 & 547 & 518 \\
\hline OPT & 876 & 753 & 807 \\
\hline PM & 516 & & \\
\hline OW & 843 & 648 & 702 \\
\hline OW/PM:3/1 & 742 & 518 & 614 \\
\hline OW/PM:1/1 & 670 & 438 & 565 \\
\hline OW/PM:1/3 & 603 & 420 & 502 \\
\hline
\end{tabular}

${ }^{c}$ Calculado suponiendo una composición de $\mathrm{C}_{n} \mathrm{H}_{a} \mathrm{O}_{b} \mathrm{~N}_{c}$ (S y $P$ no se tienen en cuenta)

Como era de esperar, las muestras con mayor porcentaje de OW mostraban un mayor potencial metanogénico, lo cual está de acuerdo con los resultados obtenidos con el potencial metanógenico teórico calculado según la ecuación de Buswell (Ecuación 1), aunque los resultados experimentales son más bajos. Esto es debido a que la ecuación de Buswell asume que toda la materia orgánica biodegradable es utilizada para la producción de biogás y no tiene en cuenta que parte de esta materia (energía) es utilizada por las bacterias para su crecimiento. De hecho, el propio Buswell, indica que durante la digestión de carbohidratos puros, una media del $12 \%$ del carbono total se pierde en el crecimiento celular de los microorganismos, aunque no lo tiene en cuenta en su fórmula.

El trabajo realizado en este apartado de la tesis ha sido utilizado para redactar el artículo titulado: "Effects of inoculum source and co-digestion strategies on anaerobic digestion of residues generated in the treatment of waste vegetable oils", el cual ha sido publicado en la revista Journal of Environmental Management listada en el JCR con factor de impacto 3.188 en su año de publicación. A continuación se presenta dicho documento: 


\title{
Effects of inoculum source and co-digestion strategies on anaerobic digestion of residues generated in the treatment of waste vegetable oils
}

\author{
Dolores Hidalgo ${ }^{a, b, *}$, Jesús M. Martín-Marroquín ${ }^{a, b}$ \\ aCARTIF Technology Centre, Parque Tecnológico de Boecillo, 47151 Boecillo, Valladolid, Spain \\ 'ITAP Instinute, Universiry of Valladolid, Po del Cauce s9, 47011 Valladolid, Spain
}

\section{A R T I C L E I N F O}

\section{Article history.}

Received 17 September 2013

Received in revised form

19 March 2014

Accepted 11 April 2014

Available online

\section{Keywords:}

Anaerobic digestion

Co-digestion

Inoculum

Lipid-rich wastewater

Pig manure

Waste vegetable oils

\begin{abstract}
A B S T R A C T
This work aims at selecting a suitable strategy to improve the performance of the anaerobic digestion of residues generated in the treatment of waste vegetable oils (WVO). Biochemical methane potential (BMP) assays were conducted at $35^{\circ} \mathrm{C}$ to evaluate the effects of substrate mix ratio between a mixture of WVo residues (M) and pig manure (PM) co-digesting by using different inocula. Inoculum from an industrial digester fed with organic waste from hotels, restaurants and catering leftovers (HORECA) showed higher methanogenic activity $\left(55.5 \mathrm{mLCH}_{4} \mathrm{gVS}^{-1} \mathrm{~d}^{-1}\right)$ than municipal wastewater treatment plant (mWW TP) inoculum ( $42.6 \mathrm{~mL} \mathrm{CH}_{4} \mathrm{gVS}^{-1} \mathrm{~d}^{-1}$ ). Furthermore, the results showed that the resistance to WVO residues toxicity was higher for the HORECA sludge than for the mWWTP sludge. HORECA inoculum produced more biogas in all the assays. Moreover, the resulting biogas was of better quality. containing an average of $71.1 \%(S D=1.6)$ methane compared to an average of $69.5 \%(S D=1.2)$ methane for test with mWWTP sludge. The maximum degradation rate occurred at the higher PM mix ratio (M PM: 1/3), reaching $26.7 \pm 4.3 \mathrm{mLCH}_{4} \mathrm{gVS}^{-1} \mathrm{~d}^{-1}$ for mWWTP inoculum, versus $42.0 \pm 1,5 \mathrm{mLCH}_{4} \mathrm{gVS}^{-1} \mathrm{~d}^{-1}$ achieved for HORECA inoculum.

A high reduction of volatile solids (between $70 \%$ and $81 \%$ ) was obtained with both inocula at all M/PM ratios assayed $(1 / 0,1 / 3,1 / 1$ and $3 / 1 \mathrm{v} / \mathrm{v})$ but, bearing in mind the operation of a full-scale anaerobic plant, the optimal scenario assayed corresponds to the ratio M/PM: $1 / 3 \mathrm{v} / \mathrm{v}$ where shorter lag periods will make it possible to operate at lower hydraulic retention times.
\end{abstract}

Q 2014 Published by Elsevier Ltd.

\section{Introduction}

Biodiesel has been produced on an industrial scale in the European Union since 1992. However, the limited availability of traditional raw materials, such as animal fat or vegetable oils (both edible and non-edible) and their high cost limits the wider use of biodiesel (Math et al., 2010).

For biodiesel producers the cost of feedstock comprises between 75 and $90 \%$ of the operating cost of their plants (Mathiyazhagan and Ganapathi, 2011). Under these circumstances, waste vegetable oils (WVO) are becoming a promising alternative to the use of edible oils as feedstock as they are low in cost and easily available.

* Corresponding author. CARTIF Technology Centre, Parque Tecnológico de Boe-
cillo, 47151 Boecillo, Valladolid, Spain. Tel: + 34983546504 ; fax + 34983546521. E-mail address: dolhidorcartif.es (D. Hidalgo).
When WVO is collected, it goes through a treatment process to eliminate moisture, bulky particulate, free fatty acids and other undesirable compounds before sending it for biodiesel production. Nowadays, the increasing amount of wastes or residual subproducts generated by these WVO processing activities represents a new environmental concem.

According to various surveys carried out along recent years among WVO industrialists on the management of their wastes, and in light of the changes in the regulation, there is a willingness to reconsider the current recovering for some types of wastes/by products, and anaerobic digestion is one possible solution (Torrijos et al., 2008). Furthermore, the WVo treatment and refining processes involve the use of steam and the related energy consumption is quite significant. In an international context of fossil fuels rising costs and greenhouse gases emissions reduction, manufacturers want to reduce the fossil fuels related energy consumption and biogas recovery can respond to this desire. 
However, it is well-known that anaerobic digestion (AD) of oilrich wastes is not always easy and simple, since anaerobes are very sensitive to lipid-rich matters as well as to intermediate compounds of oily wastes degradation process (Hidalgo et al., 2012; Hong, 2011; Neves et al., 2009b). High lipids concentrations can destabilize anaerobic digesters due to inhibition of methanogenic bacteria by possible damage to cellular membrane (Göblös et al., 2008; Femández et al., 2005). Nevertheless, lipids are attractive substrates for anaerobic digestion and co-digestion due to the higher methane yield obtained when compared to carbohydrates.

Different kinds of substrate give different methane production, which can be evaluated using the biochemical methane potential (BMP) assay. The BMP assay is a useful tool to determine the biodegradability and methane conversion yield of organic substrates (Angelidaki et al., 2009). Numerous studies have been carried out in which the BMP assay of different wastes were measured (Nieto et al., 2013; Ho and Sung, 2010; Labatut et al., 2011; Xie et al., 2011) and, in all of them, the source of inocul um played avital role in the substrate degradation efficiency, especially for complex mix of substrates, due to the different makeup of the microbial consortia within.

The purpose of this work was to study the anaerobic digestion of the residues and by-products generated during the processing of WVO for biodiesel production, and more specifically, the influence of inoculum source on methane production, in order to evaluate the potential of anaerobic digestion as an alternative to the conventional management solutions for these streams while reducing the fossil-origin energy consumption on refinery sites.

\section{Materials and methods}

\subsection{Waste streams}

The processing of WVo generates a number of residues, as shown in Fig. 1. In this study, these wastes were supplied by a biodiesel company located in Madrid (Spain).

\subsubsection{Residues from initial filtering (RIF)}

Taken at the beginning of the treatment process, it is the solid residue that remains in the filtering mesh after pouring the WVo through it. It is basically a solid residue composed by food leftovers with a high organic load.

\subsection{Drum sediment (DS)}

The storage of WVO (before treatment) leads to the sedimentation of solid particles from the oil. These solids are called "drum

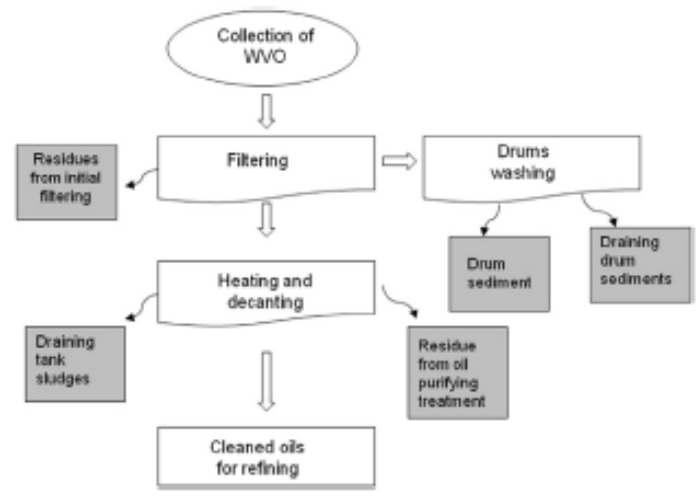

Fig. 1. Waste vegetable oil treatment steps. sediments" and remain in the drums used to collect the WVO, after pouring their content in the reception hopper and the filtering mesh.

\subsubsection{Draining drum sediments (DDS)}

Practically liquid residue resulting from the cleaning of the drums used to collect the WVO, once the drum sediments have been removed.

\subsubsection{Draining tank sludge (DTS)}

After heating the filtered oils, water and impurities are located at the bottom of the draining tanks, obtaining semi-solid sludge residues after the centrifugation of the decanted oil residues.

\subsubsection{Residue from oil purifying treatment (OPT)}

This residue is the wastewater proceeding from the draining tanks as a result of the previous heating and centrifugation treatment.

\section{Research scheme}

The experimental work has been carried out in three steps:

1) analyzing the anaerobic treatment of the individual waste streams;

2) simulating the joint digestion of these wastes (the waste mixture investigated $(\mathrm{M})$ covered the main scenario of total waste generation in the WVO treatment industry) and

3 ) simulating the co-digestion of the mixture of residues from the treatment process of WVO (M) with pig manure (PM) at different $\mathrm{M} / \mathrm{PM}$ rates $(1 / 3,1 / 1$ and $3 / 1)$.

Table 1 shows the content of each waste in the selected mixtures. Results are presented on a volatile solids percentage basis.

\subsection{Wastes analysis}

Total and volatile solid concentration (TS, VS), chemical oxygen demand (COD), total Kjeldahl nitrogen (TKN), ammonia nitrogen $\left(\mathrm{N}-\mathrm{NH}_{4}^{-}\right)$, fat content, alkalinity, $\mathrm{P}$ and $\mathrm{pH}$ were determined following Standard Methods (APHA, 2005) recommendations. Protein content was measured with the Kjeldahl method using a conversion factor of 6.25. Fatty acids (FA) concentrations were determined using a gas chromatograph (HP-Agilent) equipped with a flame ionization detector (FD). C, N, H and S contents were determined by UNE-CEN/TS 15104 EX with a LECO Truspec CHN(S) elemental analyzer. Oxygen content was not measured directly but was estimated assuming that no other elements (apart from the measured $\mathrm{C}, \mathrm{H}, \mathrm{N}, \mathrm{S}$ and $\mathrm{P}$ ) were present in the wastes.

\subsection{Biomethane potential (BMP) test}

In order to study the biodegradability and biomethane potential of lipid-rich wastes and their mixtures and, at the same time, to

Table 1

Composition of the waste mixtures

\begin{tabular}{llccccc}
\hline Mixture & \multicolumn{6}{l}{ Waste (8) } \\
\cline { 2 - 7 } & RIF & DS & DDS & DTS & OPT & PM \\
\hline M & 40 & 15 & 15 & 15 & 15 & - \\
M/PM:1/3 & 10 & 3.75 & 3.75 & 3.75 & 3.75 & 75 \\
M/PM:1/1 & 20 & 7.5 & 7.5 & 7.5 & 7.5 & 50 \\
M/PM:3/1 & 30 & 11.25 & 11.25 & 11.25 & 11.25 & 25 \\
\hline
\end{tabular}


Table 2

Waste characterisation.

\begin{tabular}{|c|c|c|c|c|c|c|c|c|c|}
\hline \multirow[t]{3}{*}{ Waste } & \multicolumn{9}{|c|}{ Physico-chemical parameters } \\
\hline & $\mathrm{pH}$ & Alkalinity & $\mathrm{N}-\mathrm{NH}_{4}$ & COD & TS & vs & vS/TS & Fat content & Protein \\
\hline & $\overline{-}$ & $\mathrm{mM}$ & $\mathrm{gN} \mathrm{L}^{-1}$ & $\mathrm{gL}^{-1}$ & $\mathrm{~g} \mathrm{~L}^{-1}$ & $\mathrm{gL}^{-1}$ & - & $\bar{x}$ & $\bar{x}$ \\
\hline DS & 5.2 & 30 & - & 1,1854 & 509.2 & 469.5 & 0.92 & 46.92 & 2.70 \\
\hline DDS & 5.1 & 15 & 0.1 & 25.6 & 10.3 & 6.02 & 0.97 & 1.5 & 52.99 \\
\hline DTS & 3.9 & 45 & 0.2 & 1710 & 842.8 & 830.1 & 0.98 & 34.68 & 5.79 \\
\hline OPT & 6.5 & 25 & - & 48.2 & 35.5 & 23.0 & 0.96 & 1.2 & 41.94 \\
\hline
\end{tabular}

compare the biogas production rate with different inoculum sources, batch experiments were run in glass serum bottles with a liquid volume of $300 \mathrm{~mL}$ ( $1000 \mathrm{~mL}$ of total volume). All the experiments were carried out at $35 \pm 1{ }^{\circ} \mathrm{C}$ in a thermostatic room, and continuously stirred on a shaking-table. After the set-up of each reactor the head space was flushed with nitrogen for $3 \mathrm{~min}$ in order to remove the oxygen.

Triplicate assays, for all the wastes and conditions, were performed. Substrate/inoculum $(\mathrm{S} / \mathrm{X})$ ratios were in the range of $0.45-$ 0.55 gVSwaste $\mathrm{gVS}^{-1}$ inoculum for all the samples.

A set of triplicate blank assays without any waste (only inoculum) was also performed for endogenous methane production determination. To avoid acidification of the assay, $\mathrm{NaHCO}_{3}$ was added as buffer $\left(6 \mathrm{gNaHCO}_{3} \mathrm{~L}^{-1}\right)$. Experiments were finished when the biogas production rate in waste assays decreased to the same level as in the blank assays.

Biogas production was measured manually by a pressure transmitter (Druck, PTX 1400, range 1 bar) in the head space of each reactor. To avoid reaching overpressure, biogas in the head space was released periodically. Pressure differences were converted to biogas volume, using the ideal gas Law and standard temperature and pressure conditions (STP, $P=1$ bar and $T=0{ }^{\circ} \mathrm{C}$ ). Biogas composition was measured before each release with a Varian $\mathrm{CP}$ 4900 Micro-GC with thermal conductivity detector. Net methane production was calculated by subtracting the amount of the methane produced by the blank assay from the methane production of each assay.

Inocula used in this experiment were the anaerobic sludges taken from two different full scale anaerobic digesters; one from a municipal wastewater treatment plant (mWWTP), with a concentration of $12 \pm 1 \mathrm{gVS} \mathrm{L}^{-1}$ and another one from an industrial digester fed with organic waste coming from hotels, restaurants

Table 3

Fatty acids in Wvo residues.

\begin{tabular}{lrrrrc}
\hline \multirow{2}{*}{ FA } & \multicolumn{7}{l}{ Fatty acids content $(\%)$} & & \\
\cline { 2 - 6 } & \multicolumn{1}{c}{ RIF } & \multicolumn{1}{c}{ DS } & DDS & DTS & OPT \\
\hline Araquid acid & 0.47 & 0.41 & - & 0.29 & - \\
Behenic acid & 0.86 & 1.07 & 0.02 & 0.72 & 0.01 \\
Capric acid & 0.03 & 0.01 & - & 0.01 & - \\
Caprilic acid & 0.05 & 0.02 & - & 0.08 & - \\
Estearic acid & 6.42 & 6.26 & 0.15 & 5.55 & 0.10 \\
Heneicosanoic acid & 0.05 & 0.02 & - & 0.01 & - \\
Lauric acid & 0.07 & 0.04 & - & 0.01 & - \\
Lignoceric acid & 0.34 & 0.43 & - & 0.01 & - \\
Linoleic acid & 35.51 & 23.47 & 40.25 & 40.80 & 28.17 \\
Linolelaidic acid & 0.07 & 0.07 & - & 0.17 & - \\
Margaric acid & 0.14 & 0.15 & - & 0.01 & - \\
Miristic acid & 0.57 & 0.40 & 0.12 & 0.73 & 0.07 \\
Oleic acid & 36.05 & 53.66 & 49.03 & 40.24 & 52.00 \\
Palmitic acid & 18.77 & 13.49 & 10.25 & 11.16 & 19.50 \\
Palmitoleic acid & 0.60 & 0.50 & 0.18 & 0.22 & 0.15 \\
\hline
\end{tabular}

and catering leftovers (HORECA), with a concentration of $14 \pm 1 \mathrm{gVS} \mathrm{L}^{-1}$. Different feeds affected the makeup of microbial consortia in each sludge. The concentration of the inoculum in all the assays was $5 \mathrm{~g} \mathrm{~L}^{-1}$ and $\mathrm{pH}$ was 7.5 .

The specific methanogenic activity (SMA) of both inocula was determined using a mixture of acetic, propionic and butyric acids in the proportion $2: 0.5: 0.5 \mathrm{~g} \mathrm{~L}^{-1}$ to give a loading of $2.5 \mathrm{gCOD} \mathrm{L}^{-1}$. The SMA assays were studied with the same inocul um concentration of $10 \mathrm{gVS} \mathrm{L}^{-1}$. The nutrients stock solution and trace elements solution were supplied to each bottle, which details were described in Raposo et al. (2011).

\section{Results and discussion}

\subsection{Waste composition}

Tables 2 and 3 gather the results obtained from the characterization of the selected raw wastes.

Differences in some characteristics were observed not only among samples, but also among the replicated samples taken in a specific sampling point. This fact highlights the heterogeneous character of this kind of residues. However, the range of variation between the replicates for a particular parameter $(<15 \%)$ could be acceptable when considering collected samples as representative of the residues produced in the WVO treatment process.

RIF is basically a solid residue with a high organic load and fat content. DS residue shows acceptable protein content and a high rate of triglyceride component. DDS residues have the highest protein content but their fat rate is low. DTS has medium protein content but it is enriched in fatty acids coming from cooking fats OPT residues have a high content of proteins and their fat rate is quite similar to that obtained from the draining drum sediments. The solids content in the different samples analyzed is very variable. Thus, whereas samples from DDS and OPT have low TS and VS content (from 1 to $4 \%)$, solids content in samples from RIF, DS and DTS ranges between 50 and $97 \%$. This suggests that these samples with high TS content must probably be diluted before their use as substrates in the biogas production process to avoid operational problems.

PM has a high content of ammonia in comparison with the other wastes. Manure possesses a high alkalinity, while the alkalinity of WVO residues is low. In addition, the $\mathrm{pH}$ of WVO residues is low, and lower than the $\mathrm{pH}$ allowing growth for methanogens (approximately 6.0). On the other hand, WVO residues have a high content of fats and proteins in contrast to manure. The characterization of the wastes indicates that co-digestion with PM could be a cost effective method to treat WVO residues without the need to add nitrogen source or chemicals for increasing buffer capacity or adjusting $\mathrm{pH}$ (Zhang et al., 2011). Furthermore, lipids concentration is lowered.

Palmitic, linoleic and oleic are the most abundant long chain fatty acids (LCFA) in the WVO residues samples (Table 3 ). The 
concentrations of the other acids were always much lower. These three compounds have been identified as inhibitors for methanogens. Even at low concentrations, these compounds can be adsorbed on the cell membrane interfering with mass transfer across the membrane (Pastor et al, 2013). However, some adaptation of the microorganisms responsible for anaerobic digestion is possible (Chen et al., 2008).

Furthermore, oleic acid has been identified as the most toxic LCFA with inhibition being observed for concentrations greater than $200 \mathrm{mg} / \mathrm{l}$ (Palatsi et al, 2009). Reductions of $50 \%$ of the activity of methanogens have been observed in the presence of $50-$ $200 \mathrm{mg} / \mathrm{l}$ of oleic acid (Angelidaki et al., 2002). Pereira et al. (2005) found evidence of mass transfer limitation caused by LCFA accumulation onto the anaerobic sludge when oleic and palmitic acids were anaerobically biodegraded.

The analysis of the elemental composition (Table 4) provides information about the theoretical methane potential $\left(B_{0, T h}\right)$ of a given waste using Buswell's equation (1). This equation assumes methane production from the complete degradation of a certain waste with a given elemental composition, where $\mathrm{C}_{n} \mathrm{H}_{a} \mathrm{O}_{b} \mathrm{~N}_{c}$ represents the chemical formula of the biodegradable organic compound subjected to the anaerobic degradation process, and the production of methane considered herein is the maximum stoichiometrically possible (Lesteur et al., 2010). For a $\mathrm{C}_{n} \mathrm{H}_{3} \mathrm{O}_{b} \mathrm{~N}_{c}$ compound the theoretical methane potential (at standard conditions for temperature and pressure) is:

$B_{0, \text { Th }}=\frac{\left(\frac{n}{2}+\frac{a}{8}-\frac{b}{4}-\frac{3 c}{8}\right) \cdot 22.4}{12 n+a+16 b+14 c}|=| \frac{L \mathrm{CH}_{4}}{g \mathrm{VS}}$

where the parameters $n, a, b, c$ refer to the stoichiometry index of $C$, $\mathrm{H}, \mathrm{O}$ and $N$ respectively.

\section{Effect of inoculum source on the specific methane potential of the individual wastes}

Fig. 2 shows the cumulative methane potential of the wastes with the two different inoculum sources assayed. All the BMP assays were conducted in triplicate and the maximum deviation reported was $\pm 25 \mathrm{mlCH}_{4} \mathrm{gSV}^{-1}$ for every assay set.

In all the cases, the methane potential is clearly impacted by the inoculum source used in the experiments, agreeing with Goncalves et al. ( 2011). The methanogenic activity of inoculum from mWWTP and HORECA were 42.6 and $55.5 \mathrm{mLCH}_{4}$ gVs $^{-1} \mathrm{~d}^{-1}$, respectively. They were similar to those reported in Ho and Sung (2010) at $51.8 \mathrm{mLCH}_{4} \mathrm{gVS}^{-1} \mathrm{~d}^{-1}$ and in Neves et al. (2009a) at $37.0-50.0 \mathrm{~mL}$ $\mathrm{CH}_{4}$ gVS $^{-1} \mathrm{~d}^{-1}$ which measured the sludge from anaerobic membrane bioreactors treating synthetic municipal wastewater and completely mixed reactor treating cow manure and food waste at

Table 4

Waste elemental composition.

\begin{tabular}{|c|c|c|c|c|c|c|c|c|}
\hline \multirow[t]{2}{*}{ Waste } & \multicolumn{7}{|c|}{ Elemental composition ${ }^{2}$} & \multirow{2}{*}{$\begin{array}{l}\text { Theoretical methane } \\
\text { potential }^{<} \\
\mathrm{B}_{0, \mathrm{n}} \mathrm{mLCH}_{4} \mathrm{gVS}^{-1}\end{array}$} \\
\hline & $\overline{x c}$ & $\overline{\mathrm{OH}}$ & $\overline{2 N}$ & SP & xS & XAsh & $980^{5}$ & \\
\hline RIF & 57.2 & 8.2 & 2.1 & 0.6 & 0.4 & 7.9 & 23.6 & 730 \\
\hline DS & 47.7 & 6.5 & 1.8 & 0.3 & 0.3 & 7.8 & 36.6 & 535 \\
\hline DDS & 71.83 & 10.3 & 6.6 & 3.0 & 0.5 & 2.9 & 4.9 & 958 \\
\hline DTS & 52.1 & 9.2 & 2.3 & 0.1 & 0.1 & 1.5 & 34.7 & 618 \\
\hline OPT & 69.1 & 9.6 & 5.9 & 0.5 & 0.1 & 3.7 & 11.1 & 876 \\
\hline PM & 34.5 & 4.7 & 2.8 & 0.4 & 0.7 & 32.2 & 25.3 & 516 \\
\hline
\end{tabular}
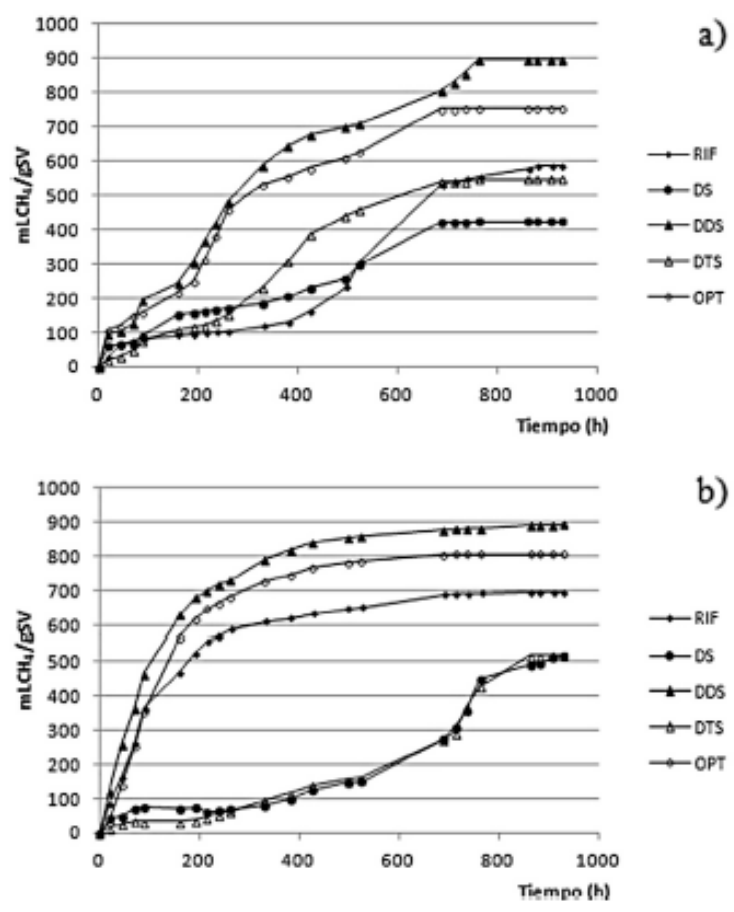

Fig. 2. Cumulative specific methane production curves of the wastes with different inoculum sources: a) mWWTP inoculum; b) HORECA inoculum.

different rates, respectively. The HORECA inoculum clearly showed higher methanogenic activity. Furthermore, initial lag phase of mWWTP inoculum was noticeably longer than that of HORECA inoculum in SMA test.

From these results it can be easily deduced that the HORECA inoculum has higher concentration of active microorganisms while mWWTP inoculum has lower concentration as exhibited by the longer lag phase on methane production, according to Dechrugsa et al. (2013).

The methane production pattern observed in Fig. 2 was similar to the ones reported by Cirne et al. (2007) for batch degradation of an oil-rich waste. The methane production rate observed was similar for DDS and OPT with both inocula, and higher than for the other wastes. A stronger inhibition was observed for the other tests, but the process recovered. This agrees with Arsova (2010) that found faster methanization rates in systems with excess of proteins and lower hydrolysis rates in the assays with an excess of lipids. However, there were also inhibitory effects observed in the assays with excess of lipids and excess of proteins due to the LCFA accumulation and ammonium nitrogen, respectively.

The initial lag phase in methane production observed for most of the tests, but especially for RIF with mWWTP inoculum and for DS and DTS with both inocula, could be attributed to the rapid build-up of LCFA, as proposed by Salminen et al. (2000). Note that RIF, DS and DTS were the waste streams with higher fat content (Table 2).

Average experimental methane production values obtained after 44 days were $585+24,424 \pm 25,885 \pm 24,547 \pm 19$, and $753 \pm 10 \mathrm{~mL} \mathrm{CH}_{4} \mathrm{gVS}^{-1}$ for RIF, DS, DDS, DTS and OPT, respectively when the BMP tests were carried out with MWWTP inoculum and $694 \pm 20,515 \pm 14,894 \pm 8,518 \pm 15$ and $807 \pm 19 \mathrm{~mL} \mathrm{CH}_{4} \mathrm{gVS}^{-1}$. when the test was inoculated with HORECA sludge. Residues with higher protein content showed higher specific methane potentials. 


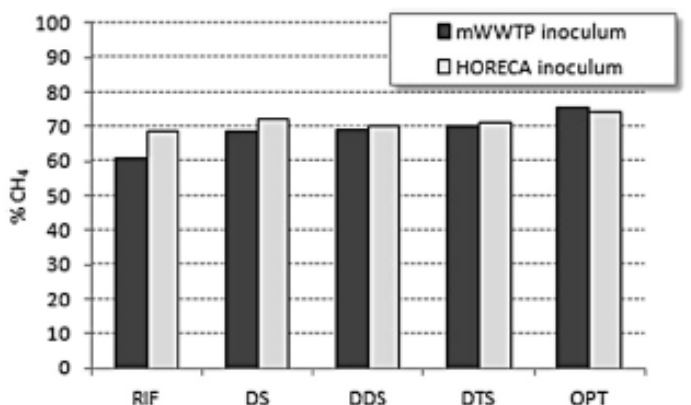

Fig. 3. Average methane content in the biogas produced during the BMP test.

This trend is in accordance with the results of the $B_{0, T h}$ calculated by the Buswell's equation (Table 4). However experimental values are slightly lower than the theoretical ones because Buswell's equation overestimates the BMP value, since part of the biodegradable organic matter, used by the bacteria to grow, does not contribute to biogas generation (de Lemos, 2007).

Methane content in the biogas ranged from $60.8 \%$ to $75.6 \%$ as showed in Fig. 3. It should be noted that the total amount of biogas produced with both inocula differed slightly. In general, the HORECA microorganisms produced a biogas with better quality, containing an average of $71.3 \%(\mathrm{SD}=2.0)$ methane compared to an average of 68.8\% ( $S D=5.3$ ) methane for the test with mWWTP inoculum.

\subsection{Co-digestion of WVO residues and pig manure}

The cumulative specific methane productions comparing test inoculated with mWWTP sludge and HORECA sludge at different M/PM ratios are illustrated in Fig. 4.
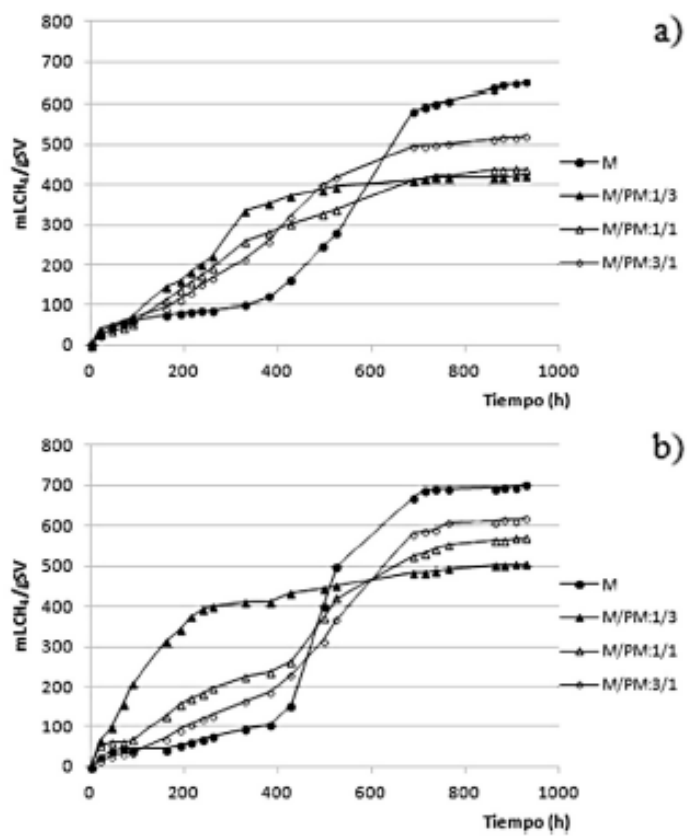

Fig. 4. Cumulative specific methane production curves at different $\mathrm{M} / \mathrm{PM}$ ratios with different inoculum sources: a) mWWTP inoculum, b) HORECA inoculum.
High average vS removal efficiencies were realized with both inocula at all $\mathrm{M} / \mathrm{PM}$ ratios $(70 \%(\mathrm{SD}=5.6), 76 \%(\mathrm{SD}=5.2), 73 \%$ $(\mathrm{SD}=3.1)$ and $71 \%(\mathrm{SD}=4.6)$ with mWWTP inoculum and $72 \%$ $(\mathrm{SD}=0.8), 81 \%(\mathrm{SD}=1.4), 79 \%(\mathrm{SD}=2.6)$ and $74 \%(\mathrm{SD}=3.9)$ with HORECA inoculum, at $1 / 0,1 / 3,1 / 1$ and $3 / 1 \mathrm{M} / \mathrm{PM}$ mixtures, respectively) and a weaker inhibition was observed for the tests where PM was added as co-substrate. In this case, the lag phases decreased from 400 to $100 \mathrm{~h}$. This phenomenon is in line with the results achieved by Angelidaki et al. (2002) that demonstrated that the co-digestion of oily wastes with non-oily wastes (as pig manure) is considered the key factor to prevent inhibition of methanogenesis since the concentration of lipids and inhibitory substances is lowered and the buffer capacity is increased.

It was also found that methane production rates during digestion of $\mathrm{M}$ al one were lower than the rates achieved when $\mathrm{M}$ and $\mathrm{PM}$ were digested together. Furthermore, it should be noted that the total amount of biogas produced at different $\mathrm{M} / \mathrm{PM}$ ratios with both inocula differed, reaching higher productions the assays with HORECA inoculum.

Taking into account the maximum slopes of the curves shown in Fig. 4, M/PM: $1 / 3$ is the substrate mixture with the highest degra dation rate $\left(26.7 \pm 4.3\right.$ and $42.0 \pm 1.5 \mathrm{~mL} \mathrm{CH}_{4} \mathrm{gVS}^{-1} \mathrm{~d}^{-1}$, test with mWWTP and HORECA inocula, respectively). The other mixtures had a slower degradation rate even though they showed a higher biogas yield $\left(20,6 \pm 3.3\right.$ and $38,9 \pm 5.6 \mathrm{~mL} \mathrm{CH}_{4} \mathrm{gVS}^{-1} \mathrm{~d}^{-1}$ at $\mathrm{M} /$ PM:1/1 with mWWTP and HORECA inoculum respectively; and $17.1 \pm 2.3$ and $32.2 \pm 5.1 \mathrm{~mL} \mathrm{CH}_{4}$ gVS $^{-1} \mathrm{~d}^{-1}$ at M/PM:3/1 with mWWTP and HORECA inoculum respectively). In all the cases, test with HORECA inoculum produced more biogas. Moreover, it was a biogas of a better quality, containing an average of $71.1 \%(S D=1.6)$ methane compared to an average of $69.5 \%(\mathrm{SD}=1.2)$ methane obtained in the test with mWWTP sludge.

\section{Conclusions}

Residues generated by WVO processing companies could be successfully treated and degraded in co-digestion with pig manure in anaerobic reactors without dilution and without adding chemical substances, with a VS reduction up to $81 \%$. This makes codigestion of WVO residues and swine manure a potential and economically feasible solution for the treatment of such wastes. Furthermore, this research has demonstrated that the use of a microbial consortium acclimated to proteins LCFA compounds (HORECA sludge) is a promising strategy to accelerate the start-up of the digestion process, and to improve the overall anaerobic treatment of real oily waste streams.

\section{Acknowledgments}

The authors gratefully acknowledge support of this work by the UFE + Program under the responsibility of the Directorate General for the Environment of the European Commission through the agreement LIFE 09 ENV/E/000451-VALUVOIL project.

\section{References}

American Public Health Association (APHA), 2005. Standard Methods for the EXamination of Water and Wastewater, 21th ed. APHA, Washington DC, USA.

Angelidaki, L, Ahring, B.K., Deng, H., Schmidt, J.E., 2002. Anaerobic digestion of olive mill effluents toggther with swine manure in USAB reactors Water Sci. Technol. 45 (10), 213-218,

Angelidaki, L., Alves, M., Bolzonella, D., Borzacconi, L., Campos, J.L., Guwy, A.J Kalyuzhnyi, S. Jenicek, P., Lier, J.B., 2009. Defining the biomethane potential (BMP) of solid organic wastes and energy crops: a proposed protocol for batch assays. Water Sci. Technol. 59, 927-934. 
Arsova, L, 2010, Anaerobic Digettion of Food Waste: Current Status, Problems and an Altemative Product. Foundation of Engineering and Applied Science, Columbia University.

Chen, Y., Cheng, H.., Creamer, KS., 2008. Inhibition of anaerobic digestion process: a review. Bioresour. Technol. 99, 4044-4064.

Cirne, D., Paloumet, X., Bjömsson, L., Alves, M., Mattiassona, B., 2007. Anaerobic digestion of lipid-rich waste - effects of lipid concentration. Renew. Energy 32 , 965-975.

Dechrugsa, S., Kantachote, D., Chaiprapat, S., 2013. Effects of inoculum to substrate ratio, substrate mix ratio and inoculums source on batch co-digestion of grass and pig manure. Bioresour. Technol. 146, 101-108.

de Lemos, CA., 2007. Anaero bic Reactors: Biological Wastewater Treatment, vol, 4. WA Publishing, London

Femández, A., Sánchez, A., Font, X., 2005, Anaerobic co-digestion of a simulated organic fraction of municipal solid wastes and fats of animal and vegetable origin. Biochem. Eng. J. 26, 22-28.

Göblos S . Portörö, P. Bordás, D. Kálmán. M. Kiss, L 2008. Comparison of the effectivities of two-phase and single-phase anaerobic sequencing batch reactors fectivities of two-phase and single-phase anaerobic sequencing batch
during dairy wastewater treatment. Renew, Energy 33 (5), 960-965.

Goncalves, M.R. Costa, J.C. Marques, I.P. Alves, M.M., 2011. Inoculum acclimation to oleate promotes the conversion of olive mill wastewater to methane. Energy 36 , 2138-2141.

Hidalgo, D., Sastre, E, Gómez, M., Nieto, P., 2012. Evaluation of pre-treatment processes for increasing biodegradability of agro-food wastes, Environ. Technol. 33 (13), 1497

Ho, J., Sung, S, 2010. Methanogenic activities in anaerobic membrane bioreactors (AnMBR) treating synthetic municipal wastewater. Bioresour. Technol. 101, 2191-2196.

Hong V., 2011. Anaerobic digestion of oil-rich solid waste. J. BiotechnoL 9 (1), 4553.

Labatut, R.A., Angenent, LA., Scott, N.R, 2011. Biochemical methane potential and biodegadability of complex organic substrates. Bioresour. Technol. 102, 22552264.

Lesteur, M., Bellon-Maurel, V., Gonzalez, C, Latrille, E., Roger, JM., Junqua, G., Steyer, J.P., 2010. Alternative methods for determining anaerobic biodegradability, a review, Process, Biochem 45, 431-440.
Math, M., Kumar, S., Soma, V., Chetty, S., 2010. Technologies for biodiesel production from used cooking oil - a review. Energy Sustain. Develop. 14 (4), 339-345.

Mathiyazhagan, M., Ganapathi, A., 2011. Factors affect ing biodiesel production. Res. Plant Biol. 1 (2), 01-05, 2231-5101.

Neves, L, Oliveira, R., Alves, M.M., 2009 a. Co-digestion of cow manure, food waste and intermittent input of fat. Bioresour. Technol. 100 (6), 1957-1962.

Neves, L., Pereira, M., Mota, M., Alves, M., 2009b. Detection and quantification of long chain fatty acids in liquid and solid samples and its relevance to understand anaerobic digestion of lipids. Bionesour. Technol. 100 (1), 91-96.

Nieto, P. Hidalgo, D. Irusta, R. Kraut, D. 2013. Biochemical methane potential (BMP) of agm-food wastes from the Cider Region (Spain). Water Sci. Technol 66 (9). $1842-1848$.

Palats, J. Laureni, M., Andrés, M.V., Flotats, X., Nielsen, H.B., Angelidaki, L., 2009. Strategies for recovering inhibition caused by long chain fatty acids on anaerobic thermophilic biogas reactors Bioresour Technol 100, 4588-4596.

Pastor, L. Ruiz, L. Pascual, A. Ruiz, B., 2013. Co-digestion of used oils and urban landfill leachates with sewage sludge and the effect on the biogas production. Appl. Energy 107, 438-445.

Pereira.M. A.Pines, O.C., Mota, M. Alves, M.M.2005. Anaerobic biodegradation of oleic and palmitic acids: evidence of mass transfer limitationscaused by long chain fatty acid accumul ation onto the anaerobic sludge. Biotech. Bioeng. 92 (1), 15-23.

Raposo, F., de la Rubia MA. Fernández-Cegri, V. Borja, R., 2011. Anaerobic digestion of solid organic substrates in batch mode, an overview relating to methane yields and experimental procedures. Renew. Sustain. Energy Rev. 16 (1), 861-

Salminen, E., Rintala, J., Lokshina, L., Vavilin, V.A., 2000. Anaerobic batch degradation of solid poultry slaughterhouse waste. Water. Sci. Technol. $41,33-41$.

Torrijos, M., Thalla, A., Sousbie, P., Bosque, F., Delgenès, J.P., 2008. Anaerobic digstion of residues from production and refining of vegetable oils as an altemative to conventional solutions. Water Sci. Technol. 58 (9), 1871-1878, Xie, S., Lawlor, P.G., Frost, J.P., Hu, Z, Zhan, X., 2011. Effect of pig manure to grass
silage ratio on methane production in batch anaerobic co-digestion of
concentrated pig manure and gass silage, Bioresour. Technol. 102, 5728-5733. concentrated pig manure and gass silage. Bioresour. Technol. 102, 5728-5733.

Zhang, L, Lee, Y.W., Jahng, D., 2011. Anaerobic cD-digestion of food waste and 102 (8) 5048-5059. 


\subsection{Estudio comparativo de sistemas de digestión anaerobia en una y dos fases a escala laboratorio}

Aunque existen numerosos estudios que han puesto de manifiesto las ventajas potenciales de la DA en dos fases frente a los sistemas monofásicos (Göblös et al., 2008; Ince, 1998; Nasr et al., 2012; Park et al., 2008; Shen et al., 2013; Solera et al., 2002; Yu et al., 2002), la mayoría de estos trabajados han utilizado efluentes diluidos 0 sintéticos.

Hasta la fecha, no existe mucha información científica disponible relativa a la comparación entre el rendimiento de sistemas de DA en una y dos fases para residuos ricos en lípidos.

En la Figura 3-20 se muestra de forma esquemática cada uno de los reactores utilizados a escala laboratorio para cada uno de los sistemas empleados y en la Figura 3-21 se presenta una fotografía de los mismos.
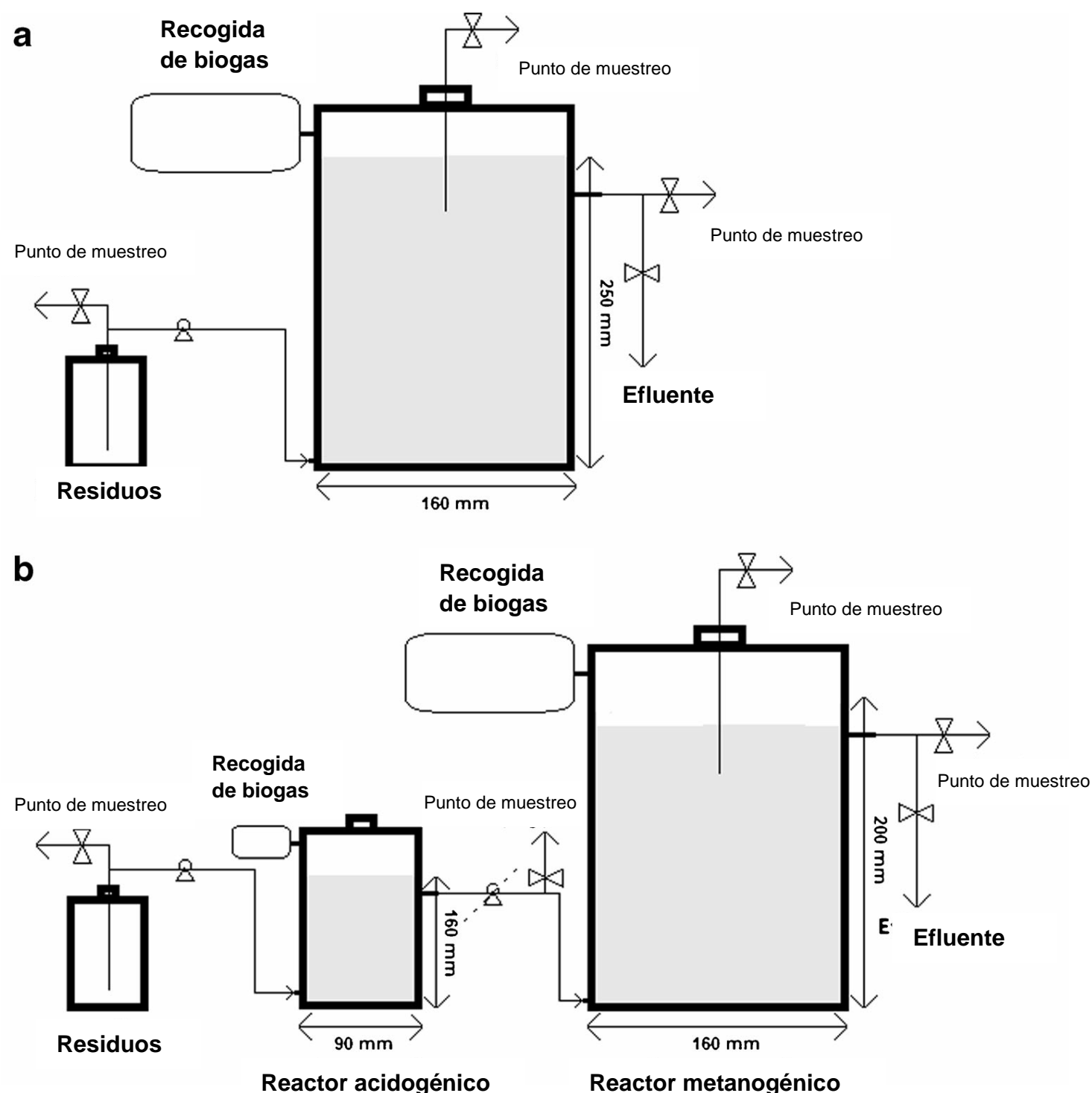

Figura 3-20. Esquema experimental: a) sistema monofásico; b) sistema de dos fases 
a)

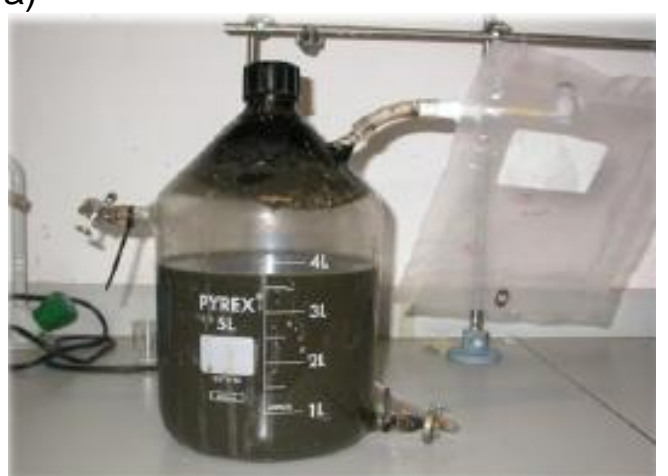

b)

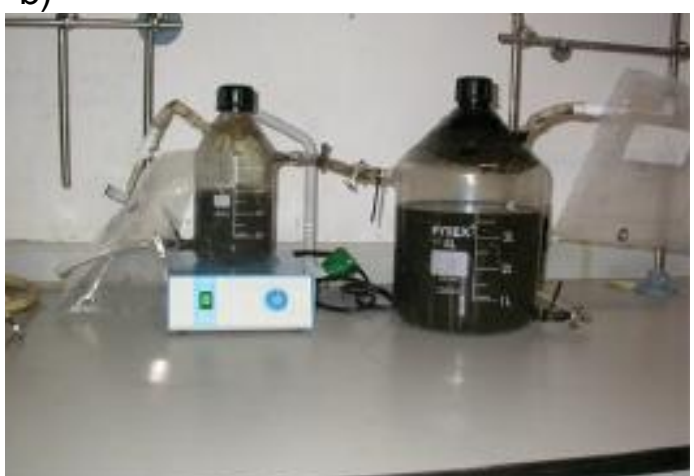

Figura 3-21. Fotografía: a) sistema monofásico; b) sistema de dos fases

Cada uno de los sistemas está formado por reactores de vidrio que disponen de una entrada para la alimentación por su parte inferior, aperturas en su parte superior para la recogida del biogás mediante bolsas Tedlar, y salida para toma de muestra de digestato mediante una jeringa. El volumen efectivo del reactor es de 5,0 $\mathrm{L}$ en el caso del sistema monofásico y de $1,0 \mathrm{~L}$ y $4,0 \mathrm{~L}$ para el reactor acidogénico y metanogénico respectivamente, en el caso del sistema en dos fases. En el sistema en dos fases, el reactor acidogénico es 4 veces más pequeño que el reactor metanogénico, ya que al ser la velocidad de reacción en la fase acidogéncia mayor que en la fase metanogénica se requieren menores THR en ese reactor (Ince, 1998; Wust, 2003).

Con el fin de aclimatar los microorganismos anaerobios al substrato rico en grasas, antes de comenzar con la experimentación ambos sistemas estuvieron operando en discontinuo durante 30 días. Para ello, el sistema se arrancó con la adición de 0,5 L de OW en el reactor de una fase, y 0,1 , y $0,4 \mathrm{~L}$ de OW para el reactor acidogénico y el metanogénico respectivamente del sistema de dos fases. Seguidamente se inocularon con un lodo anaeróbico procedente de una planta de tratamiento de aguas municipales con una concentración de $12 \pm 1 \mathrm{~g} \mathrm{SV} \cdot \mathrm{L}^{-1}$ de forma que se adicionaron $2,5 \mathrm{~L}$ al reactor del sistema monofásico, $0,5 \mathrm{~L}$ al reactor acidogénico y $2 \mathrm{~L}$ al reactor metanogénico del sistema de dos fases.

Durante el periodo experimental ambos sistemas operaron en semicontinuo de la siguiente manera:

El sistema monofásico operó como un reactor metanogéncio a $\mathrm{pH} \mathrm{7,0} \mathrm{-} \mathrm{7,4} \mathrm{y} \mathrm{a} \mathrm{un}$ tiempo hidráulico de residencia de 20 días.

En el sistema en dos fases el primer reactor operó como un reactor acidogénico a un $\mathrm{pH}$ medio $5,5 \pm 0,5$ y un THR de 2 - 3 días, y el segundo reactor como un reactor metanogénico a un pH medio 7,2 $\pm 0,5$ y un THR de 17 - 18 días.

En paralelo, para realizar el estudio comparativo entre los sistemas de digestión anaerobia en una y dos fases, se determinó el potencial metanogénico de diferentes relaciones de alimentación de OW/PM (1:0, 1:1 y 1:3 v/v) en ambos montajes. Los ensayos de biodegradabilidad se realizaron en reactores de $2 \mathrm{~L}$ de capacidad, utilizando un volumen de muestra total de $600 \mathrm{~mL}$. Todos los ensayos se realizaron en 
una sala termostatada a la temperatura de $35 \pm 1{ }^{\circ} \mathrm{C}$, con agitación continúa sobre una mesa agitadora orbital ajustada a 125 rpm.

A los reactores utilizados para realizar los test de biodegradabilidad del sistema en una fase se les añadió como inoculo el fango anaerobio procedente del reactor utilizado para el estudio del sistema monofásico a escala laboratorio, el cual tenía una concentración de $20 \pm 2 \mathrm{~g} \mathrm{SV} \cdot \mathrm{L}^{-1}$. A los reactores utilizados para realizar los test de biodegradabilidad del sistema de dos fases se les añadió como inoculo el fango anaerobio procedente del reactor metanogénico utilizado para el estudio del sistema de dos fases a escala laboratorio, el cual tenía una concentración de $21 \pm 1 \mathrm{~g} \mathrm{SV} \cdot \mathrm{L}^{-1}$. La concentración del inóculo en todos los test fue de $6,5 \mathrm{~g} \cdot \mathrm{L}^{-1}$ y el pH fue de 7,5.

Todos los ensayos fueron llevados a cabo por triplicado. La relación sustrato /inóculo $(\mathrm{S} / \mathrm{X})$ se mantuvo para todas las muestras en el rango de 0,40 a $0,60 \mathrm{gSV}_{\text {sustrato }} \mathrm{gSV}^{-1}$ inoculo. También se ha realizado por triplicado una batería de ensayos en blanco (sin sustrato, solo inóculo) para determinar la producción metanogénica endógena. Para evitar la acidificación del ensayo se añadió $\mathrm{NaHCO}_{3}$ como buffer $\left(6 \mathrm{gNaHCO}_{3} \cdot \mathrm{L}^{-1}\right)$. Los experimentos se finalizaban cuando la velocidad de producción de biogás en los ensayos con sustrato decrecía hasta los niveles del blanco.

La Figura 3-22 muestra la producción de metano en cada uno de los sistemas para las diferentes relaciones de alimentación. Los ensayos se han realizado por triplicado, por lo que en la gráfica se representa la media aritmética de las medidas con el error estándar para cada punto.

a)

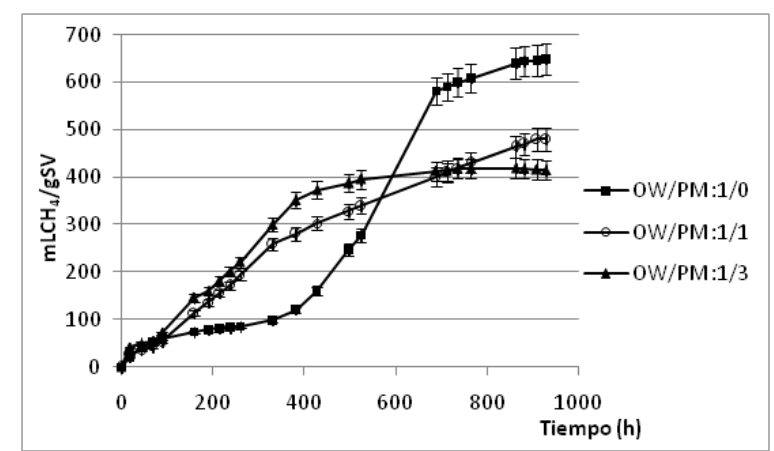

b)

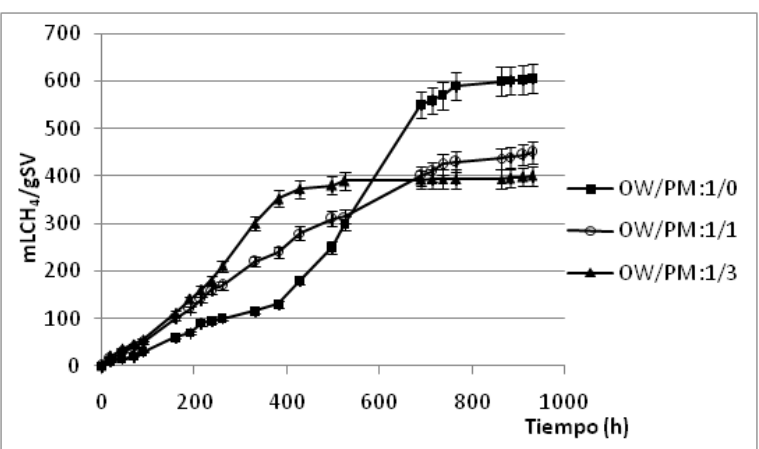

Figura 3-22. Producción acumulada de metano para diferentes relaciones de alimentación y con inoculo aclimatado: a) sistema monofásico; b) sistema de dos fases 
El patrón de producción de metano que se produce es similar al obtenido por Cirne et al., (2007) en procesos de degradación de residuos ricos en grasas. En todos los casos se produjo una alta eliminación de SV $(70,75$ y $81 \%$ en el sistema monofásico y 68, 73 y $78 \%$ en el sistema de dos fases, para relaciones OW/PM 1:0, 1:1 y 1:3 respectivamente), pero se encontró una gran inhibición inicial en los ensayos donde únicamente se utilizó OW como substrato. En este caso la fase de latencia fue de $400 \mathrm{~h}$, aunque posteriormente el proceso se recuperó. Este fenómeno ya fue constatado por Palatsi et al. (2009) que demostraron que la inhibición por acumulación de ácidos grasos de cadena larga es un fenómeno reversible que posiblemente tiene que ver más con limitaciones físicas de transporte que con funciones metabólicas.

El sistema de dos fases produce menor cantidad de biogás, pero de mayor calidad, con una concentración media de metano del $67 \%$, frente a un $65 \%$ para el sistema monofásico.

Teniendo en cuenta las pendientes de las curvas que aparecen en la Figura 3-22, se puede concluir que la mezcla OW/PM 1:3 es la mezcla de substratos que presenta una mayor velocidad de degradación. La corriente residual que únicamente tiene OW es la que presenta una menor velocidad de degradación, aunque es la corriente que produce una mayor cantidad de biogás.

Los resultados de los test de biodegradabilidad no pueden predecir los resultados que se vayan a obtener en un digestor anaerobio que opere en continuo, ya que los test de biodegradabilidad se hacen con una relación $S / X$ en el rango de $0.40-0.60 \mathrm{~g} \mathrm{SV}_{\text {residuo }}$ . $\mathrm{gSV}^{-1}$ inóculo, y en este intervalo se suelen enmascarar los problemas de inhibición que puedan ocurrir (Pastor et al., 2013). Por tanto, y con el fin de evaluar la factibilidad de tratamiento de este tipo de residuos se han realizado ensayos en semicontinuo para cada uno de los sistemas a estudiar.

De la Figura 3-23 a la Figura 3-25 se muestra la velocidad de carga orgánica (OLR), el porcentaje de SV eliminados y la producción de metano para cada uno de los sistemas estudiados. El estudio se ha realizado en ambos sistemas para diferentes relaciones de alimentación de OW/PM (1:0, 1:1 y 1:3 v/v), y a tasas de carga orgánica que van desde 0,25 a $3,1 \mathrm{~kg} \mathrm{SV} \cdot \mathrm{m}^{-3} \cdot \mathrm{dí}^{-1}$.

En la experimentación se observa que la mezcla de OW con PM neutraliza los efectos negativos de acumulación de lípidos y produce elevados porcentajes de eliminación de SV en ambos sistemas (63 y $71 \%$ en el sistema monofásico y 69 y $72 \%$ en el sistema de dos fases, para relaciones de alimentación 1:1 y 1:3 OW/PM, respectivamente). En las mismas condiciones de operación, la producción de metano fue de 0,30 y $0,22 \quad \mathrm{~m}^{3} \quad \mathrm{CH}_{4} \quad \mathrm{~kg}^{-1} \mathrm{SV}_{\text {eliminado }}$ para el sistema monofásico y 0,30 y $0,27 \mathrm{~m}^{3} \mathrm{CH}_{4} \cdot \mathrm{kg}^{-1} \mathrm{SV}_{\text {eliminado }}$ para el sistema de dos fases. Además, el sistema de dos fases presentó un funcionamiento más estable y una mayor capacidad de tratamiento. 
a)

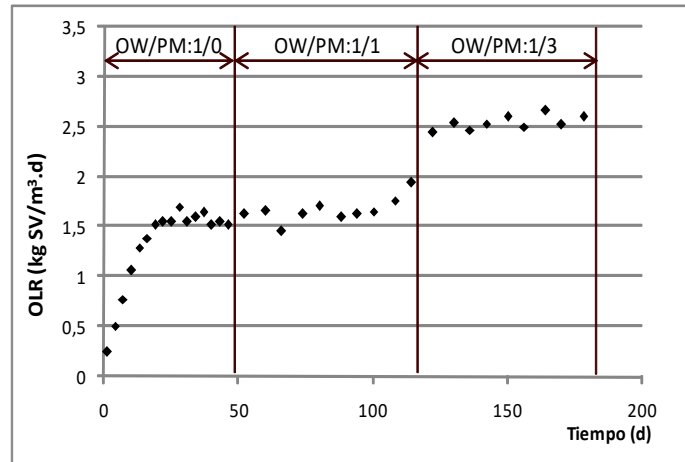

b)

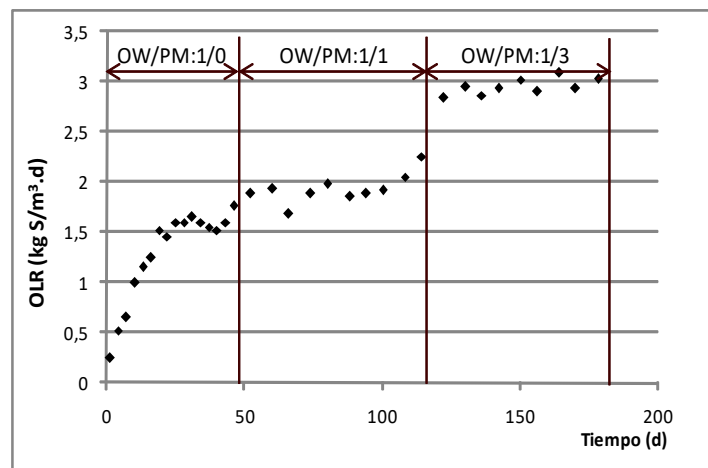

Figura 3-23. Velocidad de carga orgánica para diferentes relaciones de alimentación y con inoculo aclimatado: a) sistema monofásico; b) sistema de dos fases

a)

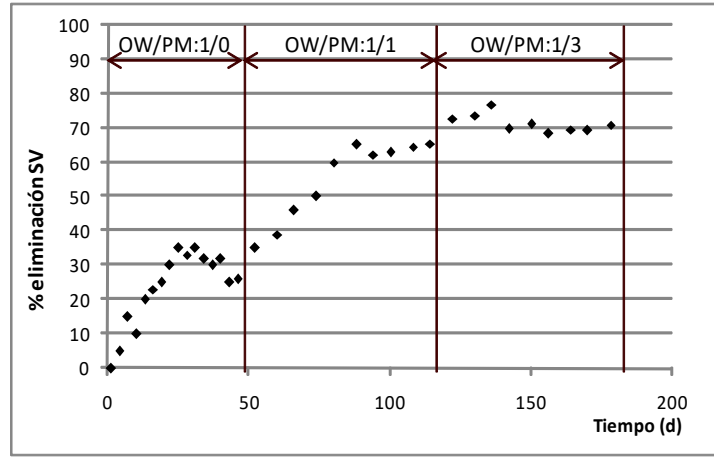

b)

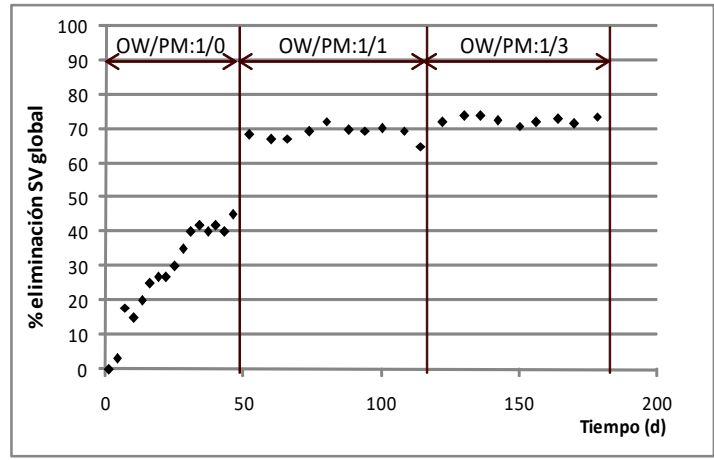

Figura 3-24. Porcentaje de eliminación de sólidos volátiles para diferentes relaciones de alimentación y con inoculo aclimatad: a) sistema monofásico; b) sistema de dos fases

a)

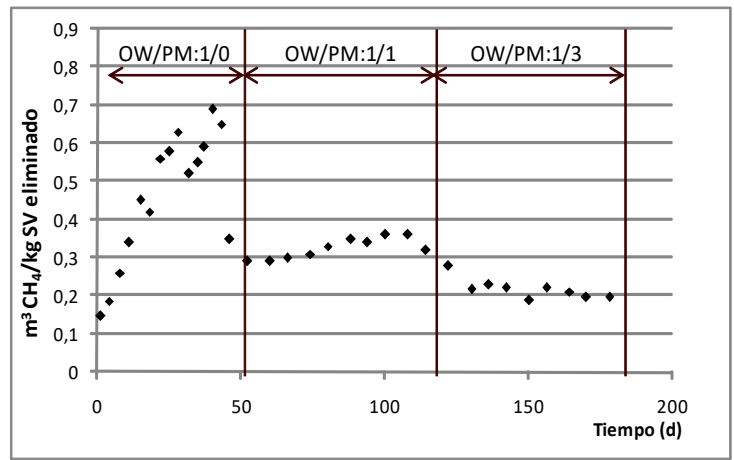

b)

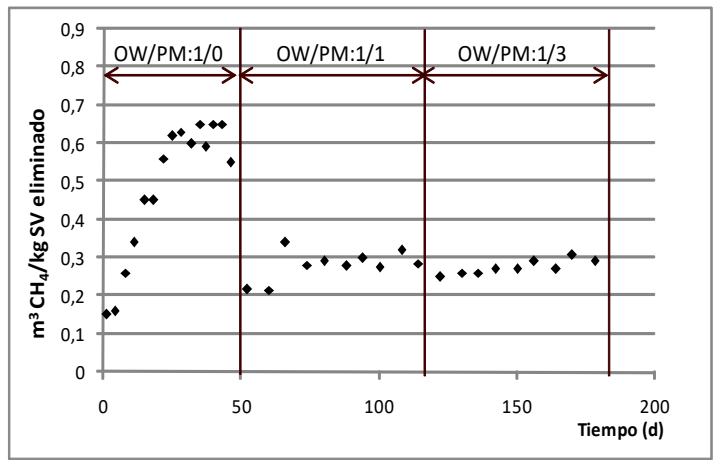

Figura 3-25. Producción de metano para diferentes relaciones de alimentación y con inoculo aclimatado: a) sistema monofásico; b) sistema de dos fases 
Como conclusiones de este estudio puede decirse que el sistema en dos fases produce un efluente de mayor calidad en términos de mayor eliminación de SV, mayor estabilidad y mayor producción de metano que el sistema monofásico.

En el sistema en dos fases no se han producido problemas de operación, en cambio en el sistema monofásico aparecieron problemas de taponamiento de las conducciones a partir del día 25 para el primer periodo de ensayos, donde existía un relación de alimentación OW/PM:1/0. Según Wust (2003), el reactor acidogénico reduce en un $50 \%$ la cantidad aceites y grasas que se cargan en el reactor metanogénico, lo que hace al sistema de dos fases más estable que el sistema monofásico. En los experimentos realizados, la digestión de OW con concentraciones de grasa mayores del 51,5\% inhiben el proceso de degradación anaerobia.

Durante el segundo y tercer periodo, la mezcla de OW con PM neutraliza el efecto negativo causado por el alto contenido en lípidos de OW, por lo que se obtienen mayores porcentajes de eliminación de SV en ambos sistemas.

El sistema en dos fases es capaz de operar de forma estable a mayores velocidades de carga orgánica $\left(3,1 \mathrm{~kg} \mathrm{SV} \cdot \mathrm{m}^{-3} \cdot \mathrm{dia}^{-1}\right)$ que el sistema monofásico $\left(2,6 \mathrm{~kg} \mathrm{SV} \cdot \mathrm{m}^{-3} \cdot \mathrm{dia}^{-1}\right)$, lo que hace que para un mismo volumen de digestor se pueda tratar mayor cantidad de residuo, lo cual implica mayor rentabilidad de proceso.

Los coeficientes de variación (CV) calculados para la producción de biogás y para la eliminación de sólidos, pueden reflejar la capacidad tampón del sistema de digestión para los nuevos sustratos alimentados y la estabilidad del proceso de digestión (Shen, 2013). En la Tabla 3-8 aparecen los CV (\%) obtenidos en este estudio.

Tabla 3-8. Coeficientes de variación calculados para la producción de biogás y eliminación de sólidos a diferentes relaciones OW/PM.

\begin{tabular}{|lccccc|}
\hline & \multicolumn{3}{c}{ CV Eliminación de sólidos } & \multicolumn{3}{c|}{ CV Producción de metano } \\
& \multicolumn{2}{c}{$(\%)$} & & \multicolumn{3}{c|}{$(\%)$} & TP \\
\hline & SP & TP & SP & 15,8 \\
\hline OW/PM=1:1 & 27,6 & 2,3 & 17,9 & 6,3 \\
\hline OW/PM=1:3 & 4,4 & 1,5 & 8,6 & \\
\hline
\end{tabular}

Los valores de los CV son mayores a medida que aumenta la cantidad de grasas en la alimentación, y especialmente en el sistema monofásico, por lo que se corrobora que el sistema en dos fases en un sistema más estable para el tratamiento de este tipo de residuos.

El trabajo realizado en este apartado de la tesis ha sido utilizado para redactar el artículo titulado: "Single-phase and two-phase anaerobic co-digestion of residues from the treatment process of waste vegetable oil and pig manure", el cual ha sido publicado en la revista BioEnergy Research, revista listada en el JCR con factor de impacto 3.398 en su año de publicación. A continuación se presenta dicho documento: 


\title{
Single-Phase and Two-Phase Anaerobic Co-Digestion of Residues from the Treatment Process of Waste Vegetable Oil and Pig Manure
}

\author{
Dolores Hidalgo • Jesús M. Martín-Marroquín · \\ Emilia Sastre
}

C. Springer Science+Business Media New York 2013

\begin{abstract}
The co-digestion of residues from the pre-treatment process of waste vegetable oil (OW) and pig manure (PM) was performed under different OW/PM feed ratios (1:0, 1:1 and $1: 3 \mathrm{v} / \mathrm{v}$ ) and at organic loading rates ranging from 0.25 to $3.1 \mathrm{~kg}$ $\mathrm{VS} \mathrm{m}^{-3}$ day $^{-1}$ in lab-scale single-phase (SP) and two-phase (TP) systems. From the experiments, it was observed that digestion of OW alone was inhibitory for the anaerobic degradation. Mixing OW with PM neutralized the negative effects of lipids accumulation and high VS removal efficiencies were realized in both systems ( 63 and $71 \%$ in SP system and 69 and $72 \%$ in TP system, at 1:1 and 1:3 OW/PM mixtures, respectively). Under the same operational conditions, the methane yield was 0.30 and $0.22 \mathrm{~m}^{3} \mathrm{CH}_{4} \mathrm{~kg}^{-1} \mathrm{VS}$ removed for the SP anaerobic digester and 0.30 and $0.27 \mathrm{~m}^{3} \mathrm{CH}_{4} \mathrm{~kg}^{-1}$ VS removed for the TP configuration. Additionally, TP digestion presented more stable operation and higher treatment capacity.
\end{abstract}

Keywords Co-digestion $\cdot$ Pig manure $\cdot$ Single-phase anaerobic digestion - Two-phase anaerobic digestion - Waste vegetable oil

\section{Introduction}

Waste vegetable oils (WVO) are a promising altemative to the use of edible oils as feedstock for biodiesel production. The European Union produces 700,000 to 1 million $t$ a year of

Electronic supplementary material The online version of this article (doi:10.1007/s12155-013-9396-2) contains supplementary material, which is available to authorized users.

D. Hidalgo $(\nabla)$ - J. M. Martín-Marroquín · E. Sastre CARTIF Technology Centre, Parque Tecnológico de Boecillo, 205 , 47151 Boecillo, Valladolid, Spain

e-mail: dolhid@cartif.es
WVO and most of them are disposed improperly [7, 18]. WVO can produce blockages in pipes and make sewage treatment more difficult when disposed through the sink. The EU strongly favors and supports the recovery of WVO for biofuel production as it fits in the strategy of reducing dependency on petrol fuels [9], minimizing greenhouse gas emissions, and decreasing engine pollution, and at the same time, it is a way to reduce waste disposal that can contaminate soils and waters.

When WVO is collected, it goes to a treatment process to eliminate moisture, bulky particulate, free fatty acids, and other undesirable compounds before sending it for biodiesel production. Nowadays, the increasing amount of wastes generated by these activities means an environmental problem. Inadequate management and uncontrolled disposal have influenced both water bodies and nearby communities and have raised health concerns.

Anaerobic digestion $(\mathrm{AD})$ of residues from the WVO treatment process has the potential to achieve an efficient pollution reduction as well as the advantage of conserving energy and providing opportunities for environmental and socioeconomic benefits [4]. On the other hand, it is well known that AD of oilrich wastes is not always easy and simple, since anaerobes are very sensitive to lipid-rich matters as well as to intermediate compounds of oily wastes degradation process $[15,16,22]$. High lipid concentrations can destabilize anaerobic digesters due to inhibition of methanogenic microorganisms by possible damage to cellular membrane $[10,14]$. Nevertheless, lipids are attractive substrates for anaerobic digestion and co-digestion due to the higher methane yield obtained when compared to proteins or carbohydrates. In this context, lipidrich waste can be regarded as a large potential renewable energy source [20]. Ahrin (2003) [1] described a significant increase $(100 \%)$ in the yield of methane when fish oil was added to a manure digester. 
$\mathrm{AD}$ is considered to take place in several steps, including the acidogenic and the methanogenic phases. In AD processes, the single-phase (SP), in which these two steps proceed simultaneously in one reactor, is commonly used because of simplicity in configuration and operation. However, the twophase (TP) system, which consists of separate acidogenic and methanogenic reactors, has several advantages over conventional SP systems, such as a shorter retention time, higher gas conversion efficiency, and higher methane concentration in the produced gas [32]. This is achieved by optimizing environmental conditions for each phase, such as $\mathrm{pH}$, substrate concentrations, and organic loading.

Little research and scientific information is available concerning a direct performance comparison between SP and TP systems in the application of AD to oil-rich waste. Most of the research on TP systems has focused on evaluating the performance, reactor design, and optimal operating conditions for treating specific industrial wastes or wastewaters. These studies have illustrated the potential advantages of two-phase anaerobic digestion over single-phase systems $[14,17,21,24$, $28,29,32]$. However, most of these studies used synthetic or diluted effluents. Therefore, taking into account this fact, and continuing the research of upgrading the anaerobic co-digestion of different wastes, the aim of the present work has been to compare the advantages of SP and TP anaerobic co-digestion of residues from the used vegetable oil processing industry $(\mathrm{OW})$ with pig manure (PM) in semi-continuous sequencing digesters operated at mesophilic temperature.

To obtain fundamental information, lab-scale SP and TP anaerobic reactors were operated continuously with once-a-day feeding using different OW/PM mixtures.

Treatment performances are discussed in this report, with the emphasis placed on the evaluation of biogas production optimal values, stability of the operation and organic matter removal efficiencies under different $\mathrm{OW} / \mathrm{PM}$ feed ratios.

\section{Materials and Methods}

\section{Wastes Analysis}

OW and PM samples were weekly collected. OW was supplied by a biodiesel company located in Madrid (Spain) and PM proceeded from a swine-raising farm located nearby the city of Valladolid (Spain). Enough amounts of OW and PM were taken for each time in order to guarantee the same sample to be used for digestion and then stored in a $4{ }^{\circ} \mathrm{C}$ fridge.

Total and volatile solid concentration (TS, VS), chemical oxygen demand (COD), ammonia nitrogen $\left(\mathrm{N}-\mathrm{NH}_{4}{ }^{+}\right)$, fat content, alkalinity, $\mathrm{P}$, and $\mathrm{pH}$ were determined following standard methods' [2] recommendations. Fatty acid(FA) concentrations were determined using a gas chromatograph (HPAgilent) equipped with a flame ionization detector. $\mathrm{C}, \mathrm{N}, \mathrm{H}$, and $\mathrm{S}$ contents were determined by UNE CEN/TS 15104 EX with a LECO TruSpec CHN(S) elemental analyzer. Oxygen content was not measured directly but was estimated assuming that no other elements (apart from the measured $\mathrm{C}, \mathrm{H}, \mathrm{N}$, $\mathrm{S}$, and $\mathrm{P}$ ) were present in the wastes. In all the cases, analysis was performed just after sampling.

\section{Biomethane Potential Test}

In order to study the biodegradability and biomethane potential (BMP) of different OW/PM mixtures and to compare the biogas production rate of the SP and TP biomass, batch experiments were run in glass serum bottles with a liquid volume of $600 \mathrm{~mL}(2,000 \mathrm{~mL}$ of total volume). All the experiments were carried out at $35 \pm 1{ }^{\circ} \mathrm{C}$ in a thermostatic room, and continuously stirred on a shaking table (adjusted $125 \mathrm{~mm})$. The SP serum bottles were seeded with anaerobic sludge from the lab-scale SP reactor, with a concentration of $20 \pm 2 \mathrm{~g} \mathrm{VS} \mathrm{L}^{-1}$. The TP serum bottles were seeded with anaerobic sludge from the lab-scale TP methanogenic reactor with a concentration of $21 \pm 1 \mathrm{~g} \mathrm{VS} \mathrm{L}^{-1}$. The concentration of the inoculum in all the assays was $6.5 \mathrm{~g} \mathrm{~L}^{-1}$ and $\mathrm{pH}$ was 7.5 . Both the SP and TP BMP tests were run at three different $\mathrm{OW} /$ PM substrate ratios (1:0, 1:1 and 1:3 v/v), and triplicate assays, for all the waste mixtures and conditions, were performed. Substrate/inoculum $(\mathrm{S} / \mathrm{X})$ ratios were in the range of 0.40 to $0.60 \mathrm{~g} \mathrm{VS}_{\text {waste }} \mathrm{g} \mathrm{VS}^{-1}$ inoculum for all the samples.

A set of triplicate blank assays without any waste (only inoculum) was also performed for endogenous methane production determination. To avoid acidification of the assay, $\mathrm{NaHCO}_{3}$ was added as buffer $\left(6 \mathrm{~g} \mathrm{NaHCO}_{3} \mathrm{~L}^{-1}\right)$. Experiments were finished when the biogas production rate in waste assays decreased to the same level as in the blank assays.

Biogas production was measured manually by a pressure transmitter (Druck, PTX 1400, range 1 bar) in the head space of each reactor. To avoid reaching overpressure, biogas in the head space was released periodically. Pressure differences were converted to biogas volume, using the ideal gas law and standard temperature and pressure conditions $(\mathrm{P}=1$ bar and $\mathrm{T}=0^{\circ} \mathrm{C}$ ). Biogas composition was measured before each release with a Varian CP-4900 Micro-GC with a thermal conductivity detector. Net methane production was calculated by subtracting the amount of the methane produced by the blank assay from the methane production of each assay.

\section{Experimental Set-Up}

In order to study the operational and performance characteristics of the SP and TP anaerobic digestion when treating a mixture of OW and PM, completely stirred tank reactors were employed. The experimental set-up is shown schematically in Fig. 1. Each system consisted of a glass reactor with ports down the wall for batch feeding, using Watson Marlow 323 
Fig. 1 Experimental set-up: a SP system; b TP system

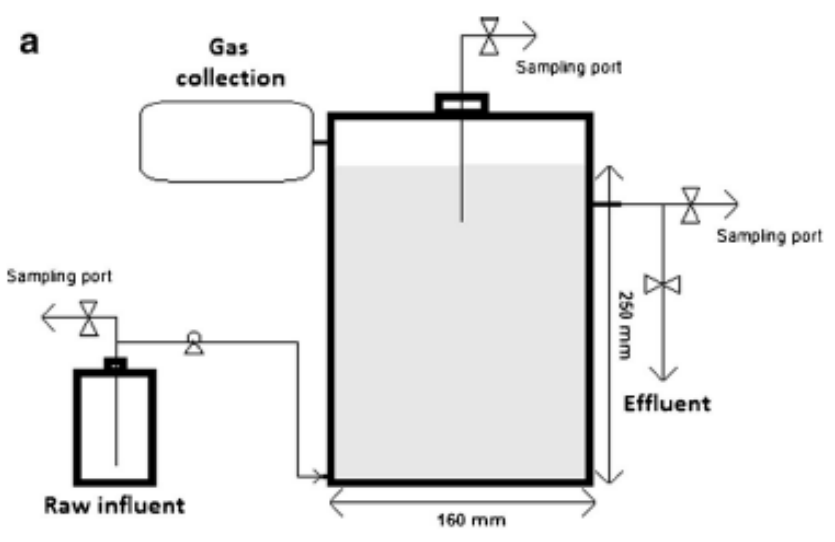

b

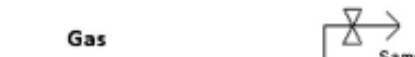
Sampling port

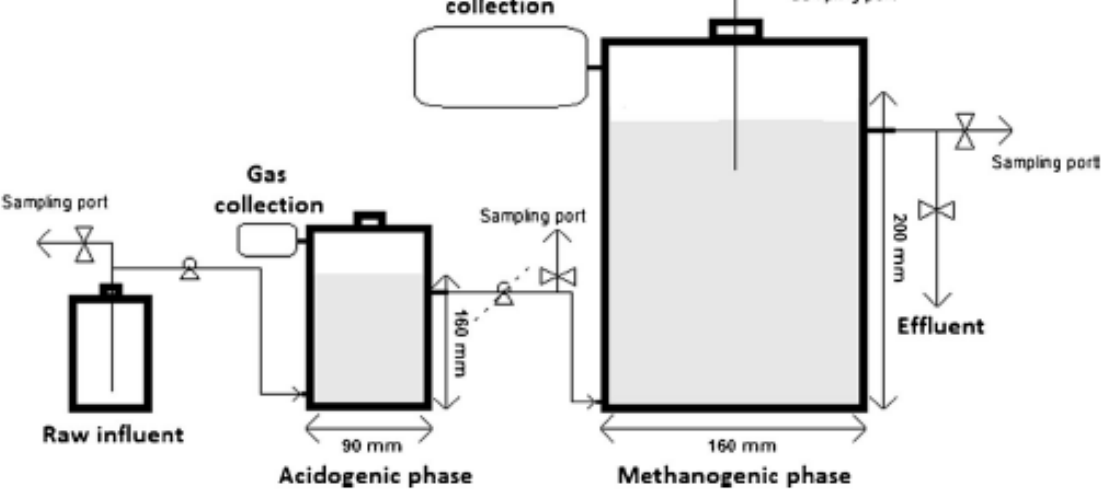

$\mathrm{S} / \mathrm{D}$ pumps, and openings in the top for biogas collection in a Tedlar bag and digestate sampling with a syringe. The effective volume was around 5.0 L for the SP digestion, and around 1.0 and $4.0 \mathrm{~L}$ for acidification stage and methanogenic stage of the TP anaerobic digestion, respectively. Typically, in a TP system, the acidogenic reactor is much smaller than the methanogenic reactor since the required hydraulic retention time (HRT) for acidogenesis is less than for methanogenesis [17, 31]. The temperature was controlled at $35 \pm 1{ }^{\circ} \mathrm{C}$ in a thermostatic room, and reactors were continuously stirred on a shaking table (adjusted $100 \mathrm{mpm}$ ).

The systems were started by the addition of $0.5,0.1$, and $0.4 \mathrm{~L}$ of $\mathrm{OW}$ to the methanogenic SP, acidogenic TP, and methanogenic TP reactors, respectively, followed by inoculation with $2.5 \mathrm{~L}$ (SP reactor), $0.5 \mathrm{~L}$ (acidogenic TP reactor), and $2 \mathrm{~L}$ (methanogenic TP reactor) of anaerobic sludge from a municipal wastewater treatment plant, with a concentration of $12 \pm 1 \mathrm{~g} \mathrm{VS} \mathrm{L}^{-1}$. Before the experiments were started, the reactors were operated under batch conditions for 30 days to set up a stable anaerobic culture acclimated to the oily substrate. In the experimental period, the reactors operating conditions were semi-continuous.
The SP reactor was operated as a methanogenic reactor with a pH between 7.0 and 7.4 and a HRT of 20 days. The SP reactor was fed raw OW/PM mixtures (1:0, 1:1, 1:3v/v ratios consecutively).

The first reactor in the TP system was operated as an acidogenic phase and the second reactor was operated as a methanogenic phase. The $\mathrm{pH}$ in the acidogenic phase averaged $5.5 \pm 0.5$ with a HRT between 2 and 3 days. The $\mathrm{pH}$ in the methanogenic phase averaged $7.2 \pm 0.5$ and the HRT was between 17 and 18 days.

As illustrated in Fig. 1, the first reactor (acidogenic) in the TP system was also fed raw OW/PM mixtures $(1: 0,1: 1,1: 3 v / v$ ratios consecutively), and a portion of the effluent from the first reactor was fed to the second reactor, whereas a similar portion of the effluent from the first reactor was wasted in order to maintain effective volumes constant in the reactor.

The single-phase and two-phase systems used in this study were fed the same raw influent and were operated in parallel to study quantitatively the effect of phase separation on the anaerobic treatment of raw waste mixtures at different OW/PM ratios.

\section{包 Springer}




\section{Results and Discussion}

\section{Waste Composition}

Parameters as TS, VS, COD, total organic carbon, and total nitrogen are the most frequently analyzed since they are the key when determining treatment optimization. Furthermore, the analysis of the elemental composition provides information about the theoretical methane potential $\left(B_{0, \text { Th }}\right)$ of a given waste using Buswell's Eq. (1). This equation assumes methane production from the complete degradation of a certain waste with a given elemental composition, where $\mathrm{C}_{n} \mathrm{H}_{\mathrm{a}} \mathrm{O}_{\mathrm{b}} \mathrm{N}_{\mathrm{c}}$ represents the chemical formula of the biodegradable organic compound subjected to the anaerobic degradation process (neglecting $\mathrm{S}$ and $\mathrm{P}$ content), and the production of methane considered herein is the maximum stoichiometrically possible [19]. For a $\mathrm{C}_{n} \mathrm{H}_{2} \mathrm{O}_{b} \mathrm{~N}_{c}$ compound the theoretical methane potential (at standard conditions for temperature and pressure) is:

$$
\begin{aligned}
& \mathrm{C}_{\mathrm{n}} \mathrm{H}_{\mathrm{a}} \mathrm{O}_{\mathrm{b}} \mathrm{N}_{\mathrm{c}}+\left(n-\frac{a}{4}-\frac{b}{2}+\frac{3 c}{4}\right) \mathrm{H}_{2} \mathrm{O} \rightarrow\left(\frac{n}{2}+\frac{a}{8}-\frac{b}{4}-\frac{3 c}{8}\right) \mathrm{CH}_{4}+\left(\frac{n}{2}-\frac{a}{8}+\frac{b}{4}+\frac{3 c}{8}\right) \mathrm{CO}_{2}+\mathrm{cNH}_{3} \\
& \mathrm{~B}_{0, T h}=\frac{\left(\frac{n}{2}+\frac{a}{8}-\frac{b}{4}-\frac{3 c}{8}\right) \cdot 22.4}{12 n+a+16 b+14 c}|=| \frac{L C H_{4}}{g V S}
\end{aligned}
$$

where the parameters $n, a, b$, and $c$ refer to the stoichiometry index of $\mathrm{C}, \mathrm{H}, \mathrm{O}$, and $\mathrm{N}$, respectively.

Tables 1, 2, and 3 gather the results obtained from the characterization of the selected raw wastes and their mixtures.

PM has a high content of ammonia in comparison with OW. Manure possesses a high alkalinity, while the alkalinity of $\mathrm{OW}$ is low. In addition, the $\mathrm{pH}$ of $\mathrm{OW}$ is low, and lower than the $\mathrm{pH}$ allowing growth for methanogens (approximately 6.0 ). On the other hand, OW has a high content of lipids in contrast to manure. The characterization of the wastes indicates that co-digestion with PM could be a cost effective method to treat $\mathrm{OW}$ without the need to add nitrogen source or add chemicals for increasing buffer capacity or adjusting $\mathrm{pH}$ [33]. Furthermore, lipids concentration is lowered.

Palmitic, linoleic, and oleic are the most abundant long chain fatty acids (LCFA) in the OW samples (Table 3). The concentrations of the other acids were always much lower. These three compounds have been identified as inhibitors for gram-positive microorganisms. According to Pastor et al. [25], methanogens are also affected by the LCFA. Even at low concentrations, these compounds can be adsorbed on the cell wall interfering with mass transfer across the wall.
However, some adaptation of the microorganisms responsible for anaerobic digestion is possible [6]. Especially rod-shaped hydrogenotrophic methanogens seem to have the strong ability to adapt to new and untypical habitats, being more resistant to oxic shock, desiccation and other disturbances [12].

Furthermore, oleic acid has been identified as the most toxic LCFA with inhibition being observed for concentrations greater than $200 \mathrm{mg} \mathrm{L}^{-1}$ [23]. Reductions of $50 \%$ of the activity of methanogens have been observed in the presence of 50 to $200 \mathrm{mg} \mathrm{L}^{-1}$ of oleic acid [3]. Pereira et al. [26] found evidence of mass transfer limitation caused by LCFA accumulation onto the anaerobic sludge when oleic and palmitic acids were anaerobically biodegraded. This is why the codigestion of these wastes with non-oily wastes (as pig manure) is considered the key factor to prevent inhibition of methanogenesis since the lipids concentration is lowered.

\section{Specific Methane Potential}

The cumulative specific methane productions comparing the SP system and the TP system acclimated sludge samples at different OW/PM ratios are illustrated in Fig. 2. Values denote

\begin{tabular}{|c|c|c|c|c|c|c|c|c|}
\hline & \multicolumn{8}{|c|}{ Physico-chemical parameters } \\
\hline & $\begin{array}{l}\mathrm{pH} \\
-\end{array}$ & $\begin{array}{l}\text { Alkalinity } \\
\mathrm{mM}\end{array}$ & $\begin{array}{l}\mathrm{N}-\mathrm{NH}_{4}{ }^{+} \\
\mathrm{gN} \mathrm{L}\end{array}$ & $\begin{array}{l}\mathrm{COD} \\
\mathrm{g} \mathrm{L}^{-1}\end{array}$ & $\begin{array}{l}\mathrm{TS} \\
\mathrm{g} \mathrm{L}^{-1}\end{array}$ & $\begin{array}{l}\mathrm{VS} \\
\mathrm{gL}^{-1}\end{array}$ & $\begin{array}{l}\text { VS/TS } \\
-\end{array}$ & $\begin{array}{l}\text { Fat content } \\
\%\end{array}$ \\
\hline \multicolumn{9}{|l|}{ Waste } \\
\hline ow & 5.1 & 55 & 0.1 & 1,010 & 448 & 350 & 0.78 & 51.5 \\
\hline PM & 7.7 & 282 & 4.9 & 49 & 45 & 31 & 0.69 & 8.2 \\
\hline Mixture 1:1 & 6.9 & 175 & 2.5 & 532 & 252 & 188 & 0.75 & 29.2 \\
\hline Mixture $1: 3$ & 7.2 & 235 & 3.8 & 258 & 150 & 108 & 0.72 & 20.3 \\
\hline
\end{tabular}

Table 1 Waste characterization 
Table 2 Waste elemental composition

${ }^{a} \%$ dry-matter weight basis

b $\% O$ estimated

${ }^{\circ}$ Calculatedassuming a $\mathrm{C}_{2} \mathrm{H}_{n} \mathrm{O}_{b} \mathrm{~N}_{6}$ composition ( $\mathrm{S}$ and $\mathrm{P}$ neglected)

\begin{tabular}{|c|c|c|c|c|c|c|c|c|}
\hline & \multicolumn{7}{|c|}{ Elemental composition ${ }^{2}$} & \multirow{2}{*}{$\begin{array}{l}\text { Theoretical methane potential } \\
B_{o, n h} \mathrm{mLCH}_{4} \cdot \mathrm{g} \mathrm{VS}^{-1}\end{array}$} \\
\hline & $\% \mathrm{C}$ & $\% \mathrm{H}$ & $\% \mathrm{~N}$ & $\% \mathrm{P}$ & $\% \mathrm{~S}$ & $\%$ Ash & $\% \mathrm{O}^{\mathrm{b}}$ & \\
\hline \multicolumn{9}{|l|}{ Waste } \\
\hline ow & 63.1 & 10.6 & 1.2 & 0.2 & 0.1 & 4.2 & 20.6 & 843 \\
\hline PM & 34.5 & 5.0 & 2.8 & 0.5 & 0.3 & 31.6 & 25.3 & 524 \\
\hline Mixture $1 / 1$ & 50.2 & 7.9 & 2.2 & 0.4 & 0.1 & 16.3 & 22.9 & 716 \\
\hline Mixture $1 / 3$ & 40.7 & 5.7 & 2.2 & 0.5 & 0.2 & 26.5 & 24.2 & 604 \\
\hline
\end{tabular}

arithmetic means plus standard errors (error bars) and are representative of three independent biodegradability assays conducted in triplicate. The maximum deviation reported was $\pm 25 \mathrm{~mL} \mathrm{CH}_{4} \mathrm{~g} \mathrm{SV}^{-1}$ for every assay set.

The methane production pattern observed was similar to the ones reported by Cime et al. [5] for batch degradation of an oil-rich waste. The initial lag phase in methane production observed for all tests could be attributed to the rapid build-up of FA, as proposed by Salminen et al. [27].

High VS removal efficiencies were realized in both systems at all OW/PM ratios (70, 75, and $81 \%$ in SP system and 68,73 , and $78 \%$ in TP system, at 1:0, $1: 1$ and $1: 3 \mathrm{OW} / \mathrm{PM}$ mixtures, respectively) but a stronger inhibition was observed for the tests where only OW was added as substrate. In this case, the lag phases extended to $400 \mathrm{~h}$, but the processes recovered. This phenomenon agrees with Palatsi et al. [23] that demonstrated that inhibition by LCFA accumulation was a reversible phenomenon more likely to be related to physical transport limitations, than to metabolic functions.

Furthermore, it should be noted that the total amount of biogas produced in both systems differed considerably. In accordance to Wust [31], the SP system produced more biogas, but the TP system produced a biogas with better quality,

Table 3 Fatty acids in ow

\begin{tabular}{lc} 
FA & Total FA (\%) \\
\hline Araquid acid & 0.35 \\
Behenic acid & 0.67 \\
Capric acid & 0.03 \\
Caprilic acid & 0.13 \\
Estearic acid & 6.18 \\
Heneicosanoic acid & 0.02 \\
Lauric acid & 0.05 \\
Lignoceric acid & 0.15 \\
Linoleic acid & 30.16 \\
Linolelaidic acid & 0.05 \\
Margaric acid & 0.10 \\
Miristic acid & 0.52 \\
Okic acid & 47.12 \\
Palmitic acid & 14.04 \\
Palmitoleic acid & 0.43 \\
\hline
\end{tabular}

containing an average of $67 \%$ methane compared to an average of $65 \%$ methane for the SP system.

As expected, mixtures with higher percentage of OW showed higher specific methane potentials. This trend is in accordance with the results of the $B_{0, \mathrm{Th}}$ calculated by the Buswell's equation (Table 2); however, experimental values are considerably lower than the theoretical (around 30\%) because Buswell's equation overestimates the BMP value, since it assumes that all the electrons donated are exclusively
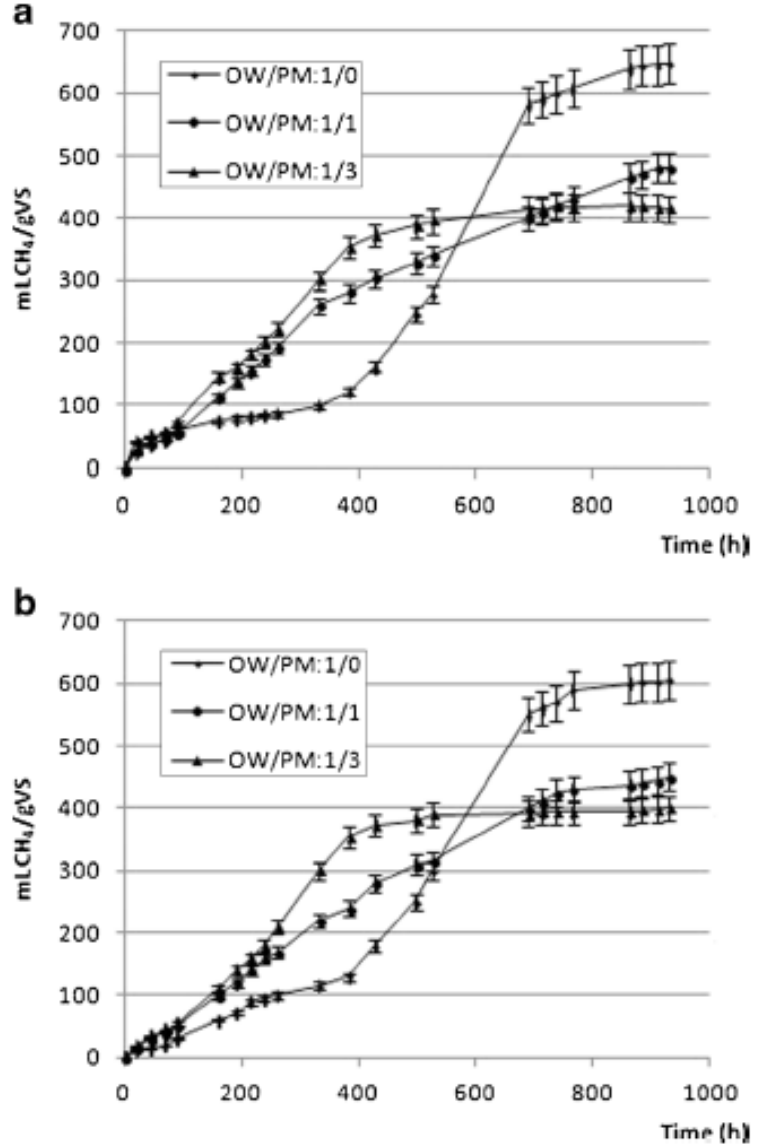

Fig. 2 Cumulative specific methane production curves at different OW/ PM ratios with acdimated sludge from a SP system; b TP system

\section{은 Springer}


used for metabolic energy. In other words, the Buswell's equation does not account for substrate biodegradability, neglecting cellular synthesis, when in reality, part of the biodegradable organic matter is used by the bacteria to grow and does not contribute to biogas generation [8]. In fact, Buswell reported that during the digestion of pure carbohydrates, an average of $12 \%$ of the total carbon fed was lost in the cell protoplasm, which was not accounted for by their formula.

Taking into account the maximum slopes of the curves shown in Fig. 2, OW/PM 1:3 is the substrate mixture with the highest degradation rate. The OW/PM 1:0 mixture had a slower degradation rate even though it showed a higher biogas yield.

Nevertheless, and according to Pastor et al. [25], BMP results cannot totally predict the results in a continuous operation mode of the anaerobic digester. The BMP tests are done with an $\mathrm{S} / \mathrm{X}$ ratio in the range of 0.40 to $0.60 \mathrm{~g} \mathrm{VS}_{\text {waste }} \mathrm{g}$ $\mathrm{VS}^{-1}$ inoculum. This ratio usually masks any real inhibition problem that might occur in the continuous operation mode. In order to assess the feasibility of oily waste in continuous operation experiments in semi-continuous mode have been also carried out.

\section{Single-Phase Digestion Performance}

The SP reactor was batch fed raw substrate (OW or OW/PM mixture) and was operated on a 1-day cycle for a total of 178 days at a HRT of 20 days. The feed volume was determined based on the desired HRT. Figure 3 represent the evolution of the different parameters over time, analyzed during the different periods. Vertical lines represent a new period.

As showed in Fig. 3a, anaerobic digestion was started up with OW as only substrate. The organic loading rate (OLR) was progressively enhanced from 0.25 to $1.5 \mathrm{~kg}$ VS $\mathrm{m}^{-3}$ day $^{-1}$ after the stable digestion was achieved at each OLR.

Figure $3 \mathrm{~b}$ represents the VS removal in the SP reactor over time. During the first period, the solids accumulate in the outlet. The batch experiments revealed that the OW starts being degraded in approximately 15-20 days. For that reason, the solids accumulation at the beginning of the experiment could indicate that the microorganisms have not totally acclimated to the new substrate.

It could be found that the percentage of VS removal was increased with the enhancement of OLR during the first 25 days, with a maximum of $35 \%$. Then, several operational problems appeared due to clogging and clumping. Afterwards, values of VS removal showed a downward trend.

As described in Fig. 3c, when anaerobic digestion was started, it could be found that the biogas production was in low levels. Afterwards, the OLR was subsequently enhanced and it could be obviously found that the daily biogas production was increased with the enhancement of OLR. The maximum biogas production in this period was $1.06 \mathrm{~m}^{3} \mathrm{~kg}^{-1} \mathrm{VS}$ removed, corresponding to a methane production of $0.69 \mathrm{~m}^{3}$ $\mathrm{CH}_{4} \mathrm{~kg}^{-1}$ VS removed (65\% $\left.\mathrm{CH}_{4}\right)$ (Fig. 3c).

During the second period, when the reactor was fed with a mixture of OW/PM 1:1 v/v, the system recovered from the operational problems. This could be due to the fact that, while HRT was maintained at a constant level, a lower amount of VS entered the digester due to the lower percentage of oil added to the mixture. Afterwards, VS removal gradually increased with a maximum at the end of the period of $65 \%$. VS concentrations start diminishing in a constant manner on day 80 , maintaining the OLR at $1.5-1.7 \mathrm{~kg} \mathrm{VS} \mathrm{m}^{-3} \mathrm{day}^{-1}$.

During the third operational period, when feeding the reactor with a mixture OW/PM 1:3 v/v, the good performance of the process was indicated by the higher effluent VS removal ( $71 \%$ average) even when the OLR increased up to $2.5 \mathrm{~kg}$ VS $\mathrm{m}^{-3} \mathrm{day}^{-1}$, which is indicative of a greater degree of biodegradation.

During the second and third operational periods the biogas production decreased with respect to the first period but it was always according to the substrates mixture composition entering the system, since mixtures with higher percentage of $O W$ showed higher methane potentials. The average biogas production in the second and third periods was 0.46 and $0.33 \mathrm{~m}^{3}$ $\mathrm{kg}^{-1} \mathrm{VS}$ removed, corresponding to a methane production of $0.30\left(65.5 \% \mathrm{CH}_{4}\right)$ and $0.22\left(66 \% \mathrm{CH}_{4}\right) \mathrm{m}^{3} \mathrm{CH}_{4} \mathrm{~kg}^{-1} \mathrm{VS}$ removed, respectively. Near the end of the study, the biogas production of the SP system began to decline.

Torrijos et al. [30] studied the anaerobic digestion of byproducts generated during the production and refining of oil in SP reactors. Their results also showed that most of the byproducts generated during the production and refining of oil had quite a high methane potential ( 465 to $850 \mathrm{ml} \mathrm{CH}_{4} / \mathrm{g} \mathrm{VS}$ ), however, they contained a mixture of rapidly and slowly biodegradable organic matter and the loading rates had to remain quite low ( 0.03 to $0.09 \mathrm{~g}$ VS suspended) to prevent any accumulation of slowly biodegradable solids in the digesters.

In the case of Ferreira et al. [11], these authors co-digested wasted sardine oil (WSO) and PM at farm scale in a SP reactor. The incremental addition of WSO to a composition $(\% v / v)$ of $95: 5$ enhanced the methane productivity four times at OLR $5.2 \mathrm{~kg} \mathrm{COD} \mathrm{m}^{-3} \mathrm{day}^{-1}$, reaching $90 \%$ COD removal and a methane production of $7.35 \mathrm{~kg} \mathrm{COD}-\mathrm{CH}_{4} /$ day.

\section{Two-Phase Digestion Performance}

The objective of the acidogenic reactor was to acidify the raw substrate in an effort to improve the performance of the methanogenic reactor by increasing the VS removal efficiencies and methane yield. In addition, it was hypothesized that 
Fig. 3 Time course results of SP system during operation: a OLR;

b VS removal; $\mathrm{e} \mathrm{CH}_{4}$ production

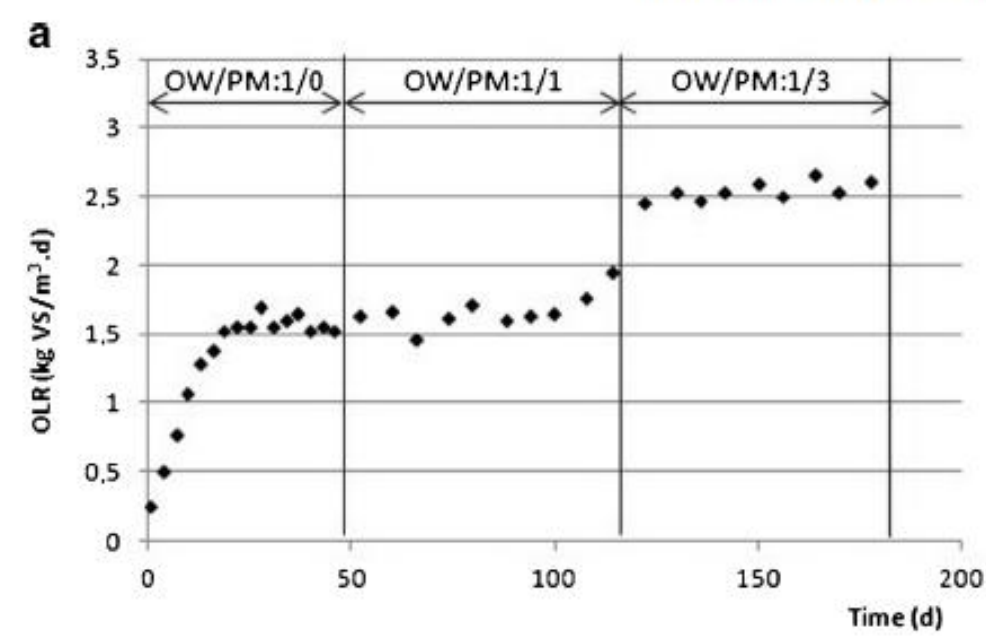

b
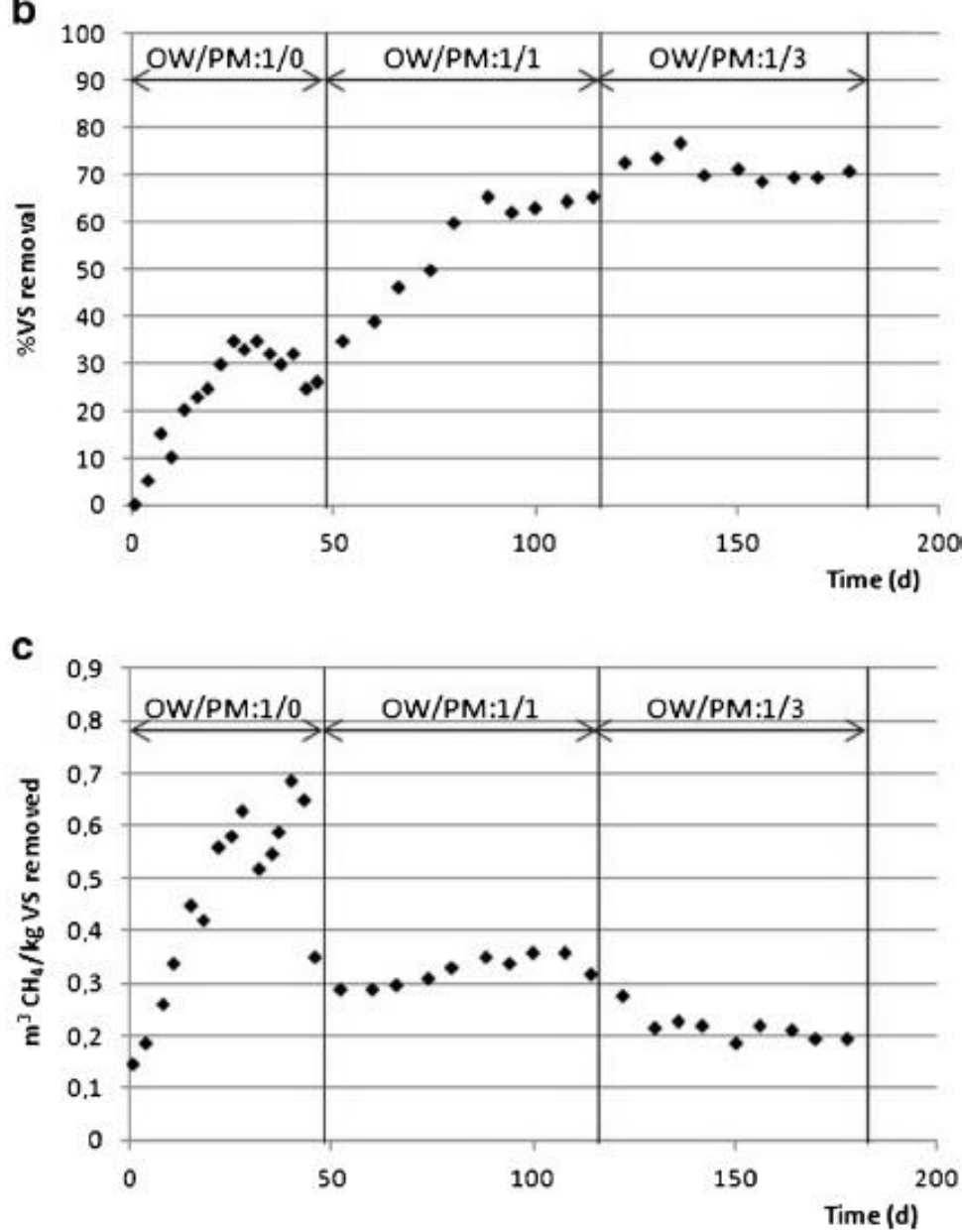

the acidogenic reactor may also reduce the effect of shock loadings to the methanogenic reactor, increasing the stability of the TP system [24].

The acidogenic reactor was batch fed raw substrate (OW or OW/PM mixture) and was operated at a HRT of 2-3 days. The feed volume was determined based on the desired HRT. This

\section{은 Springer}


reactor produced an average of $0.5 \mathrm{~L}$ of biogas per day, of which the methane content was insignificant (less than $3 \%$ ) but additional $\mathrm{H}_{2}$ production was detected (although not quantified). This is an important aspect because according to Nasr et al. [21], the TP digestion would achieve 1.7-19.8\% more bioenergy recovery than the SP digestion when the $\mathrm{H}_{2}$ production is considered.

The methanogenic reactor was batch fed acidified substrate from the acidogenic reactor and was operated at a HRT of $17-$ 18 days.

The results of the two-phase system were determined by considering the acidogenic and methanogenic reactors as two reactors operated in series on a 1-day cycle for a total of 178 days as opposed to two separate reactors.

The process was also started up with OW as the only substrate in the case of the TP system. The OLR was progressively enhanced from 0.25 to $1.6 \mathrm{~kg} \mathrm{VS} \mathrm{m}^{-3}$ day $^{-1}$ during this first operational period (Fig. 4a). It could be found that the percentage of VSremoval was increased with the enhancement of OLR during the whole experimentation, with a maximum of $42 \%$. No operational problems were detected in this case, showing the TP system a stable performance. The data in Fig. 4b demonstrate that the removal of volatile solids from the TP reactor was also very effective (around 65-75\%) while the system was fed with OW/PM mixture (second and third operational periods) even when OLR reached $3 \mathrm{~kg} \mathrm{VS} \mathrm{m}^{-3}$ day $^{-1}$.

The biogas production was maximum at the end of the first period (Fig, 4c), reaching $0.98 \mathrm{~m}^{3} \mathrm{~kg}^{-1} \mathrm{VS}$ removed, corresponding to a methane production of $0.65 \mathrm{~m}^{3} \mathrm{CH}_{4} \mathrm{~kg}^{-1} \mathrm{VS}$ removed $\left(66 \% \mathrm{CH}_{4}\right)$. During the second and third periods, the biogas production decreased which can be attributed to a decrease in the VS in the inlet. The average biogas production during the second and third periods was 0.45 and $0.40 \mathrm{~m}^{3} \mathrm{~kg}^{-1}$ VS removed, corresponding to a methane production of 0.30 $\left(67.5 \% \mathrm{CH}_{4}\right)$ and $0.27\left(67 \% \mathrm{CH}_{4}\right) \mathrm{m}^{3} \mathrm{CH}_{4} \mathrm{~kg}^{-1} \mathrm{VS}$ removed, respectively.

No operational problems were observed in the TP system during the trial at the different quantities of co-substrates tested.

Comparison on the Performances of Continuous Single-Phase and Two-Phase Digestion

The performances of SP and TP digestions were compared in terms of stability (i.e., degree of variation in biogas production and organic matter removal when maintaining constant the main operational parameters), methane production, and treatment capacity. Although the overall average HRT, OLR, and $\mathrm{pH}$ for both systems were approximately the same throughout the duration of the study, it appears that the TP system provided a higher quality effluent in terms of VS removal, more short- and long-term stability and higher methane yield, than the SP system.
Both the SP and TP systems achieved more than acceptable VS removal efficiencies throughout the study, taking into consideration the high lipids concentration in the inlet substrate.

From the experiments, it was observed that digestion of OW alone ( $51.5 \%$ fat) was inhibitory for the anaerobic degradation. This result agrees with previous studies. Cime et al. [5] determined that the maximum fat percentage in the feed mixture that can be used without causing inhibition was $18 \%$ of the total COD. In another study [10], the maximum percentage of fat was $28 \%$ of volatile solids. The highest percentage of fat found to inhibit the anaerobic digestion process was $35 \%$ over the volatile solids [13].

When fat overloading, the SP system showed the least stability. The high concentration of lipids during this experimental period led to clogging problems within the SP system while the TP reactor reached steady state with relatively stable operation.

According to Wust [31], the acidogenic reactor reduces the fats, oil, and grease loading to the methanogenic reactor by greater than $50 \%$, potentially making the methanogenic reactor and, thus, the TP system more stable to fluctuating wastewater FOG concentrations as the acidogenic reactor acted as a FOG trap.

According to Solera et al. [29], the TP system increases the stability of the process by controlling the acidification phase to prevent overloading and the build-up of toxic material.

During the second and third operational periods, mixing OW with PM neutralized the negative effects of lipids accumulation and high VS removal efficiencies were realized in both systems (63 and $71 \%$ in SP system and 69 and $72 \%$ in TP system (averages), at 1:1 and 1:3 OW/PM mixtures, respectively), although the removal efficiencies of the TP system were more consistent throughout the study despite changes in raw influent composition. Additionally, TP digestion was capable of operating at OLR of $3.1 \mathrm{~kg} \mathrm{VS} \mathrm{m}^{-3} \mathrm{day}^{-1}$ stably, higher than the OLR of $2.6 \mathrm{~kg} \mathrm{VS} \mathrm{m}^{3}$ day $^{-1}$ with SP digestion. Higher OLR implies higher treatment capacity for the same digester volume, which could bring better economic benefit.

By comparing the methane production in the two systems, it could be concluded that the SP system generally produced more biogas, but the TP system always produced biogas with higher methane content so, in terms of methane production (= biogas volume $* \% \mathrm{CH}_{4}$ in the biogas), the TP system is also advantageous, because the final net methane production is higher.

According to Shen et al. [28], the statistical coefficients of variation $\left(C_{\text {var }}\right)$ for biogas production and solids removal can directly reflect the buffering capability of digestion system to new-fed substrates and the stability of digestion performance. The statistical calculation results indicated that the $C_{\mathrm{var}}$ for solids removal and methane production in the stable periods of the SP system were, respectively, 27.6 and $17.9 \%$ (second operational period, $\mathrm{OW} / \mathrm{PM}=1: 1$ ) and 4.4 and $8.6 \%$ (third 
Fig. 4 Time course results of TP system during operation: a OLR; b VS removal; c $\mathrm{CH}_{4}$ production

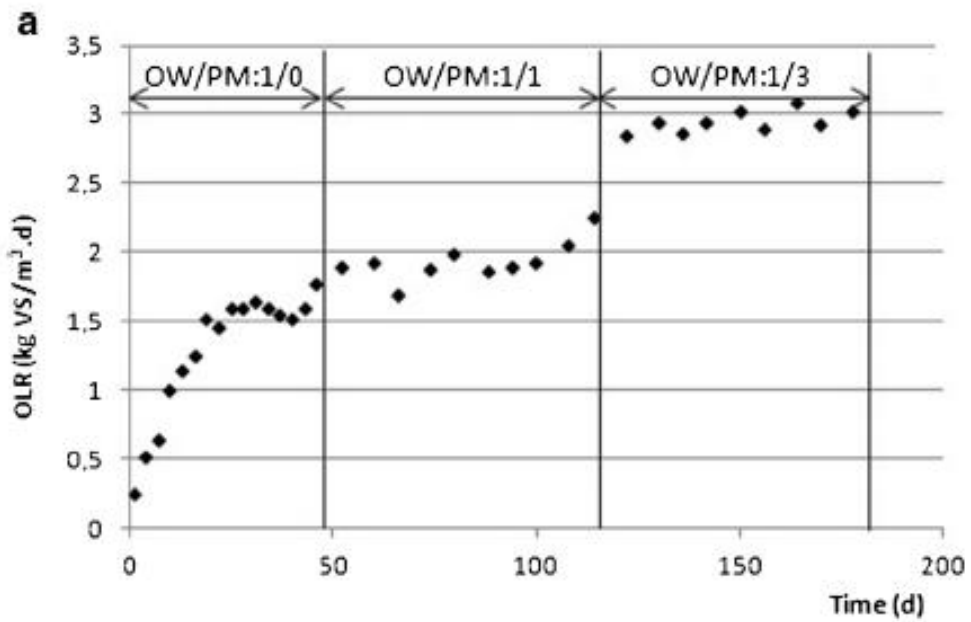

b
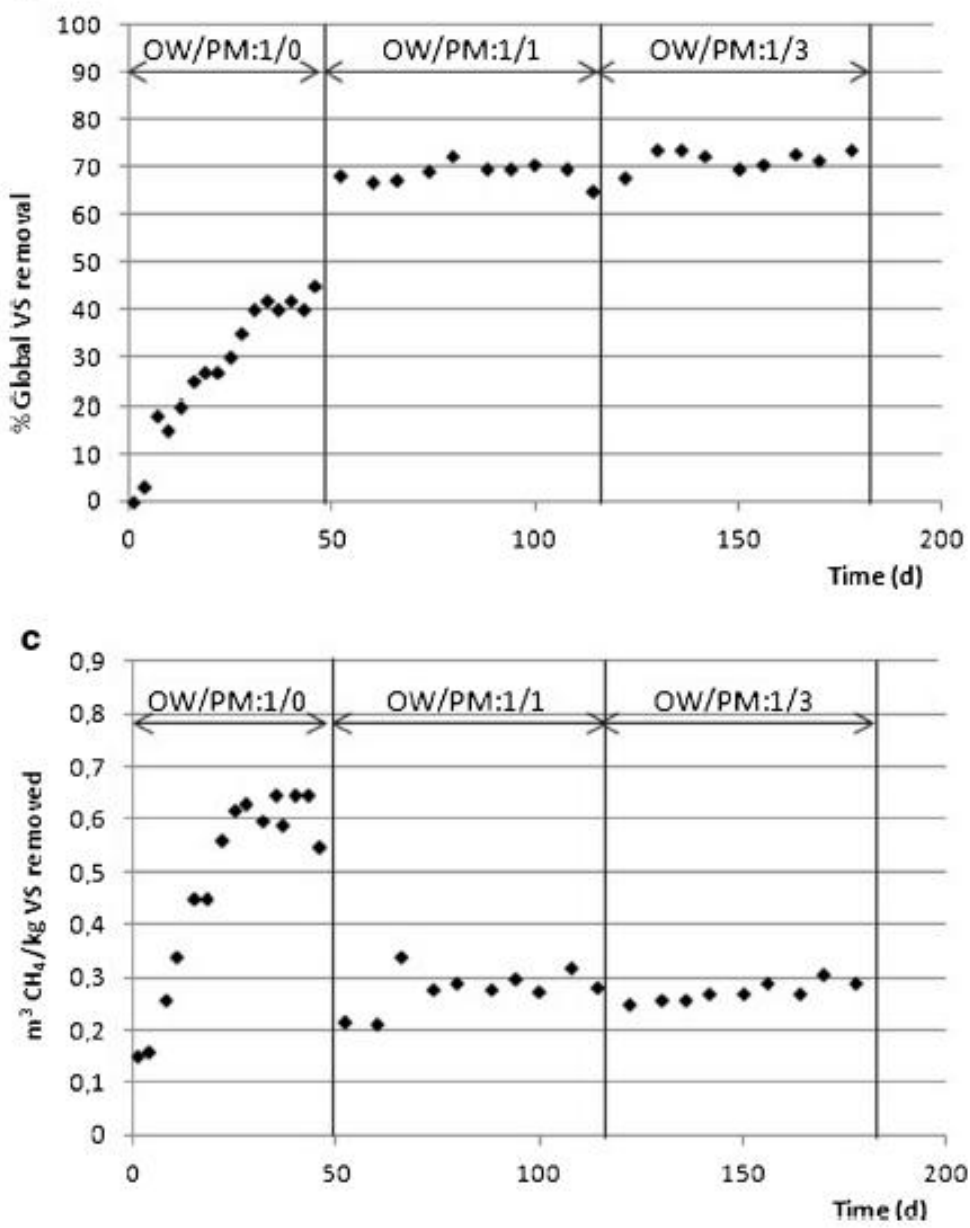

operational period, $O W / P M=1: 3)$. These figures were lower in the case of the TP system: 2.3 and $15.8 \%$ (second operational period) and 1.5 and $6.3 \%$ (third operational period).

Thus, it could be deduced again that the anaerobic digestion tended to be unstable with the increase of fats in the influent, especially in the case of the SP reactor.

\section{Q Springer}


Therefore, based on the results of this study, the TP system achieved better results than the SP system and thus a TP system is recommended.

The main advantage of TP systems is not a reported higher reaction rate, but rather, a greater biological reliability for wastes which cause unstable performance in SP systems, as it is the case of oil-rich streams.

It should be noted, however, that in the context of industrial applications, even for the challenging treatment of highly degradable biowastes, preference is still given to technically simpler SP plants due to the lower investment needed and the less operational complexity. Industrial applications have, up to now, displayed little acceptance for TS systems as these represent only circa $10 \%$ of the current treatment capacity.

\section{Conclusions}

This study shows that the waste generated by used vegetable oil processing companies can be treated successfully without dilution and without adding chemical substances if they are co-digested with substrates containing high levels of ammonium nitrogen and alkalinity to compensate for their lack in these wastes. Furthermore, this research has demonstrated that TP anaerobic digestion has given good performances conceming VS removal efficiencies and process stability compared to those given by conventional SP anaerobic digestion reactors when treating oily waste. Furthermore, comparison of these two systems with methane production revealed that TP system, overall, presented higher bioenergy yield than SP.

Adknowledgments The authors gratefully acknowledge support of this work by the LIFE + Program under the responsibility of the Directorate General for the Environment of the European Commission through the agreement LIFE 09 ENV/E/000451-VALUVOIL project.

\section{References}

1. Ahrin BK (2003) Perspectives for anaerobic digestion. In: Ahring BK (ed) Biomethanation I, vol 81, Advances in biochemical engineering/biotechnology. Sringer, Berlin, pp 1-30

2. American Public Health Association (APHA) (2005) Standard methods for the examination of water and wastewater, 21 st edn. APHA, Washington DC, USA

3. Angelidaki I, Ahring BK, Deng H, Schmidt JE (2002) Anaerobic digestion of olive mill effluents together with swine manure in USAB reactors. Water Sci Technol 45(10)213-218

4. Appels L, Lauwers J, Degrève J, Helsen L, Lievens B, Willems K, Van Impe J, Dewil R (2011) Anaerobic digestion in global bio-energy production: potential and research challenges. Renew Sust Energy Rev 15(9):4295-4301

5. Cime D, Paloumet X, Björnsson L, Alves M, Mattiassona B (2007) Anaerobic digestion of lipid-rich waste-effects of lipid concentration. Renew Energy 32:965-975
6. Chen Y, Cheng JJ, Creamer KS (2008) Inhibition of anaerobic digestion process: a review. Bioresour Technol 99:4044-4064

7. Chhetri AB, Tango MS, Budge SM, Islam MR (2008) Non-edible plant oils as new sources for biodiesel production. Internat J Mol Sci 9:169-180

8. de Lemos CA (2007) Anaerobic reactors: biological wastewater treatment Vol 4. IWA Publishing, London

9. EU (2006) Biofuels in the European Union-a vision for 2030 and beyond. Report of the Biofuel Research Advisory Council.

10. Femández A, Sánchez A, Font X (2005) Anaerobic co-digestion of a simulated organic fraction of municipal solid wastes and fats of animal and vegetable origin. Biochem Eng J 26:22-28

11. Ferreira L, Duarte E, Figueiredo D (2012) Utilization of wasted sardine oil as co-substrate with pig slurry for biogas production-a pilot experience of decentralized industrial organic waste management in a Portuguese pig farm. Bioresour Technol 116:285-289

12. Fetzer S, Bak F, Conrad R (1993) Sensitivity of methanogenic bacteria from paddy soil to oxygen and desiccation. FEMS Microbiol Ecol 12(2):107-115

13. Gelegenis J, Georgakakis D, Angelidaki I, Christopoulou N, Goumenaki M (2007) Optimization of biogas production from olive-oil mill wastewater by codigesting with diluted poultrymanure. Appl Energy 84(6):646-663

14. Göblōs S, Portōrō P, Bordás D, Kálmán M, Kiss I (2008) Comparison of the effectivities of two-phase and single-phase anaerobic sequencing batch reactors during dairy wastewater treatment. Renew Energy 33(5): $960-965$

15. Hidalgo D, Sastre E, Gómez M, Nieto P (2013) Evaluation of pretreatment processes for increasing biodegradability of agro-food wastes. Environ Technol 33(13):1497-1503

16. Hong V (2011) Anaerobic digestion of oil-rich solid waste. J Biotechnol 9(1):45-53

17. Ince O (1998) Performance of a two-phase anaerobic digestion system when treating dairy wastewater. Water Res 32(9):2707-2713

18. Kulkami MG, Dalai AK (2006) Waste cooking oil-an economical source for biodiesel: a review. Ind Eng Chem Res 45:2901-2913

19. Lesteur M, Bellon-Maurel V, Gonzalez C, Latrille E, Roger JM, Junqua G, Steyer JP (2010) Alternative methods for determining anaerobic biodegradability: a review. Process Biochem 45:431-440

20. Mobarak-Qamsari E, Kasra-Kemanshahi R, Nosrati M, Amani T (2012)Enzymatic pre-hydrolysis of high fat content dairy wastewater as a pretreatment for anaerobic digestion. Int JEnviron Res 6(2):475480

21. Nasr N, Elbeshbishy E, Hafez H, Nakhla G, Hesham E Naggar M (2012) Comparative assessment of single-stage and two-stage anaerobic digestion for the treatment of thin stillage. Bioresour Technol 111:122-126

22. Neves L, Pereira M, Mota M, Alves M (2009) Detection and quantification of long chain fatty acids in liquid and solid samples and its relevance to understand anaerobic digestion of lipids. Bioresour Technol 100(1):91-96

23. Pahtsi J, Laureni M, Andrés MV, Flotats X, Nielsen HB, Angelidaki I (2009) Strat egies for recovering inhibition caused by long chain fatty acids on anaerobic thermophilic biogas reactors. Bioresour Technol 100:4588-4596

24. Park Y, Hong F, Cheon J, Hidaka T, Tsuno H (2008) Comparison of thermophilic anaerobic digestion characteristics between singlephase and two-phase systems for kitchen garbage treatment. J Biosci Cioeng 105(1):48-54

25. Pastor L, Ruiz L, Pascual A, Ruiz B (2013) Co-digestion of used oils and urban landfill leachates with sewage sludge and the effect on the biogas production. Appl Energy 107:438-445

26. Pereira MA, Pires OC, Mota M, Alves MM (2005) Anaerobic biodegradation of oleic and palmitic acids: evidence of mass trans fer limitations caused by long chain fatty acid accumulation onto the anaerobic sludge. Biotech Bioeng 92(1):15-23 
27. Salminen E, Rintala J, Lokshina L, Vavilin VA (2000) Anaerobic batch degradation of solid poultry slaughterhouse waste. Water Sci Technol 41:33-41

28. Shen F, Yuan H, Pang Y, Chen S, Zhu B, Zou D, Liu Y, Mac J, Yu L, Li X (2013) Performances of anaerobic co-digestion of fruit and vegetable waste (FVW) and food waste (FW): single-phase vs. twophase. Bioresour Technol 144:80-85

29. Solera R, Romero LI, Sales D (2002) The evolution of biomass in a two-phase anaerobic treatment process during start-up. Chem Biochem Eng Q 16(1):25-29

30. Torrijos M, Thalla A, Sousbie P, Bosque F, Delgenes JP (2008) Anaerobic digestion of residues from production and refining of vegetable oils as an altemative to conventional solutions. Wat Sci Technol 58(9):1871-1878

31. Wust E (2003) Single-phase and two-phase cheese wastewater treatment by anaerobic SBRs. Ph.D. thesis, Civil, Construction and Environmental Engineering Department, Marquette University, Milwaukee, Wisconsin.

32. Yu HW, Samani Z, Hanson A, Smith G (2002) Energy recovery from grass using two-phase anaerobic digestion. Waste Manag 22:1-5

33. Zhang L, Lee YW, Jahng D (2011) Anaerobic co-digestion of food waste and piggery wastewater. focusing on the role of trace elements. Bioresour Technol 102(8):5048-5059 


\subsection{Diseño, construcción y operación en continuo de una planta piloto de digestión anaerobia en dos fases.}

\subsubsection{Diseño y construcción}

Como punto de partida para el diseño de la planta piloto de digestión anaerobia en dos fases se han utilizado los resultados experimentales obtenidos durante la realización de este trabajo de tesis en los ensayos previos a escala laboratorio.

En esta parte del trabajo se ha realizado el diseño y construcción de una planta a escala piloto donde poder estudiar el proceso de DA en dos fases con el fin de cumplir los siguientes objetivos:

- Validar el estudio a escala de demostración.

- Operar en continuo de forma automática.

- Mejorar el control del proceso, incluyendo monitorizando en continuo del $\mathrm{pH}$, temperatura, presión, velocidad de agitación y volumen de gas obtenido en cada uno de los reactores, así como la posibilidad de seguimiento del proceso de DA de forma remota.

- Conseguir una planta piloto transportable y fácilmente operativa con solo conectar las corrientes residuales a digerir.

- Obtener resultados que permitan el cambio de escala a una planta industrial.

Con la planta piloto se pretende codigerir residuos de naturaleza y tamaño diferente, por lo que, previamente a los reactores donde se produce la digestión anaerobia, se ha incorporado una etapa de pretratamiento de estos residuos mediante trituración de los mismos y un tanque de homogenización.

La DA en dos fases implica una configuración del proceso donde se emplean dos reactores conectados en serie, y como la velocidad de reacción de la etapa acidogénica es unas 5 veces superior a la etapa metanogénica, para una operación en continuo, el reactor metanogénico se ha diseñado con un volumen 5 veces superior al reactor acidogénico.

Con el fin de conocer la evolución de las variables que influyen en el correcto desarrollo de los diferentes microorganismos que influyen en el proceso de DA, cada uno de estos reactores incluye los siguientes equipos auxiliares:

- Un sensor de presión.

- Una camisa calefactora eléctrica con control de temperatura, lo que permite poder trabajar tanto en el rango mesófilo, como en el rango termófilo.

- Un sensor de pH.

- Un agitador de velocidad variable.

- Un contador de pulsos del volumen de biogás producido.

Cada una de las etapas se ha conectado a la siguiente mediante conducciones de acero inoxidable impulsadas por bombas peristálticas, que permiten un control del caudal, tanto de los residuos a tratar, como de los productos obtenidos en las diferentes etapas del proceso. Para el diseño propuesto, y para un THR medio de 20 días, el caudal medio que deben proporcionar la bombas es de 20 L/día. 
La planta se ha diseñado con un sistema de control y recogida de datos de los diferentes parámetros sensorizados de forma que es posible conocer en todo momento el estado del proceso.

La planta piloto se ha montado en una plataforma autoportante (dimensiones externas: Longitud $=4 \mathrm{~m}$, Profundidad $=2 \mathrm{~m}$, Altura $=2,6 \mathrm{~m}$ ) con 4 patas regulables para nivelación. Se ha realizado este diseño debido a que, en ocasiones, no es fácil llevar hasta la planta los residuos a tratar en condiciones óptimas para su procesado, y de esta forma se facilita el traslado de la planta al lugar donde se encuentran los residuos. Como la planta piloto se va a ubicar habitualmente en una nave cerrada y existe riesgo de escape de gases inflamables, y por tanto riesgo de explosión, por cuestiones de seguridad la planta se ha cerrado con paneles de metacrilato de $4 \mathrm{~mm}$ de espesor y se ha realizado una toma trasera donde se incorpora un sistema de extracción forzada del aire interior, conectado a una conducción de ventilación exterior. El extractor seleccionado es capaz de evacuar $500 \mathrm{~m}^{3} \cdot \mathrm{h}^{-1}$, lo cual equivale aproximadamente a 24 renovaciones de aire por hora de la cabina. Para acceder al interior de la planta de forma cómoda se ha incluido una puerta de doble hoja.

La construcción de la planta piloto ha sido realizada considerando la legislación vigente, para lo cual cumple con los requerimientos de las siguientes directivas:

- Directiva 2006/95/ce del Parlamento Europeo y del Consejo de 12 de diciembre de 2006 relativa a la aproximación de las legislaciones de los Estados miembros sobre el material eléctrico destinado a utilizarse con determinados límites de tensión.

- Directiva 2006/42/CE del Parlamento Europeo y del Consejo del 17 de mayo de 2006, relativa a las máquinas.

- La Directiva 2004/108/CE del Parlamento Europeo y del. Consejo, de 15 de diciembre de 2004, relativa a la aproximación de las legislaciones de los Estados miembros en materia de compatibilidad electromagnética.

En la Figura 3-26 aparece un esquema de la planta y en la Figura 3-27 una fotografía de la planta en las instalaciones de Fundación CARTIF. 


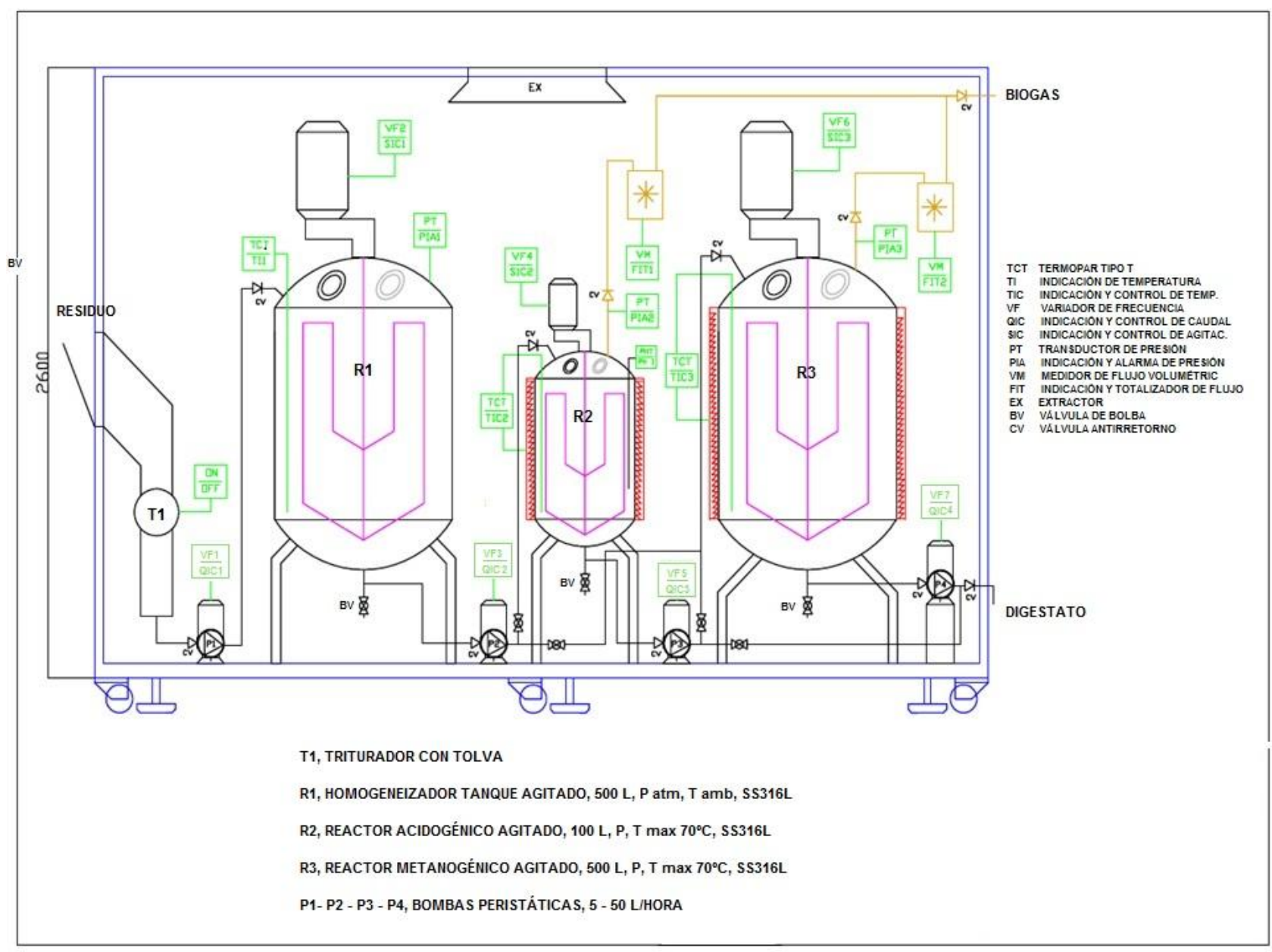

Figura 3-26. Esquema planta piloto de DA en dos fases

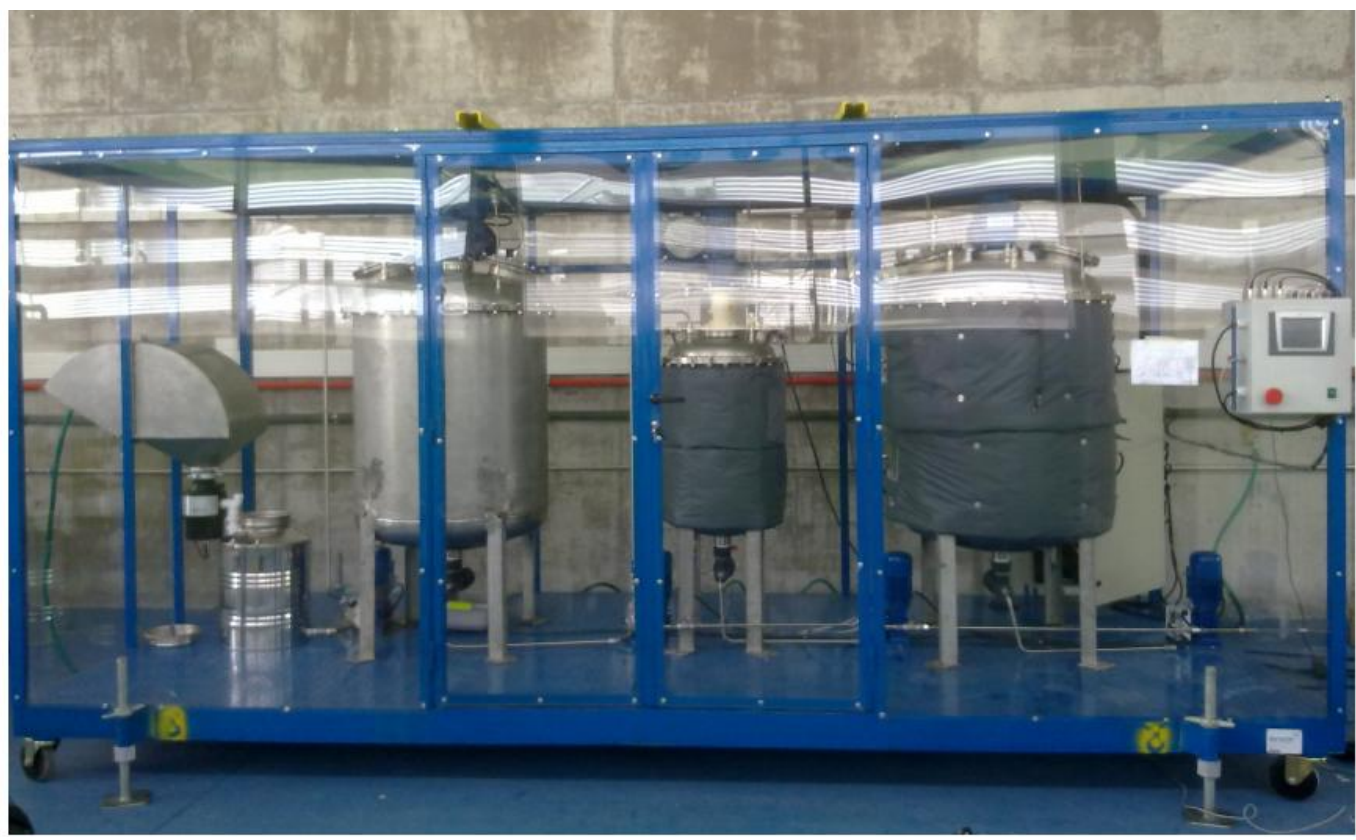

Figura 3-27. Planta piloto de DA en dos fases 
A continuación se describen los diferentes equipos que conforman la planta piloto de digestión anaerobia, así como las principales características técnicas de los subsistemas e instrumentación de que se componen:

\section{Sistema triturador con tolva (Figura 3-28)}

Consiste en una tolva de entrada de $50 \mathrm{~L}$ de capacidad, construida en acero inoxidable de $3 \mathrm{~mm}$ de espesor, con una puerta, una trampilla para vertido de producto sólido o líquido, y conectado a triturador eléctrico de residuos orgánicos con arranque y parada controlado desde el sistema de control. La descarga del triturador se realiza a un depósito de residuos de $50 \mathrm{~L}$ conectado a una bomba peristáltica Boyser, de caudal variable controlado desde el sistema de control de 0 a $20 \mathrm{~L} / \mathrm{h}$. Esta bomba dispone de un tubo de $8 \mathrm{~mm}$ de diámetro interno.

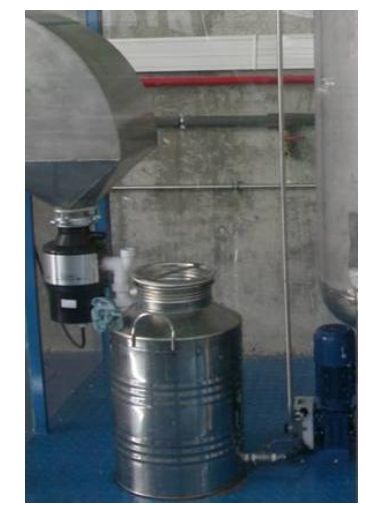

Figura 3-28. Sistema triturador con tolva

\section{Tanque homogeneizador de 500 L (Figura 3-29)}

Es un tanque de acero inoxidable con doble mirilla de $200 \mathrm{~mm}$ de diámetro que permite su visualización interior y su limpieza. Contiene un agitador en "L" con motor reductor, y control de revoluciones de 0 a $90 \mathrm{rpm}$. El elemento de agitación es de tipo áncora de $700 \mathrm{~mm}$. La sonda de temperatura es de tipo "T" envainada, de $1 \mathrm{~m}$ de longitud, monitorizada desde el control, con $\pm 0,5^{\circ} \mathrm{C}$ de precisión de medida. La válvula de sobrepresión se encuentra tarada a 350 mbar. Hay dos conexiones de 1/2" accesorias que permiten introducir instrumentación. Dispone de un orificio de descarga de $50 \mathrm{~mm}$ de diámetro con conexión en "T" para descarga inferior del producto a través de una válvula de bola de $50 \mathrm{~mm}$ de diámetro. La conexión a la bomba peristáltica es similar a la anterior.

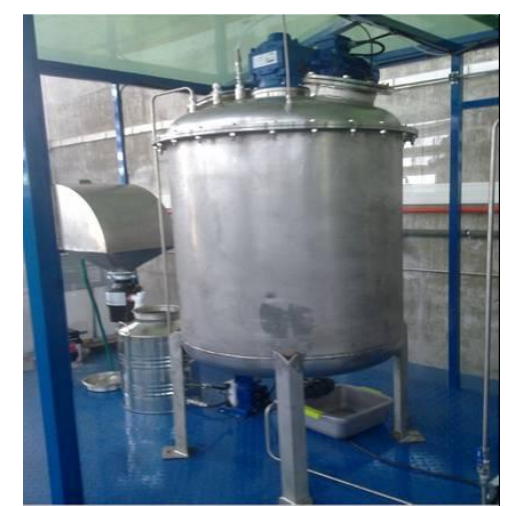

Figura 3-29. Tanque de homogeneización 


\section{Digestor acidogénico de 100 L (Figura 3-30)}

Es un depósito de acero inoxidable con doble mirilla de $90 \mathrm{~mm}$ de diámetro que permite visualizar su interior y el acceso para su limpieza. Dispone de un agitador vertical con reductora, y control de revoluciones de 0 a $90 \mathrm{rpm}$. El elemento de agitación es tipo áncora de $400 \mathrm{~mm}$ de diámetro. También tiene una sonda de temperatura tipo "T" envainada, de $800 \mathrm{~mm}$ de longitud, monitorizada desde el control, con $\pm 0,5^{\circ} \mathrm{C}$ de precisión de medida. El transductor de presión mide en el rango de 0 - 1 bar, el voltaje de trabajo es de $24 \mathrm{~V}$, la intensidad de medida se encuentra en el rango de 4 - $24 \mathrm{~mA}$, y está conectado al sistema de control mediante un lazo de aviso de alarma de sobrepresión. El sensor de indicación de $\mathrm{pH}$ mediante transductor de inserción se encuentra conectado al control permitiendo su monitorización. El sistema de calefacción es por lazo cerrado de control y agua circulante por una camisa externa calentada con resistencias eléctricas de $2.000+2.000$ Watts. La temperatura de operación se encuentra controlada desde panel de control entre la zona meso y termofílica, alcanzando $70 \stackrel{\circ}{\mathrm{C}}$ como temperatura máxima. La línea de biogás conecta la parte superior del digestor, mediante tubo de $12 \mathrm{~mm}$ de diámetro, a un contador volumétrico basado en el desplazamiento de una columna de agua, para la medida de biogás en el rango de $0-60 \mathrm{~L} \cdot \mathrm{h}^{-1}$ con una resolución de $100 \mathrm{~mL}$ por pulso, el cual está monitorizado desde sistema de control. Además, el digestor dispone de dos conexiones de $1 / 2$ " accesorias para instrumentación, y una válvula de descarga de 50 $\mathrm{mm}$ de diámetro con conexión en "T" para descarga inferior del producto contenido a través de una válvula de bola de $50 \mathrm{~mm}$ de diámetro. La conexión a la bomba peristáltica es similar a la anterior.

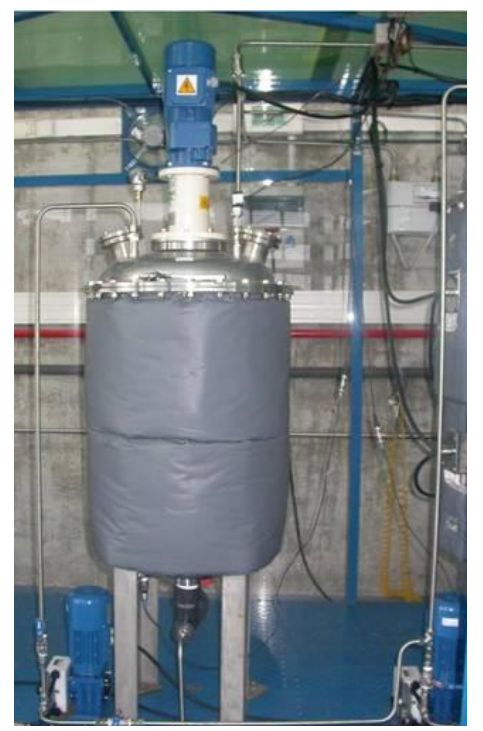

Figura 3-30. Reactor acidogénico

\section{Digestor metanogénico de 500 L (Figura 3-31)}

Es un depósito de acero inoxidable con doble mirilla de $200 \mathrm{~mm}$ de diámetro que permite visualizar su interior y el acceso para su limpieza. Dispone de un agitador vertical con reductora, y control de revoluciones de 0 a $90 \mathrm{rpm}$. El elemento de agitación es tipo áncora de $700 \mathrm{~mm}$ de diámetro. También tiene una sonda de temperatura tipo "T" envainada, de $1 \mathrm{~m}$ de longitud, monitorizada desde el control, con $\pm 0,5{ }^{\circ} \mathrm{C}$ de precisión de medida. El transductor de presión mide en el rango de 0 - 1000 mbar, el voltaje de trabajo es de $24 \mathrm{~V}$, la intensidad de medida se encuentra en el rango de 4 - $24 \mathrm{~mA}$, y está conectado al sistema control mediante un lazo de aviso de alarma de sobrepresión. El sensor de indicación de pH mediante transductor 
de inserción se encuentra conectado al control permitiendo su monitorización. El sistema de calefacción es por lazo cerrado de control y agua circulante por una camisa externa calentada con resistencias eléctricas de $4.500+4.500$ Watts. La temperatura de operación se encuentra controlada desde panel de control entre la zona meso y termofílica, alcanzando $70 \stackrel{\circ}{\mathrm{C}}$ como temperatura máxima. La línea de biogás conecta la parte superior del digestor, mediante tubo de $12 \mathrm{~mm}$ de diámetro, a un contador volumétrico basado en el desplazamiento de una columna de agua, para la medida de biogás en el rango de $0-60 \mathrm{~L} \cdot \mathrm{h}^{-1}$ con una resolución de $100 \mathrm{~mL}$ por pulso, el cual está monitorizado desde sistema de control. Además, el digestor dispone de dos conexiones de $1 / 2$ " accesorias para instrumentación, y una válvula de descarga de $50 \mathrm{~mm}$ de diámetro con conexión en "T" para descarga inferior del producto contenido a través de una válvula de bola de $50 \mathrm{~mm}$ de diámetro. La conexión a la bomba peristáltica es similar a las anteriores.

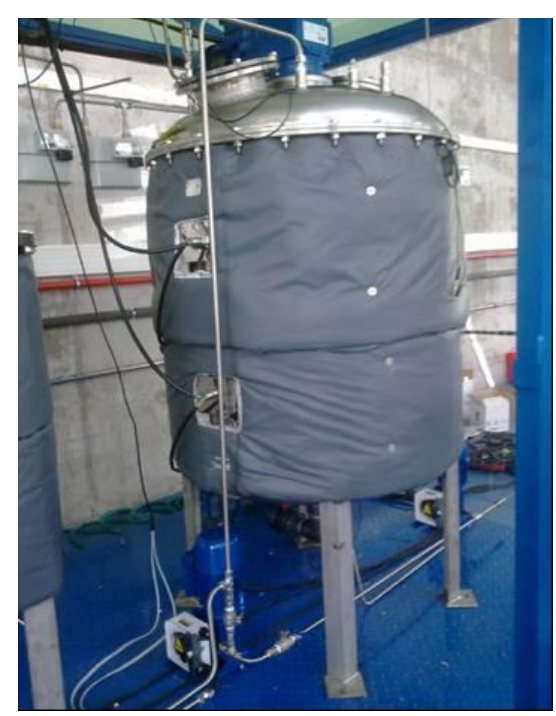

Figura 3-31. Reactor metanogénico

Sistema de control (Figura 3-32)

Consiste en un autómata programable tipo PLC de la marca Unitronics, modelo V570, instalado en un cuadro electrónico anexo a la estructura de planta. La fuente de alimentación es de $24 \mathrm{~V}$ y $50 \mathrm{~W}$ para lazos de sensores y lazos de control. El sistema SCADA se encuentra conectado a un PC que permite el almacenamiento de los datos y puede ser operado por control remoto vía Ethernet.

En el display se encuentra representado de forma esquemática el proceso, mostrando los elementos más representativos de la planta, los valores de proceso, los puntos de consigna y los botones relacionados con el control, así como los botones auxiliares para acceder a ciertas opciones de control o ayudas. 


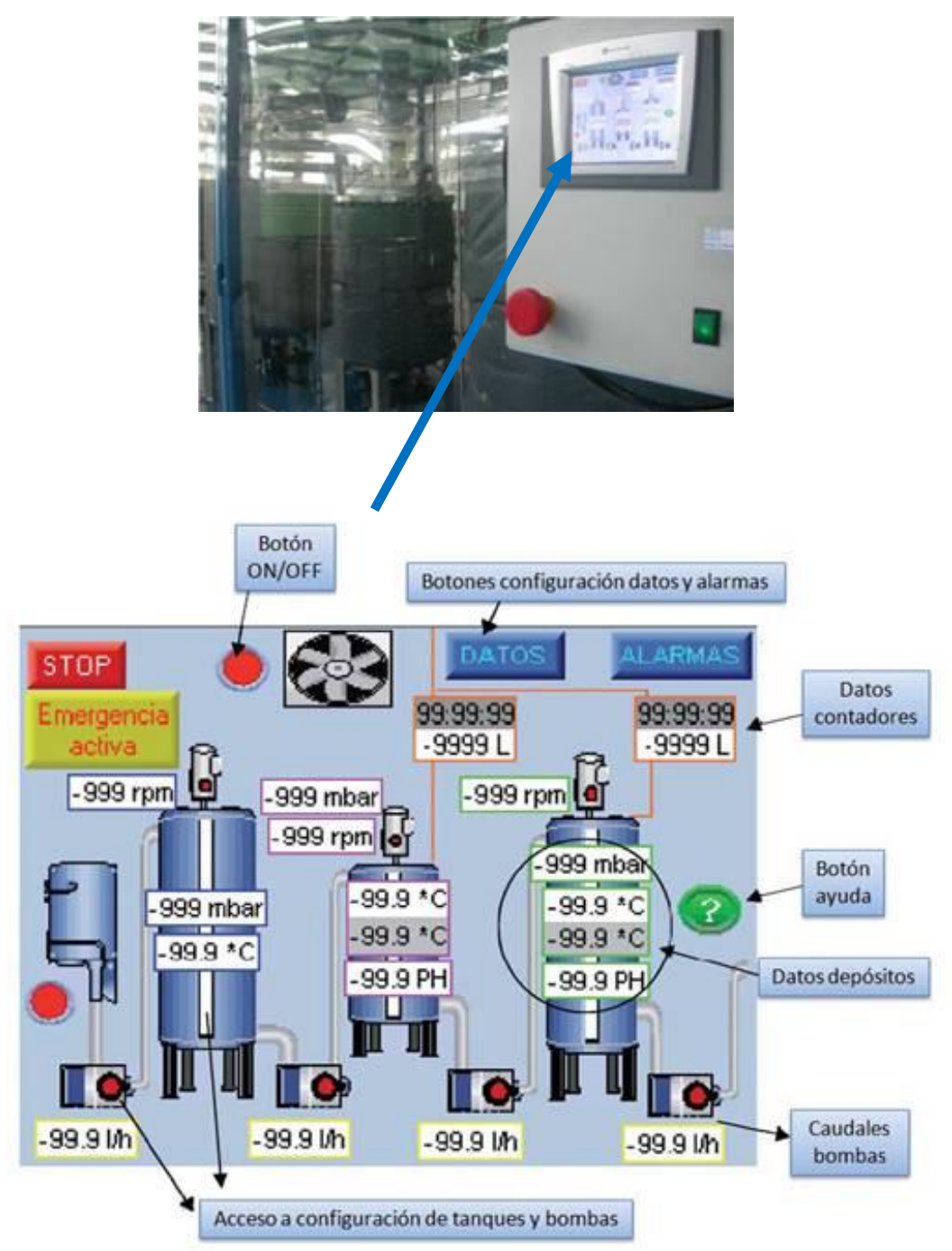

Figura 3-32. PLC de control

\subsubsection{Operación en continúo de la planta piloto}

Para la operación en continuo de la planta piloto de DA el lodo utilizado como inóculo en los reactores procedía del digestor anaerobio de una planta de tratamiento de aguas residuales municipales, previamente adaptado a las mezclas OW y PM, el cual tenía una concentración de $12 \pm 1 \mathrm{gSV} \cdot \mathrm{L}^{-1}$. Antes de cargar los reactores, el lodo fue lavado para no introducir sustancias extrañas al sistema.

Tomando como base los resultados obtenidos en los ensayos realizados a escala laboratorio, el reactor acidogénico se alimentó con una mezcla 1/5 de OW/PM, que previamente había pasado por el triturador con el fin de obtener un tamaño de partícula menor de $5 \mathrm{~mm}$ de diámetro de forma que se posibilitara su circulación por las diferentes conducciones de la planta piloto. El $\mathrm{pH}$ en este reactor se mantuvo dentro del rango 5,5 - 7,0. Transcurrido el THR determinado para esta fase, la mezcla fue bombeada al reactor metanogénico. En este último reactor el $\mathrm{pH}$ se mantuvo durante todo la experimentación, sin la adición de reactivos, a un $\mathrm{pH}$ comprendido entre $6,8-7,5$. 
Una vez estabilizado el sistema, los parámetros que permiten evaluar el rendimiento del proceso, como la eliminación de DQO soluble, el pH y la eliminación de sólidos totales disueltos en cada fase, se mantenían relativamente constantes, con una desviación estándar menor del 15\%.

Con el fin de encontrar las condiciones óptimas de operación para conseguir la mayor eliminación posible de DQO soluble, a la vez que se maximizaba la capacidad de tratamiento de la planta (THR mínimo) se realizó un experimento consistente en disminuir en cuatro etapas de forma sucesiva el THR, tanto en el reactor acidogénico, como en el metanogénico, y por ende el THR total del proceso de DA, según se muestra en la Tabla 3-9.

Tabla 3-9. THR ensayados

\begin{tabular}{|cccc|}
\hline & $\begin{array}{c}\text { THR en el reactor } \\
\text { acidogénico (días) }\end{array}$ & $\begin{array}{c}\text { THR en el reactor } \\
\text { metanogénico (días) }\end{array}$ & $\begin{array}{c}\text { THR total } \\
\text { (días) }\end{array}$ \\
\hline Etapa 1 & 4 & 20 & 24 \\
\hline Etapa 2 & 2 & 18 & 20 \\
\hline Etapa 3 & 1 & 15 & 16 \\
\hline Etapa 4 & 0,5 & 11,5 & 12 \\
\hline
\end{tabular}

Los resultados obtenidos de esta experimentación se pueden ver en las Figuras 3-33 a 3-36. 


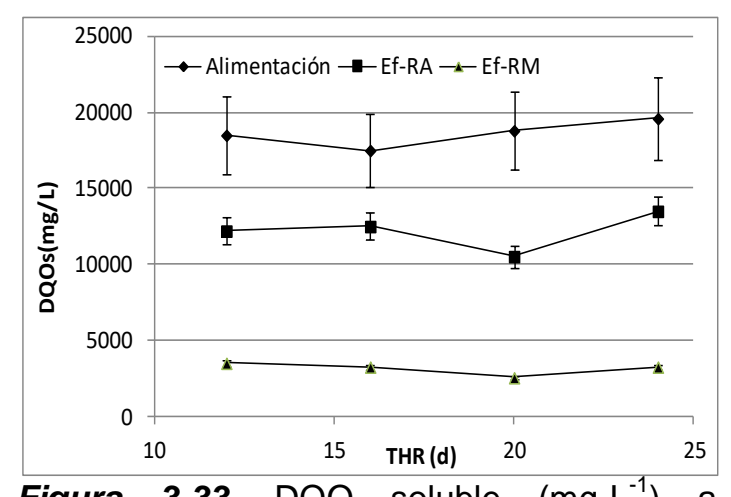

Figura 3-33. DQO soluble $\left(\mathrm{mg} \cdot \mathrm{L}^{-1}\right) \quad$ a diferentes THR

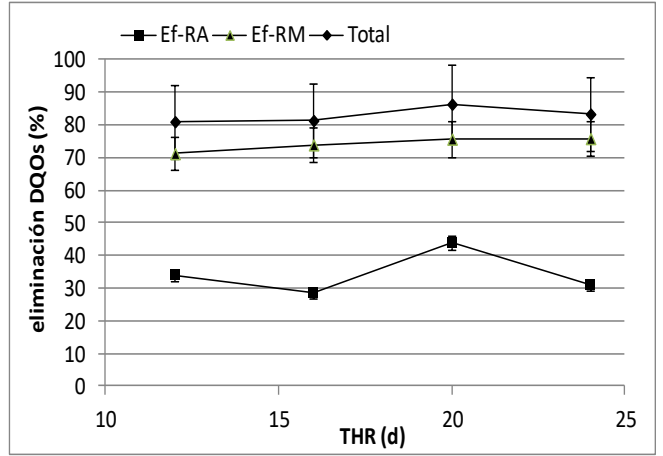

Figura 3-34. Porcentaje de eliminación de $D Q O$ a diferentes THR

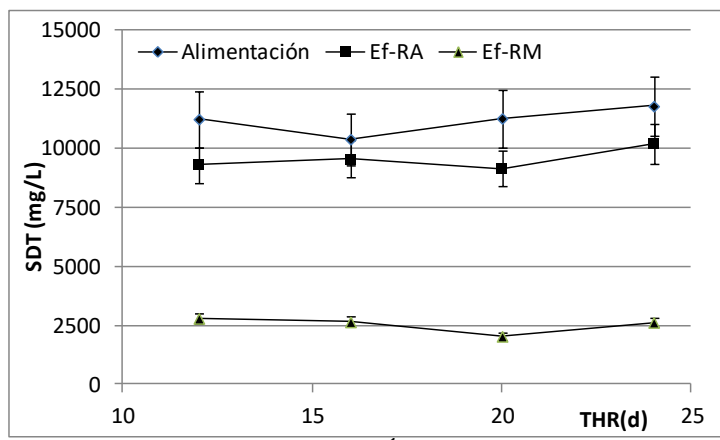

Figura 3-35. SDT $\left(m g \cdot L^{-1}\right)$ a diferentes THR

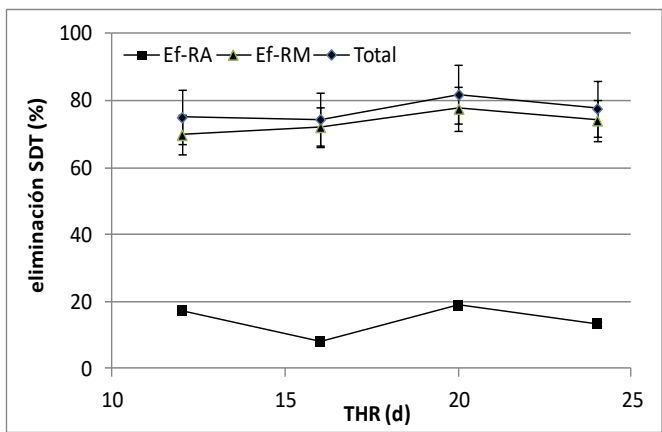

Figura 3-36. Porcentaje de eliminación de SDT a diferentes THR

Como puede observarse en la Figura 3-33 la DQO soluble (DQOs) a diferentes THR para la mezcla que alimenta el reactor acidogénico (RA) varía entre 17.500 y 19.600 $\mathrm{mg} \cdot \mathrm{L}^{-1}$, la DQOs para la salida del $R A$ varía de 10.520 a $13.500 \mathrm{mg} \cdot \mathrm{L}^{-1}$ y para el reactor metanogénico (RM) la DQOs varía de 2.550 a $3.500 \mathrm{mg} \mathrm{L}^{-1}$. De la Figura 3-34, se concluye que el porcentaje de eliminación de DQOs se encuentra en el rango de $31,1-44,0 \%$ en el RA y $71,3-75,9 \%$ en el RM para los distintos THR. El mayor porcentaje de eliminación de DQOs, $44,0 \%$, se consigue en el RA a los 20 días de THR total y en el RM a los 24 días de THR total con un porcentaje de eliminación de DQOs de $79,5 \%$. Para el conjunto de proceso, el mayor porcentaje de eliminación de DQOs, $86,4 \%$, se obtuvo a los 20 días de THR. El bajo porcentaje de eliminación de DQOs en la fase acidogénica se debe al complejo estado de la mezcla que se utiliza como substrato, la cual está formada por compuestos de cadena larga, como proteínas, grasas y carbohidratos, mientras que en la fase metanogénica el substrato entra en forma de moléculas de cadena corta, como alcoholes y ácidos grasos volátiles, después de haber pasado la mezcla por la etapa de hidrólisis y acidogénesis en el RA.

En la Figura 3-35 se observa que la concentración media de SDT para la mezcla que alimenta el reactor acidogénico varía entre 10.400 y $11.800 \mathrm{mg} \cdot \mathrm{L}^{-1}$, la concentración media de SDT para la salida del RA varía de 9.150 a $10.200 \mathrm{mg} \cdot \mathrm{L}^{-1}$ y para el $\mathrm{RM}$ la concentración media de SDT varía de 2.040 a $2.800 \mathrm{mg} \cdot \mathrm{L}^{-1}$. La Figura 3-36 muestra que la eficiencia de eliminación de SDT se encuentra entre el 8,2 - $18,9 \%$ en el RA y entre el 69,9 - $77,7 \%$ en el RM para los distintos THR ensayados.

La máxima eficiencia de eliminación de SDT, $81,8 \%$, se ha conseguido con un THR de 20 días. 
Durante el estudio, los parámetros de control utilizados para comprobar la estabilidad del reactor metanogénico fueron el $\mathrm{pH}$ y la alcalinidad.

En la Figura 3-37 se muestran los cambios de pH en el efluente de los dos reactores para los distintos THR estudiados. El pH de la mezcla utilizada como alimentación (después de su acidificación con $\mathrm{H}_{2} \mathrm{SO}_{4}$ para alimentar al reactor acidogénico) se encuentra en el intervalo de 5,42 - 5,86, la salida del reactor acidogénico tiene un $\mathrm{pH}$ en el intervalo 5.96 - 6.78 y la salida del reactor metanogénico tiene un $\mathrm{pH}$ comprendido entre 7,41 y 7,88 .

Los valores de alcalinidad para el RA varían de 320 a $360 \mathrm{mg} \cdot \mathrm{L}^{-1}$, mientras que para el $\mathrm{RM}$ los valores de alcalinidad varían de 520 a $550 \mathrm{mg} \cdot \mathrm{L}^{-1}$.

Durante los primeros días de operación se observó para todos los ensayos una acumulación de oleato y linoleato, pero posteriormente la concentración de estos ácidos disminuyó, produciéndose una elevación de la concentración de palmitato, lo cual coincide con lo experimentado por Cirne et al. (2007). Las concentraciones de los otros LCFA siempre fueron bajas.

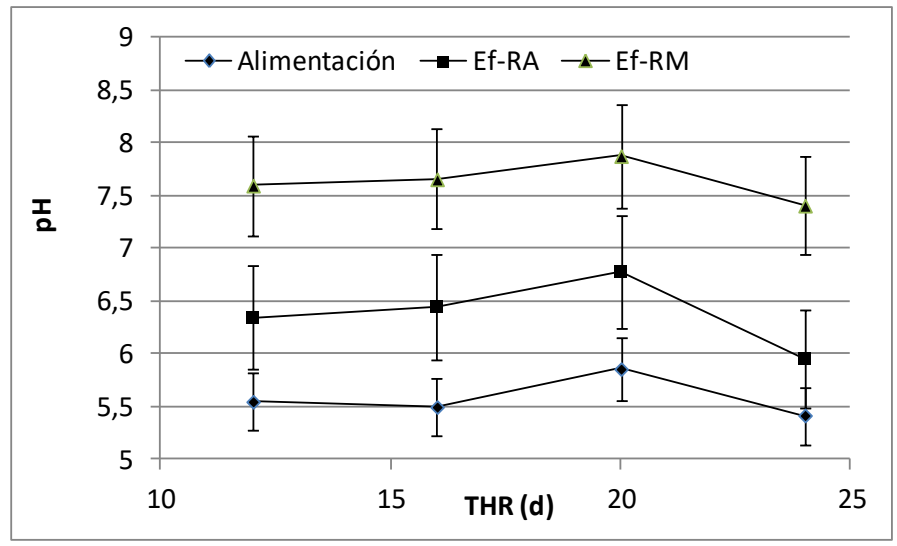

Figura 3-37. $\mathrm{pH}$ a diferentes THR

A la vista de los resultados experimentales obtenidos en la planta piloto se puede concluir que:

- El THR más eficiente para operar la planta es de 20 días.

- El máximo porcentaje de eliminación de DQOs y SDT logrado en el sistema es de 86,4 y $81,9 \%$, respectivamente.

- La producción de biogás alcanzó un máximo de $0.65 \mathrm{~m}^{3} \mathrm{kgSDV}_{\text {eliminado }}{ }^{-1}$ $\left(65 \% \mathrm{CH}_{4}\right)$ a los 20 días THR.

- $\quad$ El pH y la alcalinidad del efluente de los reactores se mantuvo estable a partir de los 20 días de THR.

El trabajo realizado en este apartado de la tesis ha sido utilizado para redactar el artículo titulado: "Two-phase anaerobic co-digestion of used vegetable oils' wastes and pig manure", el cual ha sido publicado en la revista International Journal of Environmental Science and Technology, revista listada en el JCR con factor de impacto 1.794 en su año de publicación. A continuación se presenta dicho documento: 


\section{Two-phase anaerobic co-digestion of used vegetable oils' wastes and pig manure}

\section{Hidalgo, M. Gómez, J. M. Martín- Marroquín, A. Aguado \& E. Sastre}

International Journal of Environmental Science and Technology

ISSN 1735-1472

Volume 12

Number 5

Int. J. Environ. Sci. Technol. (2015)

12:1727-1736

DOI 10.1007/s13762-014-0560-9

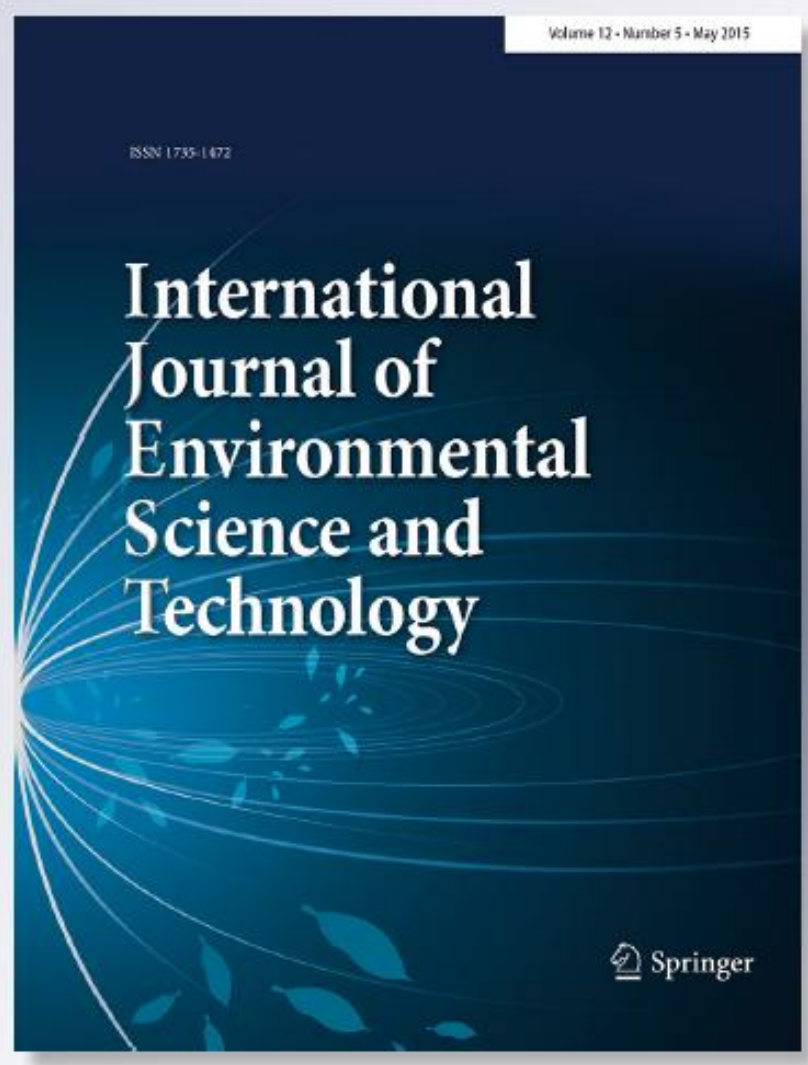

\section{Springer}


Int. J. Environ. Sci. Technol. (2015) 12:1727-1736

DOI $10.1007 / \mathrm{s} 13762-014-0560-9$

\title{
ORIGINAL PAPER
}

\section{Two-phase anaerobic co-digestion of used vegetable oils' wastes and pig manure}

\author{
D. Hidalgo $\cdot$ M. Gómez $\cdot$ J. M. Martín-Marroquín * \\ A. Aguado $\cdot$ E. Sastre
}

Received: 17 June 2013/Revised: 10 February 2014/Accepted: 17 March 2014/Published online: 9 April 2014 (8) Islamic Azad University (IAU) 2014

\begin{abstract}
The purpose of this work was to study the anaerobic co-digestion of all the by-products generated during the processing of used vegetable oils (UVO) with the objective of proposing a solution for the treatment of these wastes. More specifically, this study investigates the advantages of two-phase anaerobic digestion for treating a mixture (1/5 v/v) of UVO processing wastes (OW) and pig manure (PM) using two semi-continuous digesters operated at mesophilic temperature $\left(37 \pm 1{ }^{\circ} \mathrm{C}\right)$. The experiments were conducted at hydraulic retention time (HRT) of $0.5,1$, 2 and 4 days in the first stage (acidifier) and at HRT of 11.5 , 15,18 and 20 days in the second stage (methaniser). The results revealed that the HRT had a high influence on the soluble chemical oxygen demand (SCOD) and total dissolved solids (TDS) removal. The maximum total sCOD removal efficiency of $86.4 \%$ and TDS removal efficiency of $81.9 \%$ was achieved at 20 days of global HRT. The maximum biogas production of $0.65 \mathrm{~m}^{3}$ per kilogramme of volatile dissolved solids (VDS) was removed, corresponding to a methane production of $0.42 \mathrm{~m}^{3} \mathrm{CH}_{4} \mathrm{~kg}^{-1}$. VDS removed $\left(65 \% \mathrm{CH}_{4}\right)$ was also achieved at 20 days of HRT. The two-phase digestion system showed good stability, which was mainly attributed to the strong buffering capacity with the two-phase system and the high alkalinity from PM when co-digested with $\mathrm{OW}$. The results obtained from this study provide fundamental information for scaling up a high-performance two-phase anaerobic system in the future.
\end{abstract}

D. Hidalgo $(\triangle)$ - M. Gómez · J. M. Martín-Marroquín

A. Aguado - E. Sastre

CARTIF Centro Tecnológico, P.T. Boecillo, Valladolid, Spain e-mail: dolhid@cartif.es

D. Hidalgo - J. M. Martín-Marroquín - A. Aguado ITAP Institute, University of Valladolid, Valladolid, Spain
Keywords Co-digestion - Hydraulic retention time - Oily waste - Pig manure - Two-phase anaerobic reactor - Used vegetable oil

\section{Introduction}

Energy from waste is regarded as one of the most dominant future renewable energy sources, since it can provide a continuous power generation (Appels et al. 2011).

Used vegetable oils (UVO) are a promising altemative to the use of edible oils as feedstock for biodiesel production. The European Union produces 700,000 to 1 million tons a year of UVO, and most of them are disposed improperly (Chhetri et al. 2008; Kulkarni and Dalai 2006).

UVO can produce blockades in pipes and make sewage treatment more difficult when disposed through the sink. The EU strongly favours and supports the recovery of UVO for biofuels production as it fits in the strategy of reducing dependency on petrol fuels (EU 2006), minimising greenhouse gas emissions, decreasing engine pollution, and at the same time, it is a way to reduce waste disposal that can contaminate soils and waters.

When UVO is collected, it goes to a pre-treatment process to eliminate moisture and bulky particulate and then through a refining process to eliminate free fatty acids and other undesirable compounds before sending it for biodiesel production. Nowadays, the increasing amount of wastes generated in this sector as consequence of the pretreatment and refining processes means an environmental problem. Inadequate management and uncontrolled disposal have influenced both water bodies and nearby communities and have raised health concerns (Refaat 2010).

Anaerobic digestion $(\mathrm{AD})$ of residues from the pretreatment process and by-products of the refining process 
have the potential to achieve an efficient pollution reduction as well as the advantage of conserving energy and providing opportunities for environmental and socioeconomic benefits (Appels et al. 2011; Torrijos et al. 2008). On the other hand, it is well known that oil-rich wastes $A D$ is not always easy and simple, since anaerobes are very sensitive to lipid-rich matters, to surfactants producing during oil hydrolysis as well as to intermediate compounds of oily wastes degradation process (Hidalgo et al. 2013; Hong 2011; Neves et al. 2009; Zhang et al. 2010).

Lipids cause operational problems in anaerobic digesters due to clogging and may also cause mass transfer problems for soluble substrates, since they become adsorbed to the microbial biomass surface. The flotation of biomass due to adhesion of fat may also produce loss of active biomass because of washout (Cirne et al. 2007).

Nevertheless, lipids are attractive substrates for AD, and co-digestion due to the higher methane yield obtained when compared with proteins or carbohydrates. In this context, lipid-rich waste can be regarded as a large potential renewable energy source (Mobarak-Qamsari et al. 2012). Ahrin (2003) described a significant increase $(100 \%)$ in the yield of methane when fish oil was added to a manure digester. The benefit of adding lipids to a digester in order to enhance methane production is therefore a promising approach, which should be better explored.

Two-phase AD systems plus co-digestion have been suggested for the treatment of waste streams containing high levels of lipids such as kitchen waste ( $\mathrm{Li}$ et al. 2010; Yang et al. 2013; Zhang et al. 2007), dairy waste (Demirer and Chen 2005; Ince 1998), ice cream factory effluents (Borja and Banks 1995), fish meal processing waste (Guerrero et al. 1999), slaughterhouse waste (Wang and Banks 2003) or olive mill solid waste (Beccari et al. 1998; Borja et al. 2002; Travieso et al. 2008). These studies have illustrated the potential advantages of two-phase AD over single-phase systems when treating complex substances, e.g. shorter retention time, higher gas conversion efficiency and higher methane concentration in the produced gas (Bouallagui et al. 2005; Demirer and Chen 2005; SenthilKumar et al. 2011; Yu et al. 2002). Furthermore, on one hand, it may allow a reduction in total reactor volume (Demirel and Yenigün 2002; Ince 1998), and on the other hand, co-digestion alleviates the inhibitory effect caused by high fat concentrations (Yang et al. 2013).

The two-phase AD system permits the selection and enrichment of different bacteria in each digester, in the first phase, complex pollutants are degraded by acidogenic bacteria into volatile fatty acids (VFA), which are subsequently converted to methane and carbon dioxide by acetogenic and methanogenic bacteria in the second phase. This configuration also increases the stability of the process by controlling the acidification phase in order to prevent overloading and the build-up of toxic material (Demirel and Yenigün 2002). Moreover, the first stage may act as a metabolic buffer, preventing $\mathrm{pH}$ shock to the methanogenic population; in addition, low $\mathrm{pH}$, a high organic loading rate and a short hydraulic retention time (HRT) are all factors that favour the establishment of the acidogenic phase and preclude the establishment of methanogens. With waste containing high concentrations of lipids, the first phase serves mainly to remove solids and, hence, achieves a more stable high-rate anaerobic reactor operation (Palenzuela 1999).

Acidogenic and methanogenic microorganisms differ not only in terms of their nutritional and $\mathrm{pH}$ requirements, but also with respect to their physiology, growth and nutrient uptake kinetics, and in their particular ability to withstand environmental changes. Consequently, conditions that are favourable to the growth of acid-forming bacteria (short HRT, low $\mathrm{pH}$ ) may be inhibitory to methane-forming bacteria. An advantage of two-phase digesters is that their operating conditions may be selectively determined in order to maximise not only acid but also methane-forming bacterial growth. Nonetheless, in the case of waste with a high content of biorecalcitrant substances, a certain level of methanogenic activity is permitted in the acidogenic reactor, since these bacteria consume $\mathrm{H}_{2}$, produced in the acidogenic phase (Solera et al. 2002).

Furthermore, two-phase $\mathrm{AD}$ has given the best performance in methane productivity and COD removal efficiency compared with one-phase conventional digestion (Göblös et al. 2008; Wust 2003).

Therefore, taking into account the potential advantages of two-phase $\mathrm{AD}$ and continuing the research of upgrading the anaerobic co-digestion of different wastes, the aim of the present work has been to assess the performance of two-phase anaerobic co-digestion of residues and subproducts from the used vegetable oil processing industry (OW) with pig manure (PM) in semi-continuous sequencing digesters operated at mesophilic temperature.

This report discusses a pilot scale research with the emphasis placed on the evaluation of biogas production optimal values and organic matter removal efficiencies of effluents under different HRTs. The research described in this paper was performed in laboratories of Centro Tecnológico CARTIF, Spain, in 2012-2013.

\section{Materials and methods}

\section{Waste streams}

The treatment of UVO is intended to yield a product with a given quality that satisfies the needs of the biodiesel industries. The treatment process of UVO involves several 
chemical and physical steps which generate a mixture of residues (OW). In this study, OW were supplied by a biodiesel company located in Madrid (Spain).

PM proceeded from a swine-raising farm located nearby the city of Valladolid (Spain).

\section{Wastes analysis}

Total and volatile solid concentration (TS, VS), total and volatile dissolved solid concentration (TDS, VDS), chemical oxygen demand (COD), soluble chemical oxygen demand (sCOD), fat content, alkalinity, $\mathrm{P}$ and $\mathrm{pH}$ were determined following standard methods (APHA 2005) recommendations.

Fatty acids (FA) concentrations were determined using a gas chromatograph (HP-Agilent) equipped with a flame ionisation detector (FID). C, N, H and S contents were determined by UNE-CEN/TS 15104 EX with a LECO Truspec CHN(S) elemental analyser.

Oxygen content was not measured directly but was estimated assuming that no other elements (apart from the measured $\mathrm{C}, \mathrm{H}, \mathrm{N}, \mathrm{S}$ and $\mathrm{P}$ ) were present in the wastes.

Biomethane potential (BMP) test

In order to study the biodegradability and biomethane potential of different OW/PM mixtures, batch experiments were run in glass serum bottles with a liquid volume of $600 \mathrm{~mL}(2,000 \mathrm{~mL}$ of total volume).

All the experiments were carried out at $37 \pm 1^{\circ} \mathrm{C}$ in a thermostatic room, and continuously stirred on a shakingtable. Anaerobic sludge from a municipal wastewater treatment plant, previously adapted to OW and PM mixtures, with a concentration of $12 \pm 1 \mathrm{gVS} \mathrm{L}^{-1}$, was used as inoculum for the anaerobic test.

The concentration of the inoculum in all the assays was $6.5 \mathrm{~g} \mathrm{~L}^{-1}$, and $\mathrm{pH}$ was 7.5 . In this study, four OW/PM ratios were selected for the substrate, 1/0,1/1, 1/3 and 1/5 $\mathrm{v} / \mathrm{v}$, and triplicate assays, for all the waste mixtures and conditions, were performed. Substrate/inoculum $(\mathrm{S} / \mathrm{X})$ ratios were in the range of $0.40-0.60 \mathrm{gVS}_{\text {waste }} \mathrm{gVS}_{\text {inoculum }}^{-1}$ for all the samples.

A set of triplicate blank assays without any waste (only inoculum) was also performed for endogenous methane production determination. To avoid acidification of the assay, $\mathrm{NaHCO}_{3}$ was added as buffer $\left(6 \mathrm{gNaHCO}_{3} \mathrm{~L}^{-1}\right)$. Experiments were finished when the biogas production rate in waste assays decreased to the same level as in the blank assays.

Biogas production was measured manually by a pressure transmitter (Druck, PTX 1400, range 1 bar) in the head space of each reactor. To avoid reaching overpressure, biogas in the head space was released periodically. Pressure differences were converted to biogas volume, using the ideal gas Law and standard temperature and pressure conditions (STP, $P=1$ bar and $T=0{ }^{\circ} \mathrm{C}$ ).

Biogas composition was measured before each release with a Varian CP-4900 Micro-GC with a thermal conductivity detector. Net methane production was calculated by subtracting the amount of the methane produced by the blank assay from the methane production of each assay.

\section{Experimental set-up}

In order to study the operational and performance characteristics of the two-phased $\mathrm{AD}$ when treating a mixture of OW and PM, the pilot plant schematically illustrated in Fig. 1 was constructed.

The system is comprised of a waste grinder, a homogenisation tank $\left(0.5 \mathrm{~m}^{3}\right)$, a continuous stirred tank acidification reactor (AR) $450 \mathrm{~mm}$ inner diameter and $700 \mathrm{~mm}$ height, made up of stainless steel with a working volume of $0.1 \mathrm{~m}^{3}$, a continuous stirred tank methanogenic reactor (MR) $800 \mathrm{~mm}$ inner diameter and 1,200 $\mathrm{mm}$ height, made up of stainless steel with a working volume of $0.5 \mathrm{~m}^{3}$, and a digested effluent tank. The acidogenic and methanogenic reactors were fabricated with 1:5 volumetric ratios to maintain shorter HRT in the AR as comparable with longer HRT in the MR.

The mission of the acidogenic reactor is to acidify the raw substrate in an effort to improve the performance of the methanogenic reactor by increasing the SV removal efficiencies and methane yield. In addition, the acidogenic reactor may also reduce the effect of shock loadings to the methanogenic reactor, increasing the stability of the twophase system.

The source materials were pre-treated by the grinder, then pumped into the AR and then forced from the AR into the MR. A check valve connects the AR with the MR, which was also connected with the digested effluent tank by another check valve.

Two thermometers and two $\mathrm{pH}$-meters were installed, one in the acidification reactor and another in the methane fermentation reactor. A pressure gauge was installed on the biogas line to monitor head-gas pressure in both fermentation reactors. Biogas generated was measured using two wet gas flow meters. The exteriors of the acidification reactor and the methane fermentation reactor were coated with a $5 \mathrm{~cm}$ layer of polyurethane foam for heat insulation, and the temperature was maintained at $37 \pm 1{ }^{\circ} \mathrm{C}$ by an electric heating jacket. Several ports were installed on the walls of the fermentation system for withdrawing samples. 


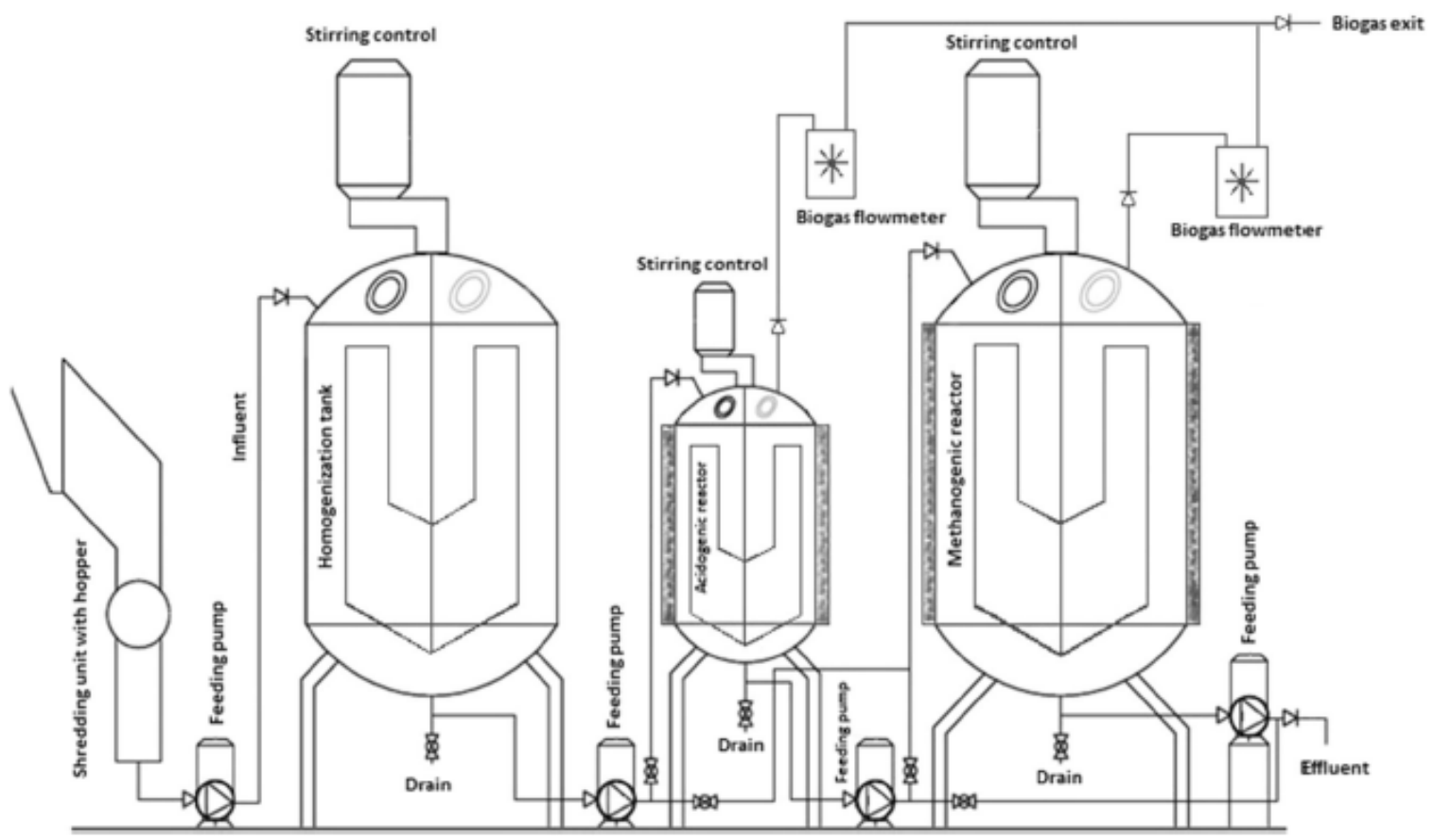

Fig. 1 Experimental set-up

\section{Results and discussion}

Waste composition

Lumped parameters as TS, VS, COD, total organic carbon (TOC) and total nitrogen (TN) are the most frequently analysed since they are the key when determining treatment optimisation. Furthermore, the analysis of the elemental composition provides information about the theoretical methane potential ( $\left.\mathrm{B}_{0, \mathrm{Th}}\right)$ of a given waste using Buswell's equation (1). This equation assumes methane production from the complete degradation of a certain waste with a given elemental composition, where $\mathrm{C}_{n} \mathrm{H}_{\mathrm{a}} \mathrm{O}_{\mathrm{b}} \mathrm{N}_{\mathrm{c}}$ represents the chemical formula of the biodegradable organic compound subjected to the anaerobic degradation process, and the production of methane considered herein is the maximum stoichiometrically possible (Lesteur et al. 2010). For a $\mathrm{C}_{n} \mathrm{H}_{\mathrm{a}} \mathrm{O}_{\mathrm{b}} \mathrm{N}_{\mathrm{c}}$ compound, the theoretical methane potential [at standard temperature and pressure conditions (STP)] is

$B_{0, \mathrm{Th}}=\frac{\left(\frac{n}{2}+\frac{a}{8}-\frac{b}{4}-\frac{3 c}{8}\right) \cdot 22.4}{12 n+a+16 b+14 c}|=| \frac{\mathrm{L} \mathrm{CH}_{4}}{\mathrm{~g} \mathrm{VS}}$

where the parameters $n, a, b, c$ refer to the stoichiometry index of $\mathrm{C}, \mathrm{H}, \mathrm{O}$ and $\mathrm{N}$, respectively.

Tables 1, 2 and 3 gather the results obtained from the characterisation of the selected raw wastes and their mixtures.

PM has a high content of ammonia in comparison with OW. Manure possesses a high alkalinity, while the

Table 1 Waste characterisation

\begin{tabular}{|c|c|c|c|c|c|c|c|c|}
\hline Waste & \multicolumn{7}{|c|}{ Physico-chemical parameters } & Protein $(\%)$ \\
\hline ow & 6.5 & 30 & - & 391.4 & 374.1 & 0.95 & 49.6 & 2.7 \\
\hline PM & 7.7 & 282 & 4.9 & 44.9 & 30.7 & 0.68 & - & - \\
\hline Mixture $1 / 1$ & 7.0 & 160 & 2.5 & 225.5 & 212.4 & 0.94 & 24.8 & 1.4 \\
\hline Mixture $1 / 3$ & 7.1 & 202 & 3.7 & 141.5 & 116.6 & 0.82 & 12.4 & 0.7 \\
\hline
\end{tabular}


alkalinity of OW is low. On the other hand, OW have a high content of fats and proteins in contrast to manure. The characterisation of the wastes indicates that co-digestion with PM could be a cost-effective method to treat OW without the need to add nitrogen source or chemicals for increasing buffer capacity or adjusting $\mathrm{pH}$, in accordance with Zhang et al. (2011).

Palmitic, linoleic and oleic are the most abundant long chain fatty acids (LCFA) in the OW samples (Table 2). The concentrations of the other acids were always much lower. Lalman and Bagley (2001) reported that palmitic acid was the main product detected from oleic and linoleic acids anaerobic degradation, so their presence in the batch experiments and in the two-phase reactor is expected in this study.

These three compounds have been identified as inhibitors for methanogens. Even at low concentrations, these compounds can be adsorbed on the cell membrane

Table 2 Fatty acids in OW

\begin{tabular}{lr}
\hline FA & $(\%)$ \\
\hline Araquid acid & 0.45 \\
Behenic acid & 0.77 \\
Capric acid & 0.01 \\
Caprilic acid & 0.05 \\
Cerotic acid & 0.01 \\
Estearic acid & 5.92 \\
Heneicosanoic acid & 0.01 \\
Lauric acid & 0.05 \\
Lignoceric acid & 0.25 \\
Linoleic acid & 31.76 \\
Linolelaidic acid & 0.09 \\
Margaric acid & 0.11 \\
Miristic acid & 0.46 \\
Oleic acid & 45.65 \\
Palmitic acid & 13.84 \\
Palmitoleic acid & 0.55 \\
\hline
\end{tabular}

interfering with mass transfer across the membrane (Pastor et al. 2013).

Previous works (Beccari et al. 1998) on the anaerobic treatment of oily wastes have shown that the inhibition of methane production is mainly caused by the high presence of lipids, this is why the co-digestion of these wastes with non-oily wastes (as PM) is a key factor to prevent inhibition of methanogenesis since the lipids concentration is lowered.

Specific methane potential

Figure 2 shows the cumulative specific methane production of the wastes at the different mixture ratios assayed. All the biodegradability assays were conducted in triplicate, and the maximum deviation reported was $\pm 15 \mathrm{mLCH}_{4} \mathrm{gSV}^{-1}$ for every assay set.

The methane production pattem observed was similar to the ones reported by Cirne et al. (2007) for batch degradation of a lipid-rich waste. The initial lag phase in methane production observed for all tests could be attributed to the rapid build-up of FA, as proposed by Salminen et al. (2000). The maximum methane production rate observed was similar for tests with mixture of OW and PM

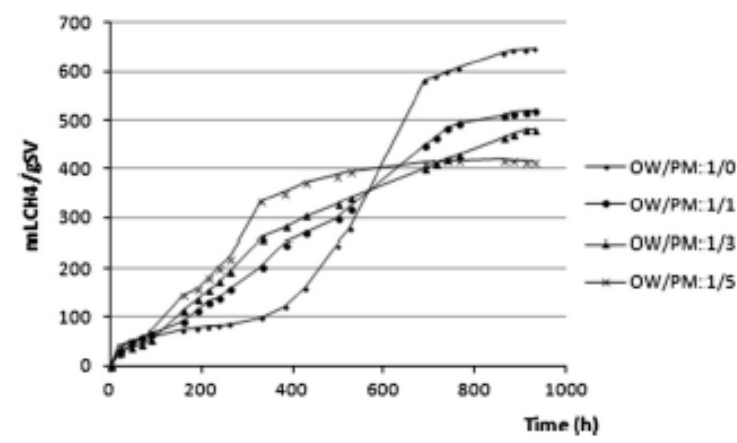

Fig. 2 Cumulative specific methane production curves of the waste mixtures at different $\mathrm{OW} / \mathrm{PM}$ ratios

Table 3 Waste elemental composition

\begin{tabular}{|c|c|c|c|c|c|c|c|c|}
\hline Waste & \multicolumn{7}{|c|}{ Elemental composition ${ }^{a}$} & $\begin{array}{l}\text { Theoretical methane potential } \\
B_{0, \mathrm{~m}}\left(\mathrm{mLCH}_{4} \cdot \mathrm{gVS}^{-1}\right)\end{array}$ \\
\hline ow & 64.13 & 9.6 & 1.2 & 0.2 & 0.1 & 4.2 & 20.6 & 824 \\
\hline PM & 34.5 & 4.7 & 2.8 & 0.4 & 0.7 & 31.6 & 25.3 & 516 \\
\hline Mixture 1/1 & 50.3 & 7.1 & 1.8 & 0.3 & 0.4 & 18.1 & 22.0 & 670 \\
\hline Mixture $1 / 3$ & 42.09 & 5.8 & 2.3 & 0.4 & 0.6 & 24.8 & 24.1 & 603 \\
\hline
\end{tabular}

${ }^{2} \%$ dry-matter weight basis

b \%O estimated

c Calculated assuming a $\mathrm{C}_{2} \mathrm{H}_{\mathrm{n}} \mathrm{O}_{\mathrm{b}} \mathrm{N}_{\mathrm{c}}$ composition ( $S$ and $P$ neglected) 
as substrate (in $\mathrm{mLCH}_{4} \mathrm{~L}^{-1} \mathrm{~h}^{-1}: 3.3,3.4$ and 5.9 for OW/ PM rates of $1 / 1,1 / 3$ and $1 / 5$, respectively) but a stronger inhibition was observed for the test where only OW was added as substrate. In this case, the lag phase extended to $400 \mathrm{~h}$, but the process recovered. This phenomenon agrees with Pereira et al. (2005) that demonstrated that inhibition by LCFA accumulation was a reversible phenomenon more likely to be related to physical transport limitations, than to metabolic functions.

As expected, mixtures with higher percentage of OW showed higher specific methane potentials. This trend is in accordance with the results of the $B_{0, \mathrm{Th}}$ calculated by the Buswell's equation (Table 3), however experimental values are considerably lower than the theoretical ones (in $\mathrm{mLCH}_{4} \mathrm{gVS}^{-1}: 648,520,480$ and 415 for OW/PM rates of $1 / 0,1 / 1,1 / 3$ and $1 / 5$, respectively). This could mean that the maximum theoretical conversion has not been reached during the experimentation (that is something usual), but also that with Buswell's equation neither the use of substrate nor other routes of conversion of organic matter are taken into consideration for the production of bacterial biomass (de Lemos 2007).

Part of the biodegradable organic matter, used by the bacteria to grow, does not contribute to the BMP value. In other words, the Buswell's equation does not account for substrate biodegradability, neglecting cellular synthesis, when in reality, part of the biodegradable organic matter is used by the bacteria to grow, and does not contribute to biogas generation. In fact, Buswell reported that during the digestion of pure carbohydrates, an average of $12 \%$ of the total carbon-fed was lost in the cell protoplasm which was not accounted for by their formula. The Buswell's equation therefore overestimates the BMP value. Furthermore, it is known that in the presence of specific inorganic donors (such as nitrate, sulphate or sulphite) and some by-products of the cellular metabolism (Zhou et al. 2013) the production of methane can decrease.

Taking in mind the operation of a two-phase anaerobic pilot plant, the optimal scenario assayed corresponds to the ratio OW/PM:1/5 v/v where shorter lag periods will make it possible to operate at lower HRT.

During the first days of the assay, methane content in biogas was low, but it increased until reaching percentages of $70.6,69.2,69.1$ and 69.5 for OW/PM rates of $1 / 0,1 / 1,1 / 3$ and $1 / 5$, respectively. A fact that is observed in all the mixtures is that the lower the OW/PM ratio is in the batch assay, the faster the methane content increases in the biogas. The breakdown of the complex substrate takes place during those first stages, with its consequent acid-components generation and buffer consumption $\left(\mathrm{NaHCO}_{3}\right)$, changing the $\mathrm{HCO}_{3}{ }^{-} /$ $\mathrm{CO}_{2}$ balance and releasing $\mathrm{CO}_{2}$ from the liquid to the gas phase. Therefore, a substrate more easily degradable will
Table 4 Experimental HRT

\begin{tabular}{llll}
\hline & $\begin{array}{l}\text { HRT acidogenic } \\
\text { reactor (day) }\end{array}$ & $\begin{array}{l}\text { HRT methanogenic } \\
\text { reactor (day) }\end{array}$ & $\begin{array}{l}\text { Total HRT } \\
\text { (day) }\end{array}$ \\
\hline Run 1 & 4 & 20 & 24 \\
Run 2 & 2 & 18 & 20 \\
Run 3 & 1 & 15 & 16 \\
Run 4 & 0.5 & 11.5 & 12 \\
\hline
\end{tabular}

produce more $\mathrm{CO}_{2}$ and in consequence a biogas with lower methane content at the beginning of the assay.

\section{Two-phase reactor behaviour}

The sludge used as inoculum in the reactors was the same used in the biodegradability test. Before loading the reactors, the sludge was clearly washed.

The AR was fed with the waste mixture of oily waste and PM (after previous grinding) at an optimum mixing ratio of $1 / 5(\mathrm{OW} / \mathrm{PM})$, and $\mathrm{pH}$ was controlled within the range 5.5-7.0 by the addition of $\mathrm{H}_{2} \mathrm{SO}_{4}$. The mixture was then pumped into the methane fermentation reactor. No chemicals addition for $\mathrm{pH}$ control was required in this stage. After stabilizing the reactor, studies were conducted under the steady state conditions. At the steady state of the bioreactors, performance parameters like COD, $\mathrm{pH}$ and solids removal were relatively constant [standard deviation (SD) $<15 \%]$.

In order to find the optimum operating conditions for SCOD and TDS removal, an experiment consisting of four runs with successively decreasing HRT in acidogenic and methanogenic reactors, and thus, total HRT, was performed. The system was operated at the HRT showed in Table 4. The $\mathrm{pH}$, temperature and biogas production of acidogenic and methanogenic reactors were monitored online using a programmable logic control.

\section{sCOD removal}

The results obtained during the process run of different HRTs are plotted in Fig. 3a. The average sCOD concentration for feed varies from 17,500 to $19,600 \mathrm{mg} \mathrm{L}^{-1}$ (min: $14,982 \mathrm{mg} \mathrm{L}^{-1}$; $\max : 23,300 \mathrm{mg} \mathrm{L}^{-1}$; SD: $13.8 \%$ ), for AR outlet varies from 10,520 to $13,500 \mathrm{mg} \mathrm{L}^{-1}$ (min: $8,928 \mathrm{mg} \mathrm{L}^{-1}$; $\max : 18,150 \mathrm{mg} \mathrm{L}^{-1}$; SD: $7.1 \%$ ) and for MR varies from 2,550 to $3,500 \mathrm{mg} \mathrm{L}^{-1}$ (min: $890 \mathrm{mg} \mathrm{L}^{-1}$; $\max : 3,895 \mathrm{mg} \mathrm{L}^{-1}$; SD: $4.2 \%$ ). From Fig. 3b, it is evident that SCOD removal efficiency was in the range of $31.1-44.0 \%$ in the AR and $71.3-75.9 \%$ in the MR at various HRT. The maximum SCOD removal efficiency of $75.9 \%$ at 24 days of HRT was achieved in the MR, and $44.0 \%$ at 20 days of HRT was achieved in the acidogenic 

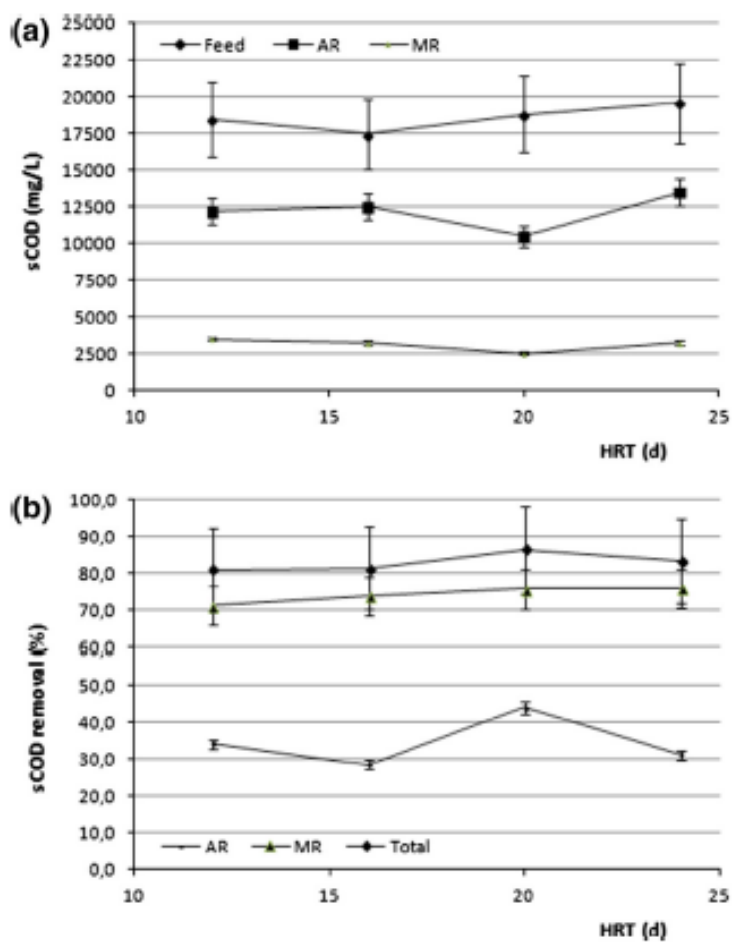

Fig 3 sCOD at different HRTs a sCOD concentration; b sCOD removal

phase. The maximum total sCOD removal efficiency of $86.4 \%$ was also achieved at 20 days of HRT. The lower efficiency of the acidogenic phase is due to the complex state of the mixture, even after grinding, while in the methanogenic phase the substrate enters as simple shortchain compounds after hydrolysis and the fermentation process in the AR.

\section{TDS removal}

The average TDS concentration for feed varies from 10,400 to $11,800 \mathrm{mg} \mathrm{L}^{-1}$ (min: $7,652 \mathrm{mg} \mathrm{L}^{-1}$; $\max$ : $13,528 \mathrm{mg} \mathrm{L}^{-1}$; SD: $10.7 \%$ ), for AR outlet varies from 9,150 to $10,200 \mathrm{mg} \mathrm{L}^{-1}$ (min: $7,925 \mathrm{mg} \mathrm{L}^{-1}$; $\max$ : $12,925 \mathrm{mg} \mathrm{L}^{-1}$; SD: $8.3 \%$ ) and for MR varies from 2,040 to $2,800 \mathrm{mg} \mathrm{L}^{-1}$ ( $\min : 1,552 \mathrm{mg} \mathrm{L}^{-1}$; $\max : 3,963 \mathrm{mg} \mathrm{L}^{-1}$; SD: $7.8 \%$ ).

Figure 4 shows the TDS removal efficiency of acidogenic and methanogenic reactors at various HRT.

It is clear that the TDS removal efficiency in the AR is in the order of $8.2-18.9 \%$ for various HRT, and in MR, TDS removal efficiency varies from 69.9 to $77.7 \%$. The maximum total TDS removal efficiency of $81.9 \%$ was achieved at 20 days of HRT.

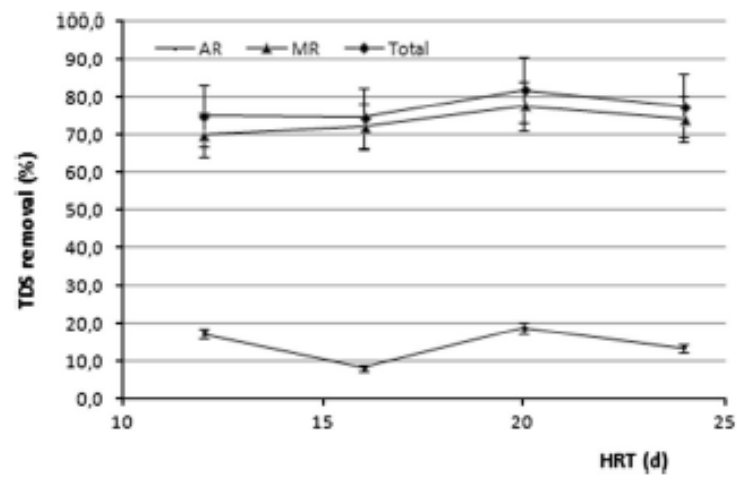

Fig. 4 TDS removal at different HRTs

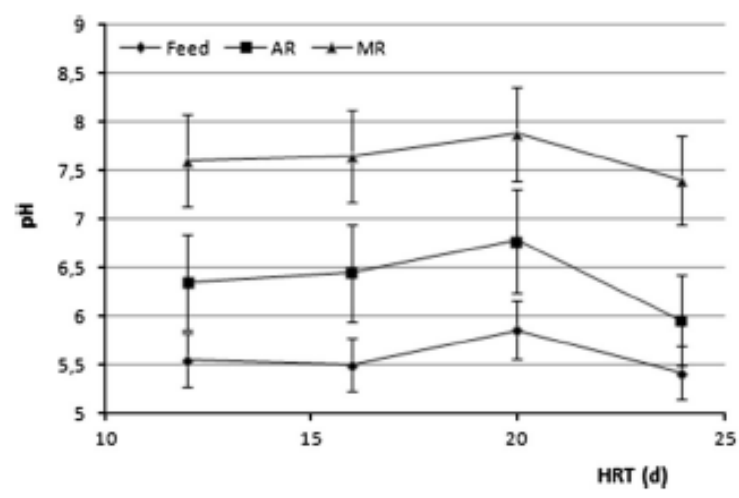

Fig. $5 \mathrm{pH}$ at different HRTs

pH, alkalinity and LCFA concentration

$\mathrm{pH}$ changes in the effluent of the reactors at various HRT are shown in Fig. 5. It is clear that the average $\mathrm{pH}$ of the raw feed (after acidification with $\mathrm{H}_{2} \mathrm{SO}_{4}$ ), AR outlet and MR outlet are in the range of 5.42-5.86 (min: $5.18 \mathrm{mg} \mathrm{L}^{-1}$; $\max : \quad 6.31 \mathrm{mg} \mathrm{L}^{-1}$; SD: 6.2\%), 5.96-6.78 (min: $5.50 \mathrm{mg} \mathrm{L}^{-1}$; $\max : \quad 7.00 \mathrm{mg} \mathrm{L}^{-1} ; \mathrm{SD}: 7.8 \%$ ) and 7.41-7.88 (min: $7.20 \mathrm{mg} \mathrm{L}^{-1}$; $\max : 8,55 \mathrm{mg} \mathrm{L}^{-1}$; SD: $4.9 \%$ ), respectively. The alkalinity values for AR vary from 320 to $360 \mathrm{mg} \mathrm{L}^{-1}$ (min: $286 \mathrm{mg} \mathrm{L}^{-1}$; $\max : 496 \mathrm{mg} \mathrm{L}^{-1}$; SD: $8.0 \%$ ), whereas for the MR the alkalinity values vary from 520 to $550 \mathrm{mg} \mathrm{L}^{-1}$ (min: $420 \mathrm{mg} \mathrm{L}^{-1}$; $\max$ : $766 \mathrm{mg} \mathrm{L}^{-1}$; SD: $5.3 \%$ ). In this study, $\mathrm{pH}$ and alkalinity values were under control for the stable operation of the MR.

Accumulation of oleate and linoleate was observed during the first days of operation for all the assays. Then, a decrease in these acids concentration, which correlated with the accumulation that occurred for palmitate was observed, in accordance with Cirne et al. (2007). The concentrations of the other LCFA were always much lower. 


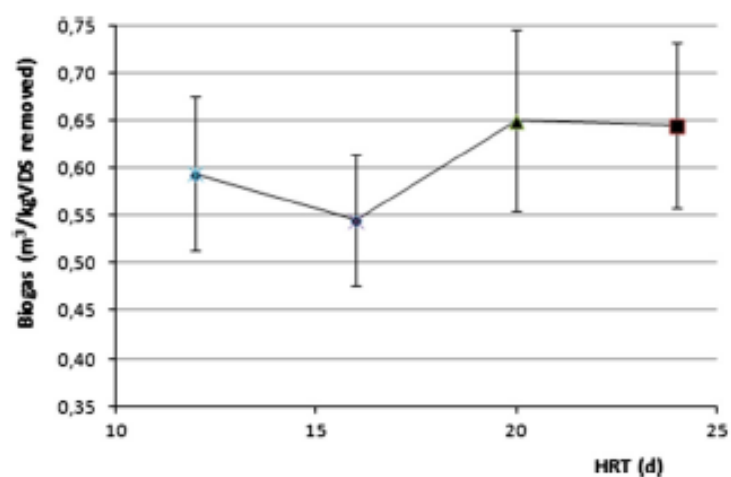

Fig. 6 Biogas production at different HRTs

Angelidaki et al. (2002) reported inhibition for oleate concentrations higher than $200 \mathrm{mg} \mathrm{L}^{-1}$. Furthermore, Salminen et al. (2000) found that palmitate concentrations were inhibitory during the degradation of solid poultry slaughterhouse waste. However, this does not seem to have been the case in the present study. No inhibition of methanogenic bacteria activity has been observed during the experimentation, even working with $\mathrm{pH}$ values in the MR inlet lower than 6.

Beccari et al. (1998) applied a two-reactor system with partial phase separation for treating olive oil effluents and reported that in the conversion between oleic acid and palmitic acid, the saturation from oleic to stearic was the limiting step, whereas the first step of $\beta$-oxidation (stearic to palmitic) proceeded quickly.

\section{Biogas}

Biogas production at different HRTs for the whole system is shown in Fig. 6. The average methane content in the biogas ranged between 63 and $65 \%$ during the experiments. The average maximum biogas production of $0.65 \mathrm{~m}^{3} \mathrm{kgVDS}^{-1}$ removed (min: $0.622 \mathrm{~m}^{3} \mathrm{kgVDS}^{-1}$; max: $0.664 \mathrm{~m}^{3} \mathrm{kgVDS}^{-1}$; SD: $\left.14.8 \%\right),\left(65 \% \mathrm{CH}_{4}\right)$ was achieved at 20 days of HRT, whereas $0.645 \mathrm{~m}^{3} \mathrm{kgVDS}^{-1}$ removed (min: $0.600 \mathrm{~m}^{3} \mathrm{kgVDS}^{-1}$; $\max$ : $0.654 \mathrm{~m}^{3}$ $\mathrm{kgVDS}^{-1}$; SD: $13.6 \%$ ) for 24 days of HRT, $0.594 \mathrm{~m}^{3} \mathrm{kgVDS}^{-1}$ removed (min: $0.585 \mathrm{~m}^{3} \mathrm{kgVDS}^{-1}$; max: $0.621 \mathrm{~m}^{3} \mathrm{kgVDS}^{-1}$; SD: $13.8 \%$ ) for 12 days of HRT and $0.545 \mathrm{~m}^{3} \mathrm{kgVDS}^{-1}$ removed (min: $0.538 \mathrm{~m}^{3} \mathrm{kgVDS}^{-1}$; $\max : 0.605 \mathrm{~m}^{3} \mathrm{kgVDS}^{-1}$; $\mathrm{SD}$ : $12.8 \%$ ) for 16 days of HRT. Biogas production is directly related to SCOD stabilization, for example without biogas production minimal SCOD and VDS removal occurs (Grady et al. 1999).
It can be observed that, also here, experimental values are lower than the theoretical ones obtained by applying Buswell's equation (Table 3 ).

According to Shen et al. (2013), the statistical coefficients of variation (SD) for biogas production can directly reflect the buffering capability of digestion system to newfed substrates and the stability of digestion performance. The statistical calculation results indicated that the SD for methane production in the stable periods of the two-phase system was always lower than $15 \%$. Thus, it could be deduced that the $\mathrm{AD}$ was stable under the whole experimentation.

This study shows that oily wastes can be treated successfully without high dilution and without adding chemical substances (apart from sulphuric acid for $\mathrm{pH}$ control) if they are co-digested with substrates containing high level of ammonium nitrogen and alkalinity to compensate for their lack in these wastes.

The same conclusion was previously stated by other authors (Angelidaki and Ahing 1997; Angelidaki et al. 2002; Fezzani and Cheikh 2007).

\section{Conclusion}

A pilot scale two-phase semi-continuous stirred tank reactor was used to treat oily waste with $\mathrm{PM}$ as co-substrate $(1 / 5 \mathrm{v} / \mathrm{v})$ at different HRTs $(12,16,20$, and 24 days). The experimental results indicated that the most suitable HRT for an efficient run of the reactor was 20 days. The maximum removal of SCOD and TDS achieved in the system was 86.4 and $81.9 \%$, respectively. The biogas production reached a maximum of $0.65 \mathrm{~m}^{3} \mathrm{kgVDS}^{-1}$ removed $(65 \%$ $\mathrm{CH}_{4}$ ) at 20 days HRT. The $\mathrm{pH}$ and alkalinity of the reactors effluent were stable under 20 days of HRT.

From the results obtained, it was clear that two-phase $\mathrm{AD}$ system has given good performances concerning methane productivity, sCOD and TDS removal efficiencies and effluent quality compared with those given by conventional one-phase $A D$ reactors.

Therefore, two-phase $\mathrm{AD}$ could be a very feasible altemative, eco-friendly and sustainable treatment system for the waste generated by used vegetable oil processing companies and pig farms.

Furthermore, co-digestion of OW and PM on a twophase anaerobic system is a promising method for the recovery of bioenergy.

Acknowledgments The authors gratefully acknowledge support of this work by the LIFE + Program under the responsibility of the Directorate General for the Environment of the European Commission through the agreement LIFE 09 ENV/E/000451-VALUVOIL project. 


\section{References}

Ahrin BK (2003) Perspectives for anaerobic digestion. In: Ahring BK (ed) Biomethanation I. Advances in biochemical engineering/ biotechnology. Sringer, Berlin, pp 1-30

American Public Health Association (APHA) (2005) Standard methods for the examination of water and wastewater, 21th edn. APHA, Washington, DC

Angelidaki I, Ahing BK (1997) Co-digestion of olive mill wastewaters with manure, household waste or sewage sludge. Biodegradation $8: 221-226$

Angelidaki I, Ahing BK, Deng H, Schmidt JE (2002) Anaerobic digestion of olive mill effluents together with swine manure in USAB reactors. Water Sci Technol 45(10):213-218

Appels L, Lauwers J, Degrève J, Helsen L, Lievens B, Willems K, Van Impe J, Dewil R (2011) Anaerobic digestion in global bioenergy production: potential and research challenges. Renew Sust Energy Rev 15(9):4295-4301

Beccari M, Majone M, Torrisi L (1998) Two-reactor system with partial phase separation for anaerobic treatment of olive oil mill effluents. Water Sci Technol 38(4-5):53-60

Borja R, Banks CJ (1995) Anaerobic digestion of ice-cream wastewater: a comparison of single and two phase reactor systems. Bull Environ Contam Toxicol 54(3):466-471

Borja R, Rincón B, Raposo F, Alba J, Martin A (2002) A study of anaerobic digestibility of two-phase olive mill solid waste (OMSW) at mesophilic temperature. Process Biochem 38:733-742

Bouallagui H, Touhami Y, Cheikh RB, Hamdi M (2005) Bioreactor performance in anaerobic digestion of fruit and vegetable. Process Biochem 40:989-995

Chhetri AB, Tango MS, Budge SM, Islam MR (2008) Non-edible plant oils as new sources for biodiesel production. Int J Mol Sci 9: $169-180$

Cirne D, Paloumet X, Björnsson L, Alves M, Mattiassona B (2007) Anaerobic digestion of lipid-rich waste-effects of lipid concentration. Renew Energy 32:965-975

de Lemos (2007) Anaerobic reactors: biological wastewater treatment, vol 4. IWA Publishing, London

Demirel B, Yenigün O (2002) Two-phase anaerobic digestion processes: a review. J Chem Technol Biotechnol 77(7):743-755

Demirer GN, Chen S (2005) Two-phase anaerobic digestion of unscreened dairy manure. Process Biochem 40:3542-3549

EU (2006) Biofuels in the European Union-A vision for 2030 and beyond. Report of the biofuel research advisory council

Fezzani B, Cheikh RB (2007) Anaerobic co-digestion of olive mill wastewater with olive mill solid waste in a tubular digester at a mesophilic temperature. Bioresour Technol 98:769-774

Gōblös S, Portörō P, Bordás D, Kálmán M, Kiss I (2008) Comparison of the effectivities of two-phase and single-phase anaerobic sequencing batch reactors during dairy wastewater treatment. Renew Energy 33(5):960-965

Grady C, Daigger G, Lim H (1999) Biological wastewater treatment, 2nd edn. Marcel Dekker, New York

Guerrero L, Omil F, Mendez R, Lema JM (1999) Anaerobic hydrolysis and acidogenesis of wastewaters from food industries with high content of organic solids and protein. Water Res $33(15): 3281-3290$

Hidalgo D, Sastre E, Gómez M, Nieto P (2013) Evaluation of pretreatment processes for increasing biodegradability of agro-food wastes. Environ Technol 33(13):1497-1503

Hong V (2011) Anaerobic digestion of oil-rich solid waste. J Biotechnol 9(1):45-53

Ince O (1998) Performance of a two-phase anaerobic digestion system when treating dairy wastewater. Water Res 32(9):2707-2713
Kulkarni MG, Dalai AK (2006) Waste cooking oil-an economica source for biodiesel: a review. Ind Eng Chem Res 45:2901-2913

Lalman JA, Bagley DM (2001) Anaerobic degradation and methanogenic inhibitory effects of oleic stearic acids. Water Res 35(12):2975-2983

Lesteur M, Bellon-Maurel V, Gonzalez C, Latrille E, Roger JM, Junqua G, Steyer JP (2010) Alternative methods for determining anaerobic biodegradability: a review. Process Biochem 45:431-440

Li R, Chen S, Li X (2010) Biogas production from anaerobic codigestion of food waste with dairy manure in a two-phase digestion system. Appl Biochem Biotechnol 160(2):643-654

Mobarak-Qamsari E, Kasra-Kermanshahi R, Nosrati M, Amani T (2012) Enzymatic pre-hydrolysis of high fat content dairy wastewater as a pretreatment for anaerobic digestion. Int Environ Res 6(2):475-480

Neves L, Pereira M, Mota M, Alves M (2009) Detection and quantification of long chain fatty acids in liquid and solid samples and its relevance to understand anaerobic digestion of lipids. Bioresour Technol 100(1):91-96

Palenzuela A (1999) Anaerobic digestion of fish processing wastewater with special emphasis on hydrolysis of suspended solids. A.A. Balkema, The Netherlands

Pastor L, Ruiz L, Pascual A, Ruiz B (2013) Co-digestion of used oils and urban landfill leachates with sewage sludge and the effect on the biogas production. Appl Energy 107:438-445

Pereira MA, Pires OC, Mota M, Alves MM (2005) Anaerobic biodegradation of oleic and palmitic acids: evidence of mass transfer limitations caused by long chain fatty acid accumulation onto the anaerobic sludge. Biotech Bioeng 92(1):15-23

Refaat A (2010) Different techniques for the production of biodiesel from waste vegetable oil. Int J Environ Sci Tech 7(1): 183-213

Salminen E, Rintala J, Lokshina LYA, Vavilin VA (2000) Anaerobic batch degradation of solid poultry slaughterhouse waste. Water Sci Technol 41:33-41

SenthilKumar M, Gnanapragasam G, Arutchelvan V, Nagarajan S (2011) Influence of hydraulic retention time in a two-phase upflow anaerobic sludge blanket reactor treating textile dyeing effluent using sago effluent as the co-substrate. Environ Sci Pollut Res 18:649-654

Shen F, Yuan H, Pang Y, Chen S, Zhu B, Zou D, Liu Y, Mac J, Yu L, Li X (2013) Performances of anaerobic co-digestion of fruit \& vegetable waste (FVW) and food waste (FW): single-phase vs. two-phase. Bioresour Technol 144:80-85

Solera R, Romero LI, Sales D (2002) The evolution of biomass in a two-phase anaerobic treatment process during start-up. Chem Biochem Eng Q 16(1):25-29

Torrijos M, Thalla AK, Sousbie P, Bosque F, Delgene's JP (2008) Anaerobic digestion of residues from production and refining of vegetable oils as an alternative to conventional solutions. Water Sci Technol 58(9):1871-1878

Travieso L, Dominguez JR, Rincón B, Sánchez E, Benítez F, Borja R, Raposo F, Colmenarejo MF (2008) Batch culture growth of chlorella zofingiensis on effluent derived from two-stage anaerobic digestion of two-phase olive mill solid waste. Electron J Biotechnol 11(2):1-8

Wang Z, Banks CJ (2003) Evaluation of a two-stage anaerobic digester for the treatment of mixed abattoir wastes. Process Biochem 38(9):1267-1273

Wust E (2003) Single-phase and two-phase cheese wastewater treatment by anaerobic SBRs. PhD thesis, Civil, Construction and Environmental Engineering Department, Marquette University, Milwaukee, Wisconsin

Yang YQ, Shen DS, Li N, Xu D, Long YY, Lu XY (2013) Codigestion of kitchen waste and fruit-vegetable waste by two- 
phase anaerobic digestion. Environ Sci Pollut Res Int $20(4): 2162-2167$

Yu HW, Samani Z, Hanson A, Smith G (2002) Energy recovery from grass using two-phase anaerobic digestion. Waste Manag 22:1-5

Zhang B, Cai W, He P (2007) Influence of lactic acid on the twophase anaerobic digestion of kitchen wastes. J Environ Sci 19:244-249

Zhang P, Chen Y, Zhou Q (2010) Effect of surfactant on hydrolysis products accumulation and short-chain fatty acids (SCFA) production during mesophilic and thermophilic fermentation of waste activated sludge: kinetic studies. Bioresour Technol 101(18):6902-6909

Zhang L, Lee YW, Jahng D (2011) Anaerobic co-digestion of food waste and piggery wastewater: focusing on the role of trace elements. Bioresour Technol 102(8):5048-5059

Zhou X, Meile L, Kreuzer M, Zeitz J (2013) The effect of saturated fatty acids on methanogenesis and cell viability of Methanobrevibacter ruminantium. Archaea. doi:10.1155/2013/106916 


\subsection{Estudio del cierre de ciclo de aprovechamiento de nutrientes mediante valorización del digestato}

Aunque el proceso de DA se lleva a cabo principalmente para el tratamiento de residuos para la producción de biogás, también permite obtener como resultado una corriente líquida y densa llamado digestato, rica en minerales y nutrientes, e ideal para ser utilizada como fertilizante, aunque su gestión entraña complicaciones debido a los elevados costes de transporte que lleva asociada por su elevado contenido en agua.

El aprovechamiento del digestato para la obtención de productos de alto valor añadido cerrará el ciclo de los nutrientes, reduciendo las emisiones de gases de efecto invernadero, y remediando un problema medioambiental en beneficio del entorno y de la sociedad, además de mejorar de forma importante los resultados económicos de las plantas de biogás.

Las ventajas que presenta el digestato como fertilizante son:

- Si los comparamos con los residuos orgánicos antes de su digestión, los digestatos son más adecuados para uso agrícola, puesto que producen menos olores y tienen una mayor calidad higiénica.

- Puesto que tras la fermentación anaerobia el nitrógeno y fósforo orgánico pasa a mineral, el digestato puede considerarse similar a un fertilizante mineral.

- Puede competir en el mercado de forma ventajosa con los fertilizantes minerales debido al precio al alza de estos últimos.

El digestato puede aprovecharse aplicándolo directamente a la tierra, o separándolo en sus fracciones sólida y líquida, normalmente por centrifugación. La fracción sólida suele someterse a un proceso de compostaje para la obtención de la llamada "enmienda orgánica compost",. La calidad de este compost se encuentra regulado por el RD 506/2013, de 28 de junio. La fracción líquida del digestato, la cual tiene en disolución una gran cantidad de nutrientes, nitrógeno y fósforo principalmente, se utiliza en actividades agrícolas como fertilizante orgánico. Son varias las tecnologías de recuperación de nutrientes que han surgido y que en algunos de los casos están en fase de desarrollo, entre las que destacan las de recuperación de nitrógeno mediante desorción o stripping (Hidalgo et al., 2004; Lei et al., 2007), y las de recuperación conjunta de nitrógeno y fósforo como estruvita (Karakashew et al., 2008; Uysal et al., 2010). No obstante, mientras que la tecnología de stripping se aplica prácticamente para la eliminación de amonio, la precipitación de estruvita tiene la ventaja de recuperar de forma simultánea amonio y fósforo (Hidalgo et al., 2016), por lo que esta última parte del presente trabajo de tesis se centra en el análisis de esta tecnología.

Con el fin de conocer las limitaciones legales existentes para el aprovechamiento del digestato, antes de profundizar en la valorización de esta corriente mediante la tecnología existente de obtención de estruvita se va a realizar un breve repaso de las regulaciones que afectan al digestato tanto a nivel europeo como español. 


\subsubsection{Usos del digestato. Ámbito legislativo}

\section{Unión Europea}

A continuación se presenta un listado de la legislación que afecta al digestato a nivel europeo:

- Reglamento 1069/2009 y Reglamento (CE) no 142/2011 (SANDACH).

- Directiva 91/676/CE (Directiva relativa a la protección de las aguas contra la contaminación producida por nitratos utilizados en la agricultura).

- Directiva 2008/98/CE (Directiva Marco de residuos).

- Reglamento CEE no 2092/91 del Consejo de la Unión Europea, de 24 de junio de 1991, sobre la producción agraria ecológica.

- Directiva 2000/54 de protección de los trabajadores contra riesgos relacionados con la exposición a agentes biológicos durante el trabajo.

\section{Reglamento (CE) no 142/2011}

En este reglamento se establecen las disposiciones de aplicación del Reglamento (CE) no 1069/2009 del Parlamento Europeo y del Consejo por el que se establecen las normas sanitarias aplicables a los subproductos animales y los productos derivados no destinados al consumo humano.

Refleja los parámetros en el producto final y digestatos de plantas de biogás que utilizan como sustratos subproductos de origen animal. En la Tabla 3-10 se muestran los requerimientos relativos al proceso de digestión que deben ser monitorizados por los operadores de plantas de biogás, mientras que en la Tabla 3-11 se presentan las condiciones aplicables al estiércol transformado y los productos a base de estiércol transformado en el caso de su puesta en el mercado.

Se definen como:

- Residuos de fermentación, los residuos resultantes de la transformación de subproductos animales en una planta de biogás.

- Estiércol, todo excremento u orina de animales de granja distintos de los peces de piscicultura, con o sin lecho. 
Tabla 3-10. Requerimientos de residuos de fermentación (Reglamento (CE) 142/2011)

\begin{tabular}{ll} 
Residuos de la fermentación & \multicolumn{1}{c}{ Estándares que debe cumplir } \\
Residuos de fermentación (durante $o$ & Escherichia coli: $\mathrm{n}=5 ; \mathrm{c}=1 ; \mathrm{m}=1.000 ;$ \\
inmediatamente después del tratamiento en & $\mathrm{M}=5.000$ en $1 \mathrm{~g}$ \\
\cline { 2 - 2 } la planta de biogás) & $\begin{array}{l}\text { Enterococcaceae: } \mathrm{n}=5 ; \mathrm{c}=1 ; \mathrm{m}=1.000 ; \\
\end{array}$ \\
\hline $\begin{array}{l}\text { Residuos de fermentación (durante o en el } \\
\text { momento salida del almacén) }\end{array}$ & $\begin{array}{l}\text { Salmonella: ausencia en } 5 \text { muestras de } \\
25 \mathrm{~g} \text { cada una }(\mathrm{n}=5 ; \mathrm{c}=0 ; \mathrm{m}=0 ; \mathrm{M}=0)\end{array}$ \\
\hline
\end{tabular}

Nota:

n: Número de muestras que deben analizarse;

c: Número de muestras cuyo contenido bacteriano puede estar entre $m$ y $M$;

m: Valor umbral del número de bacterias; el resultado se considera satisfactorio si el número de bacterias en todas las muestras no es superior a m;

M: Valor máximo del número de bacterias; el resultado se considera insatisfactorio si el número de bacterias en una o más muestras es igual o superior a $M$.

Los residuos de fermentación (o digestato) y el compost que no cumplan las condiciones establecidas en la tabla anterior serán reprocesados; en caso de presencia de Salmonella serán tratados o eliminados conforme a las instrucciones de la autoridad competente.

Únicamente se permite producir abonos y enmiendas del suelo de origen orgánico a partir de materiales de categoría 2 y 3 . Los residuos de fermentación procedentes de la transformación en biogás (digestato) pueden introducirse en el mercado y utilizarse como abonos y enmiendas del suelo de origen orgánico. Los requerimientos específicos se detallan en la Tabla 3-11.

Tabla 3-11. Requerimientos específicos del estiércol transformado para puesta en el mercado (Reglamento (CE) 142/2011)

\begin{tabular}{|c|c|}
\hline Producto & Requerimiento/Parámetro de producto \\
\hline \multirow[t]{3}{*}{$\begin{array}{l}\text { Estiércol transformado para su puesta en } \\
\text { el mercado }\end{array}$} & $\begin{array}{l}\text { Tratamiento térmico: mínimo } 70 \stackrel{\circ}{ } \mathrm{C}-60 \\
\text { minutos o equivalente }\end{array}$ \\
\hline & $\begin{array}{l}\text { Tratamiento de reducción de la presencia } \\
\text { de bacterias esporuladas y toxígenas } \\
\text { cuando hayan sido identificadas como } \\
\text { peligro relevante. }\end{array}$ \\
\hline & $\begin{array}{l}\text { Almacenamiento tras transformación en } \\
\text { silos cerrados y aislados o en bolsas de } \\
\text { plástico o sacos bien cerrados, de modo } \\
\text { que se minimice su contaminación o } \\
\text { infección secundaria así como la } \\
\text { humedad }\end{array}$ \\
\hline \multirow{2}{*}{$\begin{array}{l}\text { Estiércol transformado para su puesta en } \\
\text { el mercado (durante o inmediatamente } \\
\text { después del tratamiento en la planta de } \\
\text { biogás) }\end{array}$} & $\begin{array}{l}\text { Escherichia coli: } n=5 ; c=5 ; m=0 ; M= \\
1000 \text { en } 1 \mathrm{~g}\end{array}$ \\
\hline & $\begin{array}{l}\text { Enterococcaceae: } n=5 ; c=5 ; m=0 ; M= \\
1000 \text { en } 1 \mathrm{~g}\end{array}$ \\
\hline $\begin{array}{l}\text { Estiércol transformado para su puesta en } \\
\text { el mercado (durante o en el momento } \\
\text { salida del almacén) }\end{array}$ & $\begin{array}{l}\text { Salmonella: ausencia en } 5 \text { muestras de } \\
25 \text { g cada una }(n=5 ; c=0 ; m=0 ; M=0)\end{array}$ \\
\hline
\end{tabular}


El digestato que no cumpla estos requisitos debe ser considerado como "no transformado" y no puede ser puesto en el mercado.

En España, el Real Decreto 1528/2012 tiene por objeto establecer disposiciones específicas de aplicación en España del Reglamento (CE) n.ำ 1069/2009, del Parlamento Europeo y del Consejo, de 21 de octubre, por el que se establecen las normas sanitarias aplicables a los subproductos animales y los productos derivados no destinados al consumo humano y por el que se deroga el Reglamento (CE) n. 1774/2002 (Reglamento sobre subproductos animales), y del Reglamento (UE) $\mathrm{n}$. o 142/2011, de la Comisión, de 25 de febrero de 2011, por el que se establecen las disposiciones de aplicación del Reglamento (CE) n.ำ 1069/2009 del Parlamento Europeo y del Consejo por el que se establecen las normas sanitarias aplicables a los subproductos animales y los productos derivados no destinados al consumo humano, y la Directiva 97/78/CE del Consejo en cuanto a determinadas muestras y unidades exentas de los controles veterinarios en la frontera en virtud de la misma.

\section{Directiva de Nitratos}

Directiva 91/676/CE, de 12 de diciembre de 1991, relativa a la protección de las aguas contra la contaminación producida por nitratos utilizados en la agricultura.

Tiene por objeto proteger las aguas comunitarias contra los nitratos de origen agrario, que son la causa principal de la contaminación de las aguas desde fuentes difusas. Establece las cantidades máximas de nitrógeno $\left(210 \mathrm{~kg}\right.$. $0170 \mathrm{~kg} \mathrm{~N} \cdot \mathrm{ha}^{-1} \cdot \mathrm{año}^{-1}$ aplicado con el estiércol en el caso de zonas clasificadas como vulnerables (aquellas superficies territoriales cuyo drenaje da lugar a la contaminación por nitratos, para lo cual sus aguas subterráneas deben superar una concentración de nitratos de $50 \mathrm{mg} / \mathrm{l}$ y las aguas superficiales deben estar eutrofizadas o con más de $50 \mathrm{mg} / \mathrm{l}$ de nitratos)), y se regula la aplicación tanto de fertilizantes orgánicos como inorgánicos.

Se define como estiércol a los excrementos y residuos excretados por el ganado, solos o mezclados, aunque se hubieran transformado.

En España el R.D. 261/1996, de 16 de febrero, sobre protección de las aguas contra la contaminación producida por los nitratos procedentes de fuentes agraria es trasposición de la Directiva 91/676/CE relativa a la protección de las aguas contra la contaminación producida por nitratos de origen agrícola, e impone a los Estados miembros la obligación de identificar las aguas que se hallen afectadas por la contaminación por nitratos.

\section{Directiva de residuos}

Directiva 2008/98/CE, del Parlamento Europeo y del Consejo de 19 de noviembre de 2008 sobre los residuos.

En esta directiva se pide a la Comisión Europea que examine la pertinencia de establecer requisitos mínimos para la gestión de biorresiduos y criterios de calidad para el compost y el digestato procedentes de biorresiduos. 
En España, la Ley 22/2011, de 28 de julio, de residuos y suelos contaminados, es la trasposición al derecho español de la Directiva 2008/98/CE sobre residuos.

\section{$\underline{\text { Reglamento sobre agricultura ecológica }}$}

Reglamento CEE no 2092/91 del Consejo de la Unión Europea, de 24 de junio de 1991, sobre la producción agraria ecológica y su indicación en los productos agrarios y alimenticios, modificado por última vez por el Reglamento CE № 2254/2004 de la Comisión de 27 de diciembre de 2004.

En este Reglamento se indica que entre los fertilizantes y enmiendas del suelo, se encuentra el grupo "residuos domésticos compostados o fermentados". Entre los requisitos se encuentran: producto obtenido a partir de residuos domésticos separados en función de su origen sometido a un proceso de compostaje o a una fermentación anaeróbica para la producción de biogás, únicamente residuos domésticos vegetales y animales, únicamente cuando se produzcan en un sistema de recogida cerrado y vigilado, concentraciones máximas de metales pesados (cadmio, cobre, níquel, plomo, zinc, mercurio, cromo total, cromo VI), entre otras.

Para poder certificar el compost a partir de digestato y posteriormente poder utilizarlo en agricultura ecológica, se debe seguir el procedimiento especificado por la entidad de acreditación utilizada. En cualquier caso se debe completar un expediente que incluye una serie de documentos (registro de fertilizantes o documentación que acredita la autorización de gestión de residuos ganaderos, protocolo de fabricación detallado de los productos, analíticas iniciales según el referencial, certificados de proveedor y garantía de origen de las materias primas) y posteriormente realizar una auditoría in situ.

Directiva 2000/54 (protección de los trabajadores contra riesgos relacionados con la exposición a agentes biológicos durante el trabajo)

Directiva 2000/54/CE del Parlamento Europeo y del Consejo, de 18 de septiembre, sobre la protección de los trabajadores contra los riesgos relacionados con la exposición a agentes biológicos durante el trabajo.

Se hace referencia a los agentes infecciosos para los humanos presentes en los lodos residuales o en el estiércol líquido y los residuos orgánicos.

En España el Real Decreto 664/1997, de 12 de mayo, sobre la protección de los trabajadores contra los riesgos relacionados con la exposición a agentes biológicos durante el trabajo establece las disposiciones mínimas aplicables a las actividades en las que los trabajadores están o pueden estar expuestos a agentes biológicos. Este real decreto transpone al ordenamiento jurídico español la Directiva del Consejo 90/679/CEE de 26 de noviembre, posteriormente modificada por la Directiva del Consejo 93/88/CEE de 12 de octubre y adaptada al progreso técnico por las Directivas de la Comisión 95/30/CE de 30 de junio, 97/59/CE de 7 de octubre y 97/65/CE de 26 
de noviembre y codificada por la Directiva 2000/54/CE del Parlamento y del Consejo, de 18 de septiembre.

\section{España}

Además de los Reales Decretos que transponen las Directivas citadas anteriormente, entre las principales regulaciones españolas que afectan al digestato directa 0 indirectamente se encuentran:

\section{Real Decreto de fertilizantes}

RD 506/2013, de 28 de junio, sobre productos fertilizantes.

Establece la normativa básica en materia de productos fertilizantes. Este Real Decreto se aplica sin perjuicio de las disposiciones del Reglamento (CE) no 2003/2003 y viceversa. Se presta una especial atención a determinados fertilizantes, particularmente a los que utilizan materias primas de origen orgánico, que están sometidas a reglamentaciones competentes en materia de vigilancia y control y por todos los interesados en general, y se establece la obligatoriedad de su inscripción en el Registro de productos fertilizantes, actualizándose los requisitos de la comunicación al mismo.

Define "residuo orgánico biodegradable", como aquel residuo o subproducto de origen vegetal o animal utilizado como materia prima, cuya descripción se incluye en el Anexo IV, susceptible de transformarse por la acción de microorganismos aerobios o anaerobios y dar lugar a un tipo de enmienda orgánica. El Anexo IV "Lista de residuos orgánicos biodegradables" incluye los denominados "Licores (digestato) del tratamiento anaeróbico", dentro de los "Residuos de tratamiento anaeróbico".

Todavía no han sido establecidos criterios específicos de calidad exigibles a los digestatos para su consideración como productos en esta normativa pese a su potencial aptitud agronómica.

\section{Real Decreto 324/2000, normas de ordenación explotaciones porcinas}

Real Decreto 324/2000, de 3 de marzo, por el que se establecen normas básicas de ordenación de las explotaciones porcinas.

Su artículo 5-1-B indica que la gestión de los estiércoles de las explotaciones porcinas podrá realizarse mediante la utilización de cualquiera de los siguientes procedimientos:

1. Valorización como abono órgano-mineral.

2. Tratamiento de estiércoles mediante compostaje, secado artificial y otros.

3. Eliminación de estiércoles mediante vertido.

4. Entrega a centros de gestión de estiércoles. 
Para la utilización directa de los purines (opción 1) la normativa establece requisitos tales como disponer de balsas de estiércol con unas determinadas características, respetar en la distribución de estiércol sobre el terreno determinadas distancias mínimas o acreditar ante el órgano competente de la comunidad autónoma, que disponen de superficie agrícola suficiente, propia o concertada, para la utilización de los estiércoles como fertilizantes cumpliendo el Real Decreto 261/1996 el cual limita la cantidad máxima de estiércoles y discrimina entre zonas vulnerables y no vulnerables.

En relación con la valorización, la normativa indica que se llevará a cabo individualmente por cada explotación. Se podrá realizar a través de un programa de gestión común para varias explotaciones (BANCO DE PURINES), previa autorización del órgano competente de la comunidad autónoma.

A pesar de la normativa vigente, todavía hoy en día el digestato, debido a su elevado coste de transporte (el $90 \%$ es agua), suele utilizarse como fertilizante en terrenos agrícolas cercanos a las plantas de biogás que lo producen, por lo que en muchos casos, debido a su alto contenido de nutrientes, contamina el suelo y el agua por eutrofización.

\subsubsection{Proceso de precipitación de estruvita}

\section{Introducción}

La estruvita o fosfato de magnesio y amonio hexahidratado (MAP) es una sustancia cristalina blanca que se forma por la combinación de magnesio, fosfato y amonio en cantidades molares iguales

. La forma de la estruvita según la reacción simplificada es la siguiente:

$$
\mathrm{Mg}^{+2}+\mathrm{NH}_{4}^{+}+\mathrm{PO}_{4}^{-3}+6 \mathrm{H}_{2} \mathrm{O} \rightarrow \mathrm{MgNH}_{4} \mathrm{PO}_{4} \cdot 6 \mathrm{H}_{2} \mathrm{O}
$$

Las propiedades de la estruvita como fertilizante han sido demostradas desde los años 60. Se han efectuado muchas experiencias acerca de la utilización de la estruvita en diversos cultivos, en EE.UU., Alemania, Inglaterra Japón y Egipto (Greaves et al., 1999; Bowers, 2004; Zheng et al., 2004; Liu et al., 2011). Se ha encontrado que la estruvita constituye un buen fertilizante de liberación lenta y aporta nutrientes fundamentales como magnesio, nitrógeno y fósforo para la agricultura y la horticultura. Otro factor que apoya el uso de la estruvita como fertilizante es su baja concentración en metales pesados comparado con la roca fosfórica usualmente empleada en la fabricación de fertilizantes sintéticos. Debido a su lenta liberación, la entrega de nutrientes se efectúa paulatinamente y la planta los consume de acuerdo a sus requerimientos evitando así la lixiviación de dichos nutrientes y su llegada a las masas hídricas, como puede ocurrir cuando se aplican fertilizantes sintéticos. Se requiere, por tanto, menos frecuencia de aplicación y no se produce "la quema" de la planta, aún a altas tasas de aplicación.

Se ha demostrado que $365 \mathrm{~kg} \cdot a n ̃ 0^{-1}$ de estruvita es suficiente para fertilizar 2,6 hectáreas de tierra arable al año y dar un incremento de la producción de trigo de 3,5 


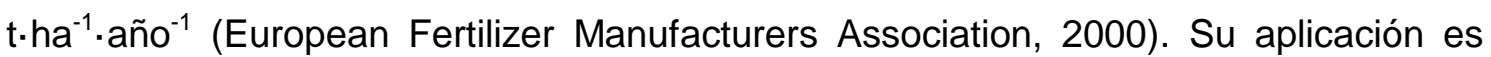
sumamente efectiva sobre todo durante el período de crecimiento de los cultivos (Gaterell et al., 2000).

Hasta el día de hoy se han llevado a cabo múltiples estudios para desarrollar una tecnología económica y efectiva para la obtención de estruvita a partir de efluentes residuales de diferente origen. Se ha investigado la precipitación de estruvita en efluentes residuales diferentes, como por ejemplo: purines (Suzuki et al., 2005), lixiviados de vertedero municipal (Oztürk et al., 2003), estiércol bovino (Shuiling y Andrade, 1999) y vacuno (Demirer et al., 2008), aguas residuales domésticas (Sanchez et al., 2011) o estiércol de aves de corral (Yetilmezsoy y Sapci-Zengin, 2009).

La literatura consultada muestra que la mayoría de los estudios a escala piloto, así como las plantas de producción de estruvita a gran escala, se basan en la utilización de la tecnología de cristalización con el empleo de reactores de lecho fluidizado para lograr la mayor efectividad del proceso. Pero los reactores de lecho fluidizado son difíciles de controlar dado que los caudales se deben mantener constantes durante el proceso de cristalización para mantener el lecho en un estado fluidizado. Es por ello que algunos autores prefieren el empleo de reactores de tanque agitado por su mayor flexibilidad y facilidad en el manejo. Otro modelo de reactor es el intercambiador iónico, como el proceso REM-NUT, el cual combina un proceso de intercambio iónico, para la eliminación simultánea de iones fosfato y amonio, y un proceso de precipitación química para la obtención de estruvita. 


\section{Opciones comerciales para la obtención de estruvita:}

En España no existen plantas de producción de estruvita a escala industrial, pero sí que se conocen algunos casos de producción y comercialización de estruvita, aunque no muchos, en otros países.

En la Tabla 3-12 se detalla una comparación de las diferentes tecnologías para la obtención de estruvita.

Tabla 3-12. Tecnologías utilizadas a escala industrial para la obtención de estruvita

\begin{tabular}{|c|c|c|c|c|}
\hline Tecnología & Ostara Pearl тм & NuReSys & Phospaq & Crystalactor ${ }^{\circledR}$ \\
\hline Tipo de reactor & $\begin{array}{l}\text { Lecho fluidizado } \\
\text { de flujo } \\
\text { ascendente }\end{array}$ & CSTR RCTA & $\begin{array}{l}\text { RCTA con } \\
\text { aire } \\
\text { difundido }\end{array}$ & $\begin{array}{l}\text { Lecho fluidizado de } \\
\text { flujo ascendente }\end{array}$ \\
\hline $\begin{array}{l}\text { Nombre del producto } \\
\text { recuperado }\end{array}$ & Crystal Green ® & BioStru ${ }^{\circledR}$ & $\begin{array}{l}\text { Fertilizante } \\
\text { Estruvita }\end{array}$ & $\begin{array}{l}\text { Estruvita, Fosfato } \\
\text { de Calcio, Fosfato } \\
\text { de Magnesio }\end{array}$ \\
\hline $\begin{array}{l}\text { \% Eficacia de } \\
\text { recuperación / tratamiento } \\
\text { (rango) }\end{array}$ & $\begin{array}{l}80-90 \% \\
10-50 \% \mathrm{~N}\end{array}$ & $45 \% \mathrm{P}$ & $80 \% \mathrm{P}$ & $\begin{array}{l}\text { 85-95\% P para la } \\
\text { estruvita, } \\
>90 \% \text { P para el } \\
\text { Fosfato de Calcio }\end{array}$ \\
\hline $\begin{array}{l}\text { Comercialización } \\
\text { producto / reventa }\end{array}$ & Ostara & - & - & $\begin{array}{l}\text { Facilitados por } \\
\text { terceros a través de } \\
\text { ProCorp }\end{array}$ \\
\hline $\begin{array}{llr}\text { Localización } & \text { de } & \text { las } \\
\text { instalaciones } & \text { a } & \text { gran } \\
\text { escala } & & \end{array}$ & $\begin{array}{l}\text { Estados Unidos, } \\
\text { Canada y Reino } \\
\text { Unido }\end{array}$ & $\begin{array}{ll}\text { Bélgica } & y \\
\text { Alemania } & \end{array}$ & Países Bajos & Estados Unidos \\
\hline $\begin{array}{l}\text { Localización de plantas } \\
\text { piloto }\end{array}$ & $\begin{array}{l}\text { Estados Unidos, } \\
\text { Europe, Oeste } \\
\text { de Asia, China y } \\
\text { Reino Unido }\end{array}$ & - & - & $\begin{array}{l}\text { Estados Unidos y } \\
\text { China }\end{array}$ \\
\hline
\end{tabular}

A continuación se comentan diferentes aspectos de cada una de las tecnologías recogidas en la Tabla 3-12. 


\section{Ostara Pearl}

El proceso Pearl de Ostara recupera nutrientes en forma de estruvita en estaciones de depuración de aguas residuales. Es aplicado sobre el líquido proveniente de la separación de fangos del digestato. Este sistema de recuperación consta de un reactor de lecho fluidizado que opera de forma continua. La Figura 3-38 ilustra el proceso.

El pH de operación del reactor está comprendido entre 7 y 8 , dependiendo de las características del influente y del tamaño deseado de los cristales, y es controlado mediante la dosificación de hidróxido de sodio. La dosificación de magnesio se realiza mediante cloruro de magnesio.

El proceso de cristalización asegura la producción de cristales de estruvita de alta pureza que se recuperan del reactor una vez han crecido hasta el tamaño óptimo para comercializarlo en forma de fertilizantes bajo el nombre Crystal Green. El diámetro de dichos cristales puede ser ajustado entre 1,00 y $3,50 \mathrm{~mm}$.

En la actualidad hay 8 Instalaciones de operación a gran escala:

- Durham AWTP, Oregón (EEUU)

- Gold Bar WWTP, Canada

- Nansemond WWTP, Virginia (EEUU)

- York WWTP, Pensilvania (EEUU)

- Rock Creek WWTP, Oregón (EEUU)

- Nine Springs WWTP, Wisconsin (EEUU)

- HM Weir WWTP, Canada

- Slough STW, Reino Unido

y 27 Instalaciones piloto en Estados Unidos, Europa, Oeste de Asia, China y Reino Unido.
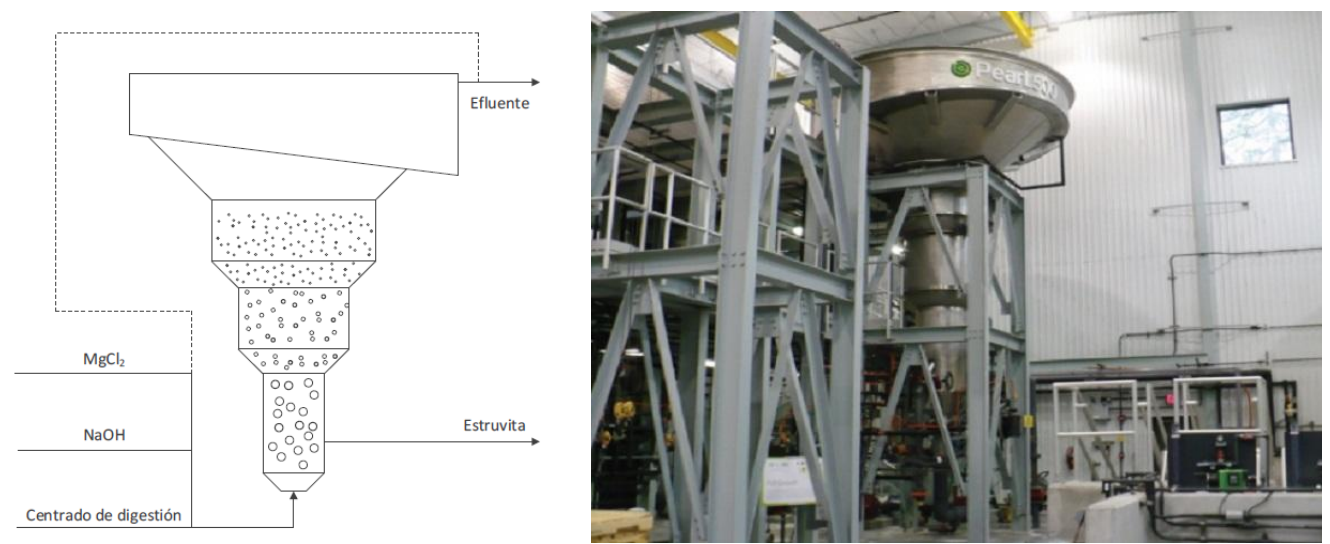

Figura 3-38. Representación gráfica del proceso y del reactor de Ostara Pearl. Fuente: adaptado de Ostara, 2015 


\section{Nuresys}

La tecnología Nuresys (Nutrient Recovery System) es una tecnología de recuperación de fósforo por precipitación de estruvita y es utilizado en sistemas de depuración de aguas residuales, tanto industriales como municipales. El proceso es aplicable a corrientes provenientes de la digestión anaerobia que contengan concentraciones de sólidos en suspensión menores al 5\%, por lo que generalmente se realiza sobre el líquido obtenido por centrifugación del digestato, reduciendo la concentración de fósforo hasta $15-20 \mathrm{mg} \cdot \mathrm{L}^{-1} \mathrm{P}-\mathrm{PO} 4$.

Se utiliza un reactor de lecho mezcla completa para la precipitación. El reactor es precedido por un reactor aireado que regula el pH por liberación de $\mathrm{CO}_{2}$, aunque también cuenta con un sistema de dosificación de hidróxido de sodio para ajustar el $\mathrm{pH}$ con mayor fiabilidad. El proceso se ilustra en la Figura 3-39.

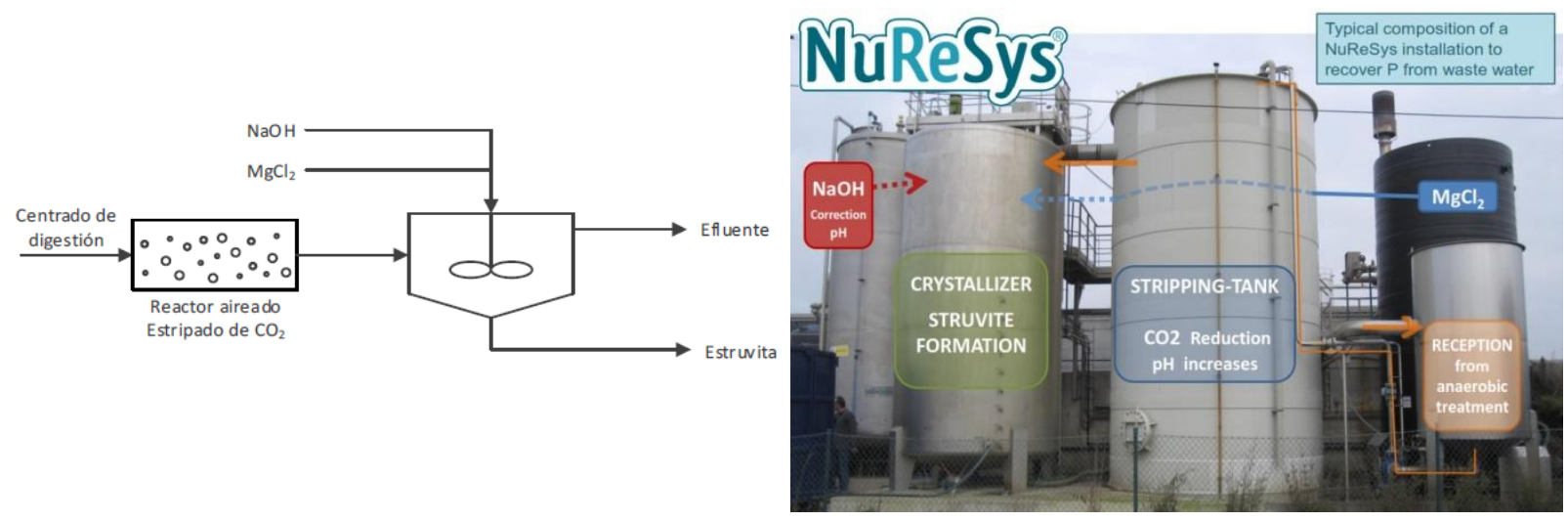

Figura 3-39. Esquema representativo del sistema Nuresys de recuperación de fósforo. Fuente: adaptado de Nuresys, 2018

En la actualidad hay 7 instalaciones a gran escala centradas en aplicaciones industriales:

- 4 plantas de procesado de patatas (Bélgica)

- 1 planta de procesado de leche (Alemania)

- 1 industria farmacéutica (Bélgica)

- 1 planta municipal (Bélgica)

- $\quad$ y 2 instalaciones piloto en Bélgica. 


\section{Crystalactor}

El proceso Crystalactor se desarrolla en un reactor de lecho fluidizado con materiales, generalmente arena o minerales, que actúan como núcleos de cristalización. La Figura 3-40 ilustra el reactor y proceso Crystalactor.

Para concentraciones de $60-80 \mathrm{mg} \cdot \mathrm{L}^{-1}$ P-PO4 en el líquido obtenido por centrifugación del digestato que alimenta el reactor se alcanzan ratios de recuperación del $70-80 \%$ (Cornel y Schaum, 2009). Esta corriente entra al reactor por la parte inferior y fluye hacia arriba con la velocidad necesaria para mantener el reactor en estado fluidizado. El pH en el reactor es controlado por dosificación de hidróxido de sodio.

La estruvita cristaliza en la superficie de la arena o mineral utilizados como núcleos de cristalización. Cuando los cristales tienen el tamaño necesario, caen hasta la parte inferior del reactor y son recogidos periódicamente, a la vez que se añade más material de nucleación para mantener constante el número de materiales que actúan como núcleos de cristalización.

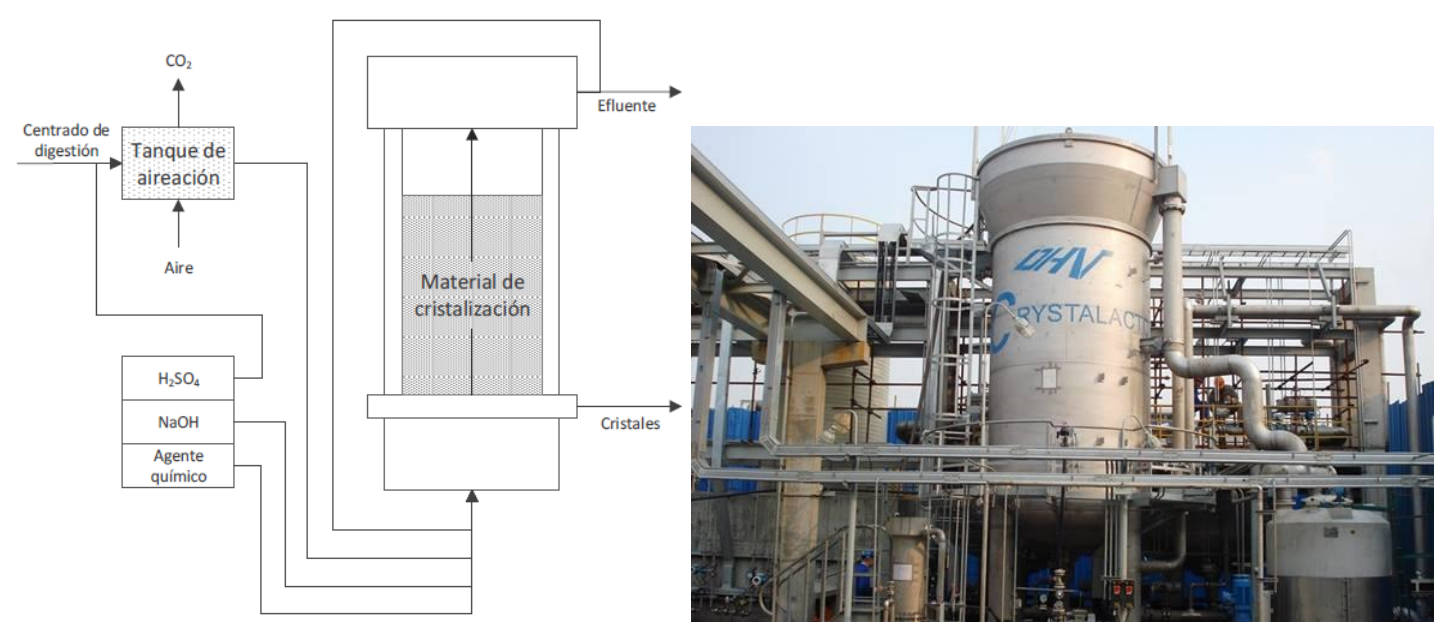

Figura 3-40. Esquema representativo del proceso y reactor Crystalactor. Fuente: adaptado de Crystalactor, 2018

DHV Crystalactor ${ }^{\circledR}$ tiene licencia de uso en Estados Unidos a través de Procop.

En la actualidad hay 4 instalaciones de plantas industriales a gran escala en Estados Unidos:

- Vaquería Alto, Wisconsin (EEUU)

- Procesado de carne WWTP, Ohio (EEUU)

- Vaquería WWTP, Ohio (EEUU)

- Digestor de residuos sólidos, Florida (EEUU)

- y 4 instalaciones piloto entre EEUU y China. 


\section{Phospaq}

El proceso Phospaq recupera fósforo por cristalización de estruvita y puede ser aplicado en sistemas de depuración de aguas residuales industriales. Paques Phosphaq ${ }^{\mathrm{TM}}$ usa reactores continuos de tanque agitado aireados con un sistema de separación de sólidos (ver Figura 3-41) y dosifica una solución de hidróxido de magnesio, $\mathrm{Mg}(\mathrm{OH})_{2}$. El pH de operación se encuentra entre 8,0 y 8,5 y es controlado por liberación de $\mathrm{CO}_{2}$ y la adición de óxido de magnesio.

Para concentraciones de $\mathrm{P}^{-} \mathrm{PO}_{4}$ de 60 - $80 \mathrm{mg} \cdot \mathrm{L}^{-1}$ del líquido procedente de la centrifugación del digestato, el ratio de recuperación de fósforo es aproximadamente el $75 \%$. El efluente resultante suele tener concentración de $\mathrm{P}-\mathrm{PO}_{4}$ comprendida entre $10-20 \mathrm{mg} \cdot \mathrm{L}^{-1}$.

Los cristales de estruvita generados tienen un tamaño aproximado de $0,7 \mathrm{~mm}$ y se recogen en un sedimentador situado en el interior del reactor.

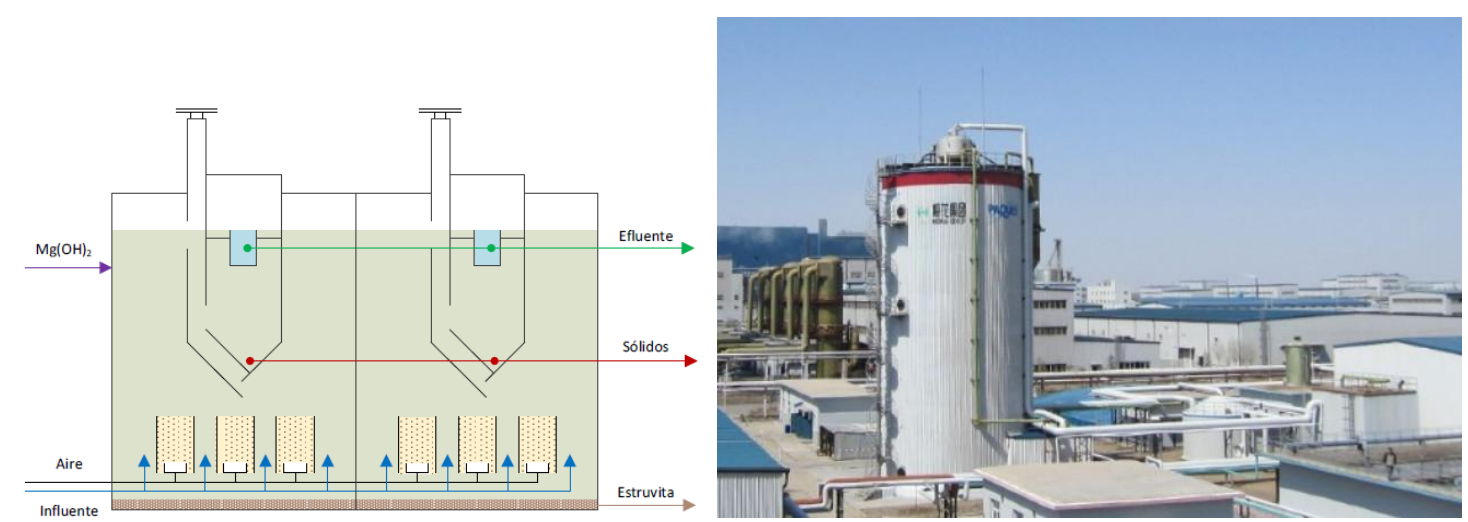

Figura 3-41. Esquema del proceso y reactor Phospaq de recuperación de fósforo. Fuente: adaptado de Paques, 2018e: adaptado de Paques, 2018

En la actualidad hay 3 instalaciones en Paises Bajos:

- Olburgen STW

- AVIKO Lomm (procesado de patatas)

- AVIKO Steenderen (procesado de patatas) 


\section{Análisis económico}

Los costes de producción de estruvita varían de los 140 \$/t en Australia, a los 460 \$/t en Japón.

Munch y Barr (2001) establecieron que el beneficio económico de la producción de estruvita varía según el volumen de producción; el mínimo, para una EDAR de capacidad de $100 \mathrm{~m}^{3}$. día ${ }^{-1}$ es de 271 \$año; el máximo, de 149.000 \$, para una EDAR con capacidad de $55.000 \mathrm{~m}^{3} \cdot$ día $^{-1}$. Los mismos autores efectuaron un análisis de costes de producción de estruvita para el caso de Oxley Creek (Brisbane, Australia) y determinaron que el coste operacional de la producción de estruvita depende de los siguientes aspectos:

- La concentración de fósforo en el efluente de partida.

- El coste de la fuente de magnesio.

- El precio de comercialización de la estruvita, en el caso de Australia entre 198 y $330 \$ / \mathrm{t}$.

Desde hace unos años se está produciendo un importante encarecimiento de las materias primas esenciales en la producción de fertilizantes, especialmente del gas natural, roca fosfórica y potasa, por lo que la valorización agronómica de corrientes residuales como estruvita es de gran importancia. Además, se debe tener en cuenta que tanto el gas natural como el fosfato roca suponen más del $60 \%$ de los costes de fabricación de los abonos nitrogenados y fosfatados respectivamente.

Por otra parte, los fertilizantes están experimentando un importante incremento de precio en todos los mercados mundiales debido a la fortaleza de la demanda derivada de las buenas perspectivas agrícolas mundiales y problemas coyunturales de suministro, lo que está provocando ciertas dificultades de abastecimiento.

El fósforo, por ejemplo, es un recurso no renovable y un importante macronutriente del que depende la vida y para el cual no hay sustituto en los seres vivos, nada que pueda ser sintéticamente creado para reemplazar este componente vital en todos los procesos de la vida. Debido a esto, el interés por recuperar el fósforo de las aguas residuales, no sólo eliminarlo, está cobrando cada vez mayor interés entre las sociedades industrializadas.

La fuente natural de fósforo son las rocas fosfóricas, que son aquellas rocas que contienen de forma natural minerales basados en fosfatos. El $85 \%$ de los principales depósitos de rocas fosfóricas a nivel mundial se encuentran fuera de Europa: en Norte América, China, Marruecos, oeste de África, Oriente Medio, ex-Unión Soviética y Sudáfrica. 


\section{CONCLUSIONES Y TRABAJOS FUTUROS}

La tesis que se ha presentado es el resultado de los trabajos realizados por el doctorando dentro del proyecto de investigación LIFE 09 ENV/E/000451-VALUVOIL del programa LIFE + de la Comisión Europea.

Dentro de este proyecto el autor se ha centrado en la codigestión de purín porcino y residuos del procesado de aceites vegetales usados para la producción de biodiesel en un sistema de digestión anaerobia en dos fases en condiciones mesófilas, y más concretamente en el diseño, construcción y operación de un sistema de digestión anaerobia en dos fases a escala piloto, tomando como punto de partida los resultados obtenidos del estudio comparativo a escala laboratorio de un sistema de digestión anaerobia en una fase, y una sistema de digestión anaerobia en dos fases.

A continuación se exponen las principales conclusiones y aportaciones y además, se proponen una serie de trabajos futuros a modo de continuación de la investigación desarrollada.

\subsection{Conclusiones y aportaciones de la tesis}

1) Tras el análisis de los resultados obtenidos de la caracterización de los residuos seleccionados (PM y OW), se puede afirmar que son dos residuos que se complementan de forma perfecta para ser utilizados en un proceso de codigestión anaerobia.

2) Como consecuencia del estudio de la influencia del inóculo utilizado para la determinación del potencial metanogénico del residuo se constata que la cantidad de biogás producido es mayor en los ensayos con inoculo procedente de HORECA, y que ese biogás es de mejor calidad, con un contenido medio en metano de $71,1 \%(S D=1,6)$, comparado con el $69,5 \%(S D=1,2)$ en metano que hay en el biogas obtenido en los ensayos realizados con inóculo procedente de fango de depuradora. Como no siempre es posible disponer de fango HORECA, el fango mWWTP es también una opción viable según los resultados obtenidos en la experimentación realizada.

3) Las muestras con mayor porcentaje de OW muestran un mayor potencial metanogénico, lo cual está de acuerdo con los resultados obtenidos con el potencial metanógenico teórico calculado según la ecuación de Buswell (Ecuación 1).

4) La velocidad de producción de metano durante la digestión de OW es menor que cuando se hace codigestión con PM.

Durante el estudio comparativo del sistema de digestión anaerobia en una sola fase con el sistema de digestión anaerobia en dos fases se observa que: 
5) En ambos sistemas aparece una gran inhibición inicial en los ensayos donde únicamente se utilizó OW como substrato. En el sistema en dos fases no se han producido problemas de operación, en cambio en el sistema monofásico aparecieron problemas de taponamiento de las conducciones a partir del día 25 para el primer periodo de ensayos donde existía un relación de alimentación OW/PM:1/0.

6) La mezcla de OW con PM neutraliza los efectos negativos de acumulación de lípidos y produce elevados porcentajes de eliminación de SV en ambos sistemas (63 y $71 \%$ en el sistema monofásico y 69 y $72 \%$ en el sistema de dos fases, para relaciones de alimentación 1:1 y 1:3 OW/PM respectivamente).

7) En los experimentos realizados, la digestión de OW con concentraciones de grasa mayores del 51,5\% inhiben el proceso de degradación anaerobia.

8) La producción de metano fue de 0,30 y $0,22 \mathrm{~m}^{3} \mathrm{CH}_{4} \mathrm{~kg}^{-1} \mathrm{SV}_{\text {eliminado }}$ para el sistema monofásico y 0,30 y $0,27 \mathrm{~m}^{3} \mathrm{CH}_{4} \mathrm{~kg}^{-1} \mathrm{SV}_{\text {eliminado }}$ para el sistema de dos fases, para relaciones de alimentación 1:1 y 1:3 OW/PM respectivamente.

9) El sistema en dos fases es capaz de operar de forma estable a mayores velocidades de carga orgánica $\left(3,1 \mathrm{~kg} \mathrm{SV} \mathrm{m}^{-3} \mathrm{dia}^{-1}\right)$ que el sistema monofásico (2,6 $\mathrm{kg} \mathrm{SV} \mathrm{m}^{-3}$ dia $\left.^{-1}\right)$, lo que hace que para un mismo volumen de digestor se pueda tratar mayor cantidad de residuo, lo cual implica mayor rentabilidad de proceso.

10) El sistema en dos fases produce un efluente de mayor calidad en términos de mayor eliminación de SV, mayor estabilidad y mayor producción de metano que el sistema monofásico.

\subsection{Trabajos futuros}

A continuación se exponen algunos de los posibles trabajos futuros que complementan el estudio realizado en este trabajo de tesis:

(a) Desarrollo e implementación de un sistema eficiente de obtención de estruvita a partir del digestato obtenido en el proceso de digestión anaerobia en dos fases.

(b) Desarrollo e implementación de sistemas para el pretratamiento de los residuos a co-digerir de forma que se aumente la producción de biogás con menores tiempos hidráulicos de residencia.

(c) Desarrollo e implementación de sistemas económicos de limpieza y purificación del biogás que permitan su utilización generalizada de forma similar a lo que ocurre en estos momentos con el gas natural. 


\section{BIBLIOGRAFÍA}

Ahring B.K. (2003). Perspectives for anaerobic digestion. In Biomethanation I. Advances in biochemical engineering/biotechnology. Springer, Berlin, pp 1-30.

American Public Health Association (APHA) (2005). Standard methods for the examination of water and wastewater, 21 st edn. APHA, Washington DC, USA.

American Society of Agricultural Engineers (2001) Committee S\&E-412 report AW-D-1, revised 6-14-73.

Amon, B., Kryvoruchko, V., Bodiroza, V., Pötsch, E., Zollitsch, W. (2006). Optimising methane yield from anaerobic digestion of manure: Effects of dairy systems and of glycerine supplementation. Int. Cong. Ser. 1293, 217- 220.

Arsova, L., (2010). Anaerobic Digestion of food waste: Current status, problems and an alternative product. Department of earth and Environmental Engineering foundation of Engineering and Applied Science, Columbia University.

Astals, S., Ariso, M., Galí, A., Mata-Alvarez, J., (2011). Co-digestion of pig manure and glycerine: Experimental and modelling study. J. Environ. Manage. 92, 1091-1096.

Astals, S., Nolla-Ardèvol, J., Mata-Álvarez, J., (2012). Anaerobic co-digestion of pig manure and crude glycerine at mesophilic conditions: biogas and digestate. Bioresource Technol. 110, 63-70.

Beccari M., Majone M., Torrisi L. (1998). Two-reactor system with partial phase separation for anaerobic treatment of olive oil mill effluents. Water Sci Technol 38(4-5):53-60.

Borja R., Banks C.J. (1995). Anaerobic digestion of ice-cream wastewater: a comparison of single and two phase reactor systems. Bulletin of environmental contamination and toxicology 54(3):466-471.

Borja R., Rincón B., Raposo F., Alba J., Martin A. (2002). A study of anaerobic digestibility of two-phase olive mill solid waste (OMSW) at mesophilic temperature. Process Biochem 38:733-742.

Bouallagui H., Touhami Y., Cheikh R.B., Hamdi M. (2005). Bioreactor performance in anaerobic digestion of fruit and vegetable. Process Biochem 40:989-995.

Bowers, K.E. (2004). Development of a Struvite Crystallizer for Reducing Phosphorus in Effluent from Livestock Waste Lagoons. PhD. North Carolina State University.

Cirne D., Paloumet X., Björnsson L., Alves M., Mattiassona B. (2007). Anaerobic digestion of lipid-rich waste-effects of lipid concentration. Renewable Energy 32(6):965-975. 
Cornel, P.; Scchaum, C. Phosphorus recovery from wastewater: needs, technologies and costs. Water Science and Technology, 2009, vol. 59, no 6, p. 1069-1076.

Crystalactor. https://www.royalhaskoningdhv.com/nl-nl/nederland/markten/crystalactor. Último acceso: 4 de abril de 2018.

Delgado, C., Rosegrant, M., Steinfeld, H., Ehui, S., \& Courbois, C. (1999). Livestock to 2020: the next food revolution. Washington: International Food Policy Research Institute; Food and Agriculture Organisation. International Livestock Research Institute.

Demirel, B., Yenigün, O. (2002). Two-phase anaerobic digestion processes: a review. Journal of Chemical Technology and Biotechnology, 77(7), 743-755.

Demirer, G. N., Chen, S. (2005). Two-phase anaerobic digestion of unscreened dairy manure. Process biochemistry, 40(11), 3542-3549.

Demirer, S.U., Demirer, G.N., Frear C., Chen, S. (2008). Anaerobic digestion of dairy manure with enhanced ammonia removal. Journal of environmental management, 86(1), 193-200.

Deublein, D., \& Steinhauser, A. (2008). Utilization of Gas to Generate Current and Heat (pp. 477-507). Wiley-VCH Verlag GmbH \& Co. KGaA.

European Fertilizer Manufacturers Association. (2000). Phosphorus: essential element for food production. European Fertilizer Manufacturers Association (EFMA), Brussels.

FAOSTAT (2013). http://faostat3.fao.org. Último acceso 6/02/2014.

Fernández, A., Sanchez, A., \& Font, X. (2005). Anaerobic co-digestion of a simulated organic fraction of municipal solid wastes and fats of animal and vegetable origin. Biochemical Engineering Journal, 26(1), 22-28.

Garg M, Makkar H (2012) Balanced feeding for improving livestock productivity: increase in milk production and nutrient use efficiency and decrease in methane emission. Animal Production and Health 173, Rome.

Gaterell, M.R., Gay, R., Wilson, R., Lester, J.N. (2000). An economic and environmental evaluation of the opportunities for substituting phosphorus recovered from wastewater treatment works in existing UK fertilizer markets. Environmental Technology. 21(9), 1067-84.

Gerardi, M. H. (2003). Alkalinity and pH. Nitrification and Denitrification in the Activated Sludge Process, 109-114.

Guerrero, L., Omil, F., Mendez, R., \& Lema, J. M. (1999). Anaerobic hydrolysis and acidogenesis of wastewaters from food industries with high content of organic solids and protein. Water Research, 33(15), 3281-3290.

Göblös, S., Portörő, P., Bordás, D., Kálmán, M., \& Kiss, I. (2008). Comparison of the effectivities of two-phase and single-phase anaerobic sequencing batch reactors during dairy wastewater treatment. Renewable Energy, 33(5), 960-965.

Greaves, J., Hobbs, P., Chadwick, D., \& Haygarth, P. (1999). Prospects for the recovery of phosphorus from animal manures: a review. Environmental Technology, 20(7), 697-708. 
Halden, R. U., \& Schwab, K. J. (2008). Environmental impact of industrial farm animal production. Pew Commission on Industrial Farm Animal Production.

Hidalgo, D., Corona, F., Martín-Marroquín, J. M., del Álamo, J., \& Aguado, A. (2016). Resource recovery from anaerobic digestate: struvite crystallisation versus ammonia stripping. Desalination and Water Treatment, 57(6), 2626-2632.

Hidalgo, D., del Alamo, J., Irusta, R. (2004). Tratamiento de purines porcinos mediante desorción con aire: Puesta en marcha de una planta piloto. Ingeniería Química 414, 163-168.

Hidalgo, D., Sastre, E., Gómez, M., Nieto, P. (2012). Evaluation of pre-treatment processes for increasing biodegradability of agro-food wastes. Environmental technology, 33(13), 1497-1503.

Hutňan, M., Kolesárová, N., Bodík, I., Czölderová, M. (2013). Long-term monodigestion of crude glycerine in a UASB reactor. Bioresource Technol. 130, 88-96.

Ince, O. (1998). Performance of a two-phase anaerobic digestion system when treating dairy wastewater. Water Research, 32(9), 2707-2713.

Jensen, P. D., Astals, S., Lu, Y., Devadas, M., \& Batstone, D. J. (2014). Anaerobic codigestion of sewage sludge and glycerol, focusing on process kinetics, microbial dynamics and sludge dewaterability. Water research, 67, 355-366.

Karakashew, D., Schmidt, J.E. y Angelidaki, I. (2008). Innovative process scheme for removal of organic matter, phosphorous and nitrogen from pig manure. Water Research, 42(15), 4083-4090.

Lei, X., Sugiura, N., Feng, C. y Maekawa, T. (2007). Pretreatment of anaerobic digestion effluent with ammonia stripping and biogas purification. Journal of Hazardous Materials, 145(3), 391-397.

Li, R., Chen, S., \& Li, X. (2010). Biogas production from anaerobic co-digestion of food waste with dairy manure in a two-phase digestion system. Applied biochemistry and biotechnology, 160(2), 643-654.

Liu, Y., Rahman, M. M., Kwag, J. H., Kim, J. H., \& Ra, C. S. (2011). Eco-friendly production of maize using struvite recovered from swine wastewater as a sustainable fertilizer source. Asian-Australasian Journal of Animal Sciences, 24(12), 1699-1705.

MAGRAMA (2015). Aceites de cocina usado. http://www.magrama.gob.es/es/calidady-evaluacion-ambiental/temas/prevencion-caly-gestionresiduos/flujos/domesticos/fracciones/aceites-cocina/. Último acceso 4/04/2016.

Mobarak-Qamsari, E., Kasra-Kermanshahi, R., Nosrati, M., \& Amani, T. (2012). Enzymatic pre-hydrolysis of high fat content dairy wastewater as a pretreatment for anaerobic digestion. International Journal of Environmental Research, 6(2), 475-480.

Montsoriu, T., \& de Dios, J. (1996). Ingeniería de aguas residuales: tratamiento, vertido y reutilización. Metcalf \& Eddy. 
Münch, E. V., \& Barr, K. (2001). Controlled struvite crystallisation for removing phosphorus from anaerobic digester sidestreams. Water research, 35(1), 151159.

Nasr, N., Elbeshbishy, E., Hafez, H., Nakhla, G., \& El Naggar, M. H. (2012).

Comparative assessment of single-stage and two-stage anaerobic digestion for the treatment of thin stillage. Bioresource technology, 111, 122-126.

Neves, L., Pereira, M. A., Mota, M., \& Alves, M. M. (2009). Detection and quantification of long chain fatty acids in liquid and solid samples and its relevance to understand anaerobic digestion of lipids. Bioresource technology, 100(1), 91-96.

NURESYS Recovers Natures Essentials. References. https://www.youtube.com/watch?v=q7A_HrrBH-I\&feature=youtu.be. Último acceso: 5 de abril de 2018.

Ostara nutrient recovery technologies. http://www.ostara.com/. Último acceso: 4 de abril de 2018.

Oztürk, I., Altinbas, M., Kotuncu, I., Arikan, O., Gomec-Yangin, C. (2003). Advanced physic-chemical treatment experiences on young municipal landfill leachates. Waste Management, 23(5), 441-446.

Palatsi, J., Laureni, M., Andrés, M. V., Flotats, X., Nielsen, H. B., \& Angelidaki, I. (2009). Strategies for recovering inhibition caused by long chain fatty acids on anaerobic thermophilic biogas reactors. Bioresource technology, 100(20), 45884596.

Palenzuela, A. (1999). Anaerobic digestion of fish processing wastewater with special emphasis on hydrolysis of suspended solids.

Paques. https://es.paques.nl/about-us-es/submenu/acerca-de-nosotros/casos. Últimos acceso: 5 de abril de 2018.

Park, Y., Hong, F., Cheon, J., Hidaka, T., \& Tsuno, H. (2008). Comparison of thermophilic anaerobic digestion characteristics between single-phase and twophase systems for kitchen garbage treatment. Journal of bioscience and bioengineering, 105(1), 48-54.

Pastor, L., Ruiz, L., Pascual, A., \& Ruiz, B. (2013). Co-digestion of used oils and urban landfill leachates with sewage sludge and the effect on the biogas production. Applied energy, 107, 438-445.

Pereira, M. A., Pires, O. C., Mota, M., \& Alves, M. M. (2005). Anaerobic biodegradation of oleic and palmitic acids: evidence of mass transfer limitations caused by long chain fatty acid accumulation onto the anaerobic sludge. Biotechnology and bioengineering, 92(1), 15-23.

Salminen, E., Rintala, J., Lokshina, L. Y., \& Vavilin, V. A. (2000). Anaerobic batch degradation of solid poultry slaughterhouse waste. Water Science and Technology, 41(3), 33-41.

Sánchez, E., Rodríguez, B., Heredero, R., García Peñuela, R., Polo, A., García, M., ... \& Sanz, R. (2011). Experiencias para la recuperación del fósforo de las aguas residuales en forma de estruvita en Canal de Isabel II. Cuadernos de I+ D+ I. 
Shen, F., Yuan, H., Pang, Y., Chen, S., Zhu, B., Zou, D., ... \& Li, X. (2013). Performances of anaerobic co-digestion of fruit \& vegetable waste (FVW) and food waste (FW): single-phase vs. two-phase. Bioresource technology, 144, 8085.

Silvestre, G. (2014). http://www.ainia.es/insights/por-que-la-fermentacion-oscurapuede-ser-una-alternativa-sostenible-para-valorizar-residuos/. Último acceso 31/03/2018.

Silvestre, G., Fernández, B., \& Bonmatí, A. (2015). Addition of crude glycerine as strategy to balance the $\mathrm{C} / \mathrm{N}$ ratio on sewage sludge thermophilic and mesophilic anaerobic co-digestion. Bioresource technology, 193, 377-385.

Senthilkumar, M., Gnanapragasam, G., Arutchelvan, V., \& Nagarajan, S. (2011). Influence of hydraulic retention time in a two-phase upflow anaerobic sludge blanket reactor treating textile dyeing effluent using sago effluent as the cosubstrate. Environmental Science and Pollution Research, 18(4), 649-654.

Steinfeld, H., Gerber, P., Wassenaar, T., Castel, V., Rosales, M., De Haan, C. (2006). Livestock's long shadow. FAO, Rome, 392.

Solera, R., Romero, L. I., \& Sales, D. (2002). The evolution of biomass in a two-phase anaerobic treatment process during start-up. Chemical and biochemical engineering quarterly, 16(1), 25-30.

Speece, R. E. (1996). Anaerobic biotechnology for industrial wastewaters. In Anaerobic biotechnology for industrial wastewaters.

Shuiling, R.D., Andrade, A. (1999). "Recovery of struvite from calf manure". Environmental Technology, 20 (7), 765-769.

Smith, A. L., Shimada, T., Raskin, L. (2017). A comparative evaluation of community structure in full-scale digesters indicates that two-phase digesters exhibit greater microbial diversity than single-phase digesters. Environmental Science: Water Research \& Technology, 3(2), 304-311.

Suzuki, K., Tanaka, Y., Kuroda, K., Hanajima, D., \& Fukumoto, Y. (2005). Recovery of phosphorous from swine wastewater through crystallization. Bioresource technology, 96(14), 1544-1550.

Thi, V. H. (2011). Anaerobic digestion of oil-rich solid waste. Vietnam Journal of Biotechnology, 9(1).

Travieso Córdoba, L., Domínguez Bocanegra, A. R., Rincón Llorente, B., Sánchez Hernández, E., Benítez Echegoyen, F., Borja, R., ... \& Colmenarejo Morcillo, M. F. (2008). Batch culture growth of Chlorella zofingiensis on effluent derived from two-stage anaerobic digestion of two-phase olive mill solid waste. Electronic Journal of Biotechnology, 11(2), 12-19.

Tokumoto, H., Tanaka, M. (2012a). Novel anaerobic digestion induced by bacterial components for value-added by products from high-loading glycerol. Bioresource Technol. 107, 327-332. 
Tokumoto, H., Kashiwagi, M. (2012b). Changes in dominant fermentation type during anaerobic digestion of high-loading glycerine with slight glucose content. Bioresource Technol. 126, 7-13.

Uysal, A., Yilmazel, Y. D., \& Demirer, G. N. (2010). The determination of fertilizer quality of the formed struvite from effluent of a sewage sludge anaerobic digester. Journal of Hazardous Materials, 181(1-3), 248-254.

Wang, C., Hong, F., Lu, Y., Li, X., \& Liu, H. (2017). Improved biogas production and biodegradation of oilseed rape straw by using kitchen waste and duck droppings as co-substrates in two-phase anaerobic digestion. PloS one, 12(8), e0182361.

Wang, Z., \& Banks, C. J. (2003). Evaluation of a two stage anaerobic digester for the treatment of mixed abattoir wastes. Process Biochemistry, 38(9), 1267-1273.

Wust, E. L. (2003). Single-phase and two-phase cheese wastewater treatment by anaerobic SBRs (Doctoral dissertation, Marquette University).

Yang, Y. Q., Shen, D. S., Li, N., Xu, D., Long, Y. Y., \& Lu, X. Y. (2013). Co-digestion of kitchen waste and fruit-vegetable waste by two-phase anaerobic digestion. Environmental Science and Pollution Research, 20(4), 2162-2171.

Yetilmezsoy, K., y Sapci-Zengin Z. (2009). Recovery of ammonium nitrogen from the effluent of UASB treating poultry manure wastewater by MAP precipitation as a slow release fertilizer. Journal Hazardous Material, 167 (1), 260-269.

Yu, H. W., Samani, Z., Hanson, A., \& Smith, G. (2002). Energy recovery from grass using two-phase anaerobic digestion. Waste management, 22(1), 1-5.

Zhang B, Cai W, He P (2007) Influence of lactic acid on the twophase anaerobic digestion of kitchen wastes. Journal of Environmental Sciences, 19(2), 244-249.

Zhang, P., Chen, Y., \& Zhou, Q. (2010). Effect of surfactant on hydrolysis products accumulation and short-chain fatty acids (SCFA) production during mesophilic and thermophilic fermentation of waste activated sludge: kinetic studies. Bioresource technology, 101(18), 6902-6909.

Zheng, F. L., Huang, C. H., \& Norton, L. D. (2004). Effects of near-surface hydraulic gradients on nitrate and phosphorus losses in surface runoff. Journal of environmental quality, 33(6), 2174-2182. 